

\section{XIt5}

Zxen/ 1.5
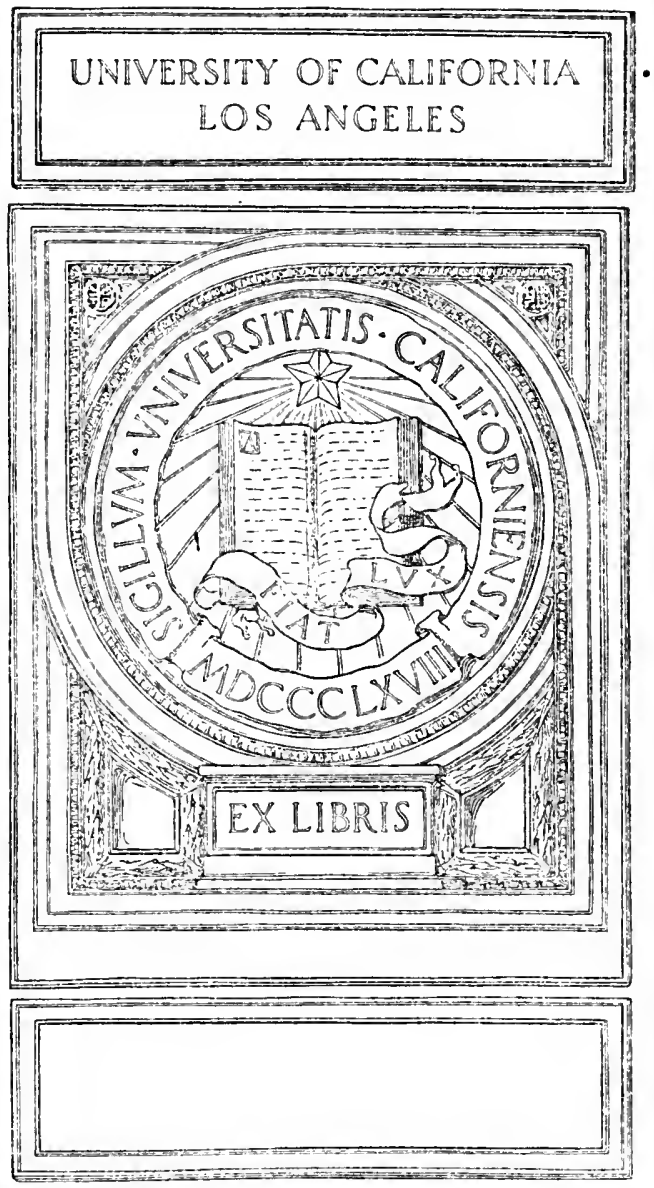



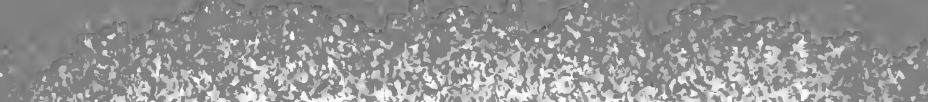

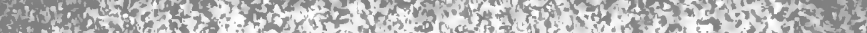

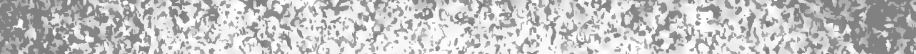
-

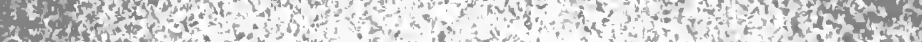

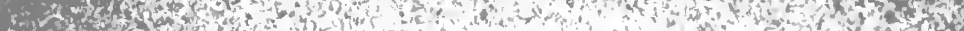

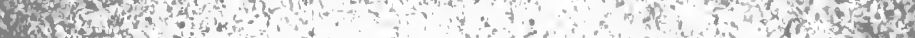

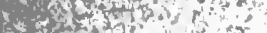
sitem

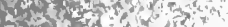

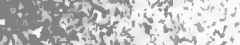

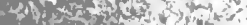

* ate $x^{2}+x+2 x$

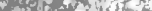

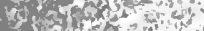

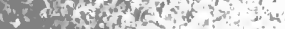

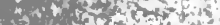

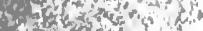

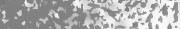

-150 in

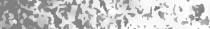
Nys 57 Ins

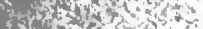
$2 x+1$ soth

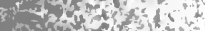

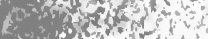
sen 5

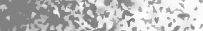

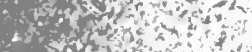 sisor. * itras +.}

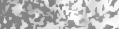

ivetefsin thisterts

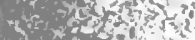
nyt? $x^{\circ}$

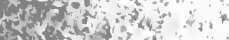

$\rightarrow$ toring

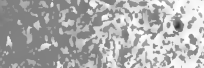

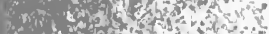

tring

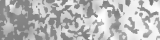

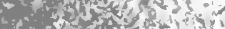

$x^{2}-20140$

stembet

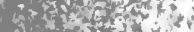

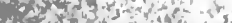

औ

Ti. $x$ -

$4 a^{2}+1$

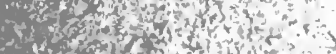

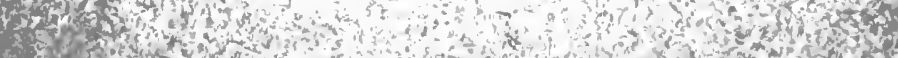

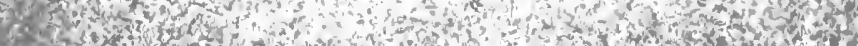

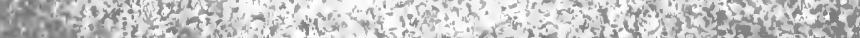

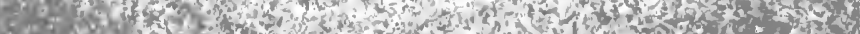
A. 30 4.

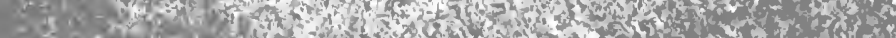

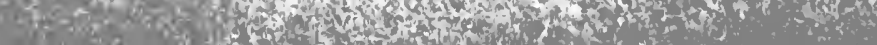




\section{THE LICENSED TRADE}




\section{Digitized by the Internet Archive in 2007 with funding from Microsoft Corporation}




\title{
THE LICENSED TRADE
}

AN INDEPENDENT SURVEY

\author{
BY EDWIN A. PRATT \\ AUTHOR OF "LICENSING AND TEMPERANCE IN SWEDEN, NORWAY \\ AND DENMARK," "THe tRANSition in agRiculture," etc.
}

\section{LONDON}

JOHN MURRAY, ALBEMARLE STREET, W. 


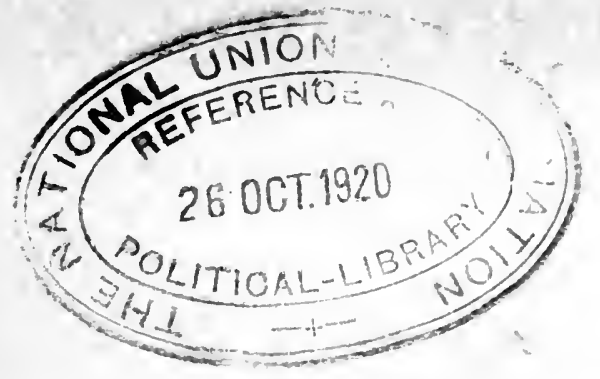

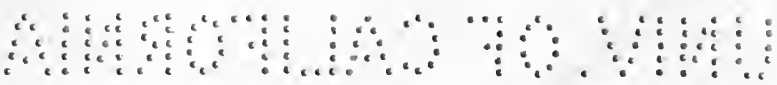

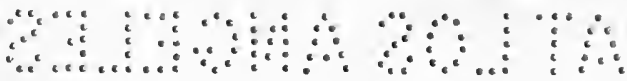

$$
\begin{aligned}
& \because \because \because \because \because \because \because \vdots \vdots \vdots \vdots: \div
\end{aligned}
$$




\section{$H V$ \\ 5087
$G 7 \mathrm{P}$}

\section{PREFATORY NOTE}

IN the course of an active journalistic career it has ef fallen to my lot to investigate various social and $w$ economic movements or developments of the day, and I have found that separate studies thereon; offered in 鱼 compact form, and containing an abundance of actual fact, rather than of merely personal opinion, have been not unacceptable to the British public, especially when such studies have dealt either with new subjects or with old controversies on new lines. It is under the latter ' category the present volume falls. It represents, in $\checkmark$ effect, an attempt to deal with 'The Licensing Prob'lem' from the point of view of the actual traders, as 岁seen, however, by an independent investigator, rather than from the more or less academical, theoretical, or idealistic standpoint of outside critics; and in this respect, therefore, it may claim to occupy an almost gunique place in the literature on the subject-apart, that is, from pamphlets or occasional review articles. I I do not necessarily commit the whole body of the said traders to a full and complete endorsement of all that I say; but in its broad outlines, and setting aside possible differences of opinion on matters of detail, my statement, I would suggest, deserves to be taken into account 
by those who are willing to look beyond the views assertions, and prejudices of individuals or organizations avowedly hostile to the trade.

The present work, therefore, differs essentially from the ordinary 'temperance' literature, of which, I fancy, most English people are beginning to grow somewhat weary. In my humble judgment the very word 'temperance' is too often used in an entirely wrong sense. Prohibitionists and other extremists are not really entitled to consider 'temperance' and 'total abstinence'-as they generally do-synonymous terms. My own view on this point was set forth in a footnote on page 105 of my little book on 'Licensing and Temperance in Sweden, Norway, and Denmark,' wherein I said :

The real meaning of the word 'temperance' is 'moderation.' It we say of a man that he is temperate in speaking, we do not imply that he abstains from speech, but that he shows moderation therein. Nor, when told that a person is temperate in eating, do we assume that he has left off taking food. If the one be 'a moderate speaker,' and the other ' $a$ moderate eater,' then the 'temperance' advocate in regard to beverages should be 'a moderate drinker.' In effect, total abstainers may be teetotallers, but they cannot, properly speaking, be described as 'temperance' people.

So I assume there is a vast number of people in the world who favour 'temperance,' in the true sense of the word, without wanting either to enforce compulsory abstinence on persons who use, but do not abuse, alcoholic beverages, or to impose undue restrictions and unreasonable interference, if not, also, unjust confiscation, on the representatives of a trade which has been 'licensed '-and therefore legalized-by the State since 
the early days of our national history. It is this class of people to whom, I trust, what I have written will specially appeal.

The chapter on 'Humanity and Stimulants' has already been published in The Monthly Review, that on 'The No-Licence Movement in New Zealand' in The Times, and those on 'Managed Houses,' 'Clubs as Unlicensed Public-Houses,' and 'Beer Past and Present,' in The Daily Telegraph.

EDWIN A. PRATT.

FARNBOROUGH, KENT,

Abril, 1907. 



\section{CONTENTS}

CHAPTER

I. INTRODUCTORY

II. MATTERS OF HISTORY -

III. HUMANITY AND STIMULANTS - - - $\quad 25$

IV. PROHIBITIONIST EXAGGERATIONS - 39

V. THE TRUE MORAL OF HABITUAL DRUNKENNESS - 54

VI. TESTIMONY OF EXPERTS - - - - $\quad$ - 69

VII. LIQUOR LEGISLATION IN THE PAST - $\quad$ - 79

VIII. 'TIED' HOUSES - $\quad$ - $\quad$ - $\quad$ - $\quad$ - $9 \mathbf{I}$

IX. 'MANAGED' HOUSES - - - - - $\quad$ - 106

X. PROHIBITION ABROAD - $\quad-\quad-\quad$ - $\quad-$ I 29

XI. MODIFIED PROHIBITION AT HOME -

XII. THE NO-LICENCE MOVEMENT IN NEW ZEALAND - I54

XIII. DISINTERESTED MANAGEMENT - - - I70

XIV. CLUBS AS UNLICENSED PUBLIC-HOUSES - - 189

$\mathrm{XV}$. 'TEMPERANCE' TEACHING IN SCHOOLS - - $20 \mathrm{I}$

XVI. TEMPERANCE DRINKS - $\quad$ - $\quad$ - $\quad 209$

XVII. BEER PAST AND PRESENT - - $\quad 227$

XVIII. LICENSING QUESTIONS OF TO-DAY: REDUCTION,

COMPENSATION, AND TIME LIMIT - $\quad-243$

XIX. THE ECONOMICS OF LICENSING - - - $\quad 268$

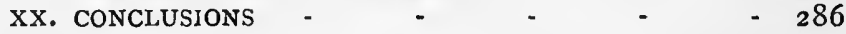

APPENDICES :

A.-TYPICAL FORM OF AGREEMENT WITH A

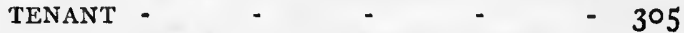

B.-TYPICAL FORM OF AGREEMENT WITH A

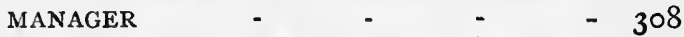

C.-FURTHER RULES FOR 'MANAGED' HOUSES 3 I I

D. - ALLIED TRADES AND INTERESTS - - 313

E. - THE USE OF ALCOHOLIC BEVERAGES - 320

F.-ALCOHOLIC BEVERAGES: STATISTICS - 32I

G. -THE TAXATION OF BREWERY COMPANIES 323

H.-PROHIBITION IN THE UNITED STATES - 324

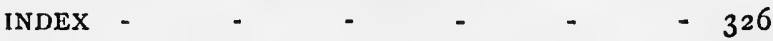

ix 


\section{THE LICENSED TRADE}

\section{CHAPTER I \\ INTRODUCTORY}

To the writing of books on the licensing question there is no end. But the vast majority of those already produced deal only with various aspects of what may be called 'the case for the prosecution,' and it is these books, or the writings and speeches akin thereto, that the larger proportion of the British public alone see or hear. They become accustomed, therefore, more or less, to the idea that the question is essentially a onesided one, incapable of any real defence. This at least is certain: that if any impartial person of inquiring mind wants to find out what can really be said on 'the other side,' he has no little difficulty in consulting adequate sources of information.

I was especially struck by this position of affairs when, after having long been accustomed to accepting teetotal assertions and contentions - whether made through the Press or on the platform-I began to look into the subject more thoroughly, with a view to seeing whether there really was anything to be said for 'the other side,' and what its own 'case ' represented. It is convenient, I know, in these busy times ('strenuous' is perhaps the more orthodox term to-day) to take one's opinions as some people buy their clothes-ready 
made. It saves a great amount of trouble just to adopt the views of the man who writes the most, or talks the loudest and most persistently, accepting from such person his catalogue of facts and figures, contentions and conclusions, without further ado. It is much easier to do this than to worry out social problems for oneself; and the tendency is especially marked in the case of persons in an influential position, who have many demands made on their time and energies, and are generally ready to put their names to apparently wellmeant schemes, when recommended to them by some ' authority' on the subject, without stopping to make any adequate investigation on their own account, or to ascertain the views or experiences of those whom the action they support may prejudice.

I do not suggest that such persons are to be blamed for their, perhaps, too ready acquiescence; but it occurred to me that I might render some public service if, placing myself in their position, as it were, for the time being, I made an independent inquiry, and ascertained what was the sort of 'case' that could be made out for the various branches of a trade that has been the subject of so much adverse comment, and also of so many merciless attacks. The results of such an inquiry, on strictly common-sense lines, might also, I thought, be no less acceptable to the great body of fair-minded English people who, themselves moderate drinkers, constitute the bulk of the community, and represent the jury by whom the final verdict in regard to the licensing question in general will have to be given. These, also, have probably heard far more of the teetotal side of the case than they have of the other, and they may, therefore, with their British sense of justice and fair play, be the more ready to read what I have here ventured to write. 
On the inquiry thus made I started, I must confess, with a good deal of prejudice, though, perhaps, with no more than is entertained by many thousands of my fellow-countrymen. Teetotal opinions I had passively adopted and had acted on since the days of my youth had led me to assume that the makers and dispensers of alcoholic drinks were-well, all that the teetotallers said of them! But when I began to question the foundations of the faith that was in me, I found that the real facts were very different indeed from what I had supposed; that the case for the teetotallers (as distinguished from the advocates of that moderation in drinking which seems to constitute the real 'temperance') was based largely on exaggerations, misconceptions, and ideal conditions altogether incapable of attainment, short of a complete revolution in some of the fundamendal traits and instincts of human nature; that, whatever the faults and shortcomings of the traders in alcoholic drinks, neither the trade nor the great majority of the persons engaged therein really deserved the bitter denunciations I had read or heard; and that many of the attempted 'reforms' of the licensing system might do far more harm than good. I found, also, that, so long as our human nature remains what it is, prudent legislators would do well to recognize as indispensable a trade which evidently responds directly to a strongly pronounced human want, taking such precautions as may be necessary to ensure effective control, but not allowing themselves to be influenced by idealists (aiming at an eventual total suppression impossible of realization) into a policy of unduly harassing, if not of showing injustice towards, the representatives of a trade whose history goes back to the very earliest days of our race.

I yield to no one in my desire to see people temperate 
and sober. But I hold that freedom and justice are greater far than even temperance and sobriety. Our forefathers were heavy drinkers, but they were sturdy fighters for freedom. They bequeathed us, not only bodies that are none the worse, physically, because they themselves loved strong ale, but a freedom which we shall either curtail or abuse if we say that, because a small proportion of the community suffer from the effects of an undue consumption of alcoholic drinks, therefore the rest of the nation shall be compelled to abstain therefrom. No less sturdily did our forefathers fight for justice. They fought against the despotism of Kings, and they struggled valiantly against the oppression of Governments; but they did not fight and struggle in order that the powers of despotism and oppression should pass into the hands of groups of citizens known as 'the majority,' who, under the shadow of so-called licensing reforms, were to make use of their own liberty to inflict a great injustice on their neighbours. Can it be that we have escaped the tyranny of rulers only to become subject to the tyranny of the ruled?

The whole matter, therefore, must be looked at from a broader point of view than is taken by the average writer or speaker from the ordinary 'temperance'- that is, teetotal-standpoint. Is total suppression practicable? Is not a body of traders, carrying on their business under the express sanction of the law, and contributing more largely than any other body to the finances of the country, entitled to a greater degree of consideration than teetotal extremists are willing to extend to them? Is further interference with the licensing laws really called for? Would renewed attacks on the liberty of the subject be justifiable?

Questions of this kind seem to me to remove the 
problem far beyond the academical standpoint from which it is so often regarded. It is one for consideration, not so much in the laboratory, in a debating society, or at temperance meetings, as by those concerned in practical politics, and accustomed to dealing with the actual conditions of to-day, rather than with conditions as one might like them to be.

It was on these lines that I began my inquiry, and in what I have written I have thought more of dealing with actual facts, and of presenting exact testimony, than merely of recording my individual views. The subject covers so much ground that there has been some difficulty in reducing a comprehensive survey of it to the proportions of a single moderately sized volume; but the story thus brought together will, I trust, be none the less acceptable and useful, not so much to the professed teetotaller, whose mind I can hardly hope to influence, but to the Average Person--open to conviction, though too busy to examine the question exhaustively for himself-to whom, with the profoundest respect, this book is hereby dedicated. 


\section{CHAPTER II}

\section{MATTERS OF HISTORY}

THE story of intoxicating drinks goes back to prehistoric times, the beginnings thereof being completely lost in the mists of antiquity. There is no doubt, however, that the first of such drinks was mead, which was prepared by adding water to wild honey, and allowing the mixture to stand for some days until fermentation had taken place, and a beverage palatable to the taste and intoxicating in its effects, when taken in any large quantity, was produced. The alternative to mead was cider, made from wild apples. Drinks of these kinds were well suited to the habits of tribes wandering from place to place, and having no fixed habitation. The raw materials were easily obtained, and the process of manufacture required little time and little or no skill.

Other wild fruits were also used in prehistoric days for the production of intoxicating beverages. Thus M. G. de Mortillet says :

The palafits, or lake dwellings, of Clairvaux and of Switzerland show that during the Neolithic epoch the inhabitants of Central Europe possessed already a fermented drink prepared from raspberries and from mulberries. The investigation of the palafits of Bourget (Savoy) and of various stations round the Alps proves that the use of this raspberry or mulberry wine continued during the Bronze Age. On the southern slopes of the 
Alps the palafits intermediate between the prehistoric and the protohistoric show the use of another fermented liquor-dogberry wine.

The next step was probably represented by a primitive sort of beer; but this must have signified an almost prodigious advance in civilization. It especially implied settlement, for it meant the planting of corn, the gradual cultivation of improved varieties thereof from original wild stocks of indifferent quality and giving only a scanty yield, the invention of the plough the use of oxen, and so on. An equal degree of advance was denoted by the planting of a vineyard and the making of wine from the product thereof, as, we read, was done by Noah. How many generations, if not thousands of years, were represented by these two stages alone in the history of the human race is more than the wisest of men can surmise.

In Egypt the brewing of beer was one of the earliest of the many arts that underwent development there, and it was in Egypt, probably, that brewing was first practised on any approach at all to scientific principles. Frescoes on the walls of ancient temples have revealed the whole story of the methods of production and consumption, and thrown light on the influence of beer-drinking on the social habits of the people. But by the time brewing had attained to the proportions of a skilled industry among them, the Egyptians must already have been beer-drinkers for ages, beer having first, it is believed, been introduced into the Nile Valley by the primitive settlers. That it was made there 5,000 years ago is well established by 'The Book of the Dead.' A thousand years later demands arose in the land for a reduction in the number of places for the sale of beer. Then there has been handed down to modern times a letter written 3,000 years ago by an 
anxious Egyptian father to his student son in the city of Pelusium (once situated in the north-east angle of the Delta, and famous in history alike for its university and its breweries), telling him of the pain with which he had heard that he was wasting his valuable time in the beer-houses, that he was getting into bad company, and that he finished up each day's carouse by rolling under the table.

It is further interesting to learn, in regard to the antiquity of beer as a beverage, that in the excavations at Phrygia, a country in Asia Minor with a history going back to prehistoric ages, small funnel-shaped vessels have been found which are believed to have been used for removing from beer any grains or husks still left in it ; while Xenophon tells in his 'Anabasis' of certain tribes who had unfiltered beer served up to them, and imbibed it through straws so as to get the liquor only in their mouths.

On the decline of the Egyptians and the rise of the Greeks and Romans, there was a corresponding decline of beer in favour of the true wine of the grape, the vine being represented in the Hellenic myth as the gift of $Z$ eus to Dionysus; but beer once more came to the front with the advent of the German 'barbarians''sons of malt,' as Julian called them, on account of their devotion to malt beverages. Just as the Egyptians had attributed the origin of beer to Osiris, so had Northern mythology related that Ægir was not only the ocean deity, but the one whose duty it was to brew enough ale for consumption by the other gods at their feasts; so that when, on one occasion, his cauldron was not sufficiently capacious to satisfy the requirements of all the gods of Asgard, who were to assemble at a banquet, Thor came to his assistance by securing (after many adventures) a still larger cauldron from the 
giant Hymir. It was further believed that, when the horsemen who died as heroes on the battle-field found their way to Valhalla, one of the greatest joys of the new life thus opened out to them would be an abundant supply of good liquor. With beliefs such as these, or with habits of daily life based on a generous consumption of mead or ale, it is no wonder that Scandinavian rovers and German 'barbarians' spread their own habits throughout the lands they conquered or in which they settled.

To illustrate still further the universality of stimulants, mention may be made of the fact that in Brazil guarana, which has an action like that of tea and coffee, is prepared from the nuts of a tree belonging to the same natural order as the horse-chestnut. In Peru the natives chew a preparation made from the leaves of the coca plant. Taken in small quantities, it enables them to make long-continued exertions without inconvenience, though when used to excess it causes dyspepsia, and sometimes also nervous depression and hallucinations. In Mexico a favourite drink, known as pulque, is prepared from the fermented juice of different species of agave. In many of the South Sea Islands a fermented liquor is made from the upper portion of the root and the base of the stem of a shrubby plant known as 'ava' or 'kava.' Along the tropical parts of the Western coast of Africa cola-nut is used as a stimulant, while in Africa generally the making of beer is so extensively practised by the various races and tribes that Africa has been described by one German writer as 'a beer-drinking continent.' In Japan there is a large consumption of saké, a beer made from rice, and generally drunk warm, in small vessels. Saké and tobacco are alike given out in regular rations to the troops in the Japanese Army, and, according to the official report of the Japanese 
medical officers concerning the health of the army in the war with China in I894-95, these daily rations of saké had a beneficial effect on the troops. They stimulated the spirits of the men, being especially serviceable in this respect in times of difficulty, and they were most useful in helping to protect them against the stomach ailments so prevalent in China. Nor does the history of the more recent war with Russia suggest that the Japanese troops were otherwise than benefited by their moderate, but nevertheless habitual, indulgence (so far as conditions permitted) in the national beverage.

Nations in the East which have refrained from alcoholic drinks have, nevertheless, indulged in opium or other drugs, representing stimulants in another form, and appealing, to a certain extent, to the same natural instincts. Altogether, therefore, one must seek not alone in the history of our social habits, but in human nature itself, for the causes of this universal indulgence in stimulants or narcotics in one form or another from the very earliest days of our civilization; and it would, indeed, appear that this human nature of ours will have to be entirely changed before there can be any hope of the natural instinct in question being entirely eradicated, even assuming that there is any adequate reason why it should be.

The original 'ale,' both in Britain and in Continental countries, was made from malt and water, without hops, though ground-ivy was used as a preservative, and to make the drink more palatable. It was also known to the Anglo-Saxons as 'beer,' but that name almost dropped out of use until it was revived to distinguish 'ale' from 'hopped ale,' hops being added to the latter for the purpose alike of imparting an agreeable bitter flavour to the liquor and of improving its keeping qualities. 
There is evidence of this practice having been followed in South Germany in I079, and in the Netherlands in the fourteenth century; but it does not seem to have been introduced into England until about the fifteenth century, when it was brought to Kent by some Flemish immigrants. At first the innovation was strongly disapproved. Hops were regarded as an adulterant, and Henry IV. in I400, Henry VI. in I450, and Henry VIII. in I530, are all said to have taken steps to check their use. According to writers of this period, hops might have the property of 'preserving liquors from corruption,' but they also 'dried up the body and increased melancholy.' The Common Council of the City of London even petitioned Parliament to prohibit the employment of hops in brewing, ' in regard that they would spoyl the taste of drinks and endanger the people.' It is further reported that a retailer of ale not only took proceedings against a brewer for 'spoiling' his ale by putting into it 'a certain weed called a hopp,' but even recovered damages on that account.

These prejudices on the part of our forefathers are the more noticeable because a law passed in Bavaria in the year 1516 had laid down that "in the making of beer nothing shall be used but barley, hops, and water,' thus legally establishing hops as a constituent of beer. But their use, even in England, came to be recognized in course of time. Beer brewed with hops began to take the place of ale brewed without them from about the time of Henry VI., though the beer-brewers kept themselves distinct for many years from the ale-brewers, who at first alone constituted the Brewers Company of London. Later on the words 'ale' and 'beer' were either used indiscriminately, or had different meanings in different localities. To-day, speaking generally, 
'beer' embraces all malt liquors, while 'ale' does not apply to either porter or stout.

The veneration of our ancestors for good malt liquor is beyond all possible doubt. One must bear in mind that the use of tea and coffee as breakfast drinks is of comparatively recent date in the history of this country. It was not until about 1657 that tea began to be used as a beverage, and the price in those days ranged from $£ 5$ to $£$ Io per pound, the former figure being for the cheaper qualities! Even in 1740 tea cost from $7 \mathrm{~s}$. to 24s. per pound. Coffee, again, did not come into use as an ordinary beverage in Great Britain before the eighteenth century. Until, therefore, tea and coffee had well established their position-and even for years afterwards with people who adhered to the habits and customs of the 'good old days'-ale represented the liquid part of the meal at breakfast, as well as at dinner and supper. 'A quart of ale is a dish for a King,' and it was regarded, also, as constituting a good enough dish for the King's subjects. In fact, a quart of ale at breakfast was the recognized allowance for each man or woman.

When Queen Elizabeth was on one of her royal progresses through the land, the Earl of Leicester wrote to Lord Burleigh : "There is not one drop of good drink for her. We were fain to send to London and Kenilworth and divers other places where ale was; her own bere was so strong as there was no man able to drink it.' Mary, Queen of Scots, found relief at Fotheringay for some of her troubles in a generous consumption of brown beer from Burton-on-Trent. Hugh Latimer drank a goblet of spiced ale with his supper the night before he was burned at the stake, and Sir Walter Raleigh, on the morning of his execution, indulged in a pipe of tobacco and a tankard of ale. 'See,' wrote 
Richard Atkinson to Leonard, Lord Dacre, in 1570 , 'that ye keep a noble house for beef and beer, that thereof may be praise given to God and to your honour'; and the real part that beef and beer have played in making us what we are as a nation is a phase of our history that would be well worth the telling. It was these commodities that helped to strengthen the arm of our forefathers in their gallant fights at home and abroad, and, granting that they still had the beef, it is doubtful if they would have had quite the same degree of vigour, and would have accomplished quite the same results-to the well-being of the nation-if they had had nothing stronger to wash down that beef than any possible equivalent, in those days, for ginger-ale and lemonade.

In the Middle Ages brewing was one of the ordinary duties of the housewife, and, outside the monasteries, was left almost exclusively to the women-folk. Alreck, King of Hordoland, is said to have chosen Geirland for his Queen by reason of her proficiency in brewing.

A brew-house was considered an indispensable adjunct to the premises of every well-to-do family, and in Germany, in the Middle Ages, brew-houses were established in most of the towns and villages for the common use of all the inhabitants. Both there and in England the wives and daughters of the household superintended the brewing even when they did not do the actual work, and the wages paid to domestic servants were fixed according as to whether the women engaged could both brew and make malt, or brew only. Domestic brewing, in fact, was still common late in the eighteenth century. Writing in I82I, William Cobbett said :

Forty years ago .... to have a house and not to brew was a rare thing indeed. Mr. Ellerman, an old man and a large farmer in Sussex, has recently given, in evidence before a Committee of the 
House of Commons, this fact: that forty years ago there was not a labourer in his parish that did not brew his own beer, and that now there is not one that does it, except by chance the malt be given him.

Women, again, were at one time the general maltsters, and our literature and historical records are full of references to the ale-wives of old, who both made and sold the ale that was so generally consumed. A survival of this fact is to be found in the word 'brewster,' which is still in vogue to-day in the phrase 'Brewster (or Licensing) Sessions.' 'These ale-wives had their faults and shortcomings, and severe measures were taken from time to time to ensure that they acquitted themselves well of their responsibilities, and did not commit the unpardonable crime of making bad ale.

In Saxon times it was a regulation of the City of London that the ale-wife who brewed bad liquor should have the same punishment as a 'scold,' by being placed on a cucking-stool and dipped in a pool of water. There were also fraudulent ale-wives, who either adulterated their ales with deleterious compounds or else gave short measure. For offenders of this type the cuckingstool was regarded as much too mild a punishment. A miracle play performed at Chester in the fourteenth century described how Christ descended into hell and saved the souls of those who dwelt in purgatory. But there was one hardened offender, a woman, whose crimes were past all forgiveness. In confessing her sins she said :

Some time I was a tavernere, A gentel gossepp, and a tapstere,

Of wine and ale a trusty brewer, Which woe hath me bewrought. Of cannes I kept no true measure, My cuppes I solde at my pleasure, Deceavinge many a creature,

Tho' my ale were nought. 
The good people of Chester would not tolerate the idea of pardon being extended to an ale-wife who could do such things as these, and the miracle play closed with the appearance of fiends who carried her off to the regions below to receive what was considered a just and well-merited punishment.

It is, in fact, interesting to find that in those early days licensing laws and regulations were directed, to a large extent, to making sure that the public got good liquor, in just measures, and at a reasonable price. Ale was regarded as an indispensable and most important item in the national dietary, and the sale of it was watched over with a jealous regard for the interests of the consumers, from the point of view either of their health or of their pocket. As early as I I 55 the Common Council of Augsburg passed an ordinance imposing certain punishments on brewers who offered 'bad beer' for sale, and ordering that such beer should be seized and-given to the poor! Considering, however, how little the real science of brewing was understood in those days, the occurrence of unsatisfactory brews can hardly be wondered at. In some instances rule-ofthumb methods were supplemented by the grossest superstition, as, for instance, in that German recipe of old which declared that, in order to secure alike a good brew and a good sale for the liquor, one should put in the vat the thumb of a man who had been hanged, and a piece of the rope which had hanged him.

In England, in the time of Henry III., ' the Assize of Bread and Ale,' which fixed the prices for those commodities, became a well-recognized institution, fines, or even corporal punishment, being inflicted on the brewsters who failed to observe the laws thus made. Juries of six lawful men were appointed in the several townships to see that the rulings of the Assize of Bread and 
Ale were kept, and to collect the pots and measures used in the ale-houses, test them, and see that they bore the official stamp. Then, also, ale-conners were appointed annually in the Court leet of each manor, and in boroughs and corporate towns, to try the ales that were brewed, and see that they were of the requisite strength and quality.

In the old Scottish laws it was enacted-

All women quha brewes aill to be sould, sall brew conforme to the use and consuetude of the burgh all the year. And ilk Browster sall put forth ane signe of her aill, without her house, be the window or be the dure, that it may be sene as common to all men; quhilk gif she does not, she sall pay ane unlaw (fine) of foure pennies.

It is statute that na woman sel the gallon of aill fra Pasch until Michaelmas, dearer nor twa pennies; and fra Michaelmas until Pasch, dearer nor ane pennie.

In the 'Borrow Lawes' (Burgh Laws) it was further laid down, in reference to the duties and obligations of a 'browster'-

Gif she makes gude ail, that is sufficient. Bot gif she makes euel ail, contrair to the use and consuetude of the burgh, and is convict thereof, she sall pay ane unlaw (fine) of aucht shillings, or sal suffer the justice of the burgh, that is, she sall be put upon one Cock-stule.

The old records of the City of London contain many allusions to disputes between the brewers and the authorities respecting the quality of the liquor they brewed and the prices they charged. But so much importance was attached to the keeping up of an adequate supply of good ale that special precautions were taken to guard against public inconvenience arising from a sudden reduction in the available quantity, either because the brewer did not want, or because he could not afford, to continue his business on the lines laid down. Thus, in the twenty-fourth year of Henry VIII. the Court of Common Council made order that ' in 
case the Maire and Aldermen of the same Citie shall hereafter knowe and perceyve or understonde that any of the saide Brewers, of their frowarde and perverse myndes, shall at any time hereafter sodenly forbere and absteyne from bruynge, whereby the King's subjects shoulde bee destitute or onprovided of Drynke,' the brew-houses of such 'wilfull and obstynate' brewers shall be taken possession of by the City, which shall allow others to brew there, and provide them with materials in case of need.

Then it is set forth in the 'Liber Albus' that 'if any shall refuse to brew, or shall brew a less quantity than he or she used to brew, in consequence of this ordinance' (fixing a specified price and quality), 'he or she shall be held to be a withdrawer of victual from the City, and shall be punished by imprisonment, and shall forswear his trade as a brewer within the liberties of the City for ever.' The suggestion that any brewer discontinuing, or reducing the quantity of, his supplies of ale was to be regarded as ' a withdrawer of victual from the City' is especially significant of the light in which malt liquor was regarded by our forefathers. A still earlier enactment, ordering the brewers to sell only by such vessels as bore the official seal, quaintly set forth that the giving of short measure, when ale was sold, was 'to the displeasure of God, and contrary to the profit of the City.'

The Brewers Company-whose official title is that of 'The Master and Keepers or Warden and Commonalty of the Mystery or Art of Brewers of the City of London' - received their first authentic charter on February 22, I445, in the reign of Henry VI.; but there is evidence that the brewers represented an important and wealthy craft-guild for many years before that time, and had attained to a position of considerable dignity as compared with that of the ale-wives of earlier days. They 
had their own hall as early as I422, and they had already established trade regulations which embraced, so far as was possible, every branch of their 'mystery or art.' There were some things, however, they could not regulate, and they more especially had to encounter many difficulties in maintaining the freedom and interests of the trade. Henry VI., for instance, prohibited them from using hops, which were just beginning to be widely utilized by English brewers, and Henry VIII. (a great lover of spiced ale) not only repeated this prohibition, but entered with much zeal on the policy of prescribing alike the quality and the price of ale. In so doing he paid no regard to such matters of detail as the high price of barley, and the depreciation he had himself brought about in the value of coin. Ale, from his point of view, was a necessary of life which must be supplied at a fixed price, whether such price paid the brewers or not, and protests against this policy were mostly raised in vain. In I59I, when Elizabeth was ruler, the Brewers Company sent in a remonstrance against their being compelled to sell at a price fixed sixty years previously, although every material employed in brewing had greatly increased in price. The Company even took it upon themselves to advance the price; but Elizabeth would not tolerate such a procedure on their part, and they were obliged to withdraw the advance, and be content with the prospect of doing increased business, both at home and abroad.

Further evidence of the importance attached to good wholesome ale in these bygone days is afforded by various entries in the 'Munimenta Academica' of the University of Oxford. It is there recorded that, in the year I434, 'seeing how great evils arise both to the clerks and to the townsmen of the City of Oxford owing to the negligence and dishonesty of the brewers of ale,' 
the Commissary brought the brewers together in the Church of the Blessed Mary the Virgin, and made each of them swear on the Blessed Evangelists that he would brew ale that was good and wholesome, 'so far as his ability and human frailty permits.' Lest there should be any doubt as to what constituted good and wholesome ale, the University authorities themselves laid down minute directions concerning the way in which the brewing should be conducted. But they found difficulty in enforcing their requirements, as shown by the fact that in 1449 the stewards and manciples of Canterbury College complained against nine of the brewers that they had brewed 'an ale of little or no strength, to the grave and no mean damage of the University and Town.' Then, in 1464 , John Janyn was ordered by the Commissary to refund the sum of $8 \mathrm{~d}$. to Anisia Barbour, to whom he had sold a cask of ale for 2od.; whereas, 'in our opinion,' the judgment said, ' and that of others who have just tasted it, it is not worth more than i2d.' At Cambridge, also, in the latter half of the eighteenth century, it was the practice of the municipality to appoint during the annual fair an official known as 'the lord of the tap,' who was required to visit all the booths and test the ale sold there, with a view to seeing that it was of sufficiently good quality for the persons visiting the fair.

The important part played by ale and beer in the social and domestic economy of the nation, and as sources of nourishment for the bodies of the English people, has, in fact, been well recognized throughout the ages; and when the rule-of-thumb methods of the old ale-wives were more and more succeeded by scientific processes, improved appliances, and ampler resources on the part of the masculine brewers who followed them, English ales and beers gained for themselves a great 
reputation throughout the world. They were, in fact, already famous in other lands so far back as the twelfth century. The introduction of French wines did but little to check their supremacy, wine being regarded as a luxury for the rich only; but the rivalry of spirits was much more pronounced, and, although the ales and beers in these bygone days were certainly potent enough, it was spirits that became mainly responsible for the evils of 'alcoholism.'

The process of distilling spirits is supposed to have been originally invented by the Arabs about the thirteenth century. By the end of the fifteenth century brandy had become an important article of manufacture in the wine countries, while, with the improvements in such manufacture brought about in the sixteenth century, the cost of production was substantially reduced, and the drinking of spirits spread rapidly throughout Europe. According to Camden, the English troops serving in the Low Countries did much towards introducing the practice into England; but, whether this be the case or not, the increasing consumption of spirits in place of the comparatively harmless malt beverages hitherto mainly in vogue led to some marked changes in the social and economic conditions of the times.

In 1673 , for example, there was presented to Parliament a petition which prayed 'that brandy, coffee, mum [a strong ale brewed chiefly from wheat malt, with the addition of various aromatic herbs], tea, and chocolate may be prohibited,' on the ground that these beverages greatly hindered the consumption of barley, malt, and wheat, products of the land; and the petition went on to say:

Before brandy (which is now become common, and sold in every little ale-house) came over into England in such quantities 
as it now doth, we drank good strong beer and ale, and all laborious people (which are far the greatest part of the kingdom), their bodies requiring, after hard labour, some strong drink to refresh them, did therefore every morning and evening use to drink a pot of ale or a flagon of strong beer, which greatly promoted the consumption of our own grain, and did them no great prejudice ; it hindered not their work, neither did it take away their senses, nor cost them much money, whereas (the petition continued) the prohibition of brandy would ... prevent the destruction of His Majesty's subjects, many of whom have been killed by drinking thereof, it not agreeing with their constitutions.

Then, in Hogarth's two pictures of 'Beer Street' and 'Gin Lane' the views of one of the shrewdest observers and most skilful satirists of the day as to the difference between malt liquors and ardent spirits were brought out in striking fashion. In 'Beer Street' there is a general appearance of prosperity and contentment, the only exception being the impoverished pawnbroker, who has barricaded himself in his dilapidated premises against a visit from the broker, and is receiving through a hole in the door a pot of the beverage to which the decline in his business is due. In 'Gin Lane,' on the other hand, poverty, wretchedness, and vice are triumphant, and there the pawnbroker alone is prosperous. The moral of the story thus so graphically told by the artist was that, while an undue indulgence in spirits produced much harm, beer was essentially a temperance drink, and one that as a wholesome and perfectly legitimate beverage was well deserving of encouragement.

Whatever the precise influence alcoholic liquors, especially in the form of ale and beer, may have had in the development of that stamina, energy, and enterprise which have distinguished us as a nation, and in helping us to achieve our triumphs in the past, no one can deny the importance of the rôle they have played alike in our social and our literary life. Beverages 
which the teetotallers despise even in their milder forms were the very foundation of the merrymakings, feasts, festivals, and functions in hall, in cottage, or on village green, which have been characteristic of our country from its earliest days, and did so much to win for it the name of 'Merrie England.' Let the reader try to imagine what the crirse of our social history would have been if prohibitionists or local optionists had got the controlling voice in those bygone centuries, had abolished the 'good old' English ale, and condemned the holders of feasts and festivals to drink nothing stronger than some possible representative in those days of ginger-beer or lemonade. Had that been done, Medieval England might have been more sober, but it would have been a dull country, and it is probable that that dullness would have descended, more or less, to the present generation, and left upon us a mark which would not have been to our advantage as a nation. Even as it is, the steady disappearance of festivals and merrymakings is one cause, at least, why village life is becoming more and more unattractive to village people, and why rural parishes are being more and more deserted for the attractions of the towns.

When we think, also, of the part that taverns have played in the literary life of the nation, as the meetingplace of the poets and wits of Shakespeare's, of Addison's, and of Johnson's days, and of all the sayings and the writings that the 'flowing bowl 'inspired at such gatherings, one cannot but think that English life and English literature would have been all the poorer if these and other of our great writers had lived in prohibition or no-licence days, and had had to work up their divine afflatus as best they could on strictly temperance drinks. As Dr. Robert Farquharson well said in an article contributed by him to Blackwood's 
Magazine for June, I892, presenting 'The Case for Moderate Drinking,' it would be difficult to recognize some of our literary heroes apart from their convivial pleasures.

We may be certain that Coleridge and Lamb did not toil up Hampstead Hill to drink water at the Salutation and Cat, and the merry coffee-housing of the club was mellowed by potations which stimulated the talk of Burke and Goldsmith and the appreciation of Reynolds.

We see Dickens and Forster and Stanfield and Maclise at their early dinners before the play, or at their suppers after the curtain fell, and we know that there was just enough liquor among them to warm, but not heat, and to set their tongues going with free but decorous elasticity. Sir Walter Scott's cheery little banquets, where the strictest moderation was recorded in his 'Journal,' were full of mirth and good-fellowship ; and is it likely that soda-water would have been equally successful in bringing out the best points of the guests and infusing them with a harmonious whole?

Taverns, again, were the recognized meeting-places of politicians in the days before the political club, in a more or less palatial building, became an institution in the land. They were the centre from which news and opinions alike radiated when newspapers were much rarer than they are to-day; and in pre-railway times they were the meeting-place of travellers, business men, and representatives of all types of society. Even the coffee-houses, which formed so important a feature in the social life of the country in the days of William III. and Anne, were little more than taverns under another name. Thus, in his 'Tour through the Whole Island of Great Britain, I724-27,' De Foe says of his visit to Shrewsbury that he found there 'the most coffee-houses round the Town House that ever I saw in any town, but when you come into them they are but ale-houses, only they think that the name of coffee-house gives a better air.'

Various causes have contributed to bring about the steady decline in reputation which the average tavern 
has undergone, but one of them is undoubtedly to be found in the ceaseless attempts of the teetotal party to discredit the character of places where alcoholic liquors are openly sold. Whether these attempts are sympathized with or not, every one must recognize that when the 'temperance' enthusiasts speak of those connected with the business as 'accomplices of Satan,' and declare that 'the drink traffic threatens to throttle the very life of the nation,' they overlook the teachings of history, and ignore the fact that, in spite of all the heavy drinking in which our forefathers indulged, and in spite of all the evils to which excessive indulgence has led, the life of the British nation is still very far indeed from having experienced the fate thus foreshadowed. 


\section{CHAP'TER III}

\section{HUMANITY AND STIMULANTS}

THE fact which I sought to demonstrate in the previous chapter, that in all times, in all stages of our civilization, and in all parts of the universe, the various peoples constituting the human race have-often quite independently of one another-resorted to the preparation and consumption of stimulants (among which alcoholic beverages have taken the first place), would suggest that there is a legitimate demand and use for those stimulants, in spite of all that teetotal extremists may now say to the contrary. Much discussion has taken place of late as to the 'food value' of alcoholic beverages, and considerable diversity of opinion still prevails thereon. Rightly or wrongly, successive generations have regarded beer as 'liquor bread,' basing their opinion on their own experience. But, literally, for thousands of years before the present controversy on 'food value' arose stimulants had been taken-as they still generally are-for other reasons than because of the amount of actual nutriment they might or might not contain. They were accepted as a palatable drink; they gave a feeling of warmth and helped to ward off chills; they modified the pangs of hunger; they produced a sense of enjoyment, gratification, and comfort; they gave greater zest to social intercourse; they 
lessened pain, relaxed nerves wearied by physical or mental labour, relieved the pressure of daily cares, deadened care, trouble, and anxiety, improved the outlook on life, imparted fresh vigour to the healthy man, and enabled him to surmount difficulties and perform deeds or actions which otherwise he would have regarded as beyond his powers. In one or other of these ways they appealed to wants or instincts of our common humanity, and rendered services throughout the ages which, until quite recent times, were considered sufficient in themselves, without regard to any question as to food value. Assuming, for the sake of argument, it could be proved beyond the shadow of a doubt (though this has not yet been done) that stimulants contain no nutritive value whatever, these old and original reasons for taking them-reasons coexistent with the race itself -would still remain.

Here we reach the fundamental factor of the whole situation, although it is one which the extreme sections of the temperance party have either ignored, obscured by side-issues, or thought to overcome by Acts of Parliament or oppressive enforcements of the licensing laws. Deep down in the heart of man we have got to recognize-whether we want to or not-the existence, as part of his nature and temperament, of a craving from time to time for some artificial stimulant capable of producing mental or physical effects that would not exist, or could not be secured, naturally. One might as well pass an Act of Parliament for the abolition of thirst as try to eradicate the feeling in question by legislative action. It may vary in form and intensity in different individuals, according to temperament, circumstances, and conditions; but every adult person is influenced by it, and yields to it some time or another. One cannot assume that, because a man does not take 
alcoholic drinks, therefore he does not take any stimulants at all. Opium, cocaine, quinine, and various other drugs, are extreme alternatives, but they are indulged in very largely, and, to a certain extent, answer the same purpose as alcohol. Tea, coffee, and tobacco also act as stimulants, and so do some of the special brands of patent medicines, or even pickles, catsup, and other table condiments; so that while temperance advocates scrupulously avoid beer or wine, they may still partake freely of stimulants, and even of alcohol itself, in some other than the recognized form.

Dr. Ashbel P. Grinnell, vice-president of the New York Medico-Legal Society, who has recently published a pamphlet on 'Drug Consumption and Alcohol as found in Proprietary Medicine,' is a firm believer in the theory that 'every human being craves some artificial stimulant,' and he gives the following interesting examples :

One of the most noted post-prandial speakers this world has ever produced never took anything with dinner but a glass of champagne. Without it he felt lost. With it he could recall anything he had ever heard in his life, and we waited for the morning paper to see what he had said the night before. Another man whose utterances have a world-wide reputation, who has made speeches in France, England, and Germany, which electrified his hearers and reflected credit upon us as a people, told me that his speeches were always prepared or delivered under the influence of black tea, and he ate nothing for some time before he was going to speak. Another man who was largely responsible for the Prohibitory Law, as it is called in Vermont, came to me for treatment. I told him under no circumstances to take acids. He said, 'Do you mean to tell me that I can't eat pickles?' I told him, 'Certainly': that he had a disease of the kidneys and bladder which made the use of acids impossible. He said, "I have pickles three times a day, made out of everything it is possible to make pickles from. I can't get along without pickles.' And yet this man went to the State Legislature and said, 'I can't drink beer, therefore you shan't.' This man died from pickles. ...

Let me tell you a little incident in regard to one of the most notable temperance lectures that ever appeared in this country. He was a temperance man, and did a great deal of good. His 
wife once said to me, "Isn't it possible to stop my husband drinking so much coffee? The coffee-pot is limited to four cups : he takes three of them with every meal.' And yet this man would not be guilty of taking an alcoholic stimulant.

Another man, a public temperance speaker, told me that it was impossible for him to lecture unless he was under the influence of compound tincture of gentian.

By what right a temperance speaker who either kills himself by over-indulgence in one kind of stimulant, or is hopelessly addicted to others, should want to pass laws to prevent his neighbours from taking stimulants in the form they happen to prefer is by no means clear. He might argue that his own stimulants only prejudice himself, whereas alcohol may lead a man to become a source of danger to others. But this is not necessarily the case, as the vast majority of people taking alcoholic beverages never do become a source of danger to others. If a man who drinks in moderation is to be restrained simply because he may, possibly, do injury to himself, it would be quite as logical to place an equal degree of restraint on the injudicious consumer of pickles or coffee, for a like reason. In any case, the fact remains that the desire for a stimulant may be quite as active in a teetotaller, even though he be an 'abstainer,' as in the average moderate drinker, at least.

This universal instinct or desire must, therefore, I would submit, be duly recognized, and it is precisely because the prohibitionists (while themselves affording personal evidence of its force and power) have refused to make due allowance for it, and have aimed at abolishing it altogether, that they have made so little real progress in their propaganda. They have thus become leaders of a hope which is at once forlorn and impracticable. The real question to be asked is not, "In what way can the desire for stimulants, which is known to have been implanted in man for five thousand 
years, or more, be eradicated ?' but, 'In what way can a natural instinct be responded to so that the least possible harm will result to the individual or to society ?' Such response is obviously not accorded either by water or by the liquids forming the ordinary (so-called) 'temperance drinks.' These (as I shall show later) may satisfy thirst, but they do not fulfil the other requirements to which an actual stimulant would directly appeal. Here again, therefore, the prohibitionists have had to record a direct failure. The substitutes they offer are not really substitutes at all. They may suggest other stimulants in the form of tea and coffee. But, taken to excess, tea and coffee may do quite as much harm to the drinker's system as alcohol taken to excess. The trouble, too, of making fresh tea or coffee whenever wanted deprives these beverages of any right to be considered ideal drinks, appropriate to every occasion, even if they were taken only in moderation.

The human race itself has long since decided (as I have already told) that the most convenient as well as the most acceptable form which the apparently indispensable stimulant can take is alcohol. The prohibitionists set up alcohol as a bogey which every one should avoid. They would have the world believe that not even the smallest possible quantity of alcohol can be taken into the system without doing harm, and that, therefore, not even the smallest quantity should be taken at all. To this it may be replied, on the authority of Dr. Max Schottelius, Professor of Hygiene at Freiburg University, that 'every one, including the strictest teetotallers, takes alcohol daily. Fresh bread contains $\frac{1}{2}$ per cent. of alcohol, and that,' he adds, 'is why fresh bread tastes so good.'

That much harm has been done to many individuals 
by an excessive use of intoxicating drinks is undeniable, and the result has been to bring a vast amount of wretchedness and misery into the world. But this fact does not nullify the conclusion-on the basis of the truths already stated-that there may be a perfectly legitimate use for alcohol, solong as it is used in reason, while there is, in effect, scarcely one thing connected with ourselves or our daily life which, however good in itself, would not prejudice either ourselves or others if carried to excess.

One must further admit that in no instance has the decline and fall of any of the nations on earth been due to alcohol. On the contrary, the peoples of Northern Europe, who have been, perhaps, the heaviest drinkers of all, are precisely those who, in regard alike to physical strength, mental vigour, and indomitable pluck and enterprise, have stood at the head of the nations, and made their influence most felt throughout the world. It would be too much to suggest that these results are due to the fact of their having been heavy drinkers. It is more probable that the drinking habits merely go with such physical strength and mental vigour, forming traits of the same character and disposition. In any case they have not seriously prejudiced national character, even if so well established and so popular a beverage as English ale has not actually strengthened it. Had there been any real foundation for the assertions so freely made by prohibitionists as to the deplorable consequences that follow the consumption of alcohol, the British people must long ago have become a nation of degenerates, considering the amount of liquor that has been consumed in these isles.

The position has been well put by Herr Karl Eugen Schmidt, in an article on 'The Conflict for and against Alcohol in France,' in which he says : 
If alcohol be really dangerous to the welfare of a nation, then the people who take least of it should rule the world. Who are the soberest people in Europe? They are the Spaniards, and so far are they from being rulers of the world that they hardly come into the reckoning at all in any question in which the great nations are concerned. Then, the nations which drink most should be in the lowest rank among the nations. Which is the nation that drinks most? It is the British, and the British nation is the one that does come nearest to ruling the world. Their influence is seen in America, in Australia, in Asia, and in Africa. They rule everywhere, and everywhere they are faithful to the beverages in which they indulge at home. So one must conclude that alcohol does not prejudice the greatness of a nation.

In spite of evidence such as this, the prohibitionists would abolish alcohol altogether; but until they can also abolish the aforesaid instinctive desire for stimulants in some form or other, their efforts to suppress or to discredit ordinary alcoholic beverages are only likely to lead to a resort to possibly still more harmful substitutes.

In my book on 'Licensing and Temperance in Norway, Sweden, and Denmark,' I have shown how, both in Norway and in Finland, people who were unable to procure the native brandy were consuming, not only ordinary methylated spirits, but the compound ('politur') used by French polishers in their work. In Lapland (as I learn from a Swedish gentleman who has travelled in that country) an attempt was made some years ago to prevent the sale of intoxicants, with the result that the people resorted to the chemist, and made stimulating beverages out of dental washes or the embrocations sold for the cure of rheumatism. Even in England, and especially in Lancashire, people who are now afraid to be seen going into a public-house, lest some local teetotaller may see and denounce them, will buy their pennyworth of methylated spirits from the chemist, and take that, instead of the liquor to which they have been accustomed. 
In his work on 'Disorders of Assimilation, Digestion,' etc., Sir Lauder Brunton says :

Another stimulant which is sometimes used in place of alcohol is ether. This is generally employed in manufacturing towns, and sometimes has been used by the population after they have taken the pledge to abstain from alcohol. . . . Its effect on the nervous system resembles that of alcohol, but it is produced more rapidly, and passes off more quickly.

Then there are the narcotics, which appeal to the same general instinct as the stimulants, the distinction between the two being thus described by Sir Lauder Brunton in the work just inentioned:

By stimulants we mean those things which seem to increase our vital powers for the time being, and thus to give us feelings of greater strength or comfort. By narcotics we mean such substances as lessen our relationship with the external world. When used to a slight extent, narcotics simply afford pleasure by lessening the restraining or depressing effect which external circumstances exert upon the individual.

In the latter class opium, whether taken internally or (as in China) smoked in a pipe, occupies a leading position, and Sir Lauder Brunton remarks concerning it :

In moderation opium-smoking, like opium-eating and alcohol, does not seem to interfere with, but rather to assist, labour, mental and bodily..... The chief disadvantage seems to be that the taste for opium gains, if possible, a firmer hold upon its victim than the taste for alcohol, and that there is a greater tendency to immoderate indulgence on account of the ease with which the system becomes accustomed to the drug, and the consequent necessity for an increase in the dose.

Morphia, Sir Lauder proceeds, has an effect much the same as opium, when taken internally or when taken by injection under the skin.

The progress of the craving is generally slow and fluctuating; some are able to take large doses for many years without any symptoms, whilst small quantities will bring on the most severe symptoms within a few months. There are frequent intermissions, 
during which the morbid symptoms begin to disappear, notwith. standing that the use of morphia is continued, though usually in smaller doses. The improvement usually lasts, however, only for a few months, when the dose is again increased, and the symptoms reappear and become aggravated. If no cure is effected, the ultimate result is prostration, emaciation, and death.

Of chloral, another narcotic now very much used, we are told that it is 'exceedingly dangerous, both from its power of causing rapid death when taken in an overdose, and from its destructive effects on the nervous system when taken in small doses for a long time together.'

That there is an increasing resort to the use of these drugs, whether by people who, as Sir Lauder Brunton says, 'have taken the pledge to abstain from alcohol,' or by others, is a generally recognized fact, confirmation of which comes in striking form from the United States of America-that home of prohibition. It is an old story (to which I shall revert in dealing with the subject of prohibition in general) that people in the so-called prohibition States can get all the liquor they want, if they know where to go for it, and that as much drinking and as much drunkenness are to be found there as in any of the other States in the Union. All the same, the action of the prohibitionists has led to the consumption of alcoholic drinks being regarded with a certain sense of shame by individuals who have not lost their desire or their liking for stimulants; and what is happening in the United States to-day is that people are taking very extensively to the consumption either of drugs or of patent medicines which contain, in many instances, a still larger proportion of alcohol than the recognized alcoholic drinks themselves.

Dr. Grinnell, to whom I have referred on p. 27, has made an inquiry into the subject, and has published some remarkable facts. After watching the effect of 
the (so-called) prohibitory law in Vermont and other States, where alcohol was not to be sold except for medical, chemical, or mechanical purposes, he arrived at the conclusion that many persons were using some artificial stimulant in lieu of alcohol, and he addressed a circular letter to the keepers of drug stores and general stores in the State of Vermont, asking for particulars as to their sales of various drugs. The replies he received were far from complete, and he concluded that the figures he got could be multiplied by five, and still remain below the consumption. He says concerning them :

In the regular drug stores and in 160 of the 172 general stores in the State of Vermont they sell every month $3,300,000$ doses of opium, besides what they dispense in patent medicines, and besides what the doctors dispense, which gives one and a half doses of opium to every man and woman in the State of Vermont above the age of twenty-one years every day in the year. (By dose I mean I grain of opium, $\frac{1}{8}$ grain of morphia, $\frac{1}{2}$ ounce of paregoric, and 20 drops of laudanum). And the amount consumed would average a dose to every man, woman, and child in the State of Vermont every day in the year.

Taking 69 out of 244 towns in the State (where 90 per cent. of the doctors dispense their own drugs), Ir6 of r3o drug stores reported total sales during the course of a single month as follows: Opium, $47 \mathrm{lbs}$. I2 ozs.; morphine powders, I9 lbs. I5 ozs.; morphine pills, 3,338 grs.; Dover powder, 25 lbs.; paregoric, 32 gals. I pt.; laudanum, 32 gals.; cocaine, 27 ozs. I dr. 30 grs.; chloral, 32 lbs. 4 ozs.; Indian hemp, 37 ozs. ; quinine powder, ${ }_{5}$ lbs. Io ozs. ; quinine pills, 74,200 grs. In one of two drug stores in a certain town the monthly sales include 3 pounds of opium, I gallon of paregoric, $\frac{3}{4}$ gallon of laudanum, 5 ounces of powdered quinine, and 1,0002 -grain quinine pills. 


\section{Dr. Grinnell further says :}

It may be urged that quinine is not a stimulant ; but any physician will verify my statement that to many it is a great stimulant, and a 2-grain quinine pill will flush the face as much as a drink of whisky, unless one is accustomed to its use. You can hardly find a man travelling who hasn't a bottle of quinine pills in his pocket; he says he is afraid he will have a cold, and keeps them as a guard against such a misfortune. . . .

For several years I appointed medical examiners for life insurance companies doing business in Vermont and New Hampshire. . . . The companies told me that the States where they had the most trouble with drunken doctors were Prohibition States, and they showed me statistics in regard to it.

The officer in command at Fort Ethan Allen told me that he had had charge of United States troops in many military stations in the West, where drinking-saloons outnumbered other places of abode, and that he never had so many in the guard-house for drunkenness as he had in Vermont.

No less significant is the enormous increase in the taking of patent medicines containing alcohol. In the report for I9O2 of the Massachusetts State Board of Health analyses were given of sixty-one well-known and widely patronized ' tonics,' 'bitters,' and other proprietary medicines, showing the percentage of alcohol in each. The range was from 6 to $47^{\circ} 5$ per cent., the average being $20^{\circ} 4$ per cent. Included in the sixty-one were nine which had been advertised as follows, the amount of alcohol they had been found to contain being appended :

' Not a rum drink' $\quad \ldots \quad \quad \ldots \quad \ldots \ldots \ldots$ I3²

'Purely vegetable, recommended for inebriates' ... $4 \mathrm{II}^{\circ} 6$

'Entirely harmless' ... , .. $\quad \ldots \quad$.. 19.5

' Not an alcoholic beverage' ... $\quad . .6 \quad \ldots \quad 66^{\circ}$

'Entirely vegetable and free from alcoholic stimu-

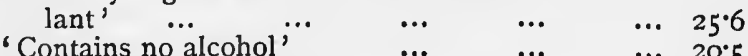

'Contains no alcohol $\quad \ldots . \quad \ldots \quad$... $20^{\circ} 5$

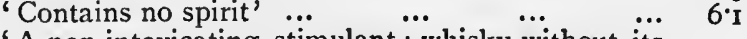

'A non-intoxicating stimulant: whisky without its sting' $\quad \ldots \quad$... $\quad \ldots \quad \ldots \quad \ldots \quad \ldots \quad 28.2$

'Recommended for treatment of alcoholic habit $\begin{array}{ll}28.5 \\ 26.5\end{array}$ 
In reproducing the full list in his pamphlet, $\mathrm{Dr}$. Grinnell says :

It will be noted in this list that thirty-four samples contain one. fifth or more of alcohol. . . Fifteen of the sixty-one samples examined contained one-fourth or more of alcohol, ten samples contained one-third or more of alcohol, four samples contained nearly one-half.

All the bottles containing these different tonics were surrounded by a label with full directions as to use, in various doses from a teaspoonful to a wineglassful, to be taken from one to four times a day, and increased as needed.

Dr. Grinnell further relates that Dr. A. J. Reed, of the Battle Creek Sanatorium, recently made for the periodical, the Lifeboat, of Himsdale, Illinois, an interesting experiment, for the purpose of further testing the amount of alcohol in patent medicines. In four different cans he put a tablespoonful each of 'Hostetter's Stomach Bitters,' 'Peruna,' 'Lydia Pinkham's Vegetable Compound,' and beer. Each was connected by a rubber tube to a gas-burner and mantle, heat was applied, and the vapour produced was ignited and burned as follows :

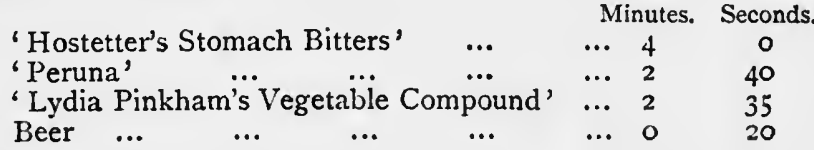

The significance of these remarkable facts becomes greater still when one learns that the tonics and bitters in question have their largest sale in those very States where the most active efforts are made to enforce prohibition. Admitting that a certain percentage are taken for strictly medical purposes, it may fairly be assumed that, in their case, as of the drugs previously referred to, a substantial part of the consumption is directly due to the craving for some stimulant to take the place of the ordinary beers, wines, or 
spirits, the use of which has been either checked by the law, or, under the influence of teetotal sentiment, discredited by public opinion.

Whether or not, however, the consumers of these pernicious drugs realize that in taking them they are consuming alcohol in one of its worst, because one of its most treacherous, forms is open to doubt. In some cases they do, but in many instances they do not. All they may know and feel is that the drug has a stimulating effect on them, and they take it accordingly, with, it sometimes happens, the most deplorable results. Towards the end of rgo6 a lady, who had been a prominent and active supporter of the temperance movement in England, died under circumstances that were somewhat mysterious, and a post-mortem examination was made. It revealed the existence of alcoholic disease of the liver, and the fact was then recalled that for a long time she had been in the habit of dosing herself with a certain tonic, which, unknown to herself, contained a large percentage of alcohol. The craving for a stimulant had been felt by the unfortunate lady, and while, probably, warning people around her of the dangers of 'drinking,' she had herself succumbed to the instinct she had sought to overcome in others.

The insidious nature of the business and the gravity of the mischief resulting from it-though the full ramifications thereof have not yet been sufficiently realizedcertainly call for legislative action; and it is satisfactory to know that in America the policy adopted in 1906 by Mr. John W. Yerkes, Commissioner of International Revenue, in requiring all druggists selling intoxicating tonics under the form of medicines to take out liquor licences, has been followed by a provision in the Pure Food Act, which came into force on January I, I907, requiring that all malt tonics and malt extracts passing 
from one State to another, and offered for sale by druggists as possessing medicinal qualities, shall bear a label setting forth the percentage of alcohol (if any) they contain.

These have clearly been steps in the right direction, and the policy thus adopted in the United States is one that may well be commended to the notice of the authorities in Great Britain, where the 'drug habit' is not only steadily growing, but is likely to receive still further encouragement if the American producers of quack medicines, finding their sales in their own country checked somewhat under the new regulations now in force, seek to find a still larger market in this country for their concoctions than they do already.

My own particular concern with this drug habit, however, is the further evidence it offers in support of the contention here advanced: (I) That the desire for occasional stimulants is so deeply implanted in human nature, as an integral part thereof, that one cannot hope to eradicate it altogether ; (2) that, if checked in the form of a moderate consumption of ordinary alcoholic beverages, it may assume some other form much more injurious to the individual, if not eventually to society; and (3) that the combination of these two facts simply serves to establish more clearly than ever the raison d'être for that trade in alcoholic drinks which aims at supplying, in legalized fashion, and under effective control, what must, in face of the truths here advanced, unquestionably be regarded as 'a public want.' 


\section{CHAPTER IV}

\section{PROHIBITIONIST EXAGGERATIONS}

Following up the arguments already advanced, one comes next to the proposition that if, as the story of the ages shows, the consumption of stimulants in the form of alcohol really responds to an undeniable need on the part of human nature, alike psychologically and physically, then such consumption must be regarded as perfectly legitimate, provided that a due distinction is maintained between use and abuse.

The prohibitionists, however, will recognize no such distinction. They seem to regard the moderate drinker, who uses alcohol discreetly, as even more deserving of their reprobation than the drunkard who abuses it persistently. International conferences where British and American teetotal extremists have come into collision with Continental temperance advocates having more liberal ideas on the question have been scenes of passionate declamation on the part of the representatives whose policy is one of the most absolute 'total abstinence.'

Just, again, as the latter party persist in confounding use and abuse, so also will they draw no distinction between beverages with different degrees of alcoholic strength. Having first confounded the moderate drinker with the drunkard, they next put even the lightest 
qualities of ale or beer under the same ban of condemnation as the strongest of spirits. They describe them both as 'drink,' irrespective of obvious distinctions, and proceed to rail against such 'drink' as though it represented only a single beverage, and that the most fiery.

An attitude of this kind is both illogical and regrettable. If the so-called 'temperance' party would direct their campaign against the abuses of alcohol, they would gain a substantially larger measure of public support. If they would even refrain from regarding beer and spirits from exactly the same standpoint, they would appeal much more to public reason. Far greater progress might thus be made by them in promoting the sobriety of the nation. Such sobriety would, indeed, be at once assured if only the British people all became strictly moderate drinkers of beer or wine. The 'liquor question,' which only came in with the introduction of spirits, would then be a question no longer.

The evils that are really caused by drink are undeniably and deplorably great. Every one is aware of that fact, not only from what he reads and hears, but also from what he sees within the limits of his own circle of acquaintance. Yet here one cannot acquit the prohibitionists of great exaggeration. They look on society from one standpoint only, and they conclude, and would have the world believe, that 'drink' is the one great cause alike of crime, lunacy, poverty, pauperism, and so on, ignoring every other consideration, and making 'drink' responsible for much more than is its due.

In regard to crime, this tendency to exaggeration has been especially marked. Every one is acquainted with the familiar declaration, 'It is drink that fills our gaols.' 
The cry is constantly being repeated, with variations, on temperance platforms throughout the land, though different speakers give different figures as to the exact proportion of crimes attributable to drink, some putting it at half, others at three-fifths, and others even at ninetenths, according to the vigour of their imagination.

I once asked the chief clerk at one of the leading police-courts in London what he thought of the allegation that the great majority of crimes and offences must be attributed to drink, and he replied:

I have often heard the statement, but, in my experience, drink is the real cause of crime in only a comparatively small number of instances. I know that in many cases drunkenness is pleaded as an extenuating circumstance, because it is supposed to influence the magistrate's mind; but, personally, I never pay any attention to it. The wife of a man who is charged with assaulting her will often say, 'Please, sir, he did it when he was drunk. He's a very good husband when he's sober.' But I generally find he's the sort of brute who would ill-treat his wife whatever his condition. As for serious crime, do you think that a burglar, a swindler, or a forger would get drunk before he committed his misdeed?

This view is well confirmed by a statement made by the Rev. J. Cartmel Robinson, of Chiswick, on the results of a mission he conducted among the convicts at Dartmoor in the autumn of 1905 :

The deepest impression I have brought away from Dartmoor is that drink is not responsible for the serious crimes to anything like. the extent some people imagine. Yes, and I was surprised myself at the discovery. Drink and crime have been so long associated in the public mind that I confess, as a teetotaller, I held the common opinion myself. My experience at Dartmoor forces me to change my opinion. It is an instructive point to all who are concerned with the problems of crime, and I submit it as one worthy of a broader consideration than it has yet received. It is so easy to generalize and say drink is the cause of nearly all crimes. No one wants to minimize the evils of drink. My impression, however, is that the men who are undergoing the long sentences are, as a general rule, not the victims of drink. Many of them, I found, had been lifelong teetotallers. Nay, some of the worst offences had been committed by teetotallers. From which it is an obvious deduction that teetotallism, whatever its undeniably good effects 
on so many people, must not be regarded, as some of its extreme adherents regard it, as a sufficient safeguard in itself against crime. Some of my friends may not like this frank admission, but I speak of what 1 found at Dartmoor.

A like conclusion was formed at Dartmoor by a special correspondent of the Tribune, who went there to inquire into the conditions of prison life. After speaking of the wonderful natural ability shown by confirmed criminals of all classes, from high-class swindlers and forgers to burglars and others, he added:

A strange statement this to make, but the bulk of these specialists in crime who represent the genius of evil are confirmed teetotallers !

When one comes to look both at the past history of our race and at the actual conditions of our everyday existence, the conclusion must be formed that, as a direct instigator of crime and evil in the world, alcohol has played, and still plays, quite a minor rôle as compared with other influences that have been leading causes of human action, including therein influences which, fundamentally, would seem to be implanted in man for the purpose of ensuring for him the greatest possible good.

Taking the religious instinct as the highest of all among these various factors, the reader of history stands appalled at that awful catalogue of crimes and merciless cruelties inspired throughout the ages by superstition, fanaticism, and bigotry. The religious wars of the Mohammedan tribes, the alternate persecutions of Protestants and Catholics, of Church and Dissent, the horrors of the Inquisition, the cold-blooded barbarities inflicted by Spain on the Netherlands, and even the massacres of Jews in Russia in our own day, far exceed in horror anything that could be set down under the head of crimes directly due to alcohol. In such catalogue, indeed, there is no suggestion that the 
evil done was due in any way to intoxicating drinks. It was not from this source that Torquemada and the Duke of Alva drew their inspiration. It was rather from the aforesaid religious instinct. Yet none but an Atheist would be likely to suggest that, because such things may have been done in the name of religion, therefore we should seek to abolish religion, and abstain entirely from whatever the religious instinct prompts us to do.

What shall we say, again, of the crimes and the evil done in the name of greed? In itself the desire for wealth, property, possessions, or higher rank, is not only natural and pardonable, but is an essential factor in that spirit of progress which raises man above the animals, and inspires the advancement both of individuals and of nations. But, carried to extremes, or not held in check by considerations of right or wrong, such desire has instigated endless cruelty, injustice, or wrongdoing on the part alike of conquerors, of peoples, and of unscrupulous persons. Did not the Apostle Paul himself write (and wrongly so, if the theory of the prohibitionists be correct) that 'the love of money,' and not of alcohol, 'is the root of all evil'? And the evil springing from such love once more far exceeds in gravity and extent the evil that has been done by an excessive consumption of intoxicating drinks. Yet, again, no one to-day suggests that we should totally abstain from money, and eradicate entirely either the desire for its possession or the instinct that inspires the wish for personal or national wealth and advancement.

Then there is the varied series of crimes and offences having their rise in that most potent of human instincts, known either as love or as lust, according to the particular form it may assume. A perfectly natural instinct in itself, for, though Dame Nature troubles herself but 
little about the individual, she is greatly concerned in the preservation of a species, and she has planted in man, in common with the animal world in general, such impulses that continuity will be assured. But what a list of shocking deeds or unhappy consequences following on the promptings of this, in itself, natural instinct one could make up! What a record we should have if we could only be told of all the enormities committed, of all the persons ruined body or soul, as the direct and direful result of what poets are pleased to call ' the tender passion'! Once more the corresponding record of like results due to alcohol becomes insignificant in comparison. Yet not even here does anyone (except a certain party of fanatics in the United States) suggest that, because these conditions exist, therefore there should be total abstinence from the said tender passion, or any uprooting of an instinct which needs only-but does indeed need-to be wisely controlled.

There are other sources of crime as well, such as anger, hatred, malice, vengeance, extravagance of living, poverty from unemployment, or an exaggerated sense of social, economic, or political injustice; while Professor Cesare Lombroso, of Turin, in his work, "The Criminal,' has shown, as the result of psychological studies carried on for twenty years, that 40 per cent. of all habitual delinquents belong to a well-defined anthropological type which he styles the 'born criminal' (delinquente nato). In this type he found atavism, moral insanity, and epileptic degeneracy, either predominating one over the other, or forming a strange admixture of psychological peculiarities in harmony with abnormalities in the anatomical structure and physiological functions. In the formation of the head and face of many criminals of this type, Lombroso observed characteristics either of prehistoric people or of people still 
living in a state of barbarism, and in their soul-life he discovered inclinations and passions (such, for instance, as cannibalism) which have been in past ages, or still are, prevalent among savage tribes.

In view of all the considerations here presented, there are obviously many other, and even much more powerful, factors in the production of crime and evil in the world than the drinking of alcoholic beverages, and the extremists who would attribute everything to this one cause cannot have studied adequately the various factors of what is really a very complex situation.

Coming into the domain of actual statistics concerning drunkenness and crime, the prohibitionists will gain no support for their arguments from the Judicial Statistics of the United Kingdom for I905, published in February, I907. In his introduction to the return, Sir John Macdonell, C.B., LL.D., Master of the Supreme Court, deals with the "difficult question whether crimes vary with the consumption of alcohol, as asserted by certain statisticians.' He finds there is no complete information on which a definite conclusion can be based, and he expresses the view that the extent of consumption follows the movements of trade, increasing when it is prosperous and decreasing when it is bad. 'Yet,' he says, 'the reverse is, generally speaking, true of crimes against property,' and that class of offences is one which constitutes a large percentage of the whole. It would seem, in effect, that when trade is good people drink more and commit fewer crimes, and when trade is bad they drink less and commit more crimes.

Sir John Macdonell naturally finds that drunkenness is the cause of many crimes, and the accompaniment of many others. These are facts which everybody admits. The real question is whether or not the actual relation- 
ship between drink and crime is not unduly magnified, and whether it exists to such an extent that society must arise, and, in defence of its own interests, insist on prohibitory measures being enacted against the entire community, with a view to the abolition of so potent a 'cause' of crime as alcoholic beverages are alleged to represent. On this point Sir John Macdonell goes on to say that the theory of correspondence between crime and drunkenness ' must be viewed with caution.'

It has been more especially represented that, while the perpetrators of crimes of the higher typeburglaries, forgeries, etc. - may avoid intoxicants when committing their deeds, drink is, nevertheless, a great instigator of acts of violence. But even here the judicial statistics do not support the prohibitionist view, for Sir John Macdonell gives a table covering ten years which suggests that there is really no relationship between cases of drunkenness and the number of assaults committed, although these, he remarks, are 'two kinds of offences as to which might be expected the closest affinity.' His table, in which the figures given are calculated per I00,000 of the population, is as follows :

\begin{tabular}{|cccc|c|c|}
\hline \multicolumn{3}{|c|}{ Year. } & & $\begin{array}{c}\text { Prosecutions } \\
\text { for } \\
\text { Drukenness. }\end{array}$ & $\begin{array}{c}\text { Prosecutions } \\
\text { for } \\
\text { Assaults. }\end{array}$ \\
& & & & \\
1896 & $\ldots$ & $\ldots$ & $\ldots$ & 608 & 237 \\
1897 & $\ldots$ & $\ldots$ & $\ldots$ & 620 & 235 \\
1898 & $\ldots$ & $\ldots$ & $\ldots$ & 643 & 230 \\
1899 & $\ldots$ & $\ldots$ & $\ldots$ & 672 & 231 \\
1900 & $\ldots$ & $\ldots$ & $\ldots$ & 634 & 203 \\
1901 & $\ldots$ & $\ldots$ & $\ldots$ & 645 & 197 \\
1902 & $\ldots$ & $\ldots$ & $\ldots$ & 636 & 186 \\
1903 & $\ldots$ & $\ldots$ & $\ldots$ & 690 & 175 \\
1904 & $\ldots$ & $\ldots$ & $\ldots$ & 674 & 163 \\
1905 & $\ldots$ & $\ldots$ & $\ldots$ & 642 & 155 \\
\hline
\end{tabular}


It will be seen from these figures that the cases of drunkenness were especially high in 1903 and I904, yet in those same years the cases of assault were especially low. Where, then, is the evidence, not merely of the closest affinity, but of any affinity at all between the two kinds of offences?

In regard to insanity, the ordinary course of reasoning is extremely simple. If a person who becomes insane is also addicted to drink, it is assumed that the insanity has been the result of the drink. In the reports of the Commissioners in Lunacy the 'causes' of the insanity of persons under detention are all duly specified and catalogued, and the fact that the total under the head of 'intemperance in drink' is always considerable is readily seized upon by the prohibitionists as proof of their assertion that 'drink fills our asylums.' Even on the basis of the official figures such a statement is an obvious exaggeration, because, apart from the many other 'physical causes,' the average annual admissions from 'intemperance in drink'-3,347-is still below the total-4,313-of those whose lunacy is attributed to exclusively 'moral causes,' such as domestic trouble, including loss of relatives and friends (responsible for I,309 cases) ; adverse circumstances, including business anxieties and pecuniary difficulties (988); mental anxiety, 'worry,' and overwork (1203) ; religious excitement (299); love affairs (254); fright and nervous shock (260).

It is, however, a matter for serious consideration whether intemperance in drink is not oftener merely a symptom than an actual cause of insanity. Many thousands of persons in this country are habitually intemperate without becoming insane. Were drink alone a cause of insanity, then a far larger number of persons should be affected. If a given number of indi- 
viduals were either to take prussic acid or to eat heartily of diseased meat, one would expect them all to show signs of poisoning, as a direct consequence of what they had taken into their system. But in no such sense as this is alcohol a cause of insanity, and the fact that only a very small proportion indeed of those who drink alcoholic liquors, even to excess, become insane suggests that there must be other causes for the insanity than merely the liquor that is consumed. The excessive drinking may be evidence of a breakdown of moral control, or an active manifestation of abnormal physical conditions indicative of actual lunacy, or of a disposition thereto; but it does not necessarily follow that drink bears the same relation to lunacy which cause does to effect.

These points were brought out very clearly by a correspondent of The Times in a series of articles on "The Growth of Insanity' published in that journal in I906, the concluding one being given on December 27 in that year. The correspondent argued, among other things-

That the commonly accepted 'causes' of insanity, such as inheritance, intemperance, emotion, and so forth, are conditions constantly affecting large numbers of persons who do not become insane, and that no 'causation,' in the proper sense of the word, can be attributed to them. The vera causa in every case must be some changed condition of the blood or tissues, of such a kind as to produce disturbance of function in the brain-cells which are sub. servient to thought, and also, if sufficiently severe or long continued, to produce degeneration of their structure.

$\mathrm{He}$ further declared that there had been no substantial advance of knowledge with regard either to the causation of insanity, to the recognition of warnings that it may be impending, or to the discovery of means by which it may be prevented or cured. He himself considered there could be little reasonable doubt that insanity is essentially toxic in its origin. 'The toxins 
may be microbic, derived from intruders from without, or they may afford illustrations of self-poisoning by the defective performance of secreting or excreting functions; but it is practically certain that they must be present.' He thought it more likely, on the whole, that excessive drinking is caused by a tendency towards insanity, with consequent diminution of self-control, than that insanity is caused by drinking, and he added on this point :

I remember that, some years ago, a remarkable increase of insanity in certain counties was coincident with an equally remarkable diminution in the quantity of beer consumed within their limits; and it then seemed probable that agricultural distress was mainly responsible for both conditions-for the insanity as well as for the sobriety.

Some of the theories advanced by this expert in the course of his articles did not escape adverse criticism; but his remarks in regard to intemperance and lunacy seem to be well founded, and to have, at least, more weight on their side than is to be found in the customary sweeping assertions of prejudiced temperance advocates.

When they come to speak of poverty and destitution as caused by undue indulgence in drink, the prohibitionists would appear to be on surer ground. There are innumerable instances of families which have been ruined and brought into dire distress because the breadwinner, with no special provocation thereto, has spent on drink the money that should have been devoted to the maintenance of his wife and children. On the other hand, there are a vast number of people who become poor first, and take to drink afterwards as a means of drowning or alleviating their trouble. Their poverty may be due to bereavement, to misfortune in business, to loss of employment, to ill-health, to old age, to natural indolence or lack of capacity, to a want of moral fibre, or to various other causes which, in them- 


\section{0 \\ PROHIBITIONIST EXAGGERATIONS}

selves, have no direct concern with intoxicants. But, becoming poor, they may find that the only harbour of refuge open to them, the only place where they can be sure of warmth, shelter, and comfort, is the publichouse; and the beverages sold there they may regard, not alone as liquid food, but as a means of ensuring them temporary forgetfulness from their troubles. So they ' take to drink,' but their drunkenness is due to their poverty, rather than their poverty to their drunkenness. They may end their days in the workhouse; but one cannot fairly include them among the 'victims' of drink. 'Victims of misfortune' would be a more appropriate term.

Then come the victims of industrial conditions. There are men of the casual type, such as dockers or other riverside labourers, whose work is intermittent, who endure much exposure, and who, on obtaining a job of work, feel the need of a stimulant to brace them up for the more or less exhausting effort that such work may involve. There are trades, such as glass-blowing or metal-working, where the nature of the occupation is naturally provocative of thirst; and there are others where the taking of liquor at certain stated hours during the day is a recognized custom, which only men who are especially strong-minded would attempt to disregard.

There are, next, the victims of social or domestic conditions-those, namely, who cannot help drinking to excess among their fellows, or who frequent the public-house as an alternative to squalid tenements or the discomforts of an unhappy home life.

These are conditions, again, that may lead to such a degree of drinking as will materially affect the circumstances of the individual; but in each instance there are factors other than drink that are concerned both in the cause and the cure of the evil, and to attribute 
entirely to 'drink' such poverty as might eventually arise in the case of men and women so situated would leave these other factors entirely out of consideration, and convey an impression that would be absolutely misleading.

No denouncer of social evils would probably be more ready than Father Bernard Vaughan to condemn alcoholic beverages if he really thought them a leading cause of destitution. Yet in a speech he delivered at Liverpool on February 5, 1907, this eminent authority on present-day conditions said:

Let them look things squarely in the face. They ought to ask themselves whether they had done their duty to their servants and to the poor in the street. The other day when he offered $2 \mathrm{~d}$. to a man in the street he was told by his companion he would only spend it upon drink. And he replied 'Why not?' Was he to be the only man without $2 \mathrm{~d}$. for a glass of beer if he wanted it? Fie upon those who prevented the poor from getting a drink while they emptied the decanter themselves! They were told by some that all this poverty was due to drink. What fudge and nonsense people could talk! It was all blithering idiocy! There was not a word of truth in it. Some of the poverty came from drink, but if these poor people were better physically set up, even that much poverty would not come from drink. The drink upset them, because they had no food to take with it. Let them have food, and the drink would not do them so much harm. Much poverty was caused by the rush from the country into the towns, people thinking that the cities were paved with gold, that every one wanted their employ, and that they would soon find work. At last they found they had gone from bad to worse, until their children were mentally, morally, and physically incapable of fighting with the aliens, who could live upon less, and the bits which they otherwise might have picked up were snatched from them by these foreigners. And thus the poor English were left to starve, and those whom they brought into this world were not properly fed and clothed, and when they grew up to an age when they ought to seek their own livelihood there was nothing they were capable of doing that was at hand. So they became numbered amongst the submerged.

The tendency to fasten upon some single cause, and to attribute thereto every possible defect, disadvantage, or shortcoming in our daily life, is one as old as humanity itself. In the childhood of our race it was 
the gods who did everything, even the ordinary natural phenomena being simply manifestations of their will or movement. In the Middle Ages plagues and pestilences were regarded as punishments inflicted on the people by the Almighty because of their sins, instead of being traced to a wholesale neglect of the laws of health and sanitation. Minor evils were all attributed to so-called witches, who were ducked, drowned, or burned at the stake with no more consideration than the average prohibitionist to-day would show in evicting (if he might) the average publican. Religious fanatics in Spain once regarded Protestants as the source of all misfortune, and burned them, too. Protestant reformers in England preached that the Mass was 'the fountain of all impurity and the source of every evil that exists in the world,' and they, in turn, tried to get rid of the Papists. Prynne, in 1633, declared that dancing was the source of all crimes. 'So many steps in a dance,' he said, 'so many paces to hell.' Now it has become the fashion to say that alcohol is the source of all evil. 'So many drinks in a public-house,' we are told (in effect), 'so many paces to the gaol, the asylum, or the workhouse.'

If all the ills that afflict mankind could thus be reduced to one primal cause, or if all the enemies to our social welfare possessed only one neck in common, capable of being severed at a single blow, the position would be greatly simplified. It would, besides, save a vast amount of mental exertion. Instead of thinking out things, collecting data from a great variety of sources, and gradually deducing trustworthy conclusions therefrom, one would start with certain conclusions ready made, accept anything that seemed to support them, and ignore everything else. You check the one source of all evil, or you take off the head of the 
one enemy whom you imagine to be doing all the mischief, and the complete regeneration of mankind begins at once.

But, as it happens, social and economic conditions in this extremely complex world of ours are not capable of being disposed of, or of being regenerated, in this very simple fashion. It is really childish to suppose that all the crime and evil done in the world would cease if only the supply of alcoholic drink were stopped. It is even doubtful if they would be seriously diminished, unless those other causes I have mentioned could all be abolished as well. Nor would lunacy, so largely due to physiological or psychological defects or influences, or poverty, so often a precursor rather than a consequence of drink, necessarily vanish, or even, again, be very materially decreased, if beer, wines, or spirits disappeared from the list of popular beverages.

As for the habitual drunkards, their position offers so many special considerations that to them I must devote a separate chapter. 


\section{CHAPTER V}

\section{THE TRUE MORAL OF HABITUAL DRUNKENNESS}

MANY of the strongest arguments advanced by prohibitionists, local optionists, and anti-alcoholists in general, are based on the more or less ' awful examples' of individuals who are 'slaves to drink'; on statistics of convictions for drunkenness ; or on statements, which never fail to produce their effect at temperance meetings, as to the extent to which drunkenness 'helps to fill our gaols and lunatic asylums.' On facts and assertions of this type is generally based the contention that, because conditions are as thus represented, therefore temptation should be removed from the path of the drunkard; therefore the opportunities for the purchase of alcoholic beverages should be greatly reduced, if not abolished altogether; and therefore those who take such beverages in moderation, and without any injury to themselves, may well be called upon to make sacrifices, forgo pleasures, and suffer inconveniences in obtaining what they regard as necessaries, in order that the interests of the possible victims of excess may be duly safeguarded.

From this point of view it becomes a matter of some importance to study the natural condition and temperament of the drunkard for whose welfare these par- 
ticular demands are made on society, and to consider whether the sacrifices in question are really called for by the circumstances of the case.

Is drunkenness, in fact, the result simply of combined social and licensing conditions, and capable of repression by a resort to severely restrictive measures; or are there psychological, neurotic, physiological, and other factors which require to be taken into most serious consideration before one can arrive at a really trustworthy conclusion?

Various German medical authorities who have studied the subject from the latter point of view are of opinion that, instead of nervous weakness or disease and various other forms of physical degeneracy being the result of drunkenness, they are very often only a cause thereof; but such of the statements to this effect as have come under my notice are somewhat lacking in completeness, and are based mainly on general lines, without confirmatory data. Much more valuable and much more convincing, from my present standpoint, is the Report presented to Parliament in November, Ig06, by the inspector under the Inebriates Acts, I879 to I900 (Mr. R. Welsh Branthwaite), for the year I905. Here one finds, in addition to the ordinary annual report, a most careful study of the characteristics of habitual drunkards, as met with in the reformatories established under the Acts in question; and this study must carry the greater weight because it is based on definite experiences, and is the work of a Government official, free from prejudices, and dealing only with facts as he has found them.

One learns from the Report that down to the end of I905 the number of persons who had been committed to the reformatories for inebriates was $I, 873$, and these are grouped, in respect to mental condition, as follows: 


\section{MORAL OF HABITUAL DRUNKENNESS}

(I) Insane (certified and sent to asylums), 48 ; (2) very defective (imbeciles, degenerates, epileptics), 27I ; (3) defective (the same as (2), but less marked, eccentric, silly, dull, senile, or subject to periodical paroxysms of ungovernable temper), 857; (4) of average mental capacity on admission or after six months' detention, 697. Thus, the insane, the very defective, and the defective, form $62^{\circ} 7$ per cent. of the total, and those of average mental capacity $37^{\circ} 3$ per cent. The significance of the former figure is most striking, but it becomes still more so as Mr. Branthwaite proceeds to deal with the various causes which lead to so high a proportion.

In regard to the first of the four groups the inspector says :

Amongst the forty-eight persons classified as insane none have been included except those actually certified during their reformatory sentence and sent to asylums. Some of these, when first admitted to reformatories, were found to be suffering from delusions; others were in an excited state which merged into mania; a third section contained persons obviously demented; a fourth melancholic and suicidal; a fifth epileptic, with attacks of violent mania; and a sixth were the subjects of recurrent mania, which developed and subsided, in some cases, two or three times during the period of their detention as inebriates. It is, therefore, certain that the large majority of inmates of this description were either actually insane during their police-court history* or in a state

* Four previous convictions in a year must be proved against an habitual drunkard before he or she can be committed to a reformatory for inebriates. In an appendix to the Report there is given the prison history of two cases so dealt with. One of these refers to a woman, now forty-one years of age, who, between January 28, I881, and December 9, I905, made no fewer than II4 appearances before the magistrates, principally for drunkenness and disorderly conduct. She 'qualified' for a reformatory in June, r881, when she was seventeen years of age, but was not actually sent to one until charged for the II 5 th time on December $29,1905$. In the other case a woman of the same age was first convicted of disorderly conduct in 1887 , and was sent to a reformatory in 1905 , âfter 99 convictions. 
bordering on insanity, and that mental disease was the condition for which they were repeatedly imprisoned-mental disease masked by alcoholic indulgence. What the exact relationship is between drunkenness and insanity in these cases is exceedingly difficult to determine. Sentenced to reformatories as 'habitual drunkards,' they were found (when admitted) to be actually lunatic, or on the verge of insanity.

Prohibitionists will at once suggest that the insanity was caused by drink, and they may assume that such facts as these only support their own theories. It is important, therefore, to see what Mr. Branthwaite has to say on this point. He proceeds :

Ordinary experience indicates that the mental disease, in some cases, may be due to tissue degeneration produced by persistent alcoholisni, to repeated alcoholic epileptiform convulsions, and recurrent attacks of delirium tremens, or to shock to the nervous system arising from the sudden discontinuance of alcohol which accompanies every prison sentence. But, notwithstanding this, I am satisfied that the majority of our insane inebriates have become alcoholic because of congenital defect or tendency to insanity, not insane as the result of alcoholism, and that the drunkenness which preceded alcoholic insanity was merely the herald-the obvious sign-of incipient mental disorder. In relation to the final insanity, drunkenness in such cases is the intensifier, perhaps, but not the cause, of the disease.

In the official statistics of insanity the persons here referred to would doubtless be described as insane owing to 'drink,' and they would be pointed to by prohibitionist speakers as melancholy victims of the publican. But in these cases, at least, we see that drunkenness was a symptom, rather than a cause, of their insanity, and the same condition would probably apply to many other inmates of lunatic asylums whose insanity is attributed to 'drink,' though they may not have passed through a home for inebriates. Apart, therefore, from the fact that there is often a good deal of exaggeration in prohibitionist references to insanity, one finds that, even where the figures themselves may be correctly given, the proportion of cases said to be 


\section{MORAL OF HABITUAL DRUNKENNESS}

due to 'drink' must be subjected to considerable modification from the point of view advanced by $\mathrm{Mr}$. Branthwaite.

Classes (2) and (3) are considered by the inspector together, the characteristics of both being the same, except in degree. In the term 'defective,' he says, he includes every person admitted to reformatories who is found to be 'below an average standard of mental capacity, but insufficiently so to justify a certificate of insanity, or only now and then certifiably insane during short, transient paroxysms.' On this point the inspector asserts that 'mental incompetence, stopping short of insanity, holds a prominent position in the causation of habitual drunkenness, and that complete irresponsibility for drunkenness may result therefrom.' He continues:

Certain peculiarities in cranial conformation, general physique, and conduct, have long been recognized as evidences of congenital defect. Nearly all the I,I 28 cases included in the defective sections of our table have given evidence of possessing some of these characteristic peculiarities, and it is morally certain that the large majority of them started life handicapped by weakness.

Perhaps the most conclusive evidence of congenital defect from a scientific point of view is the presence of certain physical signs of arrested or distorted development. Many instances of stunted growth can be found amongst our inebriates-abnormally small heads, misshapen heads, and case after case of developmental arrest or irregularity in upper and lower jaw. There are plenty of examples of the thin-faced congenital, with high cheek-bones, deeply placed eyes, projecting ears, and shifty, haunted expression; but more common in women is the heavy, repulsive, masculine type, with a tendency to violence and brutality, beady eyes, square jaws, and dull, flabby, expressionless face. Features are often asymmetrical, nose misplaced, eyes irregular, and some abnormalities in palate and in dental formation have also been noted. In short, the same physical abnormalities are to be found in defective inebriates as are present amongst idiots and imbeciles, only in less degree, because the defect is less severe.

Mr. Branthwaite professes himself more anxious to establish the existence than the cause of mental defect in the classes in question, and he describes in detail the 
behaviour, under detention, of (I) the persistently refractory, and (2) those who are dull, listless, and more or less passively amenable.

Of the former of these types we are told that they are always restless, uncertain, excitable, and ready to take umbrage on the least provocation, or on flimsy pretexts which would not be considered provocation by reasonable beings. They care nothing for the opinions of others in matters relating to conduct; they are always full of grievances, usually show no signs of sorrow, consider that everything they have done is justifiable, while, 'deficient in moral sense, they cannot be made to understand the ethics of social life, and an unfriendly attitude is manifested towards all who endeavour to exercise refining influences.'

This is as the refractory defectives are in their quieter moments. But they are liable to recurrent outbursts of uncontrollable anger, and of these the inspector says:

The mad fit, while it lasts, is not pleasant to witness-utter abandonment to passion, wanton destruction of anything handy, unneasured violence against all who happen to be near (especially if they attempt to restrain), absence of all sense of decency, and use of the vilest possible language, are some of the chief characteristics. A large number of persons now under control in reformatories, subject to these passionate, impulsive attacks, only need the possession of a lethal weapon at such times to cause injury, even death, to any person against whom the anger is directed. ... All these refractory persons, although sent to reformatories as inebriates, are mentally unsound first and inebriate afterwards. The physical demand for something to moderate restlessness and excitability, or cause temporary oblivion during the early stages of an attack of mad passion, accounts for their resort to alcohol ; or during an attack, the same ungovernable impulse which prompts them to the committal of other unreasonable actions prompts them to drink madly, regardless of result.

When, under these last-mentioned conditions, a person commits acts of violence, or is even guilty of murder, the case would inevitably be attributed to 'the 
drink' rather than to the incipient madness, though the latter, as we see, is ever ready to show itself even in the reformatory, where no drink is obtainable, and where homicide may only be prevented by the absence, as mentioned above, of a lethal weapon.

Of the second, or 'dull,' type of defectives, we learn that suspicion and delusions of persecution are as common among them as among the violent, only the reiteration of wrongs by the quiet defective leads to tears, depression, and despair, not to excitement.

Intelligence, generally, in these cases is of an extremely low order ; no power of thought or deliberation, no memory, wandering attention, and vacant expression, are obvious in all. ... The mental vacuity which is met with in defective inebriates only varies in degree from the more conspicuous inattentiveness of idiots and imbeciles.

Whether refractory or quiet, the defectives seem to be peculiarly susceptible to the action of alcohol, very small quantities of drink-no more than is taken daily without apparent physiological effect by an ordinary individual-being sufficient to cause disorderly and violent behaviour in the defectives. 'Our experience in this direction,' says Mr. Branthwaite, 'has led us to accept the view that intolerance to the exciting effect of small quantities of alcohol may be considered a fairly certain sign of impaired mental equilibrium.'

In concluding his description of the character and conduct of the defectives, the inspector maintains that the existence of defect must be considered as placed beyond the possibility of doubt, and he further suggests that 'the defect in question was probably present before the drunkenness in the majority of cases, and virtually caused it,' as indicated by the previous lives of those defective inmates concerning whom reliable information has been obtained. He continues: 
The record of a refractory defective generally includes a story of uncontrollable temper during childhood, restless, irritable, and eccentric behaviour at puberty, and dangerous conduct during late life. In regard to the quiet cases there is usually ample evidence of backward or uneducable youth, unemployable or inefficient adult life, and possession of a brain unequal to the acquirement of knowledge throughout all stages of existence. In both cases no power of thought, impaired judgment, and lack of control over impulses, all the way from birth to-reformatories.

Yet, I may point out, when these mentally defectives and morally deficients do go astray, as the result of taking an amount of liquor which would not affect an ordinary individual at all, it is once more the publican who has to bear the responsibility, and who, according to the denunciations of the prohibitionists, is alone to blame. Mr. Branthwaite's view is that 'in such cases drunkenness, and all the offences resulting therefrom, are merely the natural result of inability to sensibly direct and control thoughts, wishes, and actions.' But of this the prohibitionists take no account. The publican, they affirm, places 'temptation' in the way of the defectives, and, because such defectives cannot resist, and are so easily overcome, therefore the publican should be abolished.

The Report continues in reference to the type of person here dealt with :

The only possibility of an orderly life for such a person is total abstinence from liquor, a fact they have not the power to grasp, or, if they do grasp it, there are so many moments in their lives when insane impulse takes the place of thought and deliberation that it is hopeless to expect improvement in conduct unless preceded by improvement in mental condition. When morbid impulse is uppermost the fear of consequence is non-existent, and the meniory of past experience, which aids a strong man to resist temptation, is absent ; the impulse to drink, cause wilful damage, or assault another, comes suddenly, and is acted upon, with whatever consequence chance and circumstance may direct. As time passes continued indulgence produces further mental deterioration. Structural tissue change and constantly disordered function both aid in completing the wreck; passions run riot uncurbed, moral degradation, restlessness, and excitement become the order of the day, and we 


\section{MORAL OF HABITUAL DRUNKENNESS}

have the finished article-the insane or defective police-court inebriate.

That persons of this type should become total abstainers is a view which will be accepted by every one, publicans included-the last-mentioned because individuals of the class described must rank among the least desirable of their customers. No one, therefore, would in the least object if the anti-alcohol party would bring the full pressure of their influence to bear on the defectives, with a view to converting them to total abstinence; but because they cannot do this, or because the case of the defectives is apparently hopeless, it does not necessarily follow that restraint should be put on persons who are in no way prejudiced by the moderate amount of liquor they take.

We come next to the fourth group of inebriate reformatory inmates-those, namely, of average mental capacity, who constitute $37^{\circ} 3$ per cent. of the whole. These are 'just habitual inebriates, quiet when sober, amenable to treatment, and without obvious mental complication.' But 'Mr. Branthwaite thinks that, although there is every reason to believe transmitted weakness is largely responsible for their lapse into habitual drunkenness, it is probable that even in the case of these apparently sober-minded persons a large number of them have gradually drifted into their condition through carelessness or persistent wilful indulgence. In some cases the start in bad habits is due to early environment. But there are other causes besides, and notably ill-health, accident, and old age.

Mr. Branthwaite thinks it is hardly realized how potent ordinary disease and ill-health are in the making of inebriates.

Predisposition, in the shape of hereditary defect, may be present, and undoubtedly is present, in many persons who, nevertheless, 
manage to live sober lives. Although sometimes it necessitates a lifelong fight against inclination, their resisting power enables them to keep clear of that which would otherwise be their ruin. But when disease or ill-health impairs vitality this resisting power is lessened, and predisposition assumes unchecked sway. Many cases have been committed to reformatories whose downfall has been directly attributed to such a train of circumstances, and many more where there is reasonable cause for assuming a similar diagnosis.

In support of this view the inspector mentions a number of instances where the alcoholic habit had immediately followed on the breakdown of health or the advent of such diseases as cancer or phthisis, while in the case of women the most common cause of habitual inebriety is to be found in the functional disorders and special ailments to which their sex is liable.

The temporary relief to pain and distress which is afforded by alcohol has a fatal attraction. The increasing doses which are necessary to give comparative ease when the smaller doses fail, and the increasing frequency with which it needs to be taken to maintain the desired effect, soon form a habit which cannot be broken off unless, and until, the irregularity which caused the condition has been corrected.

There would seem to be some difficulty in demonstrating the connection between habitual drunkenness and impaired control following injury, because the effect does not always follow closely on the cause. But Mr. Branthwaite mentions two cases which sufficiently establish his point. In one, a cab-driver, previously steady and hard-working, sustained a fracture of the skull as the result of an accident. Taken to a hospital, he remained there two months, and then left, apparently cured. He returned to work, but, finding himself unfit for sustained energy, he became drunken in his habits, and, after being subjected to some years of shortsentence prison treatment, was sent to a reformatory for inebriates. Very shortly after his admission he had 
a severe convulsion, and is now a confirmed epileptic ; but his drunken habits and his epilepsy, says the inspector, were both obviously due to the accident. In the other case, a previously steady and plodding woman took to drunkenness after being kicked on the head by a horse.

In regard to the effect of old age on sobriety, $\mathrm{Mr}$. Branthwaite points to the considerable number of inmates of inebriate reformatories who are of advanced years, and says :

There is every reason to believe that nearly 65 per cent. have, in their earlier days, lived decent, useful lives, and that their drunkenness of later years has been due to naturally reduced vitality, with its accompanying defect in power of control. The sequence of events is the same in most old-age cases : loss of work from incapacity due to approaching age, consequent idleness, poverty, friendlessness, impaired power of control, drunkenness. The history is one which might well be as common among the higher as among the lower classes of society, and would certainly be so but for the fact that, in the former, there is usually some interested relative in a position to assume guidance during the later years of life ; in the latter there is neither relative able to assume control nor money to provide higher supervision. These poor old dements have all been subjected to an average of between six and seven years' treatment before being sent to reformatories.

Mr. Branthwaite considers that the facts adduced by him are sufficient to show that at least 62 or 63 per cent. of the so-called habitual drunkards sent to reformatories are to be considered as a variety of a larger complex body of insane and mentally defective persons, and that the balance show a condition far from normal. - Whether mentally defective or not, when drunkenness is confirmed, the objectionable habits of these persons are in no sense due to an effort of will, to a determination to get drink after sane deliberation, but really to an absence of power to exercise judgment at all, or to the dictates of a warped judgment.' Oft - repeated prison detention is, he argues, not only powerless to 
reform such persons, but, after the first few occasions, renders their condition worse than before. 'It is hardly pleasant to realize,' he justly observes, 'that our insane inmates, forty-eight of them, have been punished for years as sane criminals, being thrown into prison with monotonous regularity simply because their ravings were intensified by drink, or mistaken for drunken disorder. Nor can we view with greater equanimity the fact that $27 \mathrm{I}$ people, who are definitely imbecile or epileptic, have met with similar treatment, merely because drunkenness happened to be the most prominent symptom, and because the exact condition was so masked by inebriate habits as to be impossible of diagnosis by non-medical administrators of justice.'

The special purpose which the inspector has in view in entering into all these details is to suggest an improved method of treatment of habitual drunkards, and his chief recommendation is that they should be sent at an earlier stage to the reformatories for inebriates, instead of being first subjected to repeated imprisonments, and not committed to a reformatory until they have lapsed into a condition of almost complete hopelessness. With this suggestion one must certainly sympathize; but my own particular concern here is with the question of original causes. In this respect the conclusion one must draw from Mr. Branthwaite's Report is that habitual drunkenness is primarily due, not, as the prohibitionists would allege, to the 'temptations' held out by the publicans, but to the fact that the victims belong to the class either of the mentally unsound or of the feeble-minded. If this be true, practically without exception (for none is suggested in the Report), of the 1,873 persons who have been received into the reformatories for inebriates, like conditions must apply, more or less, first, to the habitual drunkards, 
who have not yet been committed to those institutes, and, secondly, to a considerable proportion of ordinary drunkards who may not yet have fully qualified for the designated 'habitual.'

On this conclusion follows another: that there has been much misconception in the past in regard to the relations between alcohol, insanity, crime, and even habitual drunkenness itself. Drunkenness may have been an incident in a particular case, or a symptom in disease, but it may also be none the less true that drunkenness would not have occurred had the persons concerned been of normal temperament and wholly responsible for their actions. 'Drink' has often got the discredit when the real causes should have been sought for in a wholly different direction. While, again, society has treated imbeciles and epileptics, defectives and feeble-minded, as ordinary criminals or offenders, temperance advocates, following in society's footsteps, have never wearied of pointing to the official statistics of 'drunkenness,' and the offences or the cases of lunacy attributed thereto, in support of their denunciation of alcoholic drinks, and have ever been ready to describe these unfortunates as 'victims' of the trade they would fain see abolished.

That the demands for this abolition, based on the grounds here indicated, are altogether illogical, must be obvious to every unprejudiced person. It is a national misfortune that there should be drunkards, habitual or otherwise. It is no less unfortunate that there should be imbeciles, epileptics, and weak-minded individuals, who, apparently, constitute so substantial a proportion of the drunkard class. But because such persons as these exist, it does not follow that the opportunity of obtaining reasonable refreshment should be denied to the entire community, or sections thereof, 
without regard to the desires or convenience of the far larger proportion of individuals who do not belong to the said class, and are perfectly well able to act with reason and self-control.

The requirements of Organized Society cannot justly be regulated by the deficiencies of its weakest members. According to proverbial philosophy it is the fate of the weakest to 'go to the wall.' The prohibitionists, on the other hand, seek to bring the weakest to the front. According to their ideas it is the weakly ones who are to fix the standard of freedom and liberty for the strong and healthy. Stimulating beverages, which the vast majority can use with reason, must be given up, social life must be remodelled, and revolutionary changes effected in our economic conditions, mainly to promote -the survival of the unfit!

Can so heroic a remedy be considered either necessary or desirable? Alike in nature and in uncivilized society the weakest do go to the wall. The defectives fall out, and the world is, in point of fact, all the better for their disappearance. In a highly civilized state of society like our own we do what we can to preserve defectives and inefficients. We look after imbeciles, epileptics, consumptives, and others, in order, apparently, not only that they shall survive, but also that they shall propagate their race. We put up palaces for paupers, and provide farms for unemployed and unemployable, while the hard-working ratepayer who bears the cost may scarcely be able to make both ends meet. We are now asked to place all sorts of restraint on the sale of popular beverages because there is among us a certain proportion of persons who, by reason of weak brains or of weak bodies, either drink to excess or cannot take even a small amount of alcohol without doing harm to themselves or to others. 
Sir Lauder Brunton has expressed the view that ' individuals in whom the hereditary craving for drink exists, or in whom the hereditary tendency to insanity renders the development of such a craving probable, ought to become total abstainers.' With that opinion everybody must thoroughly concur. The question is, rather, whether other individuals in whom such hereditary craving or tendency does not exist should be forced by law to regard themselves under a like obligation.

The policy of preserving civilization's defectives under various categories constitutes a very wide subject, which I need not stay to discuss; but one may well ask whether the survival of the unfit should be carried so far as to impose an injustice on the fit. Personally, and as an academic question, I do not think it should; but, coming to concrete facts, the excellent and most valuable Report by Mr. Branthwaite shows beyond dispute (I) that the average drunkard is an abnormal person, who requires special treatment from a psychological, a neurotic, or (in regard to provision for the aged) a social standpoint; and (2) that he or she cannot be cured or restrained in the public interests merely by changes in the; licensing laws, or even by carrying out the extreme views of the prohibitionists. That society has hitherto made some very gross, if not absolutely inhuman, blunders in its treatment of drunkards is obvious enough to those who read the Report in question. But the Legislature will do a greater wrong still if, in its sympathy with the drunken, it should ignore the good advice tendered by the Inebriates Acts inspector, and needlessly interfere instead with the rights, liberties, and rational enjoyment of the sober. 


\section{TESTIMONY OF EXPERTS}

Assuming that the reader may be prepared-even for the sake of argument-to accept my view that the evils of excessive indulgence in alcoholic beverages, however great and deplorable they may be in the case of certain types (and especially abnormal types) of individuals, have, nevertheless, been much exaggerated and also much misunderstood in the past, it is desirable to see in what light the taking of those beverages in moderation by the average healthy person is regarded by men of science. There is, certainly, a great diversity of opinion among the doctors on this question, and in the earlier days of the anti-alcoholic movement the testimony of those of them who sympathized with the prohibitionists was put before the public much more prominently than that of doctors opposed thereto. Even to-day there are in England at least two distinct schools, one of which, comprising doctors who favour the campaign against alcohol, is ready enough to support (no doubt quite sincerely) what is now a popular cry; while those who do not favour the campaign, as carried on by extremists, are mostly reluctant to declare themselves openly in favour of moderate drinking, lest they may offend some of their temperance patrons, and thus suffer from a professional 
standpoint. In effect, therefore, the opinions of medical men, put forward with so much conviction by the campaign leaders, do not necessarily express the convictions of the medical world at large.

To show that testimony in favour of a moderate use of alcoholic beverages has been offered by medical authorities quite equal in experience and position to those who are quoted by the prohibitionist party, I give a few representative opinions, and I begin with some from Germany, where, apparently, owing to the lesser popularity of the total abstinence cry, medical men are not so much afraid of expressing themselves frankly as would seem to be the case with many of our English doctors.

Dr. Ernest Zunker, Privy Councillor and Physician in Ordinary to Her Majesty the Kaiserin, has stated in the Medizinische Volksblätter, a popular medical journal published in Germany :

I am of opinion that whatever is good and legitimate in the present-day movement in favour of moderation will be only discredited by extreme demands for complete abstinence from all stimulants. A great wrong will be done to people by seeking to deprive them of the beverages to which they have been accustomed, or even of the enjoyment they have had in their consumption, for I believe that the effect, more especially, which such beverages have upon the mind is, in itself, of considerable practical importance.

As regards beer, that lightest and least harmful of all alcoholic drinks, one may regard it as certain that, consumed in large quantities, it injures more by reason of the amount of liquid taken into the system than because of the alcohol it contains. . . . No rules can be laid down as to the amount of stimulants that should be taken. The limit one ought not to exceed depends on the proportion of alcohol contained in the beverages; on conditions affecting the individuals concerned, such as climate, age, temperament, bodily health, employment ; and on mental disposition. There are some nen whom a single glass of strong ale would intoxicate ; there are others who would drink many glasses of the same liquor without showing the least sign of inebriety.

In a statement of his views, published in the German 


\section{illustrated journal Das Leben, Professor Dr. Alfred Goldscheider, Privy Councillor, of Berlin, said:}

The question whether the demand for extreme total abstinence is justifiable or not seems to me to be extraordinarily complicated, inasmuch as it is not, and cannot be, a purely medical one, so many other considerations-psychological, social, ethical, and so on-being mixed up with it.

As physician I must naturally take up the position that the only natural and reasonable treatment to prescribe for the wearied and over-wearied body is the completest possible rest. Here one has the ideal remedy. As psychologist and sociologist I must freely admit that all conditions which are based on human vitality must also reckon with human weakness, and that even although most of the beverages taken confer on us either little direct physical advantage or none at all, they may, nevertheless, be of the greater benefit to us from a psychological standpoint, by reason of their stimulating effect, or in producing even a temporary recovery, especially at a time when the rest treatment is not practicable. Stimulants serve to heighten the spirits of the individual by offering a valuable counterpoise to depression. They are calculated, by improving the state of mind, to make a man more enterprising and to reconcile him better to work he had begun to look upon as drudgery. Taking all these things into account, and notwithstanding the many reflections to which the subject of alcohol gives rise in the mind of a physician, I am bound to say that I cannot regard the extreme total abstinence movement as justifiable, or as necessary to the due maintenance of the health of the people. Certainly I believe that alcohol, even in very small quantities, has a narcotic effect; but this may operate most beneficially on the physical system by dispelling a sense of depression, and it is really this narcotic effect that inclines so many individuals to seek forgetfulness in their glass.

\section{Professor Dr. Ewald, Privy Councillor, and one of} the leading medical authorities in Berlin, has also stated in the same paper:

Stimulants represent an undeniable need on the part of human nature and for the support of the human system, being alniost as important, from the point of view of their influence on the nutritive processes, as the food itself. This fact is shown, not only by the example of individual peoples who, throughout the entire universe, and representing all stages of civilization, have known how to produce, and have themselves made use of, stimulants (fermented beverages, tobacco, tea, coffee, cocoa, etc.), but also by physiological research, which shows that nutriment without stimulant is insuffi- 
cient. . . . For the greater majority of mankind a moderate consumption of stimulants is not only allowable, but indispensable, more particularly where special demands are made on the physical or mental powers of the individual-conditions which are to be found to-day in every condition of life all the world over.

Professor H. R. Saltet, of the Amsterdam University, in an interview with the correspondent of the Deutsche Wochenschrift in den Nederlanden, adduced various statistics to show that, while the consumption of beer had increased in Holland of late years, the total consumption of alcohol had declined. He proceeded:

The comparatively small amount of alcohol contained in beer relaxes the nerves of the man tired from physical or mental labour. It diverts his thought in another direction, and relieves the pressure of his daily cares, without doing harm to his internal organs. In a word, the healthy man gains fresh vigour from a few glasses of beer. The great thing is that a man should be moderate, and show due regard to individual temperament. A blacksmith, for example, can generally take more than a tailor.

In 1904 the editor of the Deutsche Wein-Zeitung addressed a circular letter to ninety-three of the leading medical authorities in that country and in Austria, begging from them an expression of their views on the subject of total abstinence, and especially as to whether or not stimulants were beneficial to health. Of eighty-nine answers received, nearly all were in the affirmative. Here are some examples of the views expressed :

Professor Dr. Ribbert, Director of the Pathological Institute, Göttingen :

It is true that even small quantities of alcohol may do harm. To whom? Why, to the person who has defective digestion, a weak heart, who is irritable or excitable. Among the abstainers there are many who avoid alcohol for some such reasons. But it is unreasonable to forbid alcohol to those to whom it does no harm.

Professor Tuczek, Director of the Hospital for Mental and Nervous Diseases, Marburg: 
Against the moderate use of stimulants-especially fermented beverages, and those containing little alcohol-by healthy adults there is nothing to be said from the point of view of health. I hold that any general, complete, and unqualified abstinence from stimu. lants is not supported either by experience or by laboratory research, and, in respect to the real cause of sobriety, is an exaggeration.

\section{Professor Dr. Falkenheim, Königsberg :}

I regard the consumption of small quantities of alcohol as indispensable for adults of normal temperament.

\section{Dr. E. Storch, Imperial Hospital for Nervous} Diseases, Berlin :

I hold that a man in good physical and mental condition can take alcoholic beverages of good quality and in moderation without fear of injury to his health. The extreme anti-alcohol tendency must be counted among the exaggerations that need not be regarded seriously.

\section{Professor Shrötter, Vienna :}

Up to my thirty-second year I had not taken either wine or beer. Not until I made a journey through Lapland did I indulge in a moderate use of alcohol; but, as the result alike of my personal experience and of my forty-three years' experience as a medical man, I am convinced that a moderate use of alcohol is not injurious.

Professor Dr. Hauser, Obermedizinalrath, Karlsruhe :

I consider that total abstinence is unnecessary, impossible, and in certain circumstances even detrimental, while it is prejudicing the undoubtedly justifiable and timely movement in favour of moderation.

\section{Professor Dr. Schmidt, Privy Councillor, Marburg :}

A moderate use of alcohol in the form of wine or beer is unquestionably beneficial from a health point of view.

\section{Professor Dr. von Grutzner, Tübingen :}

It has not been proved, and it is not even probable, that a moderate consumption of alcoholic drinks will bring any harm to an adult healthy person. 


\section{Among British authorities Dr. Richard Quain, one of the greatest physicians of the Victorian era, once wrote :}

Dr. Brinton, who is by no means unreasonably prejudiced in favour of alcohol, has given it as the result of his very large experience that persons who abstain altogether from alcohol break down, almost invariably, after a certain number of years, if they are constantly employed in any severe intellectual or physical labour. Either their minds or their bodies give way suddenly, and the mischief, once done, is very hard to repair. This is quite in accordance with what I have myself observed, and with what I can gather from other medical men ; and it speaks volumes concerning the way in which we ought to regard alcohol. If, indeed, it be a fact that in a certain high state of civilization men require to take alcohol every day in some shape or other, under penalty of breaking down prematurely in their work, it is idle to appeal to a set of imperfect chemical or physiological experiments, and to decide on their evidence that we ought to call alcohol a medicine or a poison, but not a food.

On the part of alcohol, I venture to claim that, though we all acknowledge it to be a poison, if taken during health in immoderate quantities, it is also a most valuable medicine-food. I am obliged to declare that the chemical evidence is as yet insufficient to give any complete explanation of its exact manner of action upon the system, but that the practical facts are as striking as they could well be, and that there can be no mistake about them. And I have thought it proper that, while highly-coloured statements of the results of the new French researches are being somewhat disingenuously placed before the lay public, there should not be a total silence on the part of those members of the profession who do not see themselves called upon to yield to the mere force of agitation, and become the obsequious mouthpieces of the teetotal party.

\section{Sir James Paget, F.R.C.S., F.R.S. :}

As for the opinion of the medical profession, they are, by a vast majority, in favour of moderation. My study makes me as sure as I would ever venture to be on any such question that there is not yet any evidence nearly sufficient to make it probable that a moderate habitual use of alcoholic drinks is generally, or even to many persons, injurious, and that there are sufficient reasons for believing that such an habitual use is on the whole and generally beneficial.

\section{Sir William Gull, M.D., F.R.S. :}

For men working hard beer is a good form of food, to be recom. mended as a light feeding material. 


\section{Sir T. Lauder Brunton, F.R.S.:}

Alcohol is a true food.

\section{Dr. R. Brundenell Carter, F.R.C.S. :}

I do not hesitate to say that the advocates of total abstinence are mistaken. I affirm, alike from my own experience and from that of others, that there are some to whom it is a necessity if they are to exert the full measure of their power.

\section{Dr. Alfred B. Garrod, F.R.S. :}

The majority of adults can take a moderate quantity of alcohol in some form or other, not only with impunity, but often with advantage.

\section{Sir Dyce Duckworth, M.D.:}

I believe the use of alcohol to be beneficial to humanity. In strict moderation I see nothing harmful, but, on the contrary, much that is beneficial, in the use of alcoholics in the present stage of our civilization.

Sir James Crichton Browne, writing in the Birmingham Daily Gazette of May 29, I9o6, said:

No other drug can satisfactorily take the place of alcohol, and the doctor who has laid it aside has in some measure crippled himself in his combat with disease. Mankind has come to know that alcohol cloes very often whet a failing appetite, spur on a dilatory stomach, sustain a flagging heart, check wasting of the body, invoke sleep, numb acute pain, and restore a sense of wellbeing when that has been lost; but mankind will go on resorting to it when distressed in these ways, in spite of all warnings as to its insidious propensities, and in spite of medical prohibition.

A medical man's first object is to cure his patient in the simplest, safest, and quickest way. And in doing that a great majority of medical men believe that alcohol may from time to time be helpful to them. They are not to be intimidated from handling it by the shrieks of those whose eyes are fixed on the horrors wrought by alcohol let loose from medical control, or by unworthy suspicions of connivance with vicious tendencies.

But aid is needed in a vast number of cases that are incurable, and in these, too, a great majority of medical men believe that alcohol may be helpful. It may assuage suffering, make life more endurable, and smooth the rough passages out of it, and under such circumstances it would, it seems to me, be positively cruel to with. hold it because of pious aspirations, or in accordance with any hard. and-fast rule. 
Dr. Thomas Dutton, in the Archives of the Roentgen Ray, a publication through the columns of which medical men communicate with medical men, has written in regard to certain doctors who have expressed strong views against the use of alcohol:

The overweening arrogance of those writers would lead one to imagine that the entire store of human virtue and knowledge was their inheritance alone, and that the remainder of the medical profession were lacking either in common or in moral sense. I will venture to assert that fully 80 per cent. of the profession at large do themselves partake of alcoholic stimulants in some form or other, and order it for their patients.

Dr. Josiah Oldfield, head of the Lady Margaret Hospital, Bromley, in an interview with a correspondent of the Daily Mail, reported in that journal on August 27, I906, said:

Whether considered as an article of food or as a remedial agent, I cannot join in a wholesale condemnation of alcohol. When discreetly used it is most useful. I believe that there is less intelligent comprehension of the value of alcohol than of almost any other remedial agent to which scientific attention has been given. We English owe much to our cereals. The early Britons strengthened themselves on 'frumenty,' a kind of gruel or porridge made of wheat; the Scottish have grown great on oatmeal porridge and oatcake; and the elements in these cereals present in malt liquor have contributed to the virility of the British race. That is not to endorse indiscriminate and gluttonous drinking, but the wise use of the fruits of the earth. Indeed, I know of no body of men so sadly in need of education upon the subject on which they dogmatize as the temperance advocates. .... Good, wholesome, well-brewed beer and wine-especially Tokay-can be used to advantage by young and old alike.

Mr. G. A. Archdall Reid, M.B., F.R.S.E., in the course of an article contributed by him to the Daily Chronicle of November II, I905, under the title 'Nature's Method,' said:

Nature, in a form hardly suspected, is against the temperance reformer. Men differ naturally in their powers of resisting this or that disease, as they do in all other respects - in height, in strength, in vigour, and so forth. Thus, in a country where measles is 
prevalent, the weak in relation to it are weeded out, and the race is left to the strong..... Each disease weeds out the weak, the unfit, in relation to itself. It acts as a kind of breeder, who permits, as a general rule, only a certain type of individual to have offspring, or, at least, to have a full quota of offspring. It is what biologists term a 'selecting' agency.

Exactly the same is true of alcohol. ... To anyone who has eyes for the world around him, it is obvious that men differ as greatly in their 'susceptibility to the charm of alcohol' as they differ from their susceptibility to disease. A given experience of alcohol awakens in some men an ardent desire for deep indulgence; in others it awakens only a weak desire for moderate indulgence; in others it awakens no desire at all.

It is popularly believed that parental disease or intemperance tends to render offspring, and, as a consequence, the race, degenerate. ... If the popular belief be true, it is clear that a race of men much afflicted during many generations by disease and intemperance will grow increasingly degenerate, until at last it becomes extinct. On the other hand, if the belief be erroneous, if offspring are not, as a rule, affected by parental ill-conditions, an opposite effect will be produced, and the weeding out of the unfit will render the race, not degenerate, but increasingly resistant. Both effects cannot, of course, be produced together, for a race cannot undergo improvement and degeneration at one and the same time.

We can easily test these opposing doctrines by noting what has happened to various races of men.

Mr. Reid gives a series of illustrations, showing that every race exposed to certain diseases or conditionsmalaria, consumption, extreme heat or extreme cold-is resistant to them precisely in proportion to the duration and severity of its past sufferings. The same argument, he holds, applies to alcohol and opium. He proceeds :

Obviously, two methods of temperance reform are conceivablethe reformer's method, the elimination of drinking, and Nature's method, the elimination of the drunkard. The reformer's method has been tried by scores of Governments, on hundreds of occasions, during thousands of years, and has never succeeded, except temporarily amongst barbarous peoples. Amongst all modern peoples dwelling under the ordinary conditions of civilized life, repressive measures-at any rate, severely repressive measures-not only fail, but worse than fail. Vast numbers of people combine to break the law by all sorts of devices. Modern civilized society is so complex, means of intercommunication are so perfect, the manufacture and sale of alcohol are so easy and profitable, the desire to 
obtain it so fierce, the freedom of the individual so great, that an illegal traffic is organized at once, which swiftly grows beyond the control of the authorities. Secret debauchery is substituted for open drinking. The actual amount of drunkenness is increased. The successful evasion of one law has for its concomitant a contempt for all law, which in turn is followed by a long train of attendant evils. If the society be at all highly organized, if the population be dense, the means of communication good, and the Government democratic, the law is soon repealed.

These statements are very sweeping, but there is ample evidence to justify them.

Nature's method has invariably succeeded, but at the cost of terrible sufferings. It will succeed in spite of all we can do. It may be possible, however, to minimize the suffering by limiting the output of children by drunken parents, as by spreading abroad a knowledge of the danger of marrying into intemperate families. This, however, is a question for the social reformer and the legislator, not for the scientific man.

Then, as these pages are passing through the press, there has been published in The Lancet of March 30, I907, an important statement on 'The Use of Alcoholic Beverages,' signed by fifteen medical authorities, and representing, as they believe, 'the opinions of the leading clinical teachers as well as of the great majority of medical practitioners.' The full text of this statement -which, The Lancet says, ' as an expression of scientific opinion ... deserves to be considered carefully by medical practitioners ' - will be found in the Appendix.

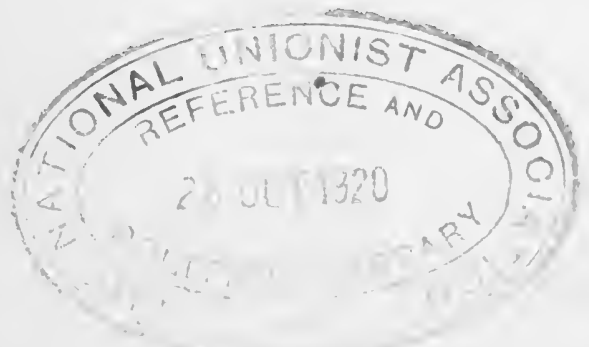




\section{LIQUOR LEGISLATION IN THE PAST}

Not alone is it a fact that the consumption of alcoholic drinks is of great antiquity; that it responds to a deeply rooted and perfectly reasonable instinct in human nature; and that, while it may, and does, prove prejudicial to certain individuals of a more or less abnormal type, it is a source of benefit and of pleasure to others ; but a further indisputable fact is that the sale of such drinks has been directly sanctioned by the Legislature from very early days, so that, although made the subject of a great number of Acts of Parliament, for the purposes of control, etc., it has hitherto been regarded as constituting alike a legal and a perfectly justifiable, if not also an altogether indispensable, trade. The legislation in question may, at times, have been harsh, unreasonable, or even unjust, towards those concerned therein; but it has, nevertheless, hitherto left untouched the proposition here maintained: that the trade in alcoholic beverages is, in itself, essentially a lawful trade.

The impression which a study of liquor and licensing legislation in the past leaves on one's mind is that, when such legislation has recognized the desire for stimulants as natural and legitimate, and has simply sought to enforce measures of efficient supervision and controlin the interests of public peace and order-without 
imposing unreasonable restrictions on facilities for purchase, it has invariably been successful; but that when it has aimed at enforcing unreasonable restrictions, together with compulsory abstinence and morality, and has interfered unduly with that 'liberty of the subject' which the majority of people in civilized countries regard as their right, then the legislation has invariably been a failure, and has increased rather than reduced existing evils.

One finds the two sets of conditions hopelessly mixed up during the four centuries over which legislative experiments in regard to the sale of liquor have extended in the United Kingdom, for there have been few fixed principles in dealing with the question, and the said experiments have ranged from undue restriction to undue laxity, with an inconsistency that has probably caused more harm than if nothing at all had been done. In fact, some of the gravest results of the situation have been directly and undeniably due to the good intentions, but ill-advised policy, of our legislators themselves, and they have not always been fully counterbalanced by the good results that may have followed in other directions.

The earliest legislation concerning the manufacture and sale of alcoholic beverages was passed at a time when, as already shown, ale was regarded as an article of diet of paramount importance to the community, and it is interesting to find that in those days the efforts alike of Governments and of local authorities were directed mainly to ensuring the three great desiderata of (I) adequate supply, (2) good quality, and (3) reasonable price. Even to-day the wholesale trade is subject only to the duties and regulations of the excise authorities, the interference of the Legislature being restricted to the sale and distribution of small quantities. 
The lawfulness of this retail trade-at one time free to anyone who cared to embark in it-was established by the earliest licensing Statutes passed in this country, though authority was, at the same time, given for a reduction in the number of ale-houses, which even then seem to have been regarded as unnecessarily numerous. Thus the first licensing Statute of all, that of II Henry VII., cap. 2. (I495), empowered any two Justices of the Peace 'to reject and put away common ale selling in towns and places where they should think convenient, and to take sureties of keepers of ale-houses in their good behaving.' By 5 and 6 Edward VI., cap. 25 ( 1552$)$, the power of suppressing ale-houses was confirmed, and it was enacted that no one should be allowed to keep an ale-house unless he obtained the authority of two justices of the peace. The justices were, also, to take sureties for the observance of rules for the conduct of the house, and were empowered to try breaches of those rules, and to punish persons who kept ale-houses without being licensed. Various other early Statutes followed, amplifying the powers of the justices on these general lines, or consolidating the various Acts then existing; but they were all based on the general principle that the sale of intoxicants was, in itself, not unlawful or harmful, though the keeping of an effective check over the individuals conducting the retail trade was, nevertheless, held to be desirable in the interests of public order.

The difficulties in the way of maintaining public order were certainly found serious enough, in view of the inefficiency of the police system of those days; but a series of developments for which the legislators themselves were directly responsible brought about excesses far greater than anything previously experienced. In I6 43 the Parliament of the Revolution imposed excise 
duties on ale and beer, in the interests of the revenue, and these duties were not only maintained but substantially increased from time to time, the tax per barrel of strong beer, fixed at $2 \mathrm{~s}$. $6 \mathrm{~d}$. in 1650 , being raised to $5 \mathrm{~s}$. in 1692 . Up to this time the ordinary people had been content to drink ale and beer; but the price of malt liquors was now substantially enhanced, owing to the duties, and a great impetus was given to the manufacture and consumption of spirits, the quantity of beer produced by licensed London brewers declining from $2,088,000$ barrels in 1690 to $1,523,000$ barrels in 1693 .

Meanwhile other causes had been operating to increase still further the substitution of spirits for ale and beer. With a view either to encourage native industries, or to spite the French, the Revolution Parliament prohibited the importation of spirits, and granted permission to all persons, on the payment of small duties, to distil and retail spirits made from English-grown corn. Possibly, also, it was considered that this concession was a setoff to the imposition of a comparatively heavy tax on ale and beer. A fresh charter granted to the Brewers' Company by Charles II. conferred upon the freemen the right to distil, and such right was confirmed by still another charter, granted to them in 1685 by James II. Between I69o and I70I a series of Statutes gave direct encouragement to the distilling industry in general.

The effect of these various concessions was an enormous increase in the manufacture and consumption of spirits. Up to the time of the Revolution, there were but few British distilleries, and the brandy imported from France was too dear for the average citizen. The distilleries now rapidly increased in number, and the people, discarding honest English ale, acquired a passion for English gin. The production of 
spirits, which stood at 527,000 gallons in 1684 , increased to $2,000,000$ gallons in I7I4, to $5,394,000$ gallons in I735, and to $7, \mathrm{I} 60,000$ gallons in 1742 .

The evils resulting from the free sale of gin and the almost universal practice of excessive gin-drinking, which now came into vogue, have been painted in the most lurid colours, and, even allowing for a certain amount of exaggeration, they must have been bad enough. But they were evils for which the legislators of the day were themselves mainly responsible; and now, having created or encouraged in the people a pronounced taste for gin, they proceeded to make matters still worse by trying to place excessive restrictions on the gratification of such taste. In 1728 a duty of $5 \mathrm{~s}$. a gallon, in addition to the existing duties, was put on the manufacture of spirits, and all retailers were required to take out an annual excise licence, for which they were to pay $£ 20$. The effect, however, was to give a great impetus to illicit trading, and the Act was repealed four years later.

In 1736 the Middlesex magistrates presented to Parliament a petition in which they said that "the drinking of Geneva and other distilled waters had for some years past greatly increased, that the constant and excessive use thereof had destroyed thousands of His Majesty's subjects, and that great numbers of others were by its use rendered unfit for useful labour, debauched in morals, and drawn into all manner of vice and wickedness.' So in this same year (I736) the famous Prohibition Act of 9 George II., cap. 23, commonly known as 'the Gin Act,' was passed.

The avowed object of the measure was to secure the entire suppression of the sale of spirits in small quantities. The Act required all persons selling less than 2 gallons of spirits at a time to take out a licence which 
would cost $£ 50$, and a duty of 20s. a gallon was to be paid by retailers, in addition to the duties payable by the distillers. Any person selling spirits without a licence was to be liable to a penalty of $£$ roo, and licences were to be granted only to keepers of victualling houses, inns, etc., who carried on no other trade.

But the Act was one that aimed at much more than the maintenance of public order. It was an exceptionally striking example of legislation directed to making people not only sober, but moral and virtuous, by Act of Parliament, for in the preamble of the measure it was set forth that-

The drinking of spirituous liquors or strong waters is become very common, especially among the people of lower or inferior rank, the constant and excessive use whereof tends greatly to the destruction of their health, rendering them unfit for useful labour and business, debauching their morals, and inciting them to perpetrate all manner of vices, and the ill consequences of such liquors are not confined to the present generation, but extend to future ages and tend to the devastation of this kingdom.

Had these declarations been the preamble of a manifesto issued by some such body as the United Kingdom Alliance they would have been in keeping therewith, but actual legislation framed in this spirit could hardly be otherwise than a failure. What actually happened cannot be better related than in the words of Dr. Shadwell in his book on 'Drink, Temperance, and Legislation' :

The first result was an apparent decrease of consumption, but that lasted a very short time, and it soon became clear that the Act was much worse than a failure. Illicit trade sprang up, and greatly augmented the evil. Although 12,000 persons were punished for infringing the law in two years, it flourished, notwithstanding, beyond all power of control. Distillers took out wine licenses and sold a concoction of gin, sugar, and spice as wine, just as they do to-day in Norway and Sweden. Druggists put up gin in physicbottles, and called it 'Cholick water' or 'Gripe water,' with the direction, "Take two or three spoonfulls of this four or five times 
a day, or as often as the fit takes you.' Gin was sold in the taverns under another name. In short, the repressive Act gave a great stimulus to the traffic. The consumption in England and Wales rose from $\mathrm{I}, 000,000$ gallons in 1733 to nearly $20,000,000$ in 1742 , and there is not the slightest doubt that a most shocking state of things prevailed.

There is no need for me to go into details with regard to the said shocking state of things resulting from the 'gin epidemic' thus brought about. My concern here is, rather, with the attitude of the Legislature in relation thereto; and what I next find is that, prohibition and high licence having proved abortive (for everyone who pleased sold gin without troubling about a licence at all, setting the law at defiance), a new experiment was now entered upon. An Act passed in I743 repealed that of 1736 , reduced the retail licence duty from $£ 50$ to 20 s., and abolished the duty of 20 . on each gallon. In effect the attempt to suppress the traffic altogether was abandoned as hopeless, and the business was brought within the means, on a legal footing, of all who could raise a sovereign for a licence ; though here the great concern of the Government was, apparently, to safeguard the interests of the revenue, the idea being that retailers who had refused to take out licences at prohibitive rates would pay for them when the charges were so substantially reduced.

Conditions now became, if possible, worse than ever. Fielding wrote in $175 \mathrm{I}$ that gin was "the principal sustenance (if so it may be called) of more than roo,ooo persons in the Metropolis,' and the scenes and incidents that occurred were unworthy of a civilized country. In the same year in which Fielding wrote the Legislature made fresh efforts, passing an Act which laid down (I) that distillers should not sell either retail or to unlicensed publicans, and (2) that debts for drink could not be recovered at law. These were 
essentially reasonable propositions, and Mr. Lecky says of them that they had 'a real and very considerable effect.' Two years later the justices had further powers of control conferred on them, and statutory authority was given to the system of annual licences; while there were enacted additional regulations in regard to licensing and management, of which Mr. Lecky says that though they were 'much less ambitious than the Act of 1736 ' (that is to say, the 'Gin Act,' referred to above), 'they were far more efficacious.' In other words, when the Legislature refrained, on the one hand, from trying to enforce impracticable restrictions, and, on the other, from a course of ill-advised laxity, and adopted instead a system of reasonable control, they secured a much greater measure of success. Their ' gin policy,' especially, had represented a series of deplorable blunderings, resulting in incalculable harm; but conditions now began to improve, even in this respect, and the less intoxicating malt liquors regained somewhat of their old position.

The 'Ale-house Act' of I828 codified or repealed a bewildering collection of then existing Statutes, and became the recognized foundation of subsequent licensing law in this country. Two years later there was a reversion to the period of experiment. Various parties in the State had, for various reasons, favoured 'free trade' in ale and ale-houses, and the Duke of Wellington's Ministry likewise supported the idea, in the belief that free trade in ale would check the consumption of spirits, then again increasing, while ale and beer licences had fallen off. A period of 'laxity' was thus again brought about by the Beer Bill of 1830 , which authorized any householder whose name was in the rate-book to sell beer, but not other intoxicating liquors, by retail, without obtaining a licence from the 
Justices, and free from any control, on payment of two guineas to the Excise.

The Act came into force in October, 1830 , and the result was the opening of 'beer-houses' (now first introduced) in such numbers, and under such conditions, as astonished and alarmed the country. By the end of the year no fewer than 24,342 persons had paid the $£ 2$ 2s. fee and obtained a beer licence from the Excise, fifty new beer-shops being opened in Liverpool alone every day for severa! weeks. Many of the places where the beer was sold were cellars or other premises quite unfit for the purpose, and, in the absence of sufficient control by either police or magistrates, conditions were brought about which suggested that, instead of having solved the liquor question, the Legislature had simply started on a fresh chapter.

It was under these circumstances that there was created the subsequently much-discussed excessive number of beer-houses, though the results which followed had not been without their effect on the fullylicenced houses as well. On the one hand, holders of beer licences were encouraged by the magistrates to take out licences for the sale of spirits, so that they could be brought under the control from which, as beer-house keepers only, they were then free. On the other, the holders of spirit licences sought to meet the greatly increased competition of the beer-houses by enlarging their establishments and increasing the attractions thereof. In the end the check which had been temporarily given to the sale of spirits disappeared, and the consumption steadily increased.

A modification of the Act of 1830 was brought about four years later, when a further Beer Act first made a distinction between 'on' and 'off' licences, the Excise duty for the off-licences being reduced to $£$, 
while the on-licences were to cost $£ 3$, and were to be granted only on the production of a certificate of good character, signed by six ratepayers in the parish. Still another Beer Act, passed in 1840 , provided that no licence, whether 'on' or 'off,' should be granted by the Excise to any person not a real resident holder and occupier of the house to be licensed, and such house must have a rateable value of $£$ I $5, £$ II, or $£ 8$, according to the number of the population.

Two years before the adoption of this last-mentioned measure there was passed an Act which enforced the closing of public-houses in London between midnight on Saturday and noon on Sunday, the disorderly scenes previously witnessed, when the public-houses remained open from Saturday to church-time on Sunday morning, thus being checked without placing any undue restraint on the reasonable requirements of the public. Hours of Sunday-closing were fixed generally in 1854-55, while in Scotland total Sunday-closing was established in 1854 under the Forbes Mackenzie Act, though in 1862 it was found necessary to pass a Scotch amending Act, in order (among other things) to check the illicit traffic to which the total Sunday-closing had given rise. The so-called Grocers' Licences were inaugurated under Mr. Gladstone's Wine and Refreshment Houses Act of 1860 .

Some great changes resulted from the passing, in I869, of the first Wine and Beer-house Act. The freedom from magisterial control which the beer-houses had hitherto enjoyed was brought to an end by the enactment that no licence, or renewal of a licence, for the sale by retail of beer, cider, or wine should be granted by the Excise except upon production of a certificate granted by the Justices assembled at the General Annual Licensing Session held under the Act 
of 1828 . But the Justices could refuse a certificate for an 'off' licence only on one or more of four specified grounds, ${ }^{*}$ and only on the same grounds were they authorized to refuse the renewal of an 'on' licence already in existence on May I, I869, although absolute discretion was given to them in regard to the granting of new licences.

This was the origin of the special privilege conferred on the 'ante-I869 beer-houses.' But though, on the one hand, the control of the magistrates had undoubtedly been widened, they subsequently chafed at the restrictions still imposed upon them, for, when the question arose as to reducing the number of licensed houses, they were powerless in regard to the 'anteI869 beer-houses,' many of which had been opened in the rush that followed the Beer-house Act of 1830 , had structural defects or afforded inadequate accommodation, and were also, it might be, in excess of the actual requirements of a neighbourhood.

These conditions continued until I904; but meanwhile the policy of reasonable control underwent development by the Licensing Act of 1872 , wherein most of the regulations now in force are laid down. Improvements were effected in the forms and conditions of licences; a 'six-day licence' was introduced; penalties were imposed with a view alike to the better management of licensed houses and to punishment for drunkenness; power was given to landlords to exclude drunken or disorderly persons; licences were to be forfeited on repeated conviction; and the hours of closing were altered, though it was by the Act of 1874 that the hours now in general force were fixed. In

* (1) Failure of applicant to produce satisfactory evidence of good character; (2) house in question disorderly or frequented by bad characters ; (3) previous forfeiture; (4) applicant or house not duly qualified by law. 
I876 a Select Committee of the House of Lords reported that the recent legislation had had 'a beneficial effect throughout the country,' and except, perhaps, in regard to the hours of closing, the Acts of 1872 and I874 were found by the licence-holders themselves to be so efficient that, in their view, no alteration of them was needed in the public interests.

Many more Acts followed, among them (to mention a few) being further experiments in prohibitory legislation in the form of Sunday-closing in Ireland (I878) and Wales (I88I), to which reference will be made later on; an Act (1882) giving Justices full discretion over 'off' beer licences; an Act (1885) defining beer, for Inland Revenue purposes, as any liquor which is made or sold as a description of beer, or as a substitute for beer, containing more than 2 per cent. of alcohol; and following on a Royal Commission, an Act (IgO2), which increased the control of the justices over the structure of licensed premises, made important changes in regard to transfer and to the costs of justices whose decisions were appealed against, gave still wider discretion to justices in regard to 'off' licences, and made various alterations of the laws relating to drunkenness, clubs, etc.

With the Act of 1904 I propose to deal subsequently; but even such a hasty and incomplete survey of past licensing legislation as that here given (and there have been various Acts to which I have not stopped to allude) should show that many of the 'evils of the liquor traffic,' for which more or less heroic remedies are now proposed, have been directly due to the experiments or to the ill-advised fluctuating policy-if not 'no policy'-from time to time of the Legislature itself. British licensing legislation, in fact, seems to have been shaped in the past four centuries on much the same principle as British wars are still conductedthat, namely, of 'blundering through-somehow!' 


\section{'TIED' HOUSES}

I PAss on now to deal with some of the various types of houses which, under legal sanction, exist for the retail supply of those alcoholic beverages that meet, as I have sought to show, a natural and a reasonable want on the part of the community ; and in this connection I propose specially to consider the so-called 'tied' (or tenanted) and 'managed' houses, the former in the present chapter, the latter in the chapter that follows.

The question of 'tied' houses constitutes one of those bugbears of the teetotal platform in regard to which there exists on the part of the general publicand especially the temperance section thereof-a vast amount of prejudice, with very little knowledge as to the real facts of the case. It represents a phase of the general controversy on which platform orators, strengthened occasionally in their arguments by the allegations, more or less untrustworthy, of so-called 'victims' of the system, have found it comparatively easy to mislead sympathetic audiences, themselves unable to judge from personal experience whether what they are told is true, false, or exaggerated, but prepared in advance to accept it all as gospel.

A like policy, again, has been too often adopted in the Press, statements being made which a very little 
inquiry would show to be either groundless or altogether misleading. Truth, for instance, in its issue of May 9, I906, published an article, under the heading 'Beerlord and Tenant,' in which, commenting on a case that had come before the courts, it declared that the tied-house system is 'mischievous and intolerable,' that the publican's interest is not to let his customers have what they want if he can help it, and that his 'one and only interest is to induce every man and woman who enter his house to swallow the greatest possible quantity of the beerlord's brew, good, bad, or indifferent.' The writer added that if the tenant 'fails to push down his customer's throat a sufficient quantity to satisfy his lord, woe betide him!' for ' in nine cases out of ten he is in the hands of a corporation which has neither soul to be damned nor body to be kicked!'

To place the British public in a position to form their own judgment as to the trustworthiness or otherwise of assertions of the type here indicated, I propose to state as briefly as possible the real position in regard both to 'tied' and 'managed' houses, the story I have to tell being based partly on a study of the past history of the developments in question, and partly on visits paid to houses of both types in various parts of the country, supplemented by conversations with individuals having personal experience in all the various phases of the question.

To begin with a definition of terms : a 'free' house is a public-house owned by the occupant, or rented otherwise than from a brewer, the publican being at full liberty to obtain his liquors wherever he thinks fit; a 'tied' tenant is one who leases or rents a house from a brewery firm, from whom he is bound to purchase his beer and, possibly, other commodities; a partially 'tied' house is one where the licence-holder has obtained 
a mortgage on his house from a brewer; while a ' managed' house is one that is under the charge of a person who receives a stated wage from the person to whom it belongs, or by whom it is rented.

Public-houses that are really free in the fullest sense of the word represent to-day a very small proportion of the whole-perhaps not more than 6 or 8 per cent. But the principle of the 'tie' is by no means of recent innovation, as many persons suppose. It has been in vogue ever since the brewing interest came into the hands of large capitalists, and it must be regarded as mainly due to the policy of our Legislature in regard to the liquor traffic in general. One inevitable result of the licensing system in its various phases of restriction and limitation has been to convert the sale of alcoholic beverages into a valuable monopoly, and a person desirous of becoming a licensed victualler or a beerhouse-keeper has required to control a large, or a comparatively large, amount of capital, especially if he wished to pay off the out-going tenant, and be entire owner of goodwill and fixtures. In very many instances the would-be publican has not had sufficient money of his own, and the practice for generations has been for an individual in this position to borrow money from a firm of brewers to enable him to complete his purchase. This money he has borrowed on mortgage, with the obligation to deal with the brewers for his beer.

Is there anything immoral or inimical to the public interests in this principle? It is difficult to see how there can be. It is a commercial arrangement which one section of traders ought to be perfectly free to make with another, to their mutual advantage. Bakers and grocers and other tradesmen of limited means are glad to be set up in business by wholesale dealers under like conditions, and it surely cannot be more immoral 
to 'tie' alcoholic drinks than it is to 'tie' the most necessary of the staple articles of food.

In the Metropolis the practice in question has prevailed in the licensed trade so long that it has become known as 'the London Custom,' and a very large proportion indeed of the 'old-fashioned publicans' were, in this way, and in this way alone, enabled to start in business, notwithstanding the enormous value to which public-house property had attained. It has been no uncommon thing for a man with, say, only $£ \mathrm{I}, 000$ of capital to buy a public-house for $£$ Io,000, borrow $£ 9$, ooo from a brewery firm at from $3 \frac{1}{2}$ to 4 or 5 per cent., tying himself, also, for beer; and then secure smaller additional loans from a whisky distiller, a gin distiller, a wine merchant, and a cigar merchant successively, undertaking in each case to deal with them for their particular class of goods. In this way he has raised not alone all the purchase money, but also sufficient working capital for making a good start with the business acquired.

It may even happen that a man with only $£ 500$ of his own may thus enter on a business which represents a capital of $£ \mathrm{II}, 000$ or $£ \mathrm{I} 2,000$. His $£ 500$ will be the equivalent of ordinary shares, while the remainder will rank, as it were, as debentures; and there is, probably, no other commercial enterprise where the same proportion is found. The tenant takes for these ordinary shares the ordinary business risk, to the extent of the value thereof; but he also takes the profit that can be made out of the house, and, if there should be a large increase in the value of the business, he can sell out and reap the benefit. Once more, there is hardly any other trade where like conditions are to be found. That a man enjoying these advantages should he held up by the temperance party to public sympathy as the 'slave' 
or the 'victim' of the brewers is a line of tactics quite inconsistent with fact and reason, and the obvious motive is, not any real sympathy for the tenant, but a desire to discredit the brewers. No man is a slave or a victim who can make a fair living, if not sometimes even a fortune, by trading mainly with the capital of his landlords.

If, again, a tenant, operating on the lines here described, becomes dissatisfied with the beer supplied to him by the brewers who were his landlords, or if he thinks he can do better elsewhere, he has only to go to a second firm, borrow sufficient from them to pay off the others, and start afresh with firm number 2, though in this case he is, of course, merely transferring his 'tie,' such tie continuing until he has made sufficient from the business to clear off the loans altogether, if he so desires. But the advantage thus possessed by the publican in facility of transfer from one brewer to another is naturally a disadvantage to the other party in the transaction, because of the element of uncertainty introduced, and a decided preference has been shown by provincial brewers for buying properties outright, instead of making loans to independent purchasers.

The concession and acceptance of tenancies went on for many years as an ordinary business proposition, regulated on strictly commercial lines; but meanwhile causes were operating in other directions to give a decided impetus to the purchase of public-house properties by brewery companies. As the attitude both of the Legislature and of the teetotal party grew more and more hostile, the 'old-fashioned publican,' who owned his house, became more and more uneasy. He had not worried much about the speeches and the annual motions in Parliament of the late Sir Wilfrid Lawson, which amused him rather than otherwise; but 
when members of the Government became supporters of local option, and proposed or foreshadowed legislation directly menacing his interests, he began to fear for the business in which he had invested his savings. As the outlook got still more unfavourable, he thought it better to make the best bargain he could with some brewery firm or other and sell out. Controlling only one house, the licence of which might be taken from him through no fault of his own, he was in a position altogether different from that of a firm of brewers who, if deprived of the licence for one of a number of houses, could spread the loss over the others.

Thus the 'free' publican of former days became ready enough to sell, and various firms of brewers, in their turn, became ready enough to buy; while still others concluded that, in the interests of their own trade, they would have to follow the example of their competitors. It was foreseen that, if the purchases thus made were carried to extreme limits, some of the brewers might eventually find themselves face to face with serious disadvantages. But the uneasiness of the individual publicans increased as the attitude towards them of politicians and teetotallers became still more aggressive, and their consequent inclination to sell was naturally strengthened by the steady inflation of prices that followed the active competition among the wouldbe purchasers. In many instances those who sold did so at a substantial profit to themselves, mainly at the cost of the brewers, and, as far as they were concerned, it cannot be suggested that the conditions were too hard.

It was under these circumstances that, in spite of the abnormal values to which public-house properties rose, the trade passed more and more from the hands of private individuals into those of brewery companies; but 
the primary cause for this transition is to be found, not in any deliberate scheme on the part of the companies to secure these properties from the individual owners (who need not have sold out unless they pleased), but in the state of alarm to which such owners were reduced by the active hostility of their parliamentary critics and the threatening attitude of their avowed enemies, who now join in denouncing the very system they have themselves done so much to bring about.

The public-house properties thus acquired by brewery firms or companies are either let to tenants, or, alternatively, are placed in charge of managers, who occupy the position of paid servants. I propose to discuss in some detail each of these systems.

In regard to tenants, they may have a lease, or, especially in the country, be under a yearly agreement or a three months' notice. In either case the agreement entered into by the tenant will require him to obtain from the brewers who are his landlords all the beer he requires for sale, and if they are dealers in wines and spirits, and manufacturers of mineral waters, he may be 'tied' in respect to these beverages also. Conditions vary with different brewery companies and in different districts; but, speaking generally, a tenant will not be entirely restricted to such beers as his landlords brew, and hardly ever to the spirits they themselves blend. Within certain limits, the tenants are allowed to order, and to sell, standard proprietary beverages, which the brewers supply when there is a demand for them by the public, and especially when non-supply might lead to a transfer of custom to some other house. Such standard articles include draught and bottled Burton beers, Edinburgh beers, Dublin stout, London stout, various lagers, British or Continental, ciders, and popular brands of spirits. In some houses I have heard of, 
which have an established reputation for a particular type of beverage-Burton beers, for example-not a single glass of the landlord's own brew will be sold. It is all a question of demand and supply. While, however, the tenant is required to obtain these proprietary articles (should he need them) through his landlords, he is not necessarily placed at a disadvantage thereby, inasmuch as the owners secure special discounts by ordering large quantities, and can thus obtain a profit for themselves, although charging the tenant exactly what he would pay if he, wanting much smaller quantities, dealt direct with the actual producers.

On the other hand, the 'certain limits' spoken of above will restrict a tenant from supplying the beers of any local brewer, apart from those of the firm or company with whom he has entered into agreement, and it is this restriction that constitutes one of his chief grievances. Should he be 'tied' to brewers whose productions are poor in quality, the grievance will be a real one, and the tenant may well regret his inability to supply the better article his patrons would like. But where the tenant is 'tied' to a really good firm, whose beverages are of undoubted excellence and in general favour, the grievance is less acute, though even in this case it may still be advanced.

The tenant may think that if he could only sell other kinds of beer and spirits, costing him less money, he would secure a higher profit for himself, and he naturally looks at the matter from the standpoint of personal interest. The brewers, in their turn, argue (I) that, inasmuch as they have invested so much of their own capital in the business, they may reasonably prefer to see their own beer sold rather than that of a local competitor; and (2)"that whilst a sale of inferior qualities might help the tenant to make larger profits for the 
time being, it would inevitably damage the reputation of the house, and this loss would fall upon them when the tenant, perhaps, had gone elsewhere. Experience has shown that, when a tenant takes over a house which has previously been under the management system, he generally begins to order cheaper qualities of liquor, and this has led some brewery firms to insert a clause in their agreement with a tenant to the effect that he shall purchase from them the same qualities as those hitherto sold in the house.

While on this subject, I might add that there are landlords of 'free' houses who are sometimes worried almost out of their lives by the agents of whisky firms desirous of, if not determined on, getting orders for the supply of that commodity. Such individuals have been known to stay a week at a time in a house, and to give a present of a silk dress to the landlady, so that she may bring her persuasive powers to bear on her husband, or to offer other bribes or commissions with a view to getting business. The landlord who finally submits to such influences may then be supplied with a palatable but still inferior kind of liquor, which he has no means of testing, and for which he must pay a price that will cover, not only cost of production, but also the outlay involved in getting the order. When, on the other hand, brewery firms buy large quantities of whisky, they subject the samples to exhaustive analysis in their laboratory to make certain that the quality is what it should be, and they save the expenses of the whisky agents, so that they are able both to supply a guaranteed quality and to give the landlord a better article for his money, while the public, in their turn, benefit as well. The temptation to a 'free' publican to put inferior whisky before his customers when he is in any way hard up is enormous; but from such a possibility as 
this whisky-drinkers are effectually safeguarded where the 'tied house' system is in operation.

The principle on which the amount of rent is fixed varies in different districts. In some, such as the Tyne, Warrington, and Wigan, the tenant pays a low rental, but is charged a higher rate for goods supplied than a free tenant would pay, so that, given two houses of equal rent but unequal trade, the tenant who did the larger business would, through his barrelage, pay the larger amount to the brewers. In the Tyne district I visited a rebuilt house which was assessed at $£$ roo, but for which the tenant paid only $£ 48$ a year; and I saw, also, houses which, rented by a brewery company itself, had been sublet to the actual tenant at a substantially lower figure. In other districts-Manchester, for example-the tenant pays full rent and only standard prices for goods supplied.

Whatever the precise conditions, the tenant gets far more in the way of repairs and improvements from his brewery landlords than a 'free' publican would be likely to get from a landlord who was not a brewer, and who looked exclusively to the rent for his return on capital invested. This is a very material point (to which sufficient attention is not always paid), inasmuch as it may make a considerable difference in the tenant's outgoings, while securing for him the maintenance of his place in such condition that it will not fall off in public favour. From the point of view of the owning companies, it is a mere matter of business that they should operate on these lines, in the interests of their own property; but, in effect, there is probably no other class of tenants in the world who get more done for them by their landlords in the way of repairs and improvements than the tenants of 'tied' houses owned by brewers. The same conditions apply to the pay- 
ment of rent in times of personal misfortune or trade depression. Here a consideration is shown by the brewers towards their tenants which would not be surpassed by any other class of landlords, and certainly could not be compared with the position in which 'free' publicans would stand in relation to a nonbrewer from whom they had borrowed money on mortgage. Some brewers, again-and especially those charging higher rates for goods supplied-are generous in providing their tenants with bar-fittings and accessories, furniture for public rooms, and other things besides. In certain houses I have visited on the northeast coast the value of such accessories (included in the rent, and entered in the schedule of the agreement) ranged from $£ 200$ to $£ 250$.

These are matters of detail which should naturally be borne in mind in considering the relations between landlord and tenant. But, in any case, the tenancy represents a perfectly free contract. It is entered into with a full knowledge of the facts, and the tenant need not sign the agreement at all if it is not to his liking. On the other hand, it is only reasonable to expect that those who do enter voluntarily into agreements, whether in the liquor or in any other branch of legitimate and recognized trade, should be required to keep them.*

The fact of a tenancy being terminable at the end of three months' notice may be thought to impose a hardship on a tenant. But the average brewery company is naturally desirous of keeping good tenants when they have once been secured; and I am informed by a certain provincial company, which controls some hundreds of

* In order that the reader may form his own opinion as to the nature of the agreements entered into between brewery companies and tenants, I give, in the Appendix, a form in use in Lancashire and Cheshire. 
tenanted houses, that the number of cases in which notice to quit is given to its tenants would scarcely amount to one a year.

From the point of view of the brewers, one disadvantage of the tenancy system that may arise is in regard to the transfer of the licence when this becomes necessary. Up to about five years ago it was considered sufficient if the incoming tenant alone appeared before the licensing justices when the application for the transfer was made; but since the passing of the Act of IgO2, the attendance of the outgoing tenant is generally required to allow of the transfer being completed, although the bench may, for good and sufficient reasons, dispense with such attendance. But an outgoing tenant who has received notice from the brewers for misconduct or incompetency is invariably a man with a grievance, and the requirement in question gives him an excellent opportunity for levying blackmail on those against whom he feels a grudge. Many instances have occurred of men in this position declining to attend the court unless it is made worth their while so to do, and this generally means that they must be given a receipt in full for all that they owe to the brewers for rent or goods, and perhaps a substantial sum in addition. Even then a maliciously-minded man will sometimes try, in open court, to spoil the prospects of the transfer if he can.

The main reason for requiring the attendance of the outgoing tenant is, apparently, to prevent the traffick: ing in licences which grew up under the earlier system, the magistrates being further empowered to limit the number of transfers, in respect of the same house, during the currency of the licence. Some benches, however, take advantage of the enactment to inquire from the outgoing tenant whether he has been able 
to conduct the business at a profit, an answer in the negative giving them the excuse for refusing the trans. fer. This course of procedure leads to a system of extortion which frequently involves the loss of hundreds of pounds over a single transfer, while in any case it handicaps the brewery companies in getting rid of undesirable tenants, and putting more competent or more trustworthy ones in their place. In point of fact, instead of the tenant being at the mercy of the landlord, the landlord may be at the mercy of the tenant alike during the period of the tenancy (since misconduct in management may endanger the licence) and also when the tenancy is expiring.

Another practical difficulty arises in this way: the Licensing Act of 1902 gives the licensing magistrates power, on the occasion of every application for the transfer of a licence, to call for the production of the tenancy agreement between the owner and the proposed licencee, so that they may learn on what terms the latter will hold the premises, and, also, following up the aforesaid interrogation of the outgoing tenant, ascertain still further what are the prospects of the house being conducted at a profit. But some benches of magistrates have gone beyond this requirement, and have insisted upon the prices at which the owners will supply the tenant with his goods being entered on the agreement; while in certain instances the magistrates have even stipulated that the price at which the goods are to be supplied shall be the minimum price for which similar goods can be obtained in the district.

In all this there is the suggestion of a serious interference with the freedom of contract, and, whatever may have been the custom centuries ago, it is doubtful if the Legislature of to-day ever contemplated such an attempt to check economic and commercial laws as 
one finds implied in the fixing by magistrates of the prices at which commodities shall be sold. Apart, however, from the important question of principle involved, the practical difficulties which arise are certainly sufficient to show the absurdity of the situation.

Everybody knows that there is beer and beer, and that the qualities brewed in one particular place may have a reputation, and hence command a heavy sale, far and wide. It is no uncommon thing for such qualities to be sent to London from provincial towns two hundred or more miles away; but the London owners receiving the consignments have to meet heavy charges for carriage and distribution, and it is not reasonable to expect them to supply these particular qualities at the same price at which the local publicans in the provincial town in question would get them direct, or at the same price as that at which beer made in London could be supplied to London houses, the cost of carriage-or, rather, cartage-and distribution in the two latter cases being extremely small in comparison. In the same way London stout could hardly be sold, say, in Yorkshire or Durham if the brewery firms there were bound to ask no more for it from their tenants than the price paid for stout made locally, and costing practically nothing for transport.

The logical result, therefore, of the requirement in question, if it were generally enforced, must be that consumers would have to be satisfied with homebrewed beverages, and submit to being deprived of those on which transport charges from a point of origin some distance away had to be paid, while the radius of distribution now open to brewers would be seriously curtailed. Extreme teetotallers might rejoice at such an issue, and those of them who are licensing 


\section{AGREEMENTS AND PRICES}

magistrates would admit, perhaps, that this is what they seek to bring about. But it is, surely, a most dangerous precedent that licensing benches thus should be authorized, not merely to interfere with that principle of freedom of contract upon which our commercial success as a nation is largely based, but also to attempt to regulate the course of trade according to their own individual ideas. It is inconceivable that the British Parliament ever clearly realized, when it passed the Act of 1902, that it was giving authority to magistrates to do such things as these; yet done they are, and the practice is even steadily growing. 


\section{'MANAGED' HOUSES}

THE managerial system - first established in Liverpool about fifty years ago-has been subjected to much adverse criticism from time to time. It represents, however, merely one phase of those ordinary commercial conditions of to-day under which companies, firms, or even individual traders in a large way of business, open a number of establishments in different towns, or in different parts of one and the same town, for the sale of boots, drapery, drugs, bread, milk, grocery, refreshments, tobacco, or other commodities, placing each in charge of a manager, who receives a stated wage, and is liable to dismissal for inefficiency, misconduct, or breach of regulations. One well-known grocery firm, for instance, has alone 560 branches. The disappearance of the small shopkeeper thus brought about may be a cause for regret, but, on the other hand, many a small trader-or many a person who might otherwise have become a small trader-has found it to his advantage to discard the idea of doing business on his own account, and become instead the manager either of some large establishment or of a local branch thereof. Yet in these other businesses no one thinks of regarding such a person as unsuitable or unfit, or of proposing that his employers should be I06 
dispossessed of their property in order that he may be installed as owner.

It is only in a certain class of public-houses that the managerial system can be adopted-that is to say, houses where the business done is sufficiently large to allow of the payment of a manager's salary, independently of the net profits. In small houses, where the takings are only just sufficient to provide for the support of a man and his family, the tenancy system would naturally be adopted by preference. But, whatever the size of the house, the most scrupulous care is, generally speaking, taken in the choice of a manager. As a rule he enters the service of the company as a second barman, though probably he is not taken on even in that capacity until his character for several years previously has been thoroughly investigated. He rises in due course to the position of head barman, and then, after he has had two or three years' experience, and been found thoroughly sober and trustworthy, it may be proposed to appoint him manager of a small house. Particulars concerning his antecedents are furnished to the police, who make their own inquiries, and raise objections to his selection if they find any occasion for so doing. Should he show capacity in his management of a small house, he will be promoted to larger and still larger houses, and in some instances a manager eventually develops into a tenant of the company he has served. Certain brewery companies recruit their barmen and prospective managers from ex-soldiers of 'exemplary' character, or from expolicemen, who are especially favoured because they can keep order well, and know better what the police and the magistrates desire. Others encourage steady and trustworthy young men to enter on a subordinate position in the hope of rising to a higher post; while 
the members of the Birmingham Wholesale Brewers' Association are considering a proposal for setting up a training-school for barmen, where pupils would be instructed in the management of licensed houses, those of them who became proficient being awarded certificates which would be recognized by the trade.

In regard to the question of remuneration, it is the almost universal practice in the trade that the manager shall be paid a stated wage, and have no interest whatever in the sales of liquor, though in some towns he will have a pecuniary interest in the sales of food. A few instances might be found in which the managers get a commission on the drink sold, but these are the exceptions that help to establish the rule. Whatever, therefore, the increase (if any) in the business done, the manager does not benefit therefrom. His promotion to a larger house, and also the amount of his Christmasbox, where this is given, will also depend, not on his sales, but on his general efficiency.

The fact seems to be recognized by most brewery firms that not only would a payment-by-results system be undesirable in principle, but it might, also, be detrimental even to their own interests, inasmuch as it would offer a direct inducement to a manager, not so much to 'press' liquor on customers as to shorten the measure, water the whisky, or to do other things which might give him undue profit on his turnover, but would eventually ruin the credit of the house. Even if these things were not done, any increase in the sales at a particular house by, say, $£ 5$ or $£$ ro a week would suggest to the officials of the brewery company that the manager was pushing business unduly by serving drunken people, or encouraging an undesirable class of customers, either of which offences would (owing to the serious risk to the licence) render him liable to instant 
dismissal. From no point of view, therefore, has a manager any personal interest in 'pushing' the sales of liquor, or is he under any incentive so to do.

The great care in the selection of managers is followed -in the case of all large brewery companies, at leastby a most thorough-going system of supervision and control. The details may differ somewhat according to the ideas of a particular company or the character of a particular district, but the following sketch of the methods adopted by a certain large provincial brewery company may be regarded as fairly typical of the system in question as a whole.

At the head of the organization there is a superintendent who is personally responsible to the directors, with whom he keeps in close communication. Operating under him is a staff of five inspectors, who divide between them, in certain defined districts, the managed houses controlled by the company. Over these houses they must keep close watch and guard, visiting them at such times, day or night, and at such intervals as may seem to them necessary or desirable, but especially paying surprise visits, so that the landlords will never know when to expect them. Their business is, among other things, to see that no serving of drunken persons goes on; that neither betting nor gambling is permitted; that everything about the place is, as far as may be, scrupulously clean, comfortable, and in good order-no sloppy tables, broken windows, or defective doors; that the quality of the liquors as sent out from the brewery is maintained; that the customer gets what he asks for, the substituting of one article for another being prevented; and that, in effect, everything is exactly as it should be. The inspectors are required to send in daily reports to the superintendent. Alternatively, inspectors may communicate with the head officials by 
telephone or otherwise. Should suspicious circumstances have been noticed which require confirmation, the services may be called into requisition of certain individuals, known only to the superintendent and a single director, who will pay further visits to the house, and send in confidential reports, on the basis of which the manager may be called upon for explanations, such action being then taken as the circumstances may render necessary or desirable.

Next to the inspectors comes a staff of stock-takers, who visit each house either once a week or every fortnight. In addition to taking stock, they are required to keep a close look-out for anything to which they consider attention should be called, and report thereon to the company. Following the inspectors is a set of men sent out from the technical side of the brewery to test the liquors sold in the houses, in order to see (for the protection of the public) that they have not been tampered with at all. Still further, there is a staff of surveyors and assistants whose attention is at once called to any structural or sanitary deficiencies by the superintendent, acting on the reports of the inspectors, serious defects being, if possible, put right the same day. To complete this elaborate system, periodical visits to the various houses are also paid by the superintendent and one of the directors.

So, in a managed house, there is not only all the ordinary police control that is exercised over a free house, but there is the very close supervision by the brewery staff as well; and the brewery inspectors, one must further remember, are exclusively engaged for the purpose, whereas looking after public-houses constitutes only one of innumerable duties to be performed by police constables during the time they are on duty. May it not be assumed, therefore, that drunkenness is 
much more likely to be kept down, and general good order maintained, in managed than in free houses? In other words, does not the managed system make for sobriety rather than for inebriety, and could any practicable system of so-called disinterested management provide more effective checks (in reason) than are already secured under the conditions stated? It is not surprising that the chief constables in various districts should have borne testimony to the efficacy of the system by declaring that the managed houses in those districts were the best conducted of any.

One drawback to the position is that, after all this extreme care has been taken by the companies to secure a perfection of good management, licensing magistrates should often be so little sympathetic, and raise such difficulties as they do in allowing the change of managers which the companies, in the exercise of their discretion, and as the result of all this supervision, may think it necessary or desirable to effect.

The real position of the brewery companies was well expressed in a report presented to quarter sessions some years ago by the Licensing Committee of the Surrey justices, and still true to-day:

' Few have greater interest than the brewer in seeing that houses are well constructed. Few have greater experience as to the steps to be taken to secure avoidance of anything like transgression of the law. The fact that complaints are constantly made that the number of transfers is greater with regard to these houses than to others proves how jealously they are watched by the owners, who will not incur the risk involved in the toleration of doubtful or careless managers.'

There arc, however, benches of licensing magistrates who put every difficulty in the way of brewery firms 
in obtaining interim transfers. Magistrates with pronounced confiscatory tendencies frequently seek to retain in possession a licencee with whose conduct the owner is dissatisfied, in order that at the annual licensing session they may bring forward such misconduct as a reason for refusing the licence altogethera course they could not so successfully adopt if, in the meantime, there had been a transfer to a man to whom no objection could be offered. Other magistrates, again, make it a rule, under the statutory provisions in operation, to refuse the transfer of a licence oftener than twice a year, owners being thus placed in a very awkward position if a manager whom they have appointed with full confidence in his capacity or trustworthiness should develop unsuspected bad qualities, or should illustrate the truth of the common experience that a man who gives every satisfaction in a subordinate position may be a failure when raised to a post involving responsibility. This same reluctance on the part of certain magistrates to sanction transfers also renders it more difficult for owners to promote efficient men when they think that promotion is deserved.

There is a popular idea that public-house managers are liable to be discharged if they do not sell sufficient liquor to satisfy the brewers, and the remarks already quoted from Truth were evidently written from this point of view. While, however, the allegation is certainly made by discharged managers, who find it a most convenient explanation of their dismissal to offer to a sympathetic acquaintance, it would probably be found that they had been got rid of for reasons which they entirely misrepresent. If, for instance, it were found by the brewers that the sales at a certain managed house had seriously declined over a given period, as compared with the same period in previous 
years, an inquiry into the reasons would naturally be made as an ordinary matter of business. Such decline might be found to be due to causes for which the manager was in no way responsible; but it might also be attributed to inefficiency or incivility on the part of that person, or to some attitude towards customers which was rendering him unpopular, and driving trade elsewhere. A change of managers might thus be found necessary. The primary cause for the inquiry leading to such action might have been declining sales, but it would be entirely wrong to say that the manager had been discharged for not sufficiently 'pushing' the business. The course of procedure here would be identically the same as in the case of the other large traders already mentioned.

Alternatively, the misrepresentation might arise in this way. A public-house manager's accounts are, naturally, subject to periodical checking, takings and stock in hand being compared with the lists of quantities supplied by the brewers. The experience of the stock-takers enables them to tell with approximate accuracy the relation that the several items should bear to one another, and, although the manager will not be blamed because his sales have not been higher, he may well run the risk of dismissal if the proper ratio between supplies and receipts is not maintained-in other words, if the sales he does account for, by the sum he pays over, are much below those that must obviously have taken place. In the event of dismissal following, a man thus capable of appropriating his employers' money would not scruple to allege that he had been turned off 'because the brewers were not satisfied with his sales.'

That the sale of liquor is 'pushed' at all is one of those popular delusions on the liquor question which 
are favoured especially by teetotallers who probably know nothing as to what goes on inside a public-house. The business of the person behind the bar is simply to serve the drinks called for, provided the individual asking for them is sober. That the sales should be forced, or that the barman will urge the excellence of his liquors in the way that a linen-draper's assistant will try to induce customers to buy more than they came in for, is an idea which no one possessed of any real knowledge of the subject will accept for one moment. Not only is the drunkard, who creates disorder, and may endanger the licence, the publican's worst patron (the risks run by encouraging his custom far outweighing the value of the few additional pence he spends), but even the regular sot, who soaks without getting actually drunk, is looked upon with disfavour by publicans possessed of a due share of common sense. I was much struck by some remarks recently made on this point by the tenant of a large licensed house in a town in Lancashire. He said, in effect:

'The man who spends too much of his time here during the day in drinking is not the sort of customer we care for. $\mathrm{He}$ is neglecting his opportunities and earning no money, so that soon he will have none left. The man we prefer is the one who may take just a glass at dinner-time, but is working steadily during the day, looks in at night, joins pleasantly in the social life of the place, and is likely to be a regular customer without ever going to excess.'

These very sensible remarks of a typical publican of to-day may fairly be set against the 'pushing-the-sales' bogey of the typical teetotaller.

There is another, and almost tragic, side to the question of the dismissal of managers-one, namely, in which they are the victims of cruel circumstance rather 
than of actual and deliberate misconduct. A policeman may, for example, notice a drunken man leave one public-house, and will follow him down the street until he sees him enter another. Arrived at the bar, the man will pull himself together, and stand perfectly steady for a time (as drunken men can do) while he asks for more drink. As he thus presents none of the appearances of a drunken man, he may very easily be served by the landlord or a barman; but by the time this has happened the policeman, after waiting outside a few moments, will have entered, and he then finds the man with a full glass before him. The landlord is thereupon summoned for serving a drunken man.* A conviction will probably be recorded against him, and, under these identical circumstances, magistrates have also suppressed the licence of a house-incidentally, to the benefit of that other house in the neighbourhood where the drinker in question had really obtained the liquor that made him drunk. But, as regards the manager, this one conviction against him probably brings his career as a public-house keeper to a close. Morally speaking, he may be absolutely blameless; but if he should trip a second time, the double conviction might afford the magistrates an excuse for closing the house altogether, and where the owners may have invested from $£ 5,000$ to $£ 8,000$ in the place they can run no risk. The unlucky manager has to go, and the

* I do not suggest that this practice is a universal one on the part of the police. On the contrary, there is at least one large provincial town where the chief constable has given orders to his men that, if they see an individual already under the influence of liquor enter a public-house, they are to follow him straight in, and say to the landlord or barman, 'Don't serve that man.' The chief constable in question rightly holds that the business of a police force is not so much to entrap offenders as to prevent the commission of offences, and the local publicans declare themselves most grateful to him for the timely warnings they receive. 
probability is that he will never be able to get a position in a public-house again.

In that case he may be much worse off than a tenant would be in like conditions. The man who becomes tenant of a country. public-house often has some trade to which he can take again should he lose his licence, and it may even be that he is working at his trade while his wife looks after the house; but the average manager will have spent all his life in the public-house business, and has really qualified for nothing else. Instances have occurred in which the manager of a large and important house, losing his post on conviction for some trivial breach of the licensing laws, has had to become an ordinary labourer in order to earn his livelihood.

Discussing this phase of the question, the managing director of a large brewery said to me:

'It is an awful state of affairs, and we often feel profoundly sorry for the unfortunate victim. But we are practically powerless in the matter. We really cannot run the risk of having what might well be an $£ 8$,ooo penalty imposed upon us by the loss of the licence. The manager's lot is not a pleasant one, and the conditions of service are most responsible; but, in our opinion, any conviction by the magistrates must necessarily lead to discharge, however much we may think that the man is not really to blame. What we have to consider is, not our own view, but the possible future view or action of the magistrates. The property is too often punished for the fault of some individual who, wilfully or accidentally, disobeys the express orders of his employers.'

The conditions here referred to are having a further result. Owing to the severity with which the licensing laws are administered, and the serious results of a con- 
viction in the case of a manager who has, say, unwittingly acted in contravention of the law, there is a steadily increasing reluctance on the part of eligible men to accept public-house appointments, the better class of such men being deterred by dread of the punishment falling upon them for some technical breach of the law, committed quite unconsciously, all their prospects in life being thus suddenly blasted. These considerations are to be kept in mind by critics disposed to make invidious comparisons between the publichouse manager of to-day and the old-fashioned publican of a decade or two ago. The wonder is, rather, that the brewery companies succeed, in the circumstances, in getting as good a type of man as they do.

A common allegation in regard both to tied and to managed houses is that the brewers make use of them in order to get rid of indifferent qualities of beer. Here it would be rash to generalize, in the way either of affirming or of denying, and it may only be suggested that the possible faults of a few should not be attributed to a class.

It is undoubtedly true that, whether from motives of economy or otherwise, certain firms of brewersespecially among those of the smaller type-may not obtain such good materials as a firm or company operating on a large scale, and with a reputation to maintain, would do; and these conditions might lead to the production of inferior qualities, which would find their way to such public-houses as the firms in question controlled. It may also happen that, in spite of the use of the best materials, and of the adoption of the most approved methods, the beer produced by a particular brewer in even the best of establishments will be what is known as 'sick.' Such beer should be kept back in the brewery for a few weeks until it has recovered 
from its ' sickness,' when it will be really fit to send out ; and any brewer who refrained from adopting this course when the contingency arose would certainly be acting contrary to his own interests.

Brewers, however, are of two types: the long-headed and the short-sighted.

The long-headed are careful to get the best materials ; they avoid the economies which it is very easy to effect by reducing the gravity of the beer, knowing, as they do, that such reduction would inevitably lead to loss of reputation; and, for a like reason, they give instructions to tenants, managers, and customers that if, by chance, a barrel of beer not of the right quality should be sent to them, they are to return it to the brewery at once. Of the head of one large provincial brewery firm it is told that he made a practice of himself going to the houses supplied, testing the beer, and ordering back anything that did not satisfy him. ' One bad barrel,' he was in the habit of saying to the tenant or manager, ' will ruin your trade for a week.'

The short-sighted brewers are those who think more of immediate profit than of reputation, so that while it may be an advantage to one publican to be 'tied' to a large firm of 'long-headed' brewers, whose name is a sufficient guarantee for the excellence of their liquor and the fairness of their dealings, it may be a disadvantage to another publican to be 'tied' either to a short-sighted firm, or to one that cannot afford good materials, and can never sell sufficient of its products to secure anything like a satisfactory business. The British working-man may, as a rule, be safely trusted to recognize any serious deterioration in the quality of the 'national beverage,' and, if any choice be open to him at all in any particular neighbourhood, he will desert the house where the liquor is not to his liking and 
go elsewhere. In country districts and small towns the actual choice may be limited; but in large towns this would not be the case, and there, at least, the competition is so keen that any idea of reducing the quality would be impracticable. The aim there is, rather, to keep on improving the quality as far as can be done without unduly increasing the cost, the fact being fully recognized that the success of a firm of brewers is always in strict proportion to the excellence of the product.

So it comes about that, whereas in some few parts of the country 'tied' houses are certainly regarded with prejudice by customers, in others they are distinctly popular, and even preferred, because of their association with brewers whose well-established beverages the public regard with favour, while in the case of a 'free' house there is not the same guarantee that the occupant may not yield to the temptation of getting cheap and inferior qualities should he happen to be 'a short-sighted publican.' Some 'free' publicans, however, have the signs of leading firms of brewers fixed on their houses by way of advertisement, and as a recommendation to prospective customers who associate excellence of quality with a certain name.

In regard to the aforesaid 'smaller' brewers, of limited resources, it should be borne in mind that, while the cost of production may be increased, by reason of the heavy taxation or of a rise in the cost of materials, there is no chance of advancing the established prices paid by the consumer for the manufactured article. In these circumstances a brewer of the smaller type, who cannot afford any reduction in profits already small, may find himself forced to adopt economies which will affect the quality of his product to the inevitable prejudice of the customer, inasmuch as that individual is much more 
likely to suffer from bad beer than from good. Each additional burden imposed increases the tendency in this direction, and renders it still more difficult for a brewer of the type in question to produce the same qualities of beer as, in other circumstances, he would probably be glad enough to supply either to 'tied ' houses or 'free.'

The reader will see from this impartial statement of facts how the story as to the distribution of inferior qualities of liquor through 'tied' houses has probably originated; but to say that the practice is widespread, or even common, would be going far beyond the truth. Though a landlord may be 'tied,' the public are not; and as long as keen competition continues, people will readily withdraw their patronage from one house, where they are served with bad or inferior liquor, and go to another-should there be one within a reasonable distance-where they can get what they want. The idea that the average public-house patron will swallow uncomplainingly whatever is put before him is an altogether baseless fiction. The sale of bad liquor must inevitably lead to the loss of trade. A public-house that gets an unfavourable reputation for its drinks can hardly hope to thrive, and the brewers who have invested capital in the place are bound to suffer, sooner or later. To suggest that practices such as those alleged prevail to any really great extent is to imply that brewers, as a class, are devoid of ordinary business instinct.

Another allegation in regard to tied and managed houses-specially referred to by the writer of the article in Truth, mentioned in the last chapter-is that the only business of tenants or managers is to get rid of as much of the brewer's beer as they possibly can. But no one who visits some scores of public-houses of all types in different parts of the country, as I have recently 
done, can fail to be struck by the almost general provision made therein for the supply either of meals or of light refreshments, as well as of the orthodox liquors. I use the words 'almost general' because, in many instances, there is no call for food, and here it would be a waste of money to lay in stocks not likely to be required. But there is abundant evidence of a willingness to cater for public requirements in the matter of food whenever it is called for. I found in country or seaside districts that, in rebuilding primitive inns on a larger scale, the owners had provided their tenant with large and commodious tea-rooms, although they, as brewers, would derive no direct benefit from the teas supplied. In the case of managed houses I found that, as a rule, ample provision was made for the supply of just such food as was likely to be required, according to local conditions.

In practice the system in force varies considerably. In some districts the whole of the catering is done for the brewery company as a part of the ordinary business of the house. In others I found that, where there was any demand for meals, the brewery company arranged to supply them at their own risk and to their own benefit; but in the case of small houses they left the manager and his wife to do the catering, with authority to keep for themselves whatever profit was thus made by them on the food. In still another district I became acquainted with a brewery company controlling some hundreds of houses who require all the managers of houses in the neighbourhood of factories to provide dinners or whatever food is wanted, furnish cooking appliances, tablelinen, knives and forks, etc., but allow the managers (who are left to do the buying) to keep for themselves all the profits arising from such food-supply, and even guarantee them against loss. This latter contingency, 
I was told, had only arisen in the case of a large club dinner, while some of the managers gained for themselves $25 \mathrm{~s}$. a week profit out of the catering, in addition to their wages, those who succeeded least still getting dinners for themselves and helpers out of the food provided, thus saving the allowance made by the company. In such examples as these one seems to get a full realization of 'disinterested management,' since the managers are deprived of all personal concern in the sales of liquor, but do have a direct incentive to ' push ' the food, or, at least, to show the greatest readiness in supplying what is wanted. But although, in the case in question, the company derive no direct benefit from the supply of meals or of food, they disclaim any suggestion that they are assuming the rôle of philanthropists. They look at the matter from a business point of view, saying that the provision of good wholesome food at essentially popular prices adds to the goodwill of the house, and brings a better connection, so that it really pays them to encourage the system they have adopted.

Generally speaking-and especially in the case of public-houses in the neighbourhood of docks, as at Liverpool or the Tyne, or of large works in manufacturing towns-the first duty of the earliest barman in attendance is to have hot coffee ready by the time he opens the doors, and this, surely, should count as a temperance measure. In all such localities, too, there will be rooms specially set apart for the supply of cheap and substantial food for labourers and other workers. In Liverpool, for instance, I saw large plates of ' hotpot ' being supplied in such roorns at twopence per head, with a free supply of pickles, the customer paying for a glass of beer in addition, if he wished for one. Then fourpenny or sixpenny dinners, well cooked, and suff- 
cient for a meal for any average person, I found to be quite an institution in both tenanted and managed houses in various parts of the country, the glass of beer taken with them being sometimes included, but more often regarded as an extra. For customers able to pay higher prices special arrangements were made in other rooms or in other houses; but I am here more especially concerned in the provision made for the feeding of the working classes.

In this connection it is no exaggeration to say that the labourer or artisan gets better food, at a lower rate, in the average 'managed' public-house than he would get at the ordinary cheap restaurant conducted by an individual trader. A brewery company owning many houses would be able to make a better contract for the supply of meat; they would see that the cooking arrangements were adequate, and, as they would not be dependent on the takings from food for their profits, they could afford to sell at lower charges than those of a person otherwise situated. I do not hesitate to affirm that many even of the most unpretending of the publichouses I visited in the dinner hour, in the neighbourhood of docks or factories, were conferring a distinct advantage on the working men of the district in the facilities they offered for the supply of good nourishing food at extremely low prices, or in the provision of rooms where men could consume the food they had brought with them, washing it down with the glass of beer which no one could conscientiously assume to be doing them any harm. I even found places where labourers could have their food cooked for them, and sit at a table on which mustard, salt, and even pickles were provided free, the only direct gain to the 'house' being such profit as was possible on the sale to them of just a single glass of beer each. In other examples that came 
under my notice men brought in their dinners when they passed the house on their way to work in the morning, and had them kept warm until dinner-time, no charge being made for the service thus rendered. One felt that the compulsory closing of such houses under some prohibition scheme or other would impose a most serious inconvenience, if not a positive injustice, upon the toilers who were using, but in no way abusing, them. There was, in fact, overwhelming evidence that the various houses in question were of great practical utility, and supplying a real public want in the particular localities in which $I$ found them.

The one factor in the situation which limits the power of the publican to supply food with liquor to an even greater extent than he is doing already is the general reluctance of licensing magistrates to allow of alterations which would involve any increase of the licensed area. The addition to existing buildings, not merely of a dining-room, but even of extra kitchen space for the cooking of meals, is often practically impossible, by reason of this disinclination to permit anything in the way of 'enlargement,' though some benches of magistrates are much more considerate in the matter than others.

Finally, I come to the disputed question whether, in regard to public-houses owned or controlled by brewers, the tenancy is preferable to the managerial system, or vice versa. Opinions are much divided. There are benches of licensing magistrates in London and elsewhere who will not recognize managers at all (though the practice of appointing them is clearly sanctioned by the law), and insist on dealing with tenants only. There are others-as at Birmingham-who offer no objection to managers. But the question is tending to settle itself. Just as the 'old-fashioned' free publican 
got uneasy as the animosity shown towards him increased and the attitude of governments and politicians became more threatening-until he was glad to sell out to the brewery companies and avoid further risk-so, in turn, are tenants becoming more and more reluctant to put much of their own money into the business. Men who, ten or twenty years ago, would willingly have invested $£ \mathrm{I}, 000$ in a public-house, hesitate to do so to-day. When they see that the whole situation is full of uncertainties, and that licences may be forfeited, under the existing severe administration of the licensing laws, for offences which a decade or two back would have been punished by fine only, they think it better to keep on the safe side. They may take a $£$ Io,ooo house, but they prefer to work as far as they can with the capital of the brewery company. If they should possess money of their own, they generally try to conceal the fact.

In these particular conditions there are disadvantages from the standpoint not only of the brewers, but also of the public. The short-term tenant who has invested very little of his own money in a house may prove to be a 'dangerous' person. His aim will probably be to make as much money as he can while he has the opportunity, and he will thus run risks, or allow things to be done, which would not be tolerated in a managed house. Should he bring about the suspension of the licence, he suffers but little loss himself, and he may, perhaps, take again to the trade he followed before he became a licencee. The tenant, on the other hand, who puts a goodly sum of his own into the business is a much more cautious person, and will probably be most careful to keep well within the four corners of the law.

It is the latter who constitutes the ideal tenant; but, under the conditions already narrated, he represents 
a steadily-diminishing quantity. In effect, therefore, the actual choice has often to be made between, on the one hand, a tenant who cannot, or will not, invest much money in a house, who wants to make what he can out of the business, who runs the risks spoken of and resents too much supervision, and, on the other, a manager who is a servant of the brewery company, has no financial interest in the amount of liquor sold, can run practically no risk at all without fear of detection and dismissal, and, generally speaking, is under a system of supervision by his employers far more efficient than the control of public-houses in general by the police. In these circumstances it is all the more striking that there should be benches of licensing magistrates who still insist on dealing exclusively with 'tenants,' and will not accept managers at all as licencees.

Whatever view may be taken, from an academic standpoint, of the respective advantages or otherwise of tenanted and managed houses, in actual practice the latter system is being increasingly resorted to, except in those districts where the former is compulsorily maintained by the licensing magistrates. Failing (for the reasons stated) tenants of a desirable class, brewery companies may well think it wiser to send their own manager to a house rather than allow it to pass into the hands of a person in whom they cannot feel complete confidence. Their own manager may sell less liquor than a tenant of the type here indicated would do; but, with such managers, and with such control as that which is enforced, there will be a greater guarantee for a strict observance of the law, and a greater security also for the full maintenance of the value of the property. The present tendencies, therefore, seem to point to a further development of the managerial system, where this is still practicable. 
There is, I believe, a certain divergence of opinion even in the trade itself in respect to this question of managed houses, and I do not wish to commit anyone to an endorsement of the views I here venture to express. But there are certain conclusions to which I have been led by such inquiries on my own account as I have been able to make, and these I beg to offer for whatever they may be worth.

I. I think that licensing magistrates should allow the system of managed houses to come into operation in London (where to-day it hardly exists), as it is already in successful and satisfactory operation in other parts of the country. As I have shown, there is great and increasing difficulty in getting tenants who, in addition to being personally capable and trustworthy, are willing to invest much money of their own in a business that has become the subject of so much attack, and the tenant who has himself very little at stake is not likely to show that scrupulous carefulness which the circumstances require. By refusing to recognize managers, and insisting that licences shall be given only to tenants, magistrates adopting this course run the risk of bringing about conditions still less desirable than those they seek to avoid. The whole question turns, not upon the relative advantages, from a theoretical standpoint, of two different systems, but upon the actual factors and possibilities of the existing situation.

2. Every facility should be given to the brewery companies to change an unsatisfactory man. The hard and fast rule made by some benches of magistrates that they will not sanction the transfer of the licence of a particular house oftener than twice a year may be to the serious prejudice not alone of the brewery company, but of the public, if the second holder should unexpectedly prove to be, in spite of previous 
careful inquiry, a wholly unsatisfactory person, of whom it is impossible to get rid until the following year.

3. The licence is, theoretically, given to the house; but if the landlord be convicted of, for instance, serving a drunken man, it is a wholly unreasonable procedure to deprive the house of the licence, as though, in effect, the house itself was no longer required in the neighbourhood. If the holder of the licence is convicted of breaking the law, it may be only right that he should be punished. But why punish the house as well? Why impose a penalty representing many thousands of pounds on the brewers, who, as I have shown, may have been most scrupulous in their efforts to maintain the proper management of the place? Why also punish the local residents who have been using the house, and in whose interests presumably the licence was originally granted? The whole situation is a mass of inconsistencies, as illogical as they are obviously unjust.

4. The licences of houses owned by brewery companies should be held jointly by the tenant and by the secretary of the company. Not only would this arrangement facilitate changes in the occupancy, but if the actual tenant committed some offence which led to the conclusion that he, individually, should no longer be allowed to conduct the place, the licence would not be lost, the secretary of the company assuming all responsibility until a new occupant could be found. In a system such as this, there would be an element of common justice and fair play which is entirely lacking in the other. 


\section{CHAPTER X \\ PROHIBITION ABROAD}

THE average unprejudiced person would assume that, after 400 years of legislative endeavour to regulate the trade in those alcoholic beverages which, in one form or another, have been in vogue since almost the earliest days of the creation of man, it was about time some definite settlement was reached. But no British Government, apparently, is happy unless it can include a new Licensing Act among its parliamentary achievements, whilst the ever-active and so-called 'temperance' party, inspired mainly by such exaggerations as those I have dealt with in Chapter IV., is ever looking forward to the time when the nations will not merely become 'temperate' (for the word 'temperance' is really equivalent only to 'moderation'), but will be forced, by Act of Parliament or otherwise, to abandon the use of alcoholic beverages altogether.

From the point of view of the 'temperance' advocate (it is difficult to avoid the use of the misnomer), all roads are regarded as leading, sooner or later, to prohibition. Reduction in the number of houses, shorter hours, increased restrictions, time limit, and all the other suggested reforms or changes, may do very well to be going on with, but the one great aspiration ever kept in "mind is the attainment of prohibition. It is true there has been a certain cleavage in the ranks of 
British teetotallers on this particular subject. While the United Kingdom Alliance maintains its original programme, and will be content with nothing but total suppression of the liquor traffic, a newer section, ranging themselves under the banner of the Temperance Legislation League, and presenting to the world a long list of names of influential people as supporters of their views, maintain that 'the effective prohibition of the sale, manufacture, and importation of intoxicating liquors is not practical politics here and now,' and they strenuously advocate rather a scheme of 'disinterested management,' the aim of which is 'to eliminate, as far as possible, personal and private interest in the retail sale of drink.' Evidently the 'disinterested management ' party would like to have prohibition if they could get it, but they see no chance of doing so 'here and now'; so they wish first to achieve the carrying out of their own scheme, which might, perhaps, facilitate the complete or, at least, the partial realization of the ultimate aim.

The position being as thus described, it is a matter of special importance to glance, however briefly, at the results of prohibition in those countries where it has already been adopted. This I propose to do in the present chapter, and, subsequently, I shall deal with some of the various forms of what I think may be called 'modified prohibition' at home; with 'no-licence' in New Zealand; and then with 'disinterested management,' especially from the point of view of experiences in Norway, in conjunction with the establishment in the rural districts there of the prohibition policy.

\section{The United States.}

In no country in the world has prohibition had a longer and more thorough-going trial than in the 
United States. In no country has the failure of prohibition been more absolute and convincing. Massachusetts adopted the system as far back as 1852 , made several modifications subsequently, revoked it in 1867 , and in 1889 defeated a prohibition constitutional amendment by a majority of 46,000 , an exhaustive investigation by a legislative commission having shown that prohibition was a great cause alike of intemperance, corruption, and general demoralization. New Hampshire, after indulging in the prohibition idea since I 855 , defeated, in I883, by a majority of 5,000 , a proposition to embody it in the State Constitution, following this up by obliterating prohibition altogether from her Statute Book a few years ago. Michigan adopted prohibition in 1856 , gave it a thirty-one years' trial, and then rejected it by a great majority. Connecticut, Delaware, Illinois, Iowa, and Rhode Island have also tried the system, found it wanting, and thrown it over; while prohibition has further been repudiated by Washington, Nebraska, Oregon, Pennsylvania, Tennessee, Texas (where the majority against was one of 90,000 ), West Virginia, Vermont, and South Dakota. To-day it is in force in three States only-Maine, Kansas, and North Dakota.

In effect, actual experience of prohibition showed that it did not, and could not prohibit, and that it produced worse evils than those it sought to remedy. Citizens did not see why they should abandon the use of alcoholic beverages simply because their neighbours had voted that they ought to ; and when the legislation sought to enforce the law that followed the vote, they saw no moral offence in still getting their liquors-if not openly, then secretly. They learned to disregard the law, to treat it with contempt, to take a pride in circumventing injunctions they thought unreasonable, 
and to drink more, very often, than if they had been left alone.

Meanwhile, too, the attempts at repression greatly checked the consumption of lager beer. This beverage, introduced into the United States, had been received there with much favour; but, on account of its greater bulk, it did not lend itself so readily to the purposes of illicit trade as the more potent spirits. These, consequently, for a time, almost entirely supplanted the consumption of the much less intoxicating beverage.

In the early colonial days Governor Oglethorpe, of Georgia, established breweries with the idea that ' cheap beer was the only means to keep out rum.' Later legislators began to upset his policy by favouring the spirits, on which greater revenue could be raised; but it was really left for the prohibitionists to establish the final supremacy of spirits over beer. What was worse still, they even drove the production of spirits more and more into the hands of unscrupulous persons, who supplied their victims with vile decoctions not far removed from absolute poison. In Portland (Maine) one such drink went by the especially significant name of ' Kill-'em-quick.'

That prohibition degenerated into a farce has long been known to all the world, but a few illustrations may be offered as suggesting the sort of thing that went on.

In his 'Experiences of Prohibition in the United States, Canada, etc.,' Sir Thomas R. Dewar says :

In 1892 , when travelling through a prohibition State, I tried the conductor of the Pullman-car very hard for some whisky, but it was, 'No, boss ; can't do it. We are in a prohibition State, and all the bars are locked up.' At length, weary of being worried, he informed me that I might get it at the store at the next stoppingplace. This I did. Going in, I boldly asked for a bottle of whisky. 'Have you a doctor's certificate?' was the query. 'No.' 'Then I can't sell you any; but I guess some of our cholera mixture 'll 
about fix you.' The assistant then, explaining what excellent stuff it was, wrote on a label, 'Cholera Mixture. A wineglassful to be taken every two hours, or oftener if required.' This was put on the side of a quart bottle, on the other side of which was a very familiar label to me, for the mixture happened to be a bottle of my own whisky!

The following I take from an article contributed to the Vossiche Zeitung, in I903, by Mr. M. v. Brandt, recording his experiences of prohibition and high licence during a tour through Canada and the United States :

When, in 1896 , I was travelling by train from Vancouver to Toronto, the head waiter came into the restaurant car whilst we were at dinner and called out, 'Gentlemen, we shall be passing through a prohibiton State to-morrow, and those who wish to have beer, wine, or whisky, must buy it to-day.' We took the hint, and the next day we had our drinks as usual, notwithstanding that we were in a prohibition State. A fortnight later I sat in a small hotel in New York which had been specially recommended to meas akind of family hotel, and I asked for a bottle of red wine. The waiter shrugged his shoulders, and said the licence cost so much that it was not worth while to get one during the summer, when there were but few visitors. On my asking if someone could not get a bottle for me, he replied, 'Yes, from a large hotel in the neighbourhood; but you will have to pay something more for it.' I agreed, and I had wine or beer each day as long as I stopped in the hotel, although the place had no licence. I had a third experience in $190 \mathrm{I}$, when going by train from New York to Buffalo. At lunch I asked for some beer, and was told that in New York State no liquor could be supplied on the Sunday. Remembering previous experiences, I sent for the head waiter, and I asked him rather sharply if he had forgotten that I had arranged the previous night for some beer. He looked somewhat disconcerted for a moment, then began to laugh, and said: 'For anyone as cute as you we can always find something.' The beer came along all right, although it was contained in a metal teapot, and had to be drunk out of teacups. Some people who sat at an adjoining table had also, apparently, ordered tea the previous night.

The general results of the system were thus summed up, in I906, by the Rev. Edward H. Newbegin, Rector of the Episcopal Church in Bangor (Maine) :

I feel impelled to say that the net result of two generations of a prohibitory law in Maine is prohibition nowhere, a measurable 
degree of restriction in some of our smaller communities, with a general disregard of the law in larger places throughout the State. The negative results have been an appalling crop of perjury, hypocrisy, and general contempt for law, and for ghastly moral pretence the name of our loved State has become a byword from Massa. chusetts to California.

Then the Waterville (Maine) Sentinel for June 28, I906, denounced in bitter terms the operation of what is known as 'Amendment Five,' which became part of the constitution of the State of Maine in 1885 , and is to the following effect :

The manufacture of intoxicating liquors, not including cider, and the sale and keeping for sale of intoxicating liquors, are, and shall be, for ever prohibited. Except, however, that the sale and keeping for sale of such liquors for medicinal and mechanical purposes and the arts, and the sale and keeping for sale of cider, may be permitted under such regulations as the Legislature may provide. The Legislature shall enact laws with suitable penalties for the suppression of the manufacture, sale, and keeping for sale of intoxicating liquors, with the exceptions herein provided.

The Sentinel declared, among other things, that this amendment had been a dead-letter for twenty years; that fines had been substituted for the penalties of the law, and a form of licence adopted; that nullification and contempt for constitutional law had been for twenty years the object-lesson to young men; that ' it has developed perjury, lying, pocket-peddling, and has relegated the bar-room to the poorer sections of our cities, where it is a terrible menace to the boys and girls who deserve better environments'; that ' more rum, and of an infinitely poorer quality, has been sold in Maine in the past twenty years than in any similar population in New England'; that 'constitutional prohibition has been the hobby of the politicians now in the saddle in this State, and under it the rumseller and the man of God have been marched arm in arm to the polls'; and that 'it has been a complete 
failure, and is so recognized by the business men of the State. The people can't trust the police department, the Sheriff can't trust the police, and the Sturgis Commission can't trust the Sheriffs.'

Still more recently Mr. E. N. Bennett, M.P., in an article contributed by him to the Nineteenth Century and After, in January, I907, under the title 'A Temperance Town,' gave an account of a visit he had paid to Portland (Maine), which has long had the reputation of being one of the best possible examples of a prohibition city. Mr. Bennett said in the course of his article :

During the week I was there no fewer than fifty-eight arrests for intoxication took place, and the average for the year actually amounts to between forty and fifty per week, which in a population of 60,000 works out for Portland to about forty per 1,000 inhabitants per annum-i.e., three times as bad as our worst drinking centres, the seaport towns and mining counties, six times as bad as London, and nine times as bad as our manufacturing towns. According, also, to the last available statistics (1898-1899), the arrests at Bangor number 46 per I,000, Augusta 29, Bath 3I, Lewiston 29, while Gardiner reaches the appalling total of 69 per $\mathrm{I}, 000$ ! Such statistics cannot, it is true, be cited as absolutely conclusive evidence in these cases, for they do not cover all the ground; but, after all, they form practically all the available clata we possess for comparisons between one town and another, and they certainly lend support to the view of practically every ordinary level-headed citizen one meets that the prohibition law is in many respects a hypocritical farce as far as the larger towns are concerned.

At Bangor, it seems, it is perfectly easy to purchase drink, and at Lewiston the sale of alcohol from the laxly-conducted agency amounts to something between I,200 and I,500 dollars weekly. Mr. Bennett continued:

Amongst those members of the community less able to resist temptation, drunkenness is quite as rife in the towns of Maine as in non-prohibition areas. Nor must it be forgotten that any wellto-do citizen of Portland, Lewiston, or Bangor who belongs to a social club can quite easily drink a whisky-and-soda upon the pre- 
mises whenever he cares to. And this easy evasion of the spirit of the prohibition ordinance really establishes the evil principle of 'one law for the rich and another for the poor.'

Finally, the worst feature of the whole system is the low tone of public morality which seems to result from it. Hypocrisy is the keynote of the situation. Drink is prohibited, but drunkenness is horribly patent. The secretary of the Young Men's Christian Association told Sir Thomas Whittaker three years ago that he had never seen a glass of spirits in Portland, and yet at that moment he could have walked into thirty saloons and purchased whisky over the counter in broad daylight. . . . This hypocrisy translates itself into a recognized system of personal blackmail. Politics in Portland are, so to speak, saturated in alcohol; all other questions of social reform sink into insignificance, and are subordinated to the one all-absorbing topic-the conditions under which this municipal hypocrisy is to be carried on.

These comments and condemnations are merely typical of a vast amount of testimony which might be advanced in support of the contention that prohibition in the United States has been something worse than a failure. It should, however, be borne in mind that in the United States there is a tendency to pass laws not so much because there is any real idea of observing them as because it 'looks well' to have them on the Statute Book, while the fact that they are there is regarded as something to the credit of the community. A typical example of this practice occurred in a small town of about 3,000 inhabitants in Florida. The local populace voted in favour of prohibition, and the town 'went dry.' But the leading saloons were at once turned into 'clubs,' of which their former patrons became 'members.' They paid a subscription of roo dollars, in return for which each of them received I5-cent coupons to the amount of such subscription. When a member wanted a drink he merely put down the necessary number of coupons, and, when more funds were wanted by the club, a further call of Io dollars per member was made, in return for which there was a reissue of coupons. The farce was not 
continued for long, however, the law becoming a deadletter soon after it was passed.

But, even taking the States where prohibition has had a full and fair trial, its failure as either a legal or a moral force has been complete, and the conditions of such failure in the United States leave no reasonable ground for expecting that it would be a success in the United Kingdom.

\section{Canada.}

In 1878 the Canadian Parliament passed the CanadaTemperance Act (better known as the Scott Act), which enabled any county or city adopting it by a simple majority of the electors to prohibit, under heavy penalties, the sale of liquor within the district for local consumption. When adopted the Act remains in force for three years. At the end of that period it may again be submitted to the vote, on a petition signed by one-fourth of the electors, and repealed should there be a majority against it. Readily adopted at first, it was found, before many years had elapsed, that the Act was a complete and admitted failure. The general result, where it was tried, appears to have been, according to the testimony of Professor Goldwin Smith,

the substitution of an unlicensed and unregulated for a licensed and regulated trade. The demand for drink remained the same, but it was supplied in illicit ways. It was found by those who were engaged in the campaign against the Scott Act that the lowest class of liquor dealers were far from zealous in their opposition to prohibitive legislation. They foresaw that the result to them would be simply sale of liquor without the licence fee. Drunkenness, instead of having diminished, appears to have increased.

Professor Goldwin Smith further quotes from a memorial signed by 300 citizens of Woodstock, saying :

The Scott Act in this town has not diminished but has increased drunkenness; it has almost wholly prevented the use of lager beer, 
which was becoming an article of common consumption; it has operated to discourage the use of light beverages, substituting therefor in a large measure ardent spirits; and it has led to the opening of many drinking-places which did not exist under the licence law, and to the sale of liquor being continued until hours after midnight.

From other towns it was reported that, under the operation of the Act, the number of places where liquor was sold had increased rather than decreased; that, owing to the persecution of the regular traders, the business was thrown into the hands of the worst classes of people, including bottle hawkers and the keepers of low dens; that cases of drunkenness among young people were becoming deplorably frequent; that spirits were generally taking the place of beer, wine, or cider, because they contained a larger percentage of alcohol in a small bulk, and could therefore be more easily smuggled; that the spirits, sold by the lowest type of dealers, were of the most pernicious kind; that people drank the more deeply because they drank in secret; that anybody who wanted drink could get it; that perjury and blackmailing had become rife; and that people adopting sneaking habits were losing respect both for themselves and for the law.

The electors had, in effect, been 'morally dragooned by a powerful organization and strong ecclesiastical influence into voting for the Act.' But they could not, apparently, be dragooned into total abstinence as well, and having voted for the Act, they seemed at once to have set themselves to consider how best they could evade its provisions. In 1887 the Act was in force in sixty-two places in Canada, but within five years of that date the total was reduced to thirty. All the counties and cities of Ontario which adopted the Scott Act (and they represented three quarters of the entire province) abandoned it, most of them at the earliest 
possible opportunity. It lingered on elsewhere, but was not adopted in any city or county which had not tried it before, and the members of the Royal Commission on the liquor traffic in Canada said in their report (I895) that, "in short, the law as an aggressive weapon has been abandoned.'

All the same, local attempts at total or partial prohibition have been made in different parts of the Dominion, and the prohibition sentiment there is, undoubtedly, still very keen. But the actual situation was well summed up by a writer in the Daily News of September 26, Ig02, when he said:

It is a rare thing to see any wine, malt liquor, or other intoxicant on a dinner-table in Canada. A good deal of drinking goes on, but not in the open. . . . In Canada legislation has got ahead of public opinion on the drinking question. The law in most of the provinces is so stringent that it is generally disregarded-not openly, but with only a pretence of disguise.

The actualities of the position are further described in the following letter, which appeared in the Hertfordshire Express of July I4, I906:

SiR,

I do not know why your paragraph on prohibition in the Saskatchewan district of the Great North-West should come in the column devoted to 'Local Notes and Notions,' but, having been in that province within the last few weeks, I can give my impressions from what I have heard and seen.

Prohibition is generally voted in new territories when there are few inhabitants but Indians, as a sort of tribute to virtue ; but as soon as the land begins to fill up with a white population and the towns multiply, it is quietly dropped in practice, if not in principle, and is followed by a kind of local option which usually leads to a system of licensing of some sort or other. The law against selling liquor to Indians is, however, in the North-West strictly enforced by the mounted police and the Indian Commissioners. I know of two brewers in the adjoining province of Alberta, near the Saskatchewan boundary - both, by the way, owned by Hertfordshire men - who are at the present time doubling their plants. They brew a very similar beer to that brewed in England, and it can be had at almost every town and at the 'meal' stations on the railways. 
Everyone in Canada would wish to see an end put to the sale of bad spirits, ' perfumes,' etc., but the executive power of the Government is so weak, owing to the vast extent of the country, that in most localities the attempt has been abandoned. The smuggling of illicit supplies over the border is only 'almost possible' in theory, as is also the case of the prohibition States of the Union. I know of a brewer in the State of New York who owned to sending many cartloads of beer into the State of Maine under the name of 'Mixed Pickles.'

Yours truly,

SaM LuCas.

To this testimony I may add that, during the controversies waged on the general subject in Canada in I902, Principal Grant declared that the more varied his experience, and the longer his life, the more impartial his study of conditions under prohibition enactments, and the more mature his reflections on the springs of human action, the more convinced he was 'that the prohibitionists are on the wrong tack, and that they have been, and are, doing more harm than good, especially to the cause of temperance. The men,' he continued, 'who use either malt or fermented or distilled liquor soberly, as all God's gifts should be used, or the men who, like myself, do not use them as beverages for one reason or another, but always for a reason which appeals to their sense of duty, and which does not bind anyone else, save in so far as it appeals also to his reason and conscience-these are temperance men.'

\section{Australia.}

Nor does prohibition seem likely to prove any greater success in Australia, judging from the following communication published in the Daily Chronicle of January 31, 1907, from the Melbourne correspondent of that journal:

Liquor trade reformers in Great Britain, who pin their faith to 'no-licence' or prohibition, will find small encouragement for their 
cause in recent developments in the one prohibition district, Mildura, on the Murray River, in Australia. Prohibition has proved such a farce that a colonial wine licence has just been granted for the township, and an agitation is growing in favour of a municipal hotel. The fact is that prohibition must always be a farce so long as clubs live; and though Mildura has no public-house, it has plenty of easily entered clubs.

On December 7 a remarkable report was presented to the Victorian Board of Public Health recording the impressions of a Dr. Robertson, who paid an official visit to Mildura as an inspector. In this document Dr. Robertson says :

'Mildura is peculiar in that it possesses no hotels. The visitor finds accommodation at a boarding-house, or, if he be staying a few days only, at the coffee palace, which corresponds to the ordinary commercial hotel in a country township. Mildura is a hot, dry, and dusty place, and in warm weather one naturally develops a thirst. The water-supply of the town being unsatisfactory as regards quality, one must quench one's thirst elsewhere. As the coffee palace does not attempt to cater for one's wants in the matter of temperance drinks, the visitor is practically forced to avail himself of the existence of clubs.

'There are three clubs holding licences to sell liquors to their members, permanent and honorary. The Mildura Club is main. tained principally by the townsmen; the Settlers' Club is supported mainly by orchardists; while the Working Men's Club explains itself. There is no haughty exclusiveness about these clubs. The members appear to be anxious to extend the right hand of good fellowship to all comers, so that no man need go athirst. No provision is made, however, for the refreshment of the woman visitor, who must content herself with water-not above suspicion-or with warm soda-water.

'It will thus be seen that Mildura cannot be regarded as a prohibition settlement. As a matter of fact, liquor is more accessible in Mildura than in places where hotels are licensed, and at much cheaper rates. Consequently, the usual method of ascertaining liquor consumption by the cost is not applicable to this alleged prohibition settlement. From a visitor's point of view a well-conducted hotel, under municipal control, would be infinitely preferable to a coffee palace plus clubs.' 


\section{CHAPTER XI}

\section{MODIFIED PROHIBITION AT HOME}

PENDING any rash experiments in the United Kingdom in regard to prohibition on the American plan, we have had various forms of what may be called a modified prohibition in the shape of Sunday closing, early closing, and holiday closing, so that we are not entirely without experience as to what may follow from attempts to effect compulsory abstinence from alcoholic beverages. Have the results thus achieved been sufficiently encouraging to warrant further endeavours in the same direction?

I deal first with Scotland, inasmuch as that country is the one included in the British Isles where compulsion on the lines stated had the best chance of success. Whereas in England the Legislature has not gone beyond restricting the number of hours during which public-houses shall be open on Sunday, in Scotland complete Sunday closing has been enforced since the passing of the Forbes Mackenzie Act in 1853, so that Scotsmen have become accustomed to such interference with their liberties as the Act in question applies, and might be thought more amenable to further curtailment than English people with no like experience. On the other hand, one must remember, in regard to Sunday closing in particular, that the average Scot is 
a more scrupulous observer of the Sabbath than the average Englishman, and that his favourite drink, whisky, would keep better, if bought on the Saturday for home consumption on the Sunday, than would the national beverage of the Englishman-beer.

If the temperance party in Scotland had been content with the conditions thus brought about, they would have shown their discretion rather than their zeal. But they allowed the latter to prevail over the former, and in I903 secured the passing of a new Licensing Act for Scotland, which came into force on January I, I904. Under this Act the licensing authorities of Edinburgh, Glasgow, Dundee, and Aberdeen had the option given to them to fix the hour of closing at Io p.m. on week-days instead of II p.m. as previously, and (among other things) the licensing magistrates of Scottish cities and towns generally were empowered to follow up Sunday closing by enforcing complete or partial closing on a specified number of holidays not exceeding four per annum, in addition to New Year's Day.

The earlier closing was adopted in May, I904, in the four cities mentioned, and ten o'clock thus became the hour for closing in important cities such as Edinburgh and Glasgow, as well as in the smallest of Scotch villages, although in the former there is naturally considerable street traffic to a much later hour.

As regards results, official statistics in respect both to Edinburgh and to Glasgow show that under the operation of the ten o'clock rule there has been an increase rather than a decrease in actual drunkenness, while it is undeniable that since this rule came into force there has been a still further multiplication of bogus clubs, shebeens, and drinking dens of all descriptions, of which a considerable number had already been 
brought into existence, more especially as a means of evading the compulsory Sunday closing in Scotland. The fact, however, that in Edinburgh 1,026 , and in Glasgow I,I77 special permits were granted during I 905 to public-houses in those cities to keep open later than ten o'clock is in itself a significant proof that this very early closing is in disaccord with the actual requirements of the community.

By way of illustrating local views as to the effects of the new rule, I cannot do better than quate the following.

The Scottish Weekly Review, in an article published May 26, I906, said :

It is in the matter of drunkenness that there is the greatest falling away, and extremists in temperance reform-who have of late had things mainly their own way-are confronted with the failure of their rigorous schemes. Early closing is apparently worse than useless, and it cannot be gainsaid that the magistrates responsible for licensing matters have not proved equal to the responsibility entrusted to them. Faddism is not reform. In Manchester there is no early closing, and the percentage of drunkenness is 5.7 per 1,000 ; in Glasgow the percentage is 18.3 . Surely it is time common sense had an innings; and there are temperate methods even of dealing with temperance reform.

The Edinburgh Evening Dispatch, May 24, Igo6, said:

A few days ago we directed attention to the evidence afforded by the weekly police-court returns of the increase of cases of drunkenness in Glasgow, an increase which upset certain Church reports which represented the state of things as being all well, because certain public men had referred to a wave of temperance as passing over the land. There has been no such wave of temperance in either Glasgow or Edinburgh, but it may be doubted if our General Assemblies will trouble themselves about it. . . . Yet the excessive drunkenness of Glasgow and Edinburgh is gross, open, palpable ; it is considerably greater than the drunkenness of less-restricted English towns, and immensely greater than the drunkenness of the much freer cities of the Continent. Are our repressionists oppressed by such facts? Not a bit of it. What do they care for constabulary statements that 'there is more drunkenness in Glasgow'? The only effect is to provoke further demands not only for additional restrictions in Glasgow, but for further curtailment of the rights and liberties of Glasgow's neighbours. 
As in Edinburgh, the curtailment of the hours of opening of licensed premises has led to a great increase in special licences, in arrests in disorderly houses, and in that extraordinary substitute the 'special licence.'

\section{Then the Scotsman of July 3, I906, stated:}

Believers in the restriction of the hours of licensed houses as a corrective of the drinking habits of the country will find the quarterly police statistics of Edinburgh a tough morsel to digest. The ten o'clock closing rule has now been in operation in the city for a couple of years. . . . But, altogether contrary to promise, crime, especially as represented in the police charge sheets by cases of drunkenness, has kept mounting briskly upward, quarter by quarter. The record for the first quarter of the present year was bad enough in all conscience. That for the second is, how. ever, much worse. The number of apprehensions by the Edinburgh police during the three months that closed on Saturday was 3,742. This is an increase of nearly 400 over the figures for the first quarter of the year. That quarter surpassed the total for the same period of 1905 by over 100 apprehensions. But the latest figures show an increase of not far short of 500 over the corresponding period of last year. There were 773 'drunk and incapables' and $\mathrm{I}, \mathrm{O} 3 \mathrm{I}$ 'drunk and disorderlies' taken into custody in the second quarter of 1906 , as compared with 694 of the former and $97 \mathrm{I}$ of the latter class of offenders in the second quarter of 1905. . . . If any faith is to be placed in figures, the course is downwards, and at a steady and accelerating rate of speed. Early closing has certainly not arrested this deplorable movement. Has it done anything to hasten the descent? The police figures seem to speak clearly to this effect.

Finally, on this point, a writer in the Glasgore Record declared :

Ten o'clock closing has had a very fair trial, and the result is a miserable fiasco, and there is no reason why the respectable lawabiding portion of the community should be penalized and put to inconvenience on account of those who become amenable to police supervision. If our magistrates have been attending to the police statistics, they must of necessity perceive that the restriction of the hours of public-houses has in this instance failed to reduce drunkenness, and it is to be hoped that, in view of what the Lord Provost of Edinburgh has been saying, our magistrates will reconsider the question and restore the stutus quo at the first opportunity.

Still more conspicuous has been the failure of total holiday closing in Scotland. Taking advantage of the powers granted to them under the new Act, the Glas. 


\section{MODIFIED PROHIBITIONN AT HOME}

gow justices ordered, in I905, that on the occasion of the Spring Holiday, April 24, the public-houses of the city should be closed for the entire day. The result was thus described in the Glasgore Evening Neres of April 25:

What happened yesterday at Paisley, Cambuslang, and elsewhere, as a result of the closing of the Glasgow public-houses is a forcible demonstration of the futility of a policy of simple prohibition. The only effect of that policy was to transfer the drinking from our own precincts to the surrounding communities, and, in so doing, to aggravate the very evil we desired to avoid. There is no need to dwell on the details of an unfortunate business. But there is clearly something wrong with a 'temperance' measure which merely results in turning loose hordes of people, clamouring for drink, upon our neighbours, inundating them with an alien invasion of a kind against which they have every right to protest, and destroying the peace of the country-side and the pleasure of others seeking enjoyment of a more innocent nature within a wide radius of the city. By such a policy we averted no evil-if anything, we made it worse than it would otherwise have been-we merely transferred a nuisance from our own shoulders to those of the surrounding communities and the travelling public.

A further experiment on the same lines was made on the occasion of 'Fair Saturday' at Greenock, on July 8, I905, when all licensed premises in Greenock and Port Glasgow were closed for the day. In this case the rush for 'reasonable refreshment' was to Gourock. According to the Glasgow Evening Times, it began shortly after 8 a.m., and continued all day. Men had to be stationed outside the public-houses to regulate the traffic, but this was so difficult of accomplishment that the houses in Shore Street closed at three o'clock in the afternoon, as the only way to keep out the crowd. The police cells were full early in the afternoon, and 'thereafter drunks were allowed to sprawl at large on the sea-front.' Commenting on the situation, the Glasgow Evening Times remarked:

The folly of attempting to keep intemperate men sober and sober men thirsty on a public holiday has received one more illustration. 
It might be successful in a village ten miles away from anywhere, and without railway or steamer facilities. But in the case of Glasgow and Greenock the experiment has merely exhibited the crass stupidity of those who devised it. It has not kept the intemperate man sober, and obviously it has made drunkards, for the day, of many thousands of people who, in ordinary circumstances, would have enjoyed their holiday, and a reasonable amount of liquor, in a sane and orderly way.

The Glasgow magistrates adhered to their all-day closing policy alike at the autumn holiday of 1905 and on New Year's Day, Igo6. On the former occasion there was again a general exodus from Glasgow to surrounding places. So dense was the crowd going to Paisley that during some parts of the day fifty electric tramcars were running per hour, and it was estimated that 40,000 persons visited Paisley alone. At Cambuslang three public-houses were closed at 3 p.m., some closed at 8 p.m., while others allowed their patrons to come in and go out in batches. The justices seem at last to have been convinced of the futility of their action, for on the occasion of the autumn holiday in Igo6 they abandoned total closing, and only restricted (to six) the hours during which the houses should remain open, thus giving both to Glasgow residents and to Glasgow visitors reasonable facilities for obtaining what they wanted. This time there were no unseemly rushes to suburban areas, and there was no drinking to excess merely out of bravado, and as a practical protest against unreasonable regulations. All-day holiday closing is hardly likely to be tried in Scotland again!

Nor did a like experiment made at Belfast, on Christmas Day, 1905, prove a greater success than the Scottish fiasco. The enforcement for the first time of all-day closing within the city led to the inevitable rush to the suburbs beyond the three-mile limits. An extra service of tramcars had to be run; jaunting-cars were at a pre-

$$
\text { ro-2 }
$$




\section{I48 MODIFIED PROHIBITION AT HOME}

mium; people who would have been satisfied with a moderate amount of liquor in ordinary circumstances now drank to excess; publicans who had increased their stock six-fold found their supplies exhausted by three o'clock in the afternoon, one of them selling no fewer than 250 dozen bottles of stout; while, in the words of the Daily Telegraph's Belfast correspondent, ' as the day advanced drunken men became painfully prominent, and the scenes witnessed were disgraceful. Young men and old lay on the roadside in a state of helpless intoxication, and hundreds staggered homewards in a maudlin condition.'

In Wales Sunday closing has been in force since I88I, and the most conspicuous result to which it has led is to be found in the considerable increase in the number of drinking clubs and shebeens in the Principality. So far back as 1895 the Stipendiary Magistrate at Cardiff, in commenting on the large number of these places to be found there, and on the numerous prosecutions which had taken place, went on to say:

It is not my province to seek the cause for, or to trace the origin of, the illicit drinking establishments of Cardiff. If the cause be a harsh or too arbitrary a limitation of the time during which liquor may be obtained legitimately on licensed premises, the Legislature may so relax the law as to remove the temptation to resort to unlicensed premises. If the difficulties in suppressing the illicit traffic in liquor at Cardiff are due to defects in the law which can be remedied without interference with the convenience, comfort, or liberty of the people, it is to be hoped that, in the interests of good order and for the removal of a public scandal, a remedy may be found and applied. It is not for me to propose a remedy, but to state what is proved by daily proceedings in this court-namely, that on the day when licensed houses are closed there is a demand by a large section of the community for intoxicating liquor, and that that demand is supplied at clubs and shebeens.

In I88I, the year in which the Welsh Sunday Closing Act came into operation, the prosecutions in Wales for illegally selling intoxicating drinks were 237 . Two years 
later the number had risen to 403 ; in 1892 it was 562 ; and in 1898 a maximum of 679 cases was reached. The figure declined to $4 \mathrm{I}_{5}$ in the following year, and has continued to decline since, being II 2 in I905. But even this lowest figure of all represents a large proportion of the 26r prosecutions in England and Wales, in I905, for illicit sales of liquor, and it appears larger still when we remember that the population of Wales is less than one-twentieth of the whole. Taking two adjoining counties, Glamorgan in Wales, and Monmouthshire in England-counties of an approximately similar typeit is significant that in the former, where Sunday closing prevails, there were in 1905 no fewer than 91 prosecutions for illicit sale, while in the latter, where Sunday opening for a fixed number of hours is in force, there were no prosecutions at all in that year. Nor does the decline in the number of prosecutions in Wales necessarily imply that there has been a corresponding decline in the practices indulged in by the populace. As for convictions for drunkenness, I leave the reader to appreciate the significance of the following little table, which gives the annual averages of such convictions per 100,000 of the population for two Welsh and two English counties which may fairly be contrasted:

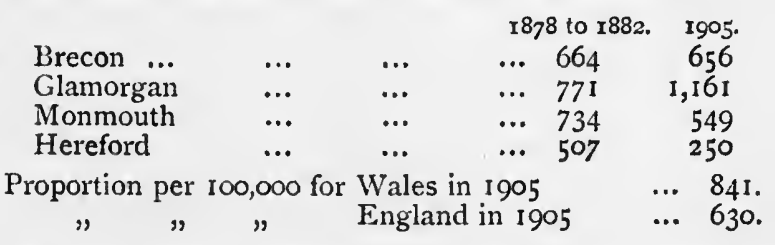

The conclusion to which I am led by all these facts and considerations is that partial prohibition, so far as it has been tried at home, has been no greater success than the attempts at complete prohibition in the United States, and that reasonable regulation, which still affords 
to people due opportunity for satisfying actual requirements, is much more likely to produce good results and to promote the public interests than undue restrictions.

There is, however, another form of modified prohibition which finds much favour in this country, and that is the one known as 'local option.' Here again we get a proposed measure which, in the view of its chief advocates, would be only a stepping-stone to an eventually full and complete prohibition; and one should not leave out of sight the fact that it is advocated mainly by an organization which was established in 1853 with the avowed object of securing. 'the total and immediate legislative suppression of the traffic in intoxicating liquors as beverages.' In the year 1907 this word 'immediate' strikes one as singularly out of place, considering that the body in question has now been actively at work for over half a century, and has got but very little, if at all, nearer to its ultimate goal than it was when it started. What it has done, mainly, has been to effect a certain change of front. The idea of 'total suppression' met with so cold a reception from practical statesmen of the day that the leaders of the movement adopted the alternative of partial suppression instead. They maintained their original aspiration, but limited the scope of their present activities. In place of immediate suppression they now seek, rather, to obtain what has been happily described as 'prohibition by instalments,' and one of the most important of these instalments is local option.

Dealing with the proposal on its merits, I should say that, as a matter of principle, a majority of the inhabitants of a particular locality have no more right to dictate arbitrarily to a minority what particular beverages they shall drink than they have to lay down what kind of viands they shall eat. If to take a glass of beer, 
wine, or spirits were a crime, or contrary to the public welfare, then interference by the majority would be warranted. In that case, indeed, it would be the function of Parliament to act and stop the practice, instead of leaving the people to decide the matter by 'local option.' The principle is, however, still more open to criticism because it would not affect those classes of the community who, having ample means, would be able to lay down supplies of liquor in their cellars so that they could help themselves, whenever they desired, to the beverages they would not allow their poorer neighbours to buy in small quantities from a licensed trader. If it be contrary to the public interests that a working man should purchase a glass or a jug of beer from a publican, it should be still more so for the merchant or the manufacturer to get a case of wine from a wholesale dealer. Should the one be stopped, why not the other? If local option is to be enforced, why not have local option all round? If a middle-class neighbourhood is to vote on the suppression of the working man's public-house, why should not a working class locality be allowed to vote on the suppression of the rich man's wine-cellar? Unless this were done, we should get class legislation of the most invidious character. Provided that the working man's publichouse be subjected to such control as to prevent abuses inimical to the public welfare, this is all that the circumstances of the case really call for.

Then, in actual practice, there must obviously be some limitation to the powers of local self-government possessed by any particular community. Such powers may well have to be curtailed where they involve inconvenience to others. Towns, suburbs, and hamlets do not exist for themselves alone, and the last word in regard to the places of refreshment to be found there 


\section{I52 MODIFIED PROHIBITION AT HOME}

has not been said when the actual residents in the neighbourhood have expressed their views thereon. There are highways leading to great cities where the village inn of some in itself insignificant hamlet is a great and substantial convenience to the streams of traffic constantly passing along. There are country resorts which, while having a very small residential population, are visited in the summer by thousands of motorists, cyclists, beanfeasters, and others, who mostly regard the local taverns as their headquarters for the time being. One might even point to the City of London, where the resident population is about 25,000 , and consists mainly of caretakers, the million or so of people entering it every day-and wanting food and drink in some form or other while they are theremostly dwelling in homes beyond the city boundary. To say that in any one of these instances the wishes of the majority of the 'local residents' are to prevail in the matter of providing hotel or public-house accommodation would be altogether absurd.

Local option would, in effect, enable a handful of people, merely because they happen to reside in a neighbourhood, to disregard, from purely selfish motives, the actual needs of thousands of others who happen to live elsewhere. The whole principle is absolutely wrong and impracticable. There might be some excuse for it if the British nation consisted of a group of strictly isolated communities, whose members never required to pass through the boundaries of their neighbours, though even then the question as to the rights of a majority to control the daily habits of a minority would arise. But, looking at the actualities of the situation, and looking especially at the ever-increasing traffic and general movement going on all through the country, the crudities of the local option movement are so self-evident that it 
is difficult to conceive how anyone with any claim to broad-minded views, to say nothing of actual statesmanship, can regard them as coming within the range of practical politics.

By way of concluding this chapter I might add, in regard to the general question of prohibition, that on December 4, 1906, there was a meeting at the Old Hall, Lincoln's Inn, of the Royal Courts of Justice and Legal Temperance Society, at which the licensing reform programme of the Temperance Legislation League was discussed; and on that occasion $\mathrm{Mr}$. Justice Bargrave Deane, who presided, said:

He had supported for many years a society which aimed at temperance. It began by persuasion. The members of it undertook never to take intoxicating drink except at meals. That put a stop to all nipping, and kept men from bodegas and wine and spirit shops. He had been struck and annoyed by the way in which some temperance reformers went beyond the views of the general body of people. They publicly stated that their object was not only temperance, but prohibition. If they continued to do this they would alienate many earnest supporters of temperance reform. The nation would never agree to such a proposition, and the advocacy of prohibition would stir up feeling which would altogether impede the cause of temperance. Temperance meant the avoidance of the abuse of drink; abstinence meant avoiding its use. His opinion was that it would be a grievous mistake to make every human being an abstainer by Act of Parliament. 


\section{CHAPTER XII}

\section{THE NO-LICENCE MOVEMENT IN NEW ZEALAND}

A CONSIDERABLE degree of importance attaches to the special phases which local option has assumed in New Zealand, not only because of their effect on the social and economic conditions of the Colony itself, but also because the particular example set there is already being closely followed in New South Wales (under the Liquor Act of 1905), and is, apparently, being regarded in Great Britain also as something worthy of emulation.

For the beginning of the movement in New Zealand we have to go back to the year I88I, when Mr. (afterwards Sir) William Fox, the prohibitionist Premier of those days, obtained the adoption of a Licensing Act, the main object of which was to enforce a system of local option. The Colony was divided into some 395 licensing districts, in each of which the ratepayers were to elect licensing committees, empowered to say whether the number of licences therein should or should not be increased, and to administer the licensing laws generally. At first the elections of these committees took place annually, but under a further Act, passed in I889, they became triennial.

Down to the early nineties the cause of sobriety was making good progress in New Zealand, and the Regis- 
trar-General of the Colony drew special attention to the decrease of drunkenness and to the spread of temperance. But meanwhile the teetotal party had greatly increased their strength, and fresh action was resolved upon. While some of the more advanced sections would gladly have promoted a policy of prohibition, the more moderate contingent thought that direct prohibition would have still less chance of success in New $Z$ ealand than in the United States, and that it would be wiser to try to secure eventually the same result, in piecemeal fashion, in other ways. There were others, again, who professed to have no desire whatever to prevent the consumption of intoxicants in domestic or social circles, but were opposed to the licensing of public bars for their sale.

Eventually there was passed, in 1893 , an 'Alcoholic Liquors Sale Control Act,' which reduced the number of licensing districts from 395 to 62 (afterwards slightly increased), made these to correspond with the electoral districts of the Colony for the election of members to the House of Representatives, and enacted that, on the occasion of the triennial parliamentary elections, a further poll of the electors should be taken on the three following questions: (I) Whether the existing number of publicans' licences shall continue; (2) whether the number shall be reduced; (3) whether no publicans' licences at all shall be granted. If an absolute majority of all the electors recording their votes is in favour of continuance, then the existing licences are to remain in force until the next poll, a three years' tenure being thus given to the holders, provided they are guilty of no misconduct in the interval in regard to management. If there is an absolute majority in favour of reduction, then the licensing committee of the district concerned is required to reduce the number of existing licences by 
not less than 5 per cent. and not more than 25 per cent. If the votes in favour of no licences being granted amount to three-fifths of all the votes recorded, then no renewals whatever are to take place. Should no one of the three proposals be carried by the prescribed majority, or should fewer than one-half of the voters on the register have recorded their votes, no change (subject to the good conduct of the licenceholders) is to be made before the next poll.

If, again, a district should already have declared in favour of no-licence, the vote is taken on the twofold issue of restoration or non-restoration of licences, a three-fifths majority being required to carry the former. In the event of there being such majority, the houses previously deprived of licences may have a chance of getting them back; but they have none other than a moral claim to first consideration among the applicants for licences, and even then there is no certainty that the constituency may not again change its mind, and revert to no-licence at the end of another three years.

General elections in New Zealand are usually held in December, and in practice the electors, on entering the polling-place, find there two returning officers, from whom they receive polling papers of different colours, one being in respect of the parliamentary election, while the other relates to the local option poll. A policeman is in attendance to see that the papers, after being filled up, are placed in the right ballot-box, according to their colour.

The fact that in 1893 women were admitted to the franchise in New Zealand invested the local option poll with exceptional interest, and the female electors, in exercising freely their newly-acquired rights, soon showed that they felt much more concern in this local 
option question than they did in the political problems involved.*

At the first local option poll in I894, under the Act of I893, one of the sixty-two districts, Clutha, voted in favour of no-licence, and Clutha has maintained that policy ever since. At the next poll, which took place in I896, no proposal was carried in ten districts (the majority in four of them in favour of no-licence was inadequate), and 'continuance' was carried in fiftytwo. In I899 a greatly increased activity was shown by the teetotal party, who then had an actual majority in favour of no-licence in sixteen districts; but four polls were declared void, and in only one district,

* On this particular aspect of the question, I quote the following from a letter from Auckland, New Zealand, signed 'Emily Nicol,' which appeared in The Times of August 18, 1906, under the heading of 'The Women's Suffrage Movement,' the main purpose of the letter being to show that the concession of the franchise to the women of that Colony has been far from an unmixed blessing to them :

'The New Zealand Herald of July 2 comments upon the very large number of women voters who went to the poll last December, no fewer than 174,615 out of 212,876 qualified to vote availing themselves of the privilege. But it must be remembered that the real issue of female franchise is not political, but the local option poll. The voting resolves itself into a serious battle between the two factions-the "trade" and prohibition; all other results are completely sunk to the furthering of these two issues, so that the vote is not exercised at its full value, nor for the principal reason for which it was granted. If you could understand the tremendous pressure brought to bear by either party at election times by their respective canvassers, the wonder is there are so many voters absent from the poll. While a candidate may send canvassers round in his own interests prior to the polling day, he may safely leave the issue upon that day entirely in the hands of the local option canvassers in bringing voters to the booth; he could neither add nor take from the result of votes polled; he receives his votes according to his prohibition or "trade" views. Although having taken the most active interest in connection with the franchise ever since its inception-and in a letter which I received from our deeply lamented Premier at the last election he said I had little to learn in election matters-I would vote to-morrow for female franchise to be erased from our Statute Book. 
Clutha (as before), was no-licence actually carried, although one other-Oamuru-voted reduction. In I 902 reduction was carried in nine districts, and nolicence in six; but in respect to three of the latter the poll was, on appeal, declared void.

At each of these latter polls there had been a substantial increase in the number of votes recorded, and it became evident that a most vigorous fight would come off in the contest of I905. In Newtown, where no-licence was carried in I9O2, but declared void on appeal, the teetotal party conducted an almost continuous campaign from that date down to the I905 elections. In other districts they began the more active form of their agitation six months or so in advance of the polling, the services of prohibitionist speakers from England or the United States being engaged for the purposes of the propaganda; while a considerable body of supporters gave weekly subscriptions of threepence, sixpence, or a shilling towards defraying the expenses. Prophecies were freely indulged in that at the 1905 elections big victories would be secured by the Prohibitionist party, some of whom then seemed to regard the liquor traffic of the Colony as practically doomed.

But by this time the liquor interest had been fully aroused to the necessity of a policy of self-defence. In the earliest polls the attitude of most of the members of the trade was one of comparative indifference. They did not think the campaign against them would be likely to assume really serious dimensions; they regarded their capital as reasonably safe; and though it was admitted a few of them might be prejudiced, the remainder did not consider their own interests gravely endangered. But on seeing the results of the polls in I902, when, as already stated, reduction was carried in 
nine districts and no-licence in six (though upheld only in three), they began to change their views and consolidate their forces. The actual losses then already sustained by the trade, as the direct outcome of the local option policy of the Colony, were estimated at no less than $£ 500,000$, and there had been no attempt made to offer the slightest compensation to those who found themselves deprived of their livelihood on the vote of the community. If that vote were carried in December in favour of either no-licence or reduction, the licences affected were simply not renewed at the end of the licensing year, the 3 oth of the following June, and the previous holders were placed under the necessity either of clearing out altogether, to start again in another district, or of staying where they were, and conducting their places for the future as boardinghouses on 'temperance' principles, not a shilling of compensation being given to them for the material difference in value between a place with a licence and the same place without. In one or two instances commodious stone-built hotels, costing $£$ ro,00o or so, had just been completed when no-licence was voted. Then, in regard to the reduction of licences in a particular district, the Act prescribes that those which have been endorsed for breaches of the law are to be abolished first, those which provide insufficient accommodation for travellers coming next; but the allegation is freely made that when the committee of selection, chosen by popular vote, has strong Prohibitionist leanings, the tendency is rather to choose first for extinction those houses which are doing the largest business.

In any case there is no doubt that a substantial number of persons in New Zealand have been ruined as the result of this policy of suppression without 
compensation. The vested and personal interests concerned may be small as compared with those in the United Kingdom, but they are, nevertheless, considerable for a Colony of the dimensions of New Zealand. The approximate capital value of all the licensed houses there is officially put at $£ 3,273,000$, and the total number of persons engaged in, or connected with, the sale or manufacture of wine, spirits, beer, cordials, etc., in New Zealand was returned in the census of rgor as 8,357 , included in this total being: hotelkeepers, I,556; relatives assisting ditto, 764 ; managers or clerks, I26; hotel servants and cooks, 3,933; barmen and barmaids, 527; managers, secretaries, and stewards of club-houses, I42; brewers, bottlers, or others engaged in brewing, 6 ro; maltsters and assistants, I47; makers and bottlers of cordials, etc., 238. Then I find that during the year ending March 3x, I904, the fees paid by holders of licences in New Zealand amounted to $£ 50,126$, which sum forms part of the revenue of the local governing bodies in the proportion of $f^{\mathrm{I} 8,68 \mathrm{I}}$ in counties, and $f_{31,445}$ in boroughs.

The practical effect of carrying out the New Zealand prohibition policy to its complete extent would be (I) to ruin, without compensation, a legitimate industry hitherto countenanced and directly sanctioned by the Legislature, and representing an invested capital of three and a quarter millions; (2) to deprive 8,000 persons of their present means of obtaining a livelihood for themselves or their families; (3) to withdraw from the local governing bodies a source of income bringing them in $£ 50,000$ a year, which amount they would have to raise, instead, by increased taxation in the community in general.

There would be less reason for protesting against these sacrifices if it could be shown that they were 
leading to the real and undoubted advantage of the community, though even then the question of the fairness of giving reasonable compensation would still remain. The evidence, however, shows that the good actually done is extremely doubtful, while, even admitting some benefits, these are completely outweighed by disadvantages in other directions.

The assumption that a substantial minority of the community will do without the use of their favourite beverages on the mere vote of a majority of their neighbours (a proportion of whom, probably, retain well-stocked cellars of their own) is as futile in New Zealand as it is elsewhere. As illustrating this fact, I may mention that, when no-licence began to be an active force in New Zealand, the representative in the Colony of a well-known firm of whisky manufacturers in Great Britain sent home an exceptionally large order for whisky in flasks, and wrote to his principals :

I may say I obtained this order solely through prokibition, for, as the law will not allow spirits to be sold on the race-course, and the people will not be without their whisky, they buy two or three flasks to put in their pockets before going to the course, so as to have a drink when they want it. Under these circumstances a large trade is being done in flasks.

Speaking generally, however, the effect in New Zealand, as in the United States and Canada, of closing hotel and public-house bars, where good liquor (more or less) is dispensed under open, lawful, and well-regulated conditions, has been that the traffic, instead of being suppressed, is driven largely into the hands of 'sly' dealers, who often serve out vile decoctions of the worst possible kind, and much more likely to cause drunkenness and injury to health than the liquors previously sold at the recognized bars. "Slygrog' selling in New Zealand has, indeed, undergone very considerable expansion. The prosecutions in- 
creased from $7 I$ (with 45 convictions) in I894 to $2 I 6$ (with $\mathrm{I}_{5} \mathrm{I}$ convictions) in $\mathrm{rg04}$. In $\mathrm{I}_{905}$ there were I69 prosecutions and II3 convictions. But, in point of fact, the police in the localities concerned have the greatest possible difficulty in enforcing the law. Public sentiment is, to a large extent, dead against them. The average reasonable citizen fails to see why the sale of a glass of beer or a glass of grog should be regarded as a moral offence, and he not only declines to help the police, but even seeks to throw difficulties in their path in this particular matter, and rejoices in rendering impossible, if he can, what he regards as an encroachment upon his liberties. In some instances the police have resorted to the expedient of employing spies who, in the spirit of agents provacateurs more worthy of the most oppressive types of Continental government than of British justice, have mingled with the workmen in their quarries or elsewhere, got to know where they bought their liquors, and then given information to the police. So intense has been the ill-feeling aroused against men of this type that they have had to be smuggled out of a district by the police in order that they might carry off their heads intact. As recorded in the Journals of the House of Representatives, Police Commissioner Tunbridge has said :

It is only by the adoption of subterfuges, or the promise of a money reward to persons to become informers-both of which practices should only be resorted to in extreme cases-that, in the majority of instances, any evidence whatever can be obtained.

Then, Police Commissioner Dinnie is reported by the same authority to have said:

The decrease in the number of prosecutions against sly-grog sellers does not necessarily indicate a decrease in the number of persons engaged in this deplorable and troublesome class of offence, but, rather, that more secrecy is adopted to prevent detection; and, although special action is taken from year to year, and frequent 
prosecutions are instituted and punishments inflicted, the result is somewhat disheartening, as it does not appear to have the desired effect in diminishing the number of such offenders or offences.

Still another police authority, Constable Thomas Griffith, says :

I have been stationed at Balclutha for over three years: I have always voted for prohibition, and my sympathies are with the temperance people; but, after three years' experience in the Clutha, I would not recommend prohibition to any other district. Prohibition here is an utter failure. . . Anyone known to assist the police is held up to the gravest odium. .. For telling the truth when forced, witnesses are shunned as if they had some fell disease.

Conditions such as these would be bad enough in themselves, even if they did lead to any substantial decrease of drunkenness; but there is no evidence that even this result is obtained. I have already spoken of the vile character of the compounds (chiefly made out of chemicals) sold in the sly-grog shops; but an incident related to me by a New Zealander who has special opportunities for knowing what goes on in the Colony in regard to these matters will indicate more clearly the real character of the business. Two Scotsmen went to a certain cottage, called out a boy, and told him to let them have a bottle of whisky. The boy went inside, and brought out a bottle, which one of the Scots uncorked and put to his lips. No sooner had he tasted the liquor than he spat it out, and said to the lad: 'Why, that's not whisky!' 'Oh yes, sir, it is,' was the reply; 'I saw father making it last night.'

Then, the local supplies still obtainable at the slygrog shops (in the form of alleged spirits rather than of beer, owing to the former taking up less room) are supplemented, either by visits to a town in the next district-perhaps ten or twelve miles off-where liquor bars are still tolerated, and where the visitors will probably drink more than they would do in normal 
circumstances; or by men clubbing together and sending one of their number by train to buy liquor in such neighbouring town, and bring it to them. Here, again, it is safe to assume that the liquor so bought would be spirits in place of beer, owing to the greater convenience in carrying the former; while it is probable that the beverage would be consumed the more freely and with the greater gusto because of the difficulty experienced in obtaining it.

Still another outcome of the situation is that, although in the no-licence districts the total amount of liquor imported has decreased, there has been a considerable advance in the small quantities bought for consumption at home, where it would be available for all the members of the family, as compared with the larger quantities for hotel bars, to which, perhaps, only the head of the same family would be likely to go. Evidence on this point is given by the following figures, which show the imports into Ashburton for the last year of licence and the first year of no-licence in that town :

\begin{tabular}{|c|c|c|c|c|c|}
\hline \multicolumn{4}{|c|}{ Quantities. } & \multicolumn{2}{|c|}{ Year ending June 30.} \\
\hline & & & & 1903. & 1904. \\
\hline \multicolumn{4}{|c|}{ ALES AND STOUT: } & & \\
\hline Cases $\ldots$ & $\ldots$ & ... & ... & 675 & 468 \\
\hline Hogsheads & $\cdots$ & ... & ... & 829 & I 55 \\
\hline Barrels ... & $\ldots$ & $\ldots$ & $\ldots$ & 185 & 57 \\
\hline Kegs $\ldots$ & $\ldots$ & $\ldots$ & $\ldots$ & 76 & 615 \\
\hline Jars $\quad \cdots$ & ... & ... & ... & 3 & 250 \\
\hline Casks ... & $\ldots$ & ... & $\cdots$ & 6 & 39 \\
\hline \multicolumn{6}{|l|}{ SPIRITS : } \\
\hline Cases $\ldots$ & ... & ... & ... & 1,207 & 731 \\
\hline Half-casks & ... & ... & ... & 85 & II \\
\hline Octaves & $\ldots$ & ... & ... & 65 & 18 \\
\hline Jars $\quad \ldots$ & $\ldots$ & $\cdots$ & ... & 50 & 256 \\
\hline
\end{tabular}


As to the effect which a policy of no-licence or of licence reduction may have had on actual drunkenness, the following table, compiled from the public records, shows that, during the seven years preceding the advent of no-licence, the convictions for drunkenness had decreased I5 per cent., whereas under ten years of no-licence conditions the cases of drunkenness reported increased I07 per cent., the year I894 marking the dividing-line:

\begin{tabular}{|c|c|c|c|c|c|c|c|}
\hline \multicolumn{3}{|c|}{ Year. } & Number. & \multicolumn{3}{|c|}{ Year. } & Number. \\
\hline I 888 & $\ldots$ & $\ldots$ & 5,402 & I 896 & $\ldots$ & ... & 5,005 \\
\hline I889 & $\ldots$ & $\ldots$ & 5,152 & 1897 & $\ldots$ & $\ldots$ & 5,204 \\
\hline $1890^{\circ}$ & $\ldots$ & $\ldots$ & 5,677 & 1898 & $\ldots$ & $\ldots$ & 5,532 \\
\hline 1891 & $\ldots$ & $\ldots$ & 5,118 & 1899 & $\ldots$ & $\ldots$ & 6,289 \\
\hline 1892 & $\ldots$ & $\ldots$ & 5,055 & 1900 & $\ldots$ & $\ldots$ & 7,299 \\
\hline 1893 & $\ldots$ & $\ldots$ & 5,048 & 1901 & $\ldots$ & $\ldots$ & 8,057 \\
\hline 1894 & $\ldots$ & ... & 4,594 & 1902 & ... & $\ldots$ & 8,269 \\
\hline 1895 & $\ldots$ & $\ldots$ & 4,636 & $\begin{array}{l}1903 \\
1904\end{array}$ & $\begin{array}{l}\cdots \\
\cdots\end{array}$ & ... & $\begin{array}{l}0,615 \\
9,615\end{array}$ \\
\hline
\end{tabular}

In the interval between the I902 and the I905 elections certain of the facts here presented, together with others, were widely distributed among the New Zealand public in the form of a pamphlet on 'Prohibition or No-Licence,' written by Mr. John McKeague, who further calculated therein that, taking the expenses incurred in conducting the local option polls, and the $£ 5^{\circ}$ or so which either party would spend in each licensing district, the cost of the five local option polls might be put at $£ I 4,500$ each, or a total of $£ 72,500$; while, adding to this the costs incurred in the prosecutions and defence of sly-grog cases, and also in the fighting of licensing appeals both in New Zealand and before the Privy Council, he estimated that the total cost to the Colony (apart from losses to the trade) 
of the no-licence policy under the Act of 1893 ' cannot be far short of $£ 90,000$.'

It is probable that the circulation of facts and considerations of this kind, coupled with practical experience of local option results and an awakening sense of reasonableness, had a great deal to do in preventing the prohibition party from achieving anything like the success at the poll in 1905 which they had anticipated. The I 902 elections had left them (as already mentioned) with six no-licence victories-reduced to three (Ashburton, Clutha, and Mataura) on appeal - and nine 'reduction' victories. In 1905 the prohibitionists again carried no-licence in six districts (three, Invercargill, Oamuru, and Gray Lynn-a town with no hotels-in addition to Ashburton, Clutha, and Mataura, which voted 'no restoration'); but the number of reductions declined from nine to four. Attempts were made by the prohibitionist party to show that, if the figures were only looked at from their point of view, they represented a moral victory; but the logic of accomplished facts showed that they had failed absolutely to gain the successes their more sanguine members had predicted, and the Nere Zealand Times of December 7, rgo5, well described the situation when it said :

It is not only in the partial arrest of the trend of prohibition throughout the Colony, but in the defeat, in some cases by big majorities, of prominent no-licence advocates, that the set-back to the prohibitionists can be clearly discerned.

In a subsequent article, published December I8, I905, the same paper, commenting on the total votes secured by each of the two parties, said :

It is evident that, though the tide is slowly rising, the gains to prohibition are curiously local, and in some parts of the west the wave is slowly receding. Taking the chief cities, not including 
suburbs, we find that, in three out of the four, the set-back to the no-licence movement is plainly discernible. The reason is, probably, that in these centres the 'trade' is, for the first time in the history of the Colony, conducting a well-organized and persistent fight. Auckland is the only city where prohibition has gone steadily onward.

The rising of the prohibition tide must, indeed, be slow, if we remember (I) that the Act in question was passed in 1893 , and (2) that, whilst there are now sixty-five licensing districts where the local option poll is taken, the prohibitionists, at the end of twelve years' fighting under the Act, carried 'no-licence' in only six of those districts (including three they had previously captured), and reduction in no more than four.

The more immediate moral of the story seems to be that, so long as the prohibitionist party are unchecked in their promises, assertions, and denunciations, they may be expected to control an increasing volume of public opinion, especially among those who are disposed to believe exaggerated or impressive statements without inquiring into them; but that, as soon as the public begin to realize the real facts of the case, and as soon, also, as the attacked party begins to bestir itself, and make a bold and gallant defence in favour of rights and of liberty, there will be a greater chance of the whole subject being regarded from a broader standpoint.

In confirmation of this fact I would remark, in passing, that in 1903 the Prime Minister in New Zealand introduced into the House of Representatives a new Licensing Bill, of which the Auckland Herald gave the following summary :

The question to be submitted to the electors is to be licence or no-licence, the existing alternative of voting for reduction being deleted.

Where no-licence is carried, no person in the district can have liquor, and a fine of $£ 20$ is provided on persons having liquor except for medical, scientific, or manufacturing purposes. 
Then, at the next licensing poll, a referendum is to be put to the people whether the succeeding licensing poll should be at the end of three years or six, a bare majority to decide this question.

The licensing committees are to be elective, as at present ; but the mayor of the borough, or chairman of a county council, is to sit with them, and interested parties are to be debarred from sitting on licensing committees, this provision being, according to the Premier's statement, applicable to prohibitionists as well as members of the trade.

Youths under eighteen years of age cannot be supplied with liquor, and those who send children for liquor can be punished.

Persons found on premises after hours can be punished, and clubs in no-licence districts cannot sell liquor.

Where a hotel has been improved at a cost of $£ 3,000$ or over, a six years' tenure is provided, although no-licence may have been carried in the district meantime.

There is a provision against tied houses, and, where there are breaches of the law, the house will be affected as well as the licensee, and when a licence is cancelled it means the closing up of the house.

These proposals awakened what has been described as 'a storm of rage' in the Colony, and in the result the House decided, by thirty-eight votes to thirty-six, against the measure being sent to a committee.

Looking, from the point of view of the highest interests of the colony, at the actual results of a local option regime in New Zealand, it is obvious that, against any real advantages which can be not only claimed, but sustained, by the prohibitionists, there are some very serious drawbacks. Assuming, for the sake of argument, that there may have been a decrease in the amount of drunkenness (though I have met with no figures which prove that this has actually occurred), we have to put against such decrease (I) the intense bitterness of the feeling which the local option propaganda has spread throughout the Colony, dividing it into two great hostile camps, and setting neighbour against neighbour; (2) the disadvantages of local option laws which fail to appeal to the moral sense of the community, excite animosity rather than support, and can 
only be carried out, even in part, by the organization of a spy system which brings the administration of justice into contempt with all honest and honourable men; (3) the inexcusable interference with personal liberty; (4) the sense of injustice inflicted on working-class and middle-class people, in depriving them of the opportunity of getting reasonable refreshment when they want it, while the well-to-do citizen can store as much liquor as he pleases in his cellars; and (5) the effect which the whole controversy has in diverting the attention of the electorate from the real problems, colonial or Imperial, a General Election should involve, and concentrating it rather upon side issues, which had much better be left to the conscience and the practical common sense of the people. 


\section{DISINTERESTED MANAGEMENT}

As already briefly mentioned in Chapter X., the policy of the disinterested management of public-houses is advocated by a certain section of the temperance party in the United Kingdom as an alternative to the effective prohibition which they do not regard as coming within the range of practical politics in this country; though, on the other hand, there are many members even of this section who regard the adoption of the principle as merely a further stepping-stone to the prohibition by which they hope to abolish altogether the traffic in intoxicants.

At the present moment Norway is the Mecca of true believers in the disinterested management faith. Here, however, I would at once suggest that, even if one admitted that the idea had been an unqualified success in Norway, it would not necessarily follow that there is an equal chance of securing such success here. The general conditions of the two countries are absolutely dissimilar.

In the first place, the drinking habits of the Norwegians (leading to what were, undoubtedly, the most deplorable results) are directly traceable to the earlier toleration of domestic distilleries, and to the consequent general and generous consumption of the native spirit 
manufactured therein. In England there has been no question of domestic distilleries, and the national beverage is beer. Secondly, Norway is a land possessed of only a few large towns, the majority of the population living in hamlets or in scattered houses situated mostly in mountain valleys, where the means of communication are limited, and the enforcement even of prohibition is comparatively easy. England has many large towns or cities in which the bulk of our population live, the means of communication are abundant, and the enforcement of prohibition is admittedly impracticable. Thirdly, the meek and mild-mannered peasant in Norway's lonesome valleys, and even the more advanced but still generally submissive worker in the towns, represent very different types of character from the average British working-man, with his sturdy independence, his strong sense of his rights and privileges, and his extreme sensitiveness in regard to "class legislation'-that is to say, when such legislation has not been framed in his own special favour.

But, leaving these comparisons aside, it may be of interest to deal with the principle on its merits, and to examine it from that point of view.

The Norwegian system is an adaptation of the older Gothenburg system; but the supporters of the former never fail to disparage the methods of the latter, and insist strongly on their own superiority. In each case the liquor bars are under the control of companies of ' philanthropists,' content with a $\mathbf{5}$ per cent. benefit for themselves; but there is an alleged point of difference in regard to the distribution of the balance of the profits. One of the main features of the Gothenburg system has been the devotion of a substantial proportion of such profits to general municipal purposes, in order to reduce the rates. The upholders of the Norwegian system say 
(quite rightly) that the creation of this municipal interest in sales and profits must lead to various undesirable results; and these results have certainly not been wanting, either in Gothenburg City or in other towns in Sweden where the same principle has been adopted. The Norwegians hold that the surplus profits accruing to their Samlags (or liquor companies) had better be devoted to objects of public benefit and to benevolent purposes which the local authorities are not bound by Act of Parliament to support; and, because they operate on these lines, they do not fail to assure inquirers (in effect), 'We are far superior in our ideas to the people in the next country.'

In making a comparison between the two systems one is, however, reminded of the well-known lines:

Strange all this difference should be

'Twixt Tweedledum and Tweedledee.

If the Samlag profits in Norway have not been applied, like the Bolag profits in Sweden, direct to the reduction of the rates, they have nevertheless been devoted largely to purposes which would otherwise have had to be provided for out of the pockets of the ratepayers. Alternatively, they have sometimes gone, in part, to support various 'philanthropic' purposes of a type which would not always have stood the very critical tests of the editor of Truth.

There is no need for me to repeat here what I have already stated on the general subject in my book on 'Licensing and Temperance in Sweden, Norway, and Denmark '; but, by way of giving testimony from another and independent quarter, I may quote the following from an article published in the Scottish Reformer* of February 9, 1907, commenting on the

* Organ of the Scottish Permissive Bill and Temperance Association. 
report of the Commission appointed by the Scottish Temperance Legislation Board to inquire into the liquor licensing laws of Norway:

Turning to the matter of Samlag profits, the Commissioners state :

'Since the establishment of the Samlags about $£_{1}, 400,000$ have been expended on "objects of public benefit." During the past eight years the proportion accruing to the State has been increased and set apart till I910 to form the nucleus of an old-age pension fund which now amounts to $£, 500,000$.'

This is only partly the truth. Previous to 1896 the profits were appropriated to the maintenance of hospitals, refuges, homes, museums, libraries, parks, baths, educational institutes, Christian missions, temperance societies, inebriate homes, summer excursions, etc. Some $£ 75,000$ per annum was distributed amongst these various institutions, and this sum in a comparatively small and poor population made the 'disinterested' liquor company directors very powerful, politically and socially, and the applicants for grants correspondingly submissive. The appeals of claimants grew faster than the profits, and 'methods' of augmenting these were invented. In one case the usual time of closing the drinkshops was suspended for a year or two by the 'disinterested' liquor company directors, and the extra profit thus obtained handed over to the authorities of a hospital who were wanting money. So immoral had this aspect of the 'disinterested' company system become that in 1894, at the instance of the temperance party, an Act was passed, which came into force in 1896 , by which the State appropriated the bulk of the profits for its own purposes, beginning with 25 per cent. in 1897, and increasing Io per cent. per annum until in I I9OI the whole of the profits-after, of course, first paying the shareholders' dividends-were divided as follows :

Sixty-five per cent. to the State.

Fifteen per cent. to the municipalities in which the companies exist.

Twenty per cent. to objects of public utility not being chargeable on any rates, but operating as counter-attractions to the public-house; in towns IO per cent., and in surrounding country districts to per cent.

The legislative changes thus brought about in I 894 were, in effect, a severe condemnation of the whole 'disinterested' principle, even as operated on the 'improved' Norwegian plan. The position to-day is shown in Appendix X. of the Scottish Commissioners' Report to be as follows: 


\section{Distribution of Samlag Surplus in 1904.}

The following table shows the application of the proportion of profits ( 20 per cent.) distributed by the Samlags themselves in 1904 :

\begin{tabular}{|c|c|c|c|c|c|c|}
\hline \multicolumn{5}{|c|}{ Object. } & $\begin{array}{l}\text { Amount } \\
\text { Sterling. }\end{array}$ & $\begin{array}{l}\text { Percentage } \\
\text { of Total. }\end{array}$ \\
\hline \multicolumn{5}{|c|}{ Education (mainly technical and domestic } & $£$ & \multirow[b]{2}{*}{$17^{\circ} I$} \\
\hline economy) & ... & ... & ... & ... & 4,290 & \\
\hline Orphanages & ... & & & & 2,480 & \multirow{2}{*}{$\begin{array}{l}9 \cdot 9 \\
8 \cdot 1\end{array}$} \\
\hline \multicolumn{5}{|c|}{ Assistance, nursing and feeding poor ... } & 2,020 & \\
\hline \multicolumn{5}{|c|}{ Museums and scientific purposes } & 2,000 & \multirow{2}{*}{$\begin{array}{l}8 \cdot 0 \\
6 \cdot 6\end{array}$} \\
\hline \multicolumn{4}{|c|}{ Friendly societies ... $\quad \ldots \quad \quad \ldots$} & ... & 1,660 & \\
\hline Public baths & & & $\ldots$ & ... & 1,360 & $5 \cdot 4$ \\
\hline \multicolumn{3}{|c|}{ Tree-planting, parks, etc. } & $\cdots$ & $\cdots$ & $\mathrm{I}, \mathrm{I} 40$ & 47 \\
\hline \multicolumn{3}{|c|}{ Music and singing $\quad \ldots$} & ... & ... & 1,100 & 44 \\
\hline \multirow{2}{*}{\multicolumn{3}{|c|}{ Hospitals $\quad \ldots$... }} & $\cdots$ & $\cdots$ & 970 & $3 \cdot 8$ \\
\hline & & & ... & $\ldots$ & 880 & 3.5 \\
\hline \multirow{2}{*}{\multicolumn{3}{|c|}{ Libraries and reading-rooms }} & ... & ... & 820 & \multirow{2}{*}{$\begin{array}{l}3: 3 \\
3 \cdot 6\end{array}$} \\
\hline & & & $\ldots$ & $\ldots$ & 760 & \\
\hline \multirow{2}{*}{\multicolumn{3}{|c|}{$\begin{array}{l}\text { Workmen's homes } \\
\text { Roads, streets, and railways }\end{array}$}} & ... & $\ldots$ & 720 & 2.9 \\
\hline & & & $\ldots$ & ... & 490 & $1 \%$ \\
\hline \multirow{3}{*}{$\begin{array}{l}\text { Waterworks } \\
\text { Other purposes }\end{array}$} & \multirow{3}{*}{$\cdots$} & ... & ... & ... & 320 & $1 \cdot 3$ \\
\hline & & \multirow[t]{2}{*}{$\cdots$} & \multirow[t]{2}{*}{$\cdots$} & \multirow[t]{2}{*}{$\cdots$} & 3,990 & $16^{\circ} 0$ \\
\hline & & & & & 25,000 & $100^{\circ} 0$ \\
\hline
\end{tabular}

Of the total profits distributed to objects of public utility during the thirty-two years to 1904 , education received 16 per cent.; roads, streets, etc., I I per cent. ; orphanages, 8 per cent. ; waterworks, 8 per cent. ; parks, 5 per cent. ; temperance societies, 2 per cent. ; and other purposes, 50 per cent.

I would invite the reader to go carefully through this list, and form his own conclusions as to the extent to which these various items would either have to be met out of the rates, or, alternatively, be subscribed to by the individuals constituting the community, if the Samlag profits were not available. In England, at least, the ratepayers would expect to pay, through the local rates, for education, roads, streets, waterworks, public baths, libraries, parks, and so on; and, if the cost thereof were partially met from some other source, the rates would 
certainly be relieved to that extent, even although the payments from this other source were not made direct to the local exchequers. In regard to orphanages and hospitals, the need for local contributions by the charitable is decreased in proportion to the amount obtained from other sources; and to this extent, again, the residents in a particular locality where such institutions have been set up are directly and financially interested in the Samlag profits.

From this point of view we can realize better that scramble for the said profits which led to the intervention of the Legislature in I894; but, even although the Samlags may now themselves distribute no more than 20 per cent. of their net profits, it is obviously idle to talk about 'disinterested management.' Apart from the philanthropic shareholders, who get a guaranteed dividend of 5 per cent. on their investments (and there is many a small capitalist in England who would gladly become a philanthropist under like conditions), what has happened is that the interest in the profits of the liquor trade has simply been diverted from a few individuals to many; and, so long as the latter do benefit directly from those profits, the particular treasury into which the money flows, or the particular head-'rates' or 'contributions'- under which a saving is effected, becomes merely a matter of detail. The distinctly ' interested ' management is there, all the same.

On this subject of management the Scottish Commissioners also say in their Report :

The Samlags still further restrict their sales by an absolute refusal to give credit or to permit customers to remain on the premises after they have been served. The managers have a fixed salary, and have no interest in the profits on the sale of liquor, though in some cases they receive a commission on the sale of food and non-intoxicants. Such a policy affords conclusive proof of the disinterestedness of the Samlags. 
Comparing these conditions with the type of ordinary licensed house in England which may most fairly be contrasted with the Norwegian Samlags - namely, ' managed houses '-I would point out (I) that brewery companies' rules in England insist that their managers shall not give credit; (2) that in England public-houses are regarded as something more than places where men gulp down liquor and then go, and are assumed to serve a certain social purpose as well; (3) that public-house managers in England also have fixed salaries, and, except possibly in one or two extremely rare instances, have no interest in the profits on the sale of liquor; and (4) that in some cases they not merely receive a commission on the sale of food, but are allowed to keep for themselves all the profits they can make from this branch of the business - a branch which their employers insist on their taking up, while affording them every possible facility for carrying it on successfully.* Why the Scottish Commissioners should represent the Norwegian conditions as 'conclusive proof of the disinterestedness of the Samlags,' and yet ignore the existence of like conditions at home, without any need for the introduction of Samlags in order to secure them, is not quite clear.

The Scottish Commissioners make very little attempt to show that in Norway prohibition in the country districts and company control in the towns have had any appreciable effect in reducing the actual consumption of alcoholic drinks. No one would gather from their report that, while the Samlag bar sales in Christiania were only 413,000 litres in 1905, the Samlag officials themselves calculate that the sales in bottles by the wine and spirit merchants of that city represented, for the same year, a total of 2,000,000 litres, a fact which 
seems to suggest that what is taking place in Norway (as in Sweden) is not so much a decline in drinking as merely a transition in the way of obtaining drink.

The Commissioners do, however, in Appendix XII., give some specially instructive figures in regard to Bergen, confirming abundantly my view that while under the influence of prohibition and disinterested management company control-whether separately or in combination - there may be a decline in public drinking at the bars, there is, at the same time, a more or less corresponding increase in private drinking out of bottles. From the figures in question I have compiled the following table :

Bergen Samlag Sales, in Litres.

\begin{tabular}{|c|c|c|c|c|c|}
\hline \multicolumn{2}{|c|}{ Year. } & Population. & Bar 'On.' & Bottle 'Off.' & Total. \\
\hline $1877^{*}$ & ... & 37,000 & 99,967 & 172,357 & 272,324 \\
\hline $1892 t$ & ... & 54,600 & 95,965 & 236,860 & 332,825 \\
\hline 1893 & ... & 55,600 & 92,830 & 244,600 & 337,430 \\
\hline I894 & $\ldots$ & 56,600 & 86,952 & 232,227 & 319,179 \\
\hline I 895 & ... & 57,800 & 83,978 & 216,627 & 300,605 \\
\hline I 896 & ... & 59,900 & 65,462 & 222,063 & 287,525 \\
\hline 1897 & ... & 62,400 & 65,108 & 272,715 & 337,823 \\
\hline I 898 & ... & 66,000 & 67,865 & 334,767 & 402,632 \\
\hline I 899 & ... & 70,000 & 67,437 & 349,534 & 416,971 \\
\hline 1900 & ... & 72,645 & 67,481 & 376,944 & 444,425 \\
\hline I 901 & ... & 72,800 & 65,234 & 387,005 & $45^{2}, 239$ \\
\hline $1902 \S$ & ... & 74,600 & - & 426,313 & 426,313 \\
\hline $1903^{\circ}$ & $\ldots$ & 74,800 & - & 417,948 & 417,948 \\
\hline 1904 & ... & 78,200 & - & 427,753 & 427,753 \\
\hline $1905 \|$ & ... & 80,000 & - & 422,034 & 422,034 \\
\hline
\end{tabular}

Decrease in bar 'on' sales in 1901 over $1877 \quad \ldots \quad 34,733$ litres. Increase in bottle 'off' sales in I90 I over I $877 \ldots 2$... 24,648 litres.

* Bergen Samlag started. † Highest bar sales since 1877 .

Local option adopted in Norway.

Bars abolished in Bergen.

II 'Temporary decline in consumption owing to stirring political events of 1905 . 
But, for the reasons already mentioned in regard to Christiania, Samlag figures alone are not sufficient. One must take into consideration, also, the sales effected throughout Norway by the private merchants. It must further be remembered that, prior to I904-when the Norwegian Government were able to impose some prohibitive import duties-any decline in the consumption of the native spirit was more than counterbalanced by an enormous increase in the consumption of 'laddevin,' a concoction 'made in Germany,' which was especially indulged in by those who had the slightest difficulty in getting liquor from the Samlags. The Commissioners admit that 'the import and consumption of this false wine continued and increased for a few years, till the country was literally flooded with it, with most disastrous effects on the sobriety of the people' (effects, they might have added, much worse in the case of so insidious a beverage than would have resulted from insobriety caused by the liquors of the country). But the Commissioners do not say, what is nevertheless a fact, that the importation and the consumption of these enormous quantities of laddevin were directly due to the line of action taken by the prohibition and disinterested management parties in attempting to force the people into their own way of thinking.

Nor do the Commissioners make out much of a case for disinterested management when they come to deal with the question of drunkenness. According to the figures they themselves adduce, the arrests for drunkenness in Bergen and Christiania respectively since 1897 have been as follows: 
Average Per i,o00 of the Population.

\begin{tabular}{|c|c|c|c|c|}
\hline \multicolumn{3}{|c|}{ Year. } & Bergen. & Christiania. \\
\hline I897 ... & $\ldots$ & ... & 29 & I I I \\
\hline $1898 \ldots$ & $\ldots$ & $\ldots$ & 28 & 94 \\
\hline I $899 \ldots$ & $\ldots$ & $\ldots$ & 26 & IOI \\
\hline $1900 \ldots$ & $\ldots$ & $\ldots$ & 30 & 90 \\
\hline $1901 \ldots$ & $\ldots$ & $\ldots$ & 29 & 75 \\
\hline $1902 \ldots$ & $\ldots$ & $\ldots$ & 27 & 59 \\
\hline $1903 \ldots$ & $\ldots$ & $\ldots$ & 24 & 58 \\
\hline $1904 \ldots$ & ... & ... & 20 & $5^{2}$ \\
\hline I905 ... & $\cdots$ & $\ldots$ & 23 & 43 \\
\hline
\end{tabular}

It might be argued that in Christiania drunkenness has declined in nine years from III per I,000 of the population to 43 per $\mathrm{x}, 000$. That would sound very well, unless one happened to know that the arrests for drunkenness per $I, 000$ of the population are only Io in London, II in Liverpool, I3 in Manchester, and I8 in Glasgow.

There are, of course, differences in compiling statistics of drunkenness, and to these the Commissioners (by way of accounting for their own depressing statement) very rightly point; but the variations in the methods of reckoning do not account for the great differences between the Norwegian and the English figures. The Commissioners further say that-

Many of the arrests for drunkenness which appear on the police records do not really belong to the town, but to the surrounding rural districts. The peasants come into the town, drink heavily, and fall into the hands of the police; and all their offences are recorded among the offences of the citizens of the town. In Bergen, for instance, 30 per cent. of the arrests for drunkenness in 1905 were arrests of non-residents, and, therefore, ought not to be included in any statistical statement from which conclusions are to be drawn.

Not only do like conditions apply more or less to English towns-especially on market days-but the 
argument advanced by the Commissioners is in itself a most grave reflection alike on prohibition and on disinterested management. In the first place, it implies, in effect, that, although the peasantry keep sober in their lonely valleys because prohibition has cut off the supplies, they indulge all the more eagerly as soon as they come into the towns, and drink there to excess -to make up for lost time-when they might only drink in moderation if they were able to satisfy their reasonable requirements from day to day in their own localities. In the second place, it involves the admission that even disinterested management of the most severe type is powerless to prevent the abnormal amount of drunkenness which follows as a natural consequence on attempts at undue restriction.

In their reluctance to accept this perfectly logical conclusion, the Scottish Commissioners say :

It is also of the very first importance, in endeavouring to establish any relation between the Samlags and the statistics for drunkenness, to remember that a great proportion of the drunkenness in all the towns of Norway is due to beer-drinking. The spirit bars are so strictly controlled, and the sale of beer is so uncontrolled, that it is reasonable to adopt the opinion, strongly held in many quarters, that the existing drunkenness is largely beer drunkenness, and that the spirit-drinkers have been replaced by beer-drinkers.

If the spirit-drinkers in Norway are really being replaced by beer-drinkers, one can only say, 'So much the better!' What I found in Norway was that a certain proportion of the spirit-drinkers were discarding the ordinary 'controlled' spirits for methylated spirits or 'politur' (furniture polish), which are infinitely worse ; and that, from whatever the exact cause, there was probably a great deal more drunkenness in Norway than even the figures already given would suggest, inasmuch as, owing to the restrictions enforced, and especially the very early closing of the bars, a great 
amount of drinking goes on either in private houses or, in summer, in the woods.

As regards beer, the tendency in Norway of late years has been to produce beers weaker and still weaker in alcoholic strength; yet the Scottish Commissioners, in their Report, draw no distinction between spirits which may contain 45 or so per cent. of alcohol and beers having so small a percentage thereof that, as one of the leading brewers in Christiania, whom I interviewed on this subject, said to me, "The human body would not contain sufficient of the beer I brew to make any ordinary man drunk.' It is true that the Commissioners say, in paragraph 4: 'Between 1860 and I884 the Legislature very gradually brought under control the trade in beer and wine, which were originally deemed temperance drinks.' (The italics are mine.) But they ignore the fact that beers containing only a small percentage of alcohol are still deemed temperance drinks in Norway; that they have been formally ' recognized' by most of the temperance societies; that temperance advocates on the platform, when they preach abstinence, take it for granted their hearers understand they mean abstinence from 'strong drink,' and not from harmless beers; and that such temperance advocates themselves drink in public certain brands of beer, containing a low percentage of alcohol, as openly as teetotallers in England or Scotland take ginger-beer or lemonade.

It is difficult to realize that a deputation going expressly from Scotland to Norway to investigate the whole subject of licensing could have failed to hear of these facts, and it is significant that they should refrain from mentioning them; that they should seek, rather, to make it appear that the acceptance of beer as a temperance drink was a matter of many years ago 
rather than a factor of to-day; and that, in trying to relieve disinterested management of any discredit for the drunkenness this system may have failed to check, they should seek to remove the responsibility from the strong drinks which the system does profess to control to the weak beers which are still outside the monopoly. It is easy to understand why the defenders of the system in Norway should try to find a scapegoat for its imperfections, or, changing the analogy, should accuse the lamb drinking down-stream of troubling the waters. But one hardly expects that a deputation of British inquirers should be taken in by such representations.

There is no need to deal in further detail with this Report of the Scottish Commissioners, who went to Norway with the evident intention of collecting all the arguments they could in favour of disinterested management, and have, in truth, brought back an armoury of facts for the use of those who would oppose its adoption!

To sum up in a single line the whole position of disinterested management in both Norway and Sweden, in regard to the actual consumption of alcoholic beverages, it is simply a case of 'Down with the bars-and up with the bottles!'

In this country the movement in favour of disinterested management is based, mainly, on the belief (I) that under the system of private ownership of public-houses "the business is "pushed" in every way that can be devised '; and (2) that if the licences were placed in the hands of men 'who have no interest in increasing or maintaining the sale, and have accepted them for the purpose of reducing the evils of drinking to the smallest possible dimensions,' then 'all pushing of the sale of drink would cease, and all questionable practices and extraneous attractions therewith would 
disappear,' while ' in place of powerful opponents we shall have proposers and supporters of curtailments and reductions.' It is expressly stipulated, however, that ' the licences should not be granted to, or be managed by, the licensing authority or the local municipal authority, but should be entrusted to a specially constituted body of suitable persons, who would provide the capital required, upon which they would receive only a moderate amount of interest.' The locality is not to have any direct or appreciable financial interest in the houses. The surplus profits are to go to the national exchequer in the first instance, and 'should not in any way be used to relieve local rates.'

In the suggestion here made as to the 'pushing' of sales in ordinary public-houses, there is (as I have shown in connection with managed houses) far more of imagination than of fact. If a man goes into a public-house to get a drink he does so because he wants it, and he is certainly not induced to enter by the landlord standing at the door and proclaiming aloud the good quality of his wares, like a butcher in a poor neighbourhood. If, having had one glass, he takes a second, it is again because he wishes for it, and not because of any persuasive powers brought to bear on him by landlord or barman, who, in effect, merely supply what is asked for. As for 'questionable practices,' these are least likely to be found in breweryowned houses, where the supervision and control are as strict as anything that could be enforced under a system of disinterested management. A special feature is made of the disappearance of 'extraneous attractions,' and also of the carrying out of 'curtailments and reductions'; but if the places are made too dull, too uninviting, and too few, and if rigid control is carried to an extent that will repel the average 
customer, the effect must inevitably be to give a still further impetus to secret drinking, whether in clubs or elsewhere. Men may be driven away from the houses, but they will not necessarily abandon their favourite beverages. On the contrary, they may indulge in them still more freely when they revolt against a system of control which is carried in their opinion to undue or, at least, unpleasant extremes.

The stipulation that the local municipal authority is not to hold the licences, or even to have any share in the handling of the profits, is in itself a severe condemnation of the fundamental basis of disinterested management as originally adopted by the city of Gothenburg. It means, in effect, that the disinterestedness of the local authority cannot be depended on, and with that admission the whole argument as to the superiority of public control over private management falls to the ground. It is proposed to appoint instead a 'specially constituted body of suitable persons.'

How such a body could be got together to manage the public-houses in (say) a city like Birmingham is not explained. The fact seems to be ignored that the business of managing even a single public-house is one that presents as many difficulties and as many pitfalls as any retail trade under the sun. The man who undertakes it without having first had practical experience in regard both to the duties and to the grave and most complicated responsibilities of the position is doomed to failure, even if such failure should not lead to forfeiture of the licence. Brewery companies controlling a number of houses appoint as inspectors and superintendents men who have spent their lives in the trade, and count as experts therein; yet even under these conditions the work of management calls for the display of personal qualities and special knowledge of a 
kind and to an extent that few outsiders could realize. Under ' disinterested management' the experts would all be cleared out, and their places taken by a set of wellintentioned amateurs, possessed, probably, of much zeal, but no practical knowledge at all of the realities and the intricacies of the business, and starting mainly with the idea of remodelling on an entirely new basis that distribution of intoxicants which is as old as humanity itself.

The result could not possibly fail to be a huge fiasco. Assuming, for the sake of argument, that the 'specially constituted body of suitable persons' at the head of the combination proved fully equal to the task undertaken in the matter of supreme control (though, in effect, this is extremely unlikely), great difficulties would still be found in securing suitable and absolutely trustworthy managers for the individual houses. Such difficulties are met with in an acute form by the directors of the public-house trusts already established; they would be increased many times over when the whole of the public-houses were controlled by representatives of disinterested management; and it cannot be doubted that if the police and the magistrates then enforced the law with anything like the same stringency as that shown under existing conditions, the end of it all would be chaos.

It may be suggested that I am using exaggerated language, inasmuch as there are already in existence in the United Kingdom a number of disinterested management houses which are being conducted with more or less success. One must not assume, however, that the favourable results secured in rural or suburban localities, under the best possible conditions, would necessarily follow also in the case of 'Trust' public-houses situate in densely populated working-class neighbourhoods of busy industrial towns. It is the latter conditions rather than the former that would represent the real 
test of the system ; and such a test, on any satisfactory basis, has still, I believe, to be made.

Meanwhile we get an illustration of what may happen under disinterested management by a prosecution instituted at Morpeth in November, I906, against Mr. John Oswin Bell, licence holder of the Earl Grey Arms, Broomhill, for permitting drunkenness on Sunday, October 2I. Mr. Bell (who is a county justice for Northumberland) is secretary of the local Public-house Trust Company, and the house in question belongs to that company, having been built by and named after Earl Grey, who obtained a licence for it in I9or, the place being opened for business in February, rgo2. Mr. Bell did not live at the house, which was in charge of a manager, so that it compares with the 'managed houses' of a brewery firm, with this material difference : that there seems to have been no such effective supervision of the manager himself as a brewery firm would have adopted. According to a newspaper report-

Police evidence was given to the effect that on the Sunday in question about 70 men came out of the hotel, and Sergeant Short alleged that 50 per cent. of them were under the influence of drink, two miners being so helpless that they had to be led away by companions. The sergeant added that he had never seen a worse conducted house, and when it emptied at $2.30 \mathrm{p} . \mathrm{m}$. there was a drunken procession down the road.

The magistrates imposed a penalty of forty shillings and costs. In commenting on the case, the Temperance Leader said :

This was the first of these houses opened, and, if our information is correct, its record is no improvement on the ordinary pub. There have been eight managers within five years. Within five weeks of the opening there was a prosecution for permitting drunkenness, and the second manager was sent to gaol for four months, besides the conviction we recorded. The noble Earl has not proved himself to be a very successful publican. Both Bishop Potter in America and Earl Grey in this country have been, indeed, conspicuous failures as public-house patrons. 
If the facts be as here stated, then the Temperance Leader puts the matter very mildly in suggesting that this 'Trust' house was 'no improvement on the ordinary pub.' Not only was it clearly no improvement, but it was far worse, and any 'ordinary pub' which had such a record would be deprived of its licence without the slightest mercy. But the additional facts given by the Temperance Leader confirm in a striking manner the suggestion I have already made, that one of the greatest practical difficulties likely to be experienced by the controllers of 'Trust' publichouses consists in the finding of capable and efficient managers.

Altogether, therefore, the idea of putting a 'specially constituted body of suitable persons' in charge, not merely of a few isolated public-houses, but the whole of the licensed houses in a particular town or district, in place of the practical and experienced men now controlling them, does not seem to be at all promising when one gets beyond the limits of purely rural communities. Nor does the municipalization of publichouses offer a more promising outlook, judging from the views entertained by Mr. Arthur Chamberlain, who, in a letter read at a United Kingdom Alliance meeting in Birmingham on November 27, I906, declared himself opposed to municipal management, saying ' a licensing justice's experience had shown him that many of the municipally managed houses were amongst the worst in the town, while the protection that the name and influence of the corporation provided made them more difficult to control than those of private owners.'

Disinterested management is being advocated at the present time with a vast amount of energy as the great panacea for all the evils, real or supposed, of the trade in intoxicants. I cannot but conclude, however, 
that as a general measure, apart from experiments or partial adoption here and there, it is doomed to failure. No real arguments in support of its adoption are to be drawn from Norway. The keeping of public-houses represents a skilled business in which few amateurs can hope to succeed. Isolated examples of success in rural parishes at home have no significance as regards urban centres. Arm-chair theorists who can draw up elaborate schemes on paper, or, leaving their armchairs, make stirring speeches on public platforms, are not necessarily competent to direct doubtful experiments in the practicalities of everyday existence.

The advocates of disinterested management have, indeed, an active time before them if they hope still to achieve success for their wholly impracticable scheme. Their most vigorous opponents at present are within the circle of the temperance party itself, the United Kingdom Alliance people, ever aiming at total suppression, being bitterly opposed to anything that would, as they generally express it, " tend to make the liquor traffic respectable.' They have still more to convert the larger body of the British public who are without prejudice in the matter, and are prepared to consider fairly the pros and cons of the situation. What they have hitherto done has been mainly to secure the allegiance of a certain number of Bishops and influential laymen who have given in their names as supporters, probably without first taking any trouble to investigate thoroughly all that the proposals involve and the real nature of the experience already gained. When such investigation is made on exhaustive and impartial lines, the verdict must inevitably be that a general application of disinterested management, as in the case of a general application of prohibition, does not come within the range of practical politics. 


\section{CLUBS AS UNLICENSED PUBLIC-HOUSES}

THE vigorous efforts which have been made of late years by licensing magistrates-inspired thereto, more or less, by teetotal sentiment-to bring about a substantial reduction in the number of places licensed for the sale of alcoholic beverages has so far succeeded that there has been an actual decline of about 4 per cent. in the number of 'on-licences' during the past nine years. But side by side with this diminution in licensed public-houses-brought about, to a large extent, at a considerable cost, and with much hardship, to the recognized trader-there has been an even greater increase in the number of those unlicensed public-houses which pass by the courtesy title of 'clubs,' but in many instances, under present-day conditions, are merely alternatives to the legalized houses-with the very material difference that they are absolutely outside police supervision and (except in extreme cases) beyond magisterial control; that they have no legal hours; that they pay no licence duty, and that they are assessed on a much lower scale of value than the ordinary public-houses. Prior to 1903 clubs were not registered, and statistics up to that date were therefore unreliable, though it was stated to the Royal Commission on the Licensing Laws that in 1896 the 
number of clubs in England and Wales in which intoxicants were supplied was 3,655 , as compared with $I, 982$ in 1887 . In 1903 the total number registered was 6,37x. By Igo4 the number had increased to 6,468 , and in Igo5 it rose still further to 6,554 .

But these figures are less impressive, perhaps, than those referring to individual towns. Statistics show that in Igo6 Bradford had I6I clubs, with 44,912 members; Leeds IOI clubs, with 27, I50 members; Glamorgan II2 clubs, with 25,000 members; Huddersfield 8I clubs, with 20,000 members; Halifax borough 50 clubs, with I4,47 I members; Halifax (West Riding area) 40 clubs, with 5,167 members; Todmorden District 32 clubs, with 2,808 members; York 29 clubs, with 5,070 members; Barnsley I2 clubs, with 2, I96 members; and so on with practically every town of any importance in the country, while even in small villages the trade in alcoholic beverages is being steadily transferred from the licensed and controlled public-house to the unlicensed and uncontrolled club.

It has been suggested that the increase in the figures here given is more apparent than real, because, when the Act of 1902 came into force, various masonic lodges and other societies not previously regarded as clubs had to register. No doubt this did occur. But, on the other hand, there was a considerable number of clubs which would not face registration at all, and it is a question to what extent the one item made up for the other. Then, in three years 202 clubs were struck off the register. Further, it should not be too readily assumed that because an institution has a name which suggests that it can only technically be a club requiring registration it may therefore be left out of consideration in reckoning the increase of clubs. It should also be specially noticed that it is not only an increase in the 
number of clubs where intoxicants are supplied which has to be considered, but the increase in membership. Here are two examples from the Brewster Sessions of I907: At Consett (Durham) Sessions 'the chairman observed that the magistrates had no control over clubs. The membership was, however, increasing to an alarming degree. The total membership of the clubs in that division was now 12,302 , an increase of over 2,000 during the year.' At Halifax an increase of over I,500 was reported in the membership of the clubs, but a decline (owing to amalgarnation) of one in the number of clubs.

A certain proportion of the increase, as of the total figures, would be due to bona fide clubs, with which no one would wish to interfere; but there is no doubt that a much larger proportion, especially of those formed of recent years, are of a type that may well rank as 'unlicensed public-houses.'

Membership of a drinking club is generally obtained in return for a nominal subscription of a few shillings the year. In the case of one club at Oldham, now struck off the register, a single shilling entitled a newcomer to all the privileges of membership for twelve months, and $I, 580$ persons gave in their names and their shillings in the course of a year. Another club, at Bradford, bought property worth $£ 750$, and spent a like amount on alterations; but was well able to do this, the purchases of liquor by 650 members leaving a clear profit of over $£ 400$ a year.

Inasmuch as the clubs do not come within the operation of the Licensing Acts, they can open and close when they please. Instances have been known where they open at $3 \mathrm{a} . \mathrm{m}$. and close at II p.m. In at least one case each member had a key of the premises, so that he could enter whenever he felt so disposed. 
Then, that the clubs should be open on Sundays for from six to nine hours longer than the ordinary publichouse is quite a recognized thing. Men will spend the Sunday morning drinking at their 'club,' and, when the public-houses open, will go there for still more liquor. By that time they may already have had too much, and in certain districts the publicans have to station trusty assistants at their door at openingtime on Sundays, lest one of these drunken club members might, possibly, gain admission to the house, with a consequent risk to the licence, should he be found there by a policeman. Sunday concerts and entertainments at the drinking clubs have also become quite a feature in their operations. A programme of one of these functions in London shows that the performers on the occasion in question were of the ordinary music-hall type. It directs special attention to the 'refreshment bar,' saying that 'members and friends will please note price list,' while a further intimation reads: 'The committee desire that children be taken out of the club as early as possible after the entertainment,' presumably in order that the fathers may continue their drinking undisturbed.

That this phase of the 'club' business has undergone considerable and widespread development is well shown in an article contributed to the Manchester Evening Newes of February I5, 1907. As the result of inquiries made by him, the writer of the article finds that variety entertainments and unrestrained drinking go on each Sunday in working-men's clubs throughout Lancashire, Cheshire, and Yorkshire, the whole thing being regarded as a strictly business affair. He gives a form of agreement made between a baritone vocalist and a 'concert secretary,' under which the former agrees to appear 'at the above-mentioned club on 
Sunday, January -, from 3 p.m. to 6.15 p.m., for the sum of — and checks,' the latter being exchangeable for refreshments; and he adds to this a list of thirtyseven towns in different parts of the country where Sunday sing-songs are in vogue at the local clubs. $\mathrm{He}$ proceeds :

Each of these institutions is equipped with a small stage. . . There is a properly appointed chairman and pianist, and an entertainment precisely similar to that which a few years ago obtained at a low public-house is given. In one of the Accrington clubs some 700 men will be found almost every Sunday afternoon. Drinking of both beer and spirits is freely indulged in, and, as the club proprietors have no excise licences to pay for, they can afford to sell them cheap. In some of the clubs, after the commencement of the entertainment, the price of each drink is raised a halfpenny, the theory being that this pays for the artist. It is by no means uncommon for men to leave the clubs at public-house time in such a state of intoxication that the publicans will not serve them.

The existence of these drinking clubs helps to explain one fact which might otherwise seem inexplicablenamely, that while, during the past decade, there has been a decrease of several thousands in the number of on-licences in the country, there has, in some parts of the country, been an increase in the convictions for drunkenness. People who drank in moderation when they were under the eye both of the publican (anxious about his licence) and of the policeman (ever on the look out for offenders), no longer feel the same restraint when they can drink as they please in the privacy of their club. They can also go on drinking there longer than in the public-house, or they can go to their club when the ordinary public-houses close, and stop there till the small hours of the morning, instead of going home at once, as they would probably otherwise do. When, in exceptionally suspicious cases, raids have been made by the police, it has been no uncommon 
thing for the place to be found crowded with men in various stages of drunkenness. This was so with a 'musical institute' visited by the police at Aberdare, and it is not surprising that one of the magistrates before whom the matter came should have declared that, 'speaking generally, one club did more harm than a dozen public-houses.' This view would probably be endorsed by the Chief Constable of Manchester, Mr. Robert Peacock, who, in opening a bazaar at Shaw on the afternoon of February I4, I907, said:

He knew from practical experience that clubs were really the cause of a large number of the cases of drunkenness. Last year, in Manchester alone, between the hours of midnight and six o'clock in the morning, 1,375 persons were arrested for drunkenness. The publicans of Manchester were not to blame for it. The people must have obtained the drink at clubs or at private houses, and he did not think there was much drinking done at private houses after twelve o'clock at night. In the case of the last club he had had raided in Manchester, any female could be a member for $2 \mathrm{~d}$. a week, and any man for $3 \mathrm{~d}$. a week. There were three dances a week, and one of them was held on Sunclay afternoon. It was useless putting further restrictions on the publicans if the clubs were left free.

Harm is done, however, in other ways besides causing drunkenness, for there is reason to believe that a good deal of gambling is sometimes indulged in, and that many of the clubs are made use of by betting men, who more especially regard them as harbours of refuge from police interference in the streets. In Glamorgan it has further been asserted that in crowded centres some clubs are so managed that working-men are precluded from obtaining employment unless they become members.

It is sufficiently obvious that any good done in reducing the number of licensed houses may be more than nullified by the corresponding increase in the number of unlicensed ones, since the latter represent 
the substitution of secret and uncontrolled for public and controlled drinking. It is no less obvious that the whole system represents a great injustice to the legalized trade, which, after making great sacrifices in the interests of public-house reduction, finds itself faced by competition of the severest possible type, since the clubs operate with everything in their favour, while the public-houses are severely handicapped alike by magisterial supervision, police control, and heavy taxation. Equally certain is it that the changes now being brought about in the increasing resort to secret drinking cannot fail to be detrimental to the best interests of society.

When we pass on to inquire as to the possible reasons for these changes, we meet with certain factors which are no less deserving of serious consideration. The increase in the number of clubs has, undoubtedly, been coincident with (I) the decrease in the number of licensed houses; (2) the severe, if not sometimes the drastic, manner in which the licensing laws are administered; (3) the greater restrictions imposed; and (4), owing, no doubt, to magisterial and other local influences, the greater zeal of the police in carrying out their supervision.

I. Whatever the justification for decreasing the number of licensed houses, one inevitable effect even of abolishing the small beer-shops, which could, apparently, well be spared, has been the displacement of many a little coterie of individuals accustomed to spend their leisure in one another's society, and such coteries may have been readily disposed to join, or to form themselves into, small clubs with a view to maintaining the old fellowship. When, again, magistrates have refused to grant licences for new suburban districts, local residents have had to resort to other means 
of obtaining both reasonable refreshment and opportunities for social intercourse, and so have naturally resorted to the formation of a club.

2. The drastic administration of the licensing laws, coupled with the attitude taken up by the extreme sections of the temperance party, has cast a certain stigma on the public-house, so that men in no way disposed to give up the use of alcoholic beverages have been ready enough to avail themselves of any opportunity that may be offered for obtaining them elsewhere; and, from this point of view, no better opportunity could be presented to them than membership of a club. 'I shall look in at my club' is thought to sound more respectable, and to meet temperance sentiment better, than 'I am going to the Spotted Dog'; though it may happen that the individual having this choice of phrases would be much more likely to get drunk at the former place than at the latter.

3. As for the restrictions enforced, these have tended more and more to reduce public-houses to mere places for the consumption of drink. Games of all kinds (except billiards) are rigidly proscribed. Even dominoes and air-guns seem to be regarded as having hidden dangers which must not be allowed to develop themselves; and if patrons of a house which does not possess a billiard-table want to do more than drink, smoke, and talk, they are not likely to find much further recreation open to them than that of looking at the illustrated papers. But man is something more than a creature with a thirst to quench. $\mathrm{He}$ is possessed of social instincts as well, and these may cause him to visit a public-house (to find there companionship and entertainment) quite as much as his need for liquid refreshment. While, therefore, the public-house of to-day, under the existing system of severe restrictions, 
still satisfies the one feeling (which alone is generally recognized by licensing magistrates and teetotallers), it may fail to satisfy the other. In a club, on the other hand, there is a sense of freedom which naturally appeals to the English temperament; though, when such sense of freedom is at last enjoyed, it may readily happen that, from the one extreme of severe repression men will allow their newly acquired liberty to drift into the other extreme of licence. Is it not an historical fact that the severities of the Puritans were followed by the excesses of the Restoration? And may it not be that the same lesson, though in a different manner, is being repeated to-day?

4. Concerning the stricter police supervision, there is no doubt that this has been mainly due to pressure from outside the force; but in certain instances, at least, it has assumed such forms that one cannot be surprised at Englishmen cherishing a spirit of resentment, and making their escape to places where they can empty their glass free from police control. It is an admitted fact that in one town in the North a former chief constable and his officers subjected the publichouses to an amount and a kind of visitation which became repugnant in the extreme alike to landlords and customers. Entering a smoke-room, they would call upon all the men there to stand up and arrange themselves in semi-military fashion, so that it might be seen whether or not they could hold themselves erect, any swaying or divergence from the perpendicular being regarded as an indication that they were 'the worse for liquor.' In the result a 'Recreation Club' was formed in the town, four houses being bought to provide comfortable quarters, and the club soon had a membership of $I, 000$ persons.

In another town in the North of England it was, up 
to a short time ago, the practice of plain-clothes policemen (specially delegated to public-house supervision) to go to a man standing at the bar, deliberately turn him round, and look at him well in order to judge better of his condition. If the man got angry, this was regarded as certain proof that he had had too much, and the landlord might think himself fortunate if he escaped prosecution for serving a drunken man. These practices excited so much ill-feeling that after a time they were abolished; but it still remained customary for the plain-clothes policemen to go round the rooms and peer into the face of each and every customer to see whether or not he was really sober.

In the various conditions here set forth it is really not surprising that even working-men should be taking readily to club life, and be entering into the joys thereof with much more freedom than discretion. What is actually happening is that, in a quiet way, a distinct revolt has set in on the part of considerable sections of the British people against the severities of one kind and another that are being enforced in order to curtail their liberties in choosing for themselves the particular beverages in which they may indulge. They cannot fight against the law, but they will do all they can to evade it. If they are not to be allowed to have a glass of beer or spirits comfortably, and under reasonable conditions, in a public-house, they will obtain it elsewhere. If they may not hope to escape more or less ' control,' ' supervision '-one might almost add 'persecution'-when they drink in public, they will resort to the expediency of drinking in private ; and history and human nature both suggest that the new conditions are likely to be somewhat worse than the old.

That an undesirable state of things, provocative of much drunkenness and other evils, has already been 
brought about is only too evident. How is it to be met? By a further resort to that severely repressive legislation and to that equally severe supervision which have already done little more than diffuse what they were intended to abolish? Is there really any reasonable hope that they would now succeed? Are there not also practical difficulties in the way? Theoretically, the members of the working classes are as much entitled as their social superiors to form clubs among themselves. If certain of those clubs are of so crude a type that they cannot be defended, a little experience will soon show how they can be improved. If, again, a system of inspection is to be introduced, it would be necessary to apply it to clubs of every type, and not simply to those patronized exclusively by working-men. Even then such a system could not do very much more than make it unlawful for people to get drunk at their clubs. So long as they drank only in moderation, working-men would still be as much entitled to have their clubs as anyone else. So long, too, as the members of leading clubs in London can have their brandy - flask filled there for 'off' consumption, or arrange to have hampers sent to them at the Derby, workmen will have an equal right to buy liquor at their clubs for consumption at home.

The difficulty of drawing distinctions and avoiding 'class legislation' will be almost insuperable. In a speech delivered at Westgate-on-Sea on January II, I907, Mr. H. H. Marks, M.P., mentioned that in the case of the National Liberal Club the receipts from sales of provisions, wines, etc., cigars, and cards in one year (the report does not say which) were $£ 33$, I83, the profit thereon being $£ 8,703$, which saved the club from a loss on the year's working of $£ 8,3$ r 3 . It is quite conceivable that an argument would be adduced from these figures 
by the leaders of any working-men's clubs which it was sought to abolish on the ground that they were kept going by the money spent on refreshments. In any case, it is certain that a Government attempting to suppress workmen's clubs, whether with or without interference with the clubs patronized by the members of the middle and upper classes, will have a difficult, if not, from a political standpoint, a dangerous, problem before them.

On the other hand, unless the question is taken in hand and dealt with as effectively as may be, more repression and more restriction enforced against the public-houses that are licensed will inevitably lead to a still further increase in the number of those that are not. 


\section{'TEMPERANCE' TEACHING IN SCHOOLS}

Finding that the advocacy of their extreme views of total abstinence is securing fewer converts among adults capable of forming an independent judgment thereon than they could desire, the teetotal party in Great Britain is making a strong effort to promote the teaching of 'temperance' to school-children, such teaching being added to the list of regular subjects on which instruction is to be given during the ordinary school hours. So far has this movement already gone that Sir Victor Horsley, of University College, London, informed the members of the Ontario Branch of the Dominion Temperance Alliance, on the occasion of a luncheon given at Toronto in August, Igo6, in honour of the British Medical Association, that three years previously the medical profession throughout the United Kingdom issued a petition to the Government asking it to introduce compulsory teaching in domestic hygiene and temperance in the elementary schools; and he added that 'the feeling in the old country that every child should be taught the elements of domestic hygiene and temperance was overwhelmingly strong, and had produced a very powerful effect on the Government.' Since then various other attempts have been made to influence the Government in the same direc- 
tion. The possibility, therefore, of this 'very powerful effect' being transformed into definite action invests with special interest the results of a careful, if not exhaustive, inquiry into the United States system of compulsory 'scientific temperance education' made by a sub-committee of 'The Committee of Fifty to Investigate the Liquor Problem.'

The system in question had its origin in 1879 , when Mrs. Mary H. Hunt presented to the National Convention of the Woman's Christian Temperance Union a scheme for 'thorough text-book study of scientific temperance in public schools as a preventive against intemperance.' A standing committee, with Mrs. Hunt as chairman, appointed to carry this scheme into effect, was reorganized in 1880 as a 'Department of Scientific Temperance Instruction in Schools and Colleges,' Mrs. Hunt then becoming ' national superintendent' in place of the standing committee. Eight years later the movement was incorporated as a department of the World's Woman's Christian 'Temperance Union, Mrs. Hunt assuming the title of 'National and International Superintendent,' while the work was now spread to 'twenty different countries besides the United States.' An Advisory Board of educators, reformers, physicians, and clergymen was created to assist Mrs. Hunt in her propaganda, and especially to give its 'approval and endorsement' to the text-books on the basis of which the teaching was to be founded. The movement thus, as the sub-committee point out, "had behind it the powerful* influence of the text-book publishing firms throughout the country.' It was avowedly a teetotal movement, and the sub-committee say that, 'as is generally the case when feeling and preju-

* 'And,' the report might have added, 'perhaps not "disin. terested" 
dice run high, the temptation has been irresistible to either manufacture evidence or stretch it over points that it does not cover; to call "scientific" everything that happens to agree with particular prejudices, and to relegate to the limbo of human error all the evidence that appears for the other side.' The promoters, nevertheless, secured such measure of support that nearly all the States in the Union enacted laws to enforce 'scientific temperance education.' The promoters also arranged for the issue of 'approved and endorsed' public-school books, in series of three or four, such approval and endorsement being given by Mrs. Hunt and the Advisory Board; but as to the nature of these text-books the committee speak in terms of strong disapproval. The physiological teaching of the "endorsed and approved' differs entirely from that of the 'standard' text-books. Thus, one of the latter (W. H. Howell's 'American Text-book of Physiology,' I896) states: 'It may, perhaps, be said with safety that in small quantities it (alcohol) is beneficial, or at least not injurious, barring the danger of acquiring an alcohol habit, while in large quantities it is directly injurious to various tissues'; whereas in one of the 'endorsed and approved ' text-books it is said: "Alcohol is universally ranked among poisons by physiologists, chemists, physicians, toxicologists, and all who have experimented, studied, and written upon the subject, and who, therefore, best understand it.' Then, Fothergill's 'Practitioner's Handbook of 'Treatment' (London, I897) says: 'In practice we find that in many persons a small quantity of alcohol improves digestion, and that a meal by its means can be digested which would be wasted'; while American school-children are taught in their compulsory temperance lessons: 'Alcohol is not a food or drink. Medical writers, without exception, class 


\section{alcohol as a poison.' Here are some other examples of the sort of thing that passes for 'temperance teach- ing' in American schools:}

'Alcohol sometimes causes the coats of the bloodvessels to grow thin. They are then liable at any time to cause death by bursting.'

'Worse than all, when alcohol is constantly used it may slowly change the muscles of the heart into fat. Such a heart cannot be so strong as if it were all muscle. It is sometimes so soft that a finger could easily be pushed through its walls. You can think what would happen if it is made to work a little harder than usual. It is liable to stretch and stop beating, and this would cause sudden death.'

'Many people are made crazy by the use of alcoholic liquors. In some asylums where these people are kept it has been found that nearly one-half of the crazy people were made crazy from this cause. Not all of these were drinkers themselves. It often happens that the children of those who drink have weak minds or become crazy as they grow older.'

'Sometimes the stomach is so hurt by alcohol that the drinker dies.'

'There is one form of this disease, called alcoholic consumption, which is caused by alcohol. The drinker looks well, till suddenly comes a "dropped stitch," or a pain in the side; then follows difficulty of breathing and vomiting of blood; then a rapid passage to the grave, for medicine, food, change of air, all prove useless.'

'A noted murderer confessed that never but once did he feel any remorse; then he was about to kill a babe, and the little creature looked up into his face and smiled. "But," he said, "I drank a large glass of brandy, and then I didn't care." "

These are just a few representative samples of the sort of teaching given in the approved text-books; but they 'seem to indicate,' the sub-committee say in their report, "that the text-books are written with a deliberate purpose to frighten the children-the younger the better -so thoroughly that they will avoid all contact with alcohol, an attempt fraught with danger on account of the natural reaction of healthy children, boys especially, to such exaggerated statements. . . The books, especially those intended for the lower grades, fairly bristle with statements of a character to work upon the fears of the reader, and remind one in this respect of patent medicine advertisements.' To give 
greater weight to such statements, and also to flatter the vanity of the individuals who compile them, the leaders of the movement describe the writers of the text-books, or the individuals who favour their views, by such terms as 'greatest living authority,' 'foremost scientist,' 'author of great prominence,' ' most skilled in his profession,' 'eminent scholar,' etc., though the report significantly tells us that these phrases are rarely, if ever, applied to persons who are recognized by men of science as authorities on the question.

As regards the actual results of scientific temperance instruction in the schools, several investigations have been made by or among those concerned in the work of education in the United States.

Mr. George H. Martin, agent of the Massachusetts State Board of Education, personally examined schools in which the temperance instruction had been given, and, among the conclusions at which he arrived, he found that, while the 'sentiment' was good, the outcome in accurate knowledge resulting from much of the work done was meagre and out of all proportion to the time spent upon it; and 'that where exaggerated notions of the effects of stimulants have been acquired, there is danger of a reaction of sentiment in the light of afterknowledge.'

Another investigation was made in Massachusetts by Dr. G. W. Fitz, who, in answer to letters of inquiry he sent out, received replies from 83 cities and towns, representing II3,000 children and 4,000 teachers. An analysis of the answers to the question, "What are the results of this (temperance) instruction?' shows'Excellent, if well taught,' 2 per cent.; 'good,' II per cent.; ' medium,' I5 per cent. ; 'little,' I4 per cent.; 'none,' 55 per cent.; ' bad,' 3 per cent. To the further question, 'What value has the instruction in mental 
and moral discipline ?' the answers were- ' Great,' I per cent.; ' good,' I6 per cent.; ' as much as other subjects,' 24 per cent.; ' 'little,' 3 I per cent.; ' none,' 28 per cent.

The sub-committee of the Committee of Fifty also made an independent inquiry among the teachers of New York, Massachusetts, and Wisconsin, the total replies to the following questions being as stated:

I. 'Do you approve the teaching of alcohol physiology as promoted by the department of scientific temperance instruction of the Woman's Christian Temperance Union ?' 'Yes,' 54 ; ' no,' IIg.

2. 'Do you favour such instruction being made compulsory by State law ?' 'Yes,' 57 ; ' no,' I04.

3. "What do you think of the "approved and endorsed " school physiologies ?' 'Good,' 47 ; 'bad,' 86.

4. 'In your opinion are results of the instruction now given good or bad ?' 'Good,' 59 ; 'bad,' 84 .

As typical of the opinions of the teachers on the approved text-books, the sub-committee quote a few replies to the third question from teachers in each of the three States. The following answers from New York State (where the law is 'very stringent') are especially significant :

' Most of them are pernicious, scientifically and ethically.'

'I find that, according to our best authority, the successful physician, they are inaccurate and unscientific.'

'They are very much exaggerated.'

'They are worse than useless. They defeat the very object for which the Woman's Christian Temperance Union labours. They entirely suppress the few beneficial effects of alcohol, and unduly exaggerate the evil effects. All youths pass through an age of unbelief, of cynicism, of agnosticism. This age generally comes during the latter part of the high-school course. When they learn from authoritative sources of the benefits of alcohol the reaction is marked. They immediately question the truth of the evils of alcohol, and term what the books teach "a lie." Such has been my experience.'

'In many cases they do not stand the searchlight of scientific truth, besides containing disgusting details.' 
'I should judge many of them to be extravagantly inaccurate as regards alcohol, according to the teachings of the University of ?'

'So far as I have examined them I believe them to be unscientific, and in some instances ridiculous.'

'They are extreme; hence they do not serve the purpose intended.'

In giving the conclusion at which they arrive on this particular question, the sub-committee say:

It is thus apparent that, under the name of 'Scientific Temperance Instruction,' there has been grafted upon the public-school system of nearly all our States an educational scheme relating to alcohol which is neither scientific, nor temperate, nor instructive. Failing to observe the diametrically opposite conceptions of "use" and "abuse," some of its advocates have not hesitated to teach our children that the terrible results of a prolonged abuse of alcohol may be expected to follow any departure from the strict rules of total abstinence. The success which has attended the efforts of the Woman's Christian Temperance Union to secure the desired legislation may be readily explained by the sympathy sure to be felt by all intelligent people for any sincere attempt to combat one of the most gigantic evils of modern times. There can be no doubt that the abuse of alcohol is a threat to our civilization, and any honest effort to diminish its consumption is certain to be welcomed without any very critical examination of the methods employed. That the originators of this educational scheme were honest in their intentions there is no reason to doubt; but they have violated sound principles of pedagogy in forcing subjects upon the attention of children at an age when their minds cannot possibly be adapted to comprehend them, and have shown themselves absolutely in. different to the demoralization of our educational system resulting from forcing teachers to give instruction in a way which their experience has shown them to be ill-adapted to accomplish the ends in view, and from compelling children to memorize statements sure to be contradicted by the experience of their later lives.

It may fairly be assumed that many sympathetic people in the United States supported this particular scheme in the first instance because they thought the idea a good one, and were impressed by the apparent excellence of the motive, without stopping to inquire as to the special conditions under which it would be carried out. They could not have foreseen that those operating the movement would stoop to such gross exaggerations, if not deliberate misrepresentations, with the idea, 
apparently, that the end would justify the means; nor could they have anticipated that the policy in question, while aiming at securing public benefits, would bring about results that were unspeakably bad and eminently calculated to deprive the temperance cause of the respect of those whom, in their younger days, it had been sought to 'capture.' Whatever may be the views of Sir Victor Horsley, and of the other medical men who may agree therewith, the British Government would be ill-advised if they made any attempt, in this respect at least, to follow American example, or allowed the extreme teetotal party any loophole for repeating here the ill. advised tactics adopted by the propagandists on the other side of the Atlantic.

To the foregoing I will only add that the confusion of ideas which this 'temperance' teaching may develop in immature minds, unable rightly to understand the questions on which the so-called instruction is given, was well shown at Hull recently, on the occasion of a competition among school-children for a prize offered to them for the best essay on the evils of drink. Some I2,660 children competed, and I give below a few examples of the reflections in which these juvenile moralists indulged :

'When a man is overcome by drink he should be taken, or go to a hot place.'

'Seafaring men who are in the habit of drinking are liable to collide with other vessels.'

'To-day many people are in gaol for committing suicide while under the influence of drink.'

'Alcohol has an effect upon a medical man's conclusions.'

'Doctors say that fatal diseases are the worst.'

'Doctors say that the increased death-rate shortens lives.'

'Some men turns into lunatices, and have to go to the Lunatic of Sylum.'

'Some people think that the abuse of drink is right ; some take it as a medicine.'

'Alcohol is a mocker. At last it biteth like a servant and stingeth like a hatter.' 


\section{CHAPTER XVI}

\section{TEMPERANCE DRINKS}

Assuming that the prohibitionists, with the help of their political sympathizers, succeeded in bringing about a total or, falling short of that, a material suppression of the trade in alcoholic beverages, what other drinks would they propose to substitute in the place thereof?

In considering this essentially practical phase of the general question, we have to bear in mind the articular purposes served by the said alcoholic beverages. In the first place, they satisfy the physical sensation of thirst ; secondly, they respond to the instinctive desire for a stimulant; and, thirdly, they are supplied in a form that makes them readily available, without special preparation. The ideal substitutes should meet all these purposes. Even the prohibitionists would not attempt to suppress 'the physical sensation of thirst' by Act of Parliament, though they do seem to cherish the delusion that the natural craving for a stimulant, apart from actual thirst, may be abolished by adequately repressive legislative effort. They must admit, also, that the best substitutes will be found in those that can be furnished promptly, and without trouble, whenever they are required. A fourth condition is that the ideal substitutes should themselves be wholesome, and not (at least) more injurious to the human system, if at all, than those whose place they are to take. 
If the matter were, indeed, one solely of alleviating thirst, our wants could be supplied by cold water, subject to the proviso that the purity thereof was beyond all doubt-a proviso which is of the greater importance, considering that the germs of typhoid fever, cholera, and various other diseases, are especially spread by means of drinking-water, and that the water-supply of many foreign countries visited by English travellers is far from being above suspicion. But whilst cold water alone might satisfy the purely physical requirements of the human system in regard to liquid nourishment, just as it meets those of the animal world in general, it would not exercise the special functions of a 'stimulant' from either a psychological or a social standpoint, and thus would fail to satisfy the wants of our common nature, as long as man remains the being he is.

But for the fact that they require the aforesaid 'special preparation,' tea and coffee undoubtedly come nearest to the ideal substitute. They not only allay thirst, but they also act as, and are, literally, stimulants. The good service they render, when taken in moderation, is undeniable. They do not, however, meet all the social and other requirements that are served by wine, spirits, and beer; they are not suitable for all occasions, and they have their pernicious results, just the same as in the case of alcoholic drinks, when taken, as they often are, to excess.

Much has been heard from time to time concerning experiments as to the effect of alcohol on animals, but there have also been investigations into the effects on animals of the alkaloid caffein, or theine, which is found in tea. These have shown that, given to frogs, the alkaloid produces tetanus, while, when very large doses are administered, the tetanic convulsions are succeeded by paralysis and death. As regards the possible effects 
of tea on the human system, Sir Lauder Brunton, M.D., says in his book 'On Disorders of Assimilation, Digestion,' etc. :

In large quantity tea causes sleeplessness, and, in larger still, produces excitement of the circulation and such a disturbance of the nervous system that the patient suffers from hallucinations of vision and trembling of the muscles, somewhat resembling that in delirium tremens. These symptoms are produced much more readily by green than by black tea. In some exceptional cases the susceptibility to the action of tea is so great that a few cups of green tea will bring on marked muscular tremors. Others, again, are so readily rendered wakeful by tea that they cannot drink a cup of tea after two o'clock in the day. Sometimes people suffer from sleeplessness without understanding the reason, when it is really due to their having drunk mixed tea instead of black. ... Poor women, who are much underfed, and whose only comfort is a cup of tea, generally take it very hot, so as to add the stimulant effect of warmth on the circulation to the stimulant effect of the tea on the nervous system. The same class of people are accustomed to take their tea not only hot, but strong, and, in order that no particle of its virtue may be lost, they infuse it for a very long time. In this way they extract a quantity of the tannin, and the combined effects of the tannin and the excessively hot tea upon the stomach produce a condition of dyspepsia.

\section{Concerning coffee, the same authority says :}

Coffee is more apt than tea to disorder the digestion in many people, and in some is apt to cause a condition of biliousness. When taken to excess it not only produces digestive disturbance, but nervous symptoms, palpitation, restlessness, irritability, sleeplessness, and general nervous depression. . . .

In most cases of dyspepsia coffee does not agree, and from its tendency to excite the nervous system it should also be avoided by those who are liable to suffer from various forms of nervous disturbance, such as functional palpitation of the heart and liability to attacks of neuralgia, hysteria, or epilepsy.

Coffee is not only often adulterated by admixture with other substances, but sometimes fraudulent imitations, which do not contain a particle of coffee, are sold under its name. The most common adulteration of coffee is chicory.... Some coffees are made entirely of roasted figs. Other adulterations are roasted wheat and beans, flour, acorns, mangel-wurzel. To give it a colour burnt sugar is added. Some coffee is entirely made out of such substances. If no other adulterations are present, these substances are not actually injurious to health, only they have not the stimulating action of coffee. The infusion made with them is, in fact, a kind of toast and water, the burnt toast being replaced by burnt flour or burnt roots. 
In the case of tea and coffee, therefore, one can say that, taken in moderation, they serve a useful purpose; taken in excess, they do harm; while there are certain individuals who should not indulge in one or other of them at all. But this is precisely what the vast majority of people would say concerning alcoholic beverages, and in regard to one, at least, of these-the workingman's beer-there could be no suggestion of the use of any such adulterants as those spoken of by Sir Lauder Brunton in respect to coffee.

I pass on now to consider the position occupied by those aerated and mineral waters which more especially come into consideration when one discusses possible substitutes, since these waters, unlike tea and coffee, can be presented, without special preparation, immediately on demand, and therefore do offer the same advantages as bottled beer, wine, or spirits, in regard to sale or transport.

It is difficult, if not impossible, to give really trustworthy data as to the actual extent of the mineral water industry, no official statistics thereon being available. There is, however, reasonable ground for the estimate that, whereas half a century ago there were scarcely fifty manufacturers of them, to-day there are about 4,000. According to Mr. William Kirkby, as stated in his book, 'The Evolution of Artificial Mineral Waters,' there are in the United Kingdom about 23,000 persons directly engaged in the manufacture of these waters, while in London alone the number employed indirectly - that is, in branches of trade more or less dependent upon the mineral water industry-is put at 25,000. As for the quantities produced, it was stated in the House of Commons on June 2, I8gI, that the consumption of aerated and other temperance drinks in this country amounted to $20,000,000$ dozen bottles per annum. 
That was sixteen years ago, and one may be quite sure that production and consumption have greatly increased since then.

We have here, therefore, at least a general idea of the way the industry has grown, and the position to which it has attained among the industries of the country. It is obvious, however, that for this position the mineral water trade is mainly indebted to the teetotal campaign, and that it stands to benefit from any fresh discredit which may be cast upon alcoholic beverages, and from any further substantial increase in the number of 'abstainers.' There are certainly suggestions-though one cannot prove whether or not they are well founded-that the teetotal campaign may have been encouraged by mineral water makers as a matter of trade rivalry and business enterprise. Be this as it may, the direction in which the sympathies, at least, of the mineral water manufacturers are likely to tend is indicated by the following remarks in the course of an article, 'On the Road,' published in the Mineral Water Trade Review for February I8, 1907:

All manner of legislation for the encouragement of temperance is in the wind, and this should be good news for the aerator. I have heard it suggested by a living authority that any legislation affecting the wine, beer, and spirit trade would not affect the aerator. Also that the total abolition of the tied-house system would not be to the aerator's profit. I fail to see the argument. Personally, I am of opinion, from what I know of the trade throughout the country, that any Act of Parliament bursting the iron bands that brewers have forged round their managers and tenants will open the road for the sale of more 'minerals.' ... By the abolition of the tied-house system the sale of 'minerals' would be as real an asset as beers.

It does not follow that the 'temperance drinks' produced in the increasing quantities indicated are consumed exclusively by teetotallers. It is probable, for example, that more soda water is drunk with whisky 
than without. But, speaking generally, temperance drinks are especially favoured by teetotallers, who consider that they are perfectly safe in using them, and are apt to pity, if not to despise, those who still keep to their glass of beer or other alcoholic liquor; and there is no doubt that the great increase in the trade is due mainly, though not exclusively, to the advance in the teetotal movement in this country. From the standpoint of the abstainers, therefore, it is desirable to inquire what is the real nature of the bottled beverages on which they depend; while from the standpoint of the world in general one may ask how the said beverages compare with those that are avowedly alcoholic, and whether or not they can be generally accepted as adequate and desirable substitutes for the latter.

The severest criticism of the mineral water trade comes, not from the makers and purveyors of intoxicants, as the teetotal party might assume would be the case, but from within the trade itself. In the introduction to a little volume of recipes issued some years ago by a leading firm of dealers in essences, etc., for mineral water manufacturers, due account is taken of the great progress which has been made in the various departments, but the writers proceed:

We regret exceedingly that the great competition amongst mineral water manufacturers is causing them to reduce materially the quality of their manufactures. The sugar is stinted, the bottles are made to hold less than their proper quantity, low-priced and deleterious flavouring-agents are used, the water is badly and slovenly aerated, and, lastly, mineral acids are sometimes substituted for the fruit acids, the result being that some beverages offered for sale are a scandal to the trade. But who reaps the advantage? Only the retail dealer, who does not reduce his price to the public, so the latter suffers by receiving a much inferior article. Then, again, we cannot impress upon the mineral water maker too strongly the importance of using the best quality of sugar. Inferior qualities are incompletely purified, so there often 
exist traces of the various chemicals used in their purification, and also traces of vegetable matter, which cause the beverage to become cloudy, and often cause fermentation to set in after bottling. ... .

There is no doubt whatever the mineral water trade has a most prosperous future before it, providing the beverages offered to the public are made palatable, tempting, and wholesome. But this end is obtainable by the use only of the best sugar, the purest water, fruit acids, and the finest flavouring matter (upon which the palatability of the drink depends).

There would seem to be special difficulties and risks in the making of mineral waters, just as there are in the production of alcoholic liquors, for the booklet goes on to say :

There are numerous kinds of fermentation which trouble the mineral water maker in all seasons, and even cause him great loss and anxiety-one kind especially, that of mucous fermentation, where the whole contents of the bottle become one gelatinous mass. A little vegetable matter in the sugar, an unclean bottle containing a fermenting germ, the syrup pan not being absolutely clean, are all reasons for causing fermentation.

Reverting, later on, to this subject of mucoid fermentation, the booklet further states:

It is a true fermentation set up by living structures, just as the alcoholic fermentation is set up by the yeast plant. It is more readily propagated with beet than with cane sugars, and experiments on the subject show that it can be more easily propagated with crude than with refined sugars; a trace of phosphates in the sugar aids considerably the growth when once started. How these living germs are conveyed in to the aerated beverage it is difficult to say; they may exist in a dormant state in the sugar, or even in the air, and when once the fermentation gets into the mineral water factory it is very difficult to get out ; it comes as a sort of pest or disease. Everything, therefore, must be thoroughly overhauled or disinfected - pots, pans, machinery, tanks, and vessels of every descriptionand the beverages strongly dosed with antiseptics until the plague is removed, and then the ordinary amount of preservative added to the drinks can be resumed.

Nor is it very appetizing to read the following note in regard to the syrups of which aerated waters largely consist : 
Do not let the syrups stand about exposed, as, in addition to the numerous bees, wasps, and flies, which generally infest the mineral water factory, finding their last resting-place in the syrup, it also becomes tainted with the ferment germs and dust in the air.

In a similar booklet, issued by another wholesale firm, one may read:

It is obvious that good aerated waters and cordials cannot be made without good essences, and the better the essences the better results will the aerated water maker achieve.

There is one point in particular we should like our friends to be quite clear about. When we advertise and guarantee in our pricelist any essential oil or essence to be genuine, it is genuine, and not adulterated.... We should also wish it to be understood that we have never had a single gallon of methylated spirit on our premises, and that all our essences are, and always have been, made from the finest rectified spirit, and not from illegally purified methylated spirit. It is, unfortunately, the fact that this partially purified methylated spirit has been used for such purposes, and we draw special attention to the fact because the users as well as the makers and vendors of such essences are liable to very heavy penalties. As is well known, methylated spirit is a disgusting compound, quite unfit for essence-making; but the fact of its being duty free has been too great a temptation, the difference in price being that methylated spirit is worth about $2 \frac{1}{2} d$. per pound and rectified spirit $2 s$. $6 \mathrm{~d}$. per pound, so that it would not take long to make a fortune on the lines indicated. ...

The vast increase in the consumption of aerated beverages during the past few years is a fact to be noted with great satisfaction, and this increase is to be attributed in no small degree to the conscientious endeavours of the majority of high-class manufacturers to produce their beverages of a quality worthy of the increased confidence of the public. We regret to note that all manufacturers are not alike in this respect. With some the sole object appears to be the production of goods at the lowest possible price, and quite irrespective of quality. When, for instance, a bottle of lemonade is asked for, the purchaser expects to receive something better than a solution of sugar and water, feebly aerated, unflavoured, and acidified with one of the concoctions of mineral acid which are put upon the market under various misleading titles.

From some 'notes' in the same booklet on the materials used by mineral water and cordial manufacturers, further enlightenment can be gained. Acetic acid, one finds, is used by some manufacturers as a cheap substitute for citric or tartaric acid, though its 
only recommendation is its comparatively low price. Manufacturers have been warned against the use of hydrochloric acid for the production of carbonic acid, 'owing to the gas containing chlorinated compounds which few metals will resist, and to the taste and odour imparted thereby to aerated beverages, which no washing will remove.' The writers continue :

It certainly did not occur to us at the time that an attempt would be made to introduce this strongly corrosive mineral acid as a substitute for pure fruit acids in aerated beverages. We regret that this attempt has been made. And the hydrochloric acid mixture is stated to be harmless because it is derived from common salt (chloride of sodium). On this reasoning vitriol might just as well be used at once, as it is present in Epsom salts (sulphate of magnesia). For such beverages as lemonade, etc., which are sold to the public as fruit drinks, pure fruit acids should alone be used.

Salicylic acid is recommended as the most efficient preservative of all sweet aerated beverages which are to be kept for any length of time or exported to hot climates. It is suggested that care should be taken to ascertain that the sulphuric acid used for the generation of carbonic acid gas is of good quality, and guaranteed made from sulphur. 'Much of the cheapest vitriol is now made from pyrites and refuse from copper works, and is frequently contaminated with arsenic and other impurities.' The 'head' on non-alcoholic herbal or botanic beers, giving them ' a freshness and piquancy which are not generally found in beers containing little or no alcohol,' can, it seems, be produced by a certain foam syrup, I pound of which, added to 40 gallons of plain syrup, ' will give to aerated beverages of every description a rich, sparkling, close, and lasting head, free from large bubbles,' while I pound of foam powder 'is sufficient to produce a rich, close, and sparkling head on 600 gallons of liquor.' Caramel (burnt sugar) occupies a leading position among the colourings, 
especially for ginger ale. Absolutely pure carbonic acid gas must be used to produce high-class beverages, but 'it is, unfortunately, a fact that many mineral water makers give very little attention to the purity of the vitriol, whiting, or other materials used.' Brewed ginger beer, it is further stated, can be produced, by means of a certain powder, at a cost not exceeding threepence a gallon.

Concerning essential oils the booklet says :

Essential oils, sometimes known as essences, are derived from plants by various processes. The essential oils of most interest to the mineral water manufacturer are extracted by expression or by distillation. Our selected qualities of lemon, orange, and bergamot are manufactured solely for our firm, under our own direction, and are extracted by hand direct from the respective peels of selected fruits. In this respect they differ from the oils generally offered to the trade, which are inade from refuse fruits, unfit for eating, and more or less mixed with distilled oil of lemon, or adulterated with various admixtures.

\section{Of oil of lemon it is said:}

There is no article imported into this country which is so generally and largely adulterated as oil of lemon. This adulteration is carried on to an enormous extent by so-called manufacturers in Sicily, who purchase a certain quantity of oil of lemon, oranges, etc., from the small growers, and mix it with various adulterants. Those mixed oils are generally shipped to England through agents, at a price which sufficiently indicates the quality of the produce and the character of the shippers. ... We strongly recommend all users of oil of lemon to be most careful when purchasing. It is an easy matter for unscrupulous dealers to produce a so-called oil of lemon at a very low price, but after a few weeks this mixture smells strongly of turpentine or paraffin, and is completely useless.

On this same subject the writers state, later on, under the heading 'Tests for Adulterations and Impurities ':

As an example, we may refer to the well-known scandalous adulteration of oil of lemon with turpentine. If a perfectly pure oil of lemon can be purchased for, say, 8s. per pound, and an oil of lemon containing 50 per cent. of turpentine is offered at $4 \mathrm{~s}$., it is obvious that the purchaser of the latter obtains only half a pound 
of oil of lemon for 4s., and half a pound of turpentine, which is worse than useless, and the flavour of the drink made therefrom is not palatable, even when freshly bottled, and in a few days a disgusting flavour of turpentine predominates, injurious alike to the reputation of the manufacturer and the confidence of the consumer. We cannot too strongly urge the importance of purchasing the best and purest materials from houses of repute. The adulteration referred to above is no exaggeration, but a fact.

In the actual manufacture of aerated waters the usual procedure (judging from the recipes given in the trade publications) is to take a gallon of plain syrup (made from sugar and water), and add (I) from I to 2 ounces either of citric or of tartaric acid, (2) the particular sort of essence or essences needed to produce the special kind of drink required, (3) so much colouring matter, and (4) a varying quantity either of 'foam syrup' or of 'French cream' to give the beverage a good 'head.' The differences between the various drinks seem to depend mainly on the flavours em. ployed. Indeed, one of the publications in question says, frankly enough: 'It must be admitted that the flavours are the life of the aerated drink.' (The words italicized are so given in the original.)

Strictly speaking, these essences, or flavours, should be obtained mainly from fruits, herbs, spices, and suchlike sources. Fresh fruit essences, according to Mr. Peter MacEwan, author of 'Pharmaceutical Formulas: a Book of Useful Recipes for the Drug Trade,' are made by covering the fruit with rectified spirit (I pint to 4 to 6 pounds of fruit), and macerating for ten days. Five per cent. of artificial essence is then added, the liquor is filtered, and colouring matter follows.

It is mainly owing to these essences that there has been so great an increase in the variety of beverages now offered to the consumers of temperance drinks. Half a century ago the fifty manufacturers already spoken of produced little more than lemonade, ginger 
beer, and soda water. The position to-day is indicated by a little book, 'Temperance Drinks for Summer and Winter,' compiled by Mr. Frederick Davies, whose recipes for syrups, cordials, and drinks number no fewer than 589. He throws, however, further light on the reason for the rapid growth of the business when he says that beverages made with a machine or drawn from the fountain, such as aerated lemonade, ginger ale, etc., 'may be produced at a cost not exceeding $6 \mathrm{~d}$. per dozen drinks. Indeed,' he adds, 'soda and other mineral waters can be produced for half that amount.'

It is a matter of special interest to know of what these all-important fruit essences are really composed, and it would seem from some recipes given in $\mathrm{Mr}$. MacEwan's book that not only genuine fruit essences are employed, but artificial ones, which are made out of various chemicals, and need not contain any portion whatever of the fruit they are supposed to represent. The following examples of these purely artificial essences may suffice, the figures given representing parts by measure for 100 parts of rectified spirit :

Cherry.-Acid, benzoic, I ; ether, acetic, 5 ; ether, benzoic, 5 ; ether, œnanthic, I; glycerine, 3 .

CIDER.-Alcohol, amylic, 4 ; chloroform, 4 ; ether, amyl-acetic, 4 ; ether, amyl-butyric, 4 ; ether, amyl-valerianic, 8.

Currant.-Acid, benzoic, I ; acid, œnanthic, I ; acid, succinic, I ; acid, tartaric, 5; aldehyde, I ; ether, acetic, 5; ether, benzoic, $\mathrm{I}$.

GRAPE.-Acid, succinic, 3; acid, tartaric, 5 ; aldehyde, 2 ; chloroform, 2 ; ether, formic, 2 ; ether, methyl-salicylic, I ; ether, œnanthic, Io; glycerine, 10.

ORANGE.-Acid, tartaric, I ; aldehyde, 2 ; chloroform, 2 ; ether, acetic, 5 ; ether, amyl-acetic, I ; ether, benzoic, I ; ether, butyric, I ; ether, formic, I ; ether, methyl-salicylic, I ; glycerine, Io; oil, orange, 10.

PEACH.-Alcohol, amylic, 2 ; aldehyde, 2 ; ether, acetic, 5 ; ether, butyric, 5 ; ether, formic, 5 ; ether, sebacylic, 1 ; ether, valerianic, 5 ; glycerine, 5 ; oil, peach kernel, 5 . 
PINEAPPLE.-Ether, amyl-acetic, I ; ether, amyl-butyric, IO ; ether, butyric, 5 ; glycerine, 3 ; oil, lemon, $0^{\circ} 1$; oil, orange, $0^{\prime} 2$.

Plum.-Aldehyde, 5 : ether, acetic, 5 ; ether, butyric, 2 ; ether, formic, I ; glycerine, 8 ; oil, peach kernel, 4 .

Then an American writer, Mr. G. H. Dubelle, of New York, has published a book entitled: "The "Ne Plus Ultra" Soda Fountain Requisites of Modern Times,' in which he gives a large number of formulæ, including fruit syrups, 24; new improved artificial fruit syrups, 28 ; fancy soda-fountain syrups, 22 ; artificial fruit essences, 28 ; concentrated fruit phosphates, 29; new malt phosphates, 36; foreign and domestic wine phosphates, 9 ; cream fruit lactarts, 28; soluble flavouring extracts or essences, I2; new modern punches, I8; nonsuch fruit punches, 32; and new superior fruit champagnes, $\mathrm{I} 7$.

These various drinks are in great favour among the teetotallers of the United States, most of whom, probably, while taking their 'malt' or 'wine' phosphates, their fruit 'punches,' or their fruit 'champagnes,' would scout the idea of drinking a glass of beer made of malt and hops. What they may get is suggested by the following examples of the formulæ given by $\mathrm{Mr}$. Dubelle for the said 'soda water fountain requisites,' the figures representing in each instance fluid ounces :

ApPLE EsSENCE.-Deodorized alcohol, 40; pure apple jack (brandy), 40; valerianate of amyl, Io; glycerine, 5 ; aldehyde, 2 ; chloroform, acetic ether, and nitric ether, $\mathrm{I}$ each.

APRICOT ESSENCE.-Deodorized alcohol, 50; pure apricot juice, 25 ; butyric ether, 10; valerianic ether, 5 ; glycerine, 5 ; amyl alcohol, 2; butyrate of amyl, chloroform, and bitter almond oil, I each.

BANANA ESSENCE.-Deodorized alcohol, 80 ; butyrate of amyl, Io; butyric ether, 5; glycerine, 3; chloroform and aldehyde, I each.

BLACKBERRY ESSENCE.-Deodorized alcohol, 70 ; pure blackberry juice, 20 ; glycerine, 7 ; tincture of orris root, apple oil, and quince oil, I each. 
GooseberRy EsSENCE.-Deodorized alcohol, 70 ; pure gooseberry juice, 20; acetic ether, 5 ; benzoic ether, benzoic acid, œnanthic ether, grape-seed oil, and aldehyde, I each.

LEMON ESSENCE.-Deodorized alcohol, 60 ; pineapple essence, acetic ether, and oil of lemon, 5 each ; glycerine, 5 ; aldehyde, 2 ; chloroform, nitrous ether, and acetic acid, I each.

LIME FRUIT ESSENCE.-Deodorized alcohol, 60; pineapple essence, acetic ether, and oil of lemon, 10 each; glycerine, 4; aldehyde and acetic acid, 2 each ; chloroform and nitrous ether, I each.

RASPBERRY ESSENCE.-Deodorized alcohol, 50 ; pure raspberry juice, 20; tincture of orris root, 1o; acetic ether, 5 ; glycerine, 3 ; nitrous ether, aldehyde, formic ether, butyric ether, benzoic ether, grape-seed oil, oil of wintergreen, acetate of amyl, butyrate of amyl, cenanthic ether, chloroform, and spirit of rose, I each.

STRAWBERRY ESSENCE.-Deodorized alcohol, 40 ; pure strawberry juice, 20 ; raspberry essence, 10; pineapple essence, acetic ether, tincture of orris root, and butyric ether, 5 each ; acetate of amyl, 3 ; butyrate of amyl, 2 ; nitrous ether, formic ether, oil of wintergreen, acetic acid, and glycerine, I each.

On the facts here presented various considerations arise.

It would seem, in the first place, that manufacturers of temperance drinks are to be divided into two classes -(I) those who carry on a genuine business under the best conditions, and (2) a swarm of reckless traders, who use the cheapest materials and follow the worst of methods, regardless of all other conditions so long as they can make money out of the teetotallers whose prejudices they exploit. No one who reads between the lines of the extracts given above can fail to admit that this conclusion is abundantly warranted.

In the second place, even if one granted that this latter class of manufacturers did not really exist, and that the whole of the aerated and mineral waters put on the market were produced under the best possible conditions, one is still left with the question: Can such drinks compare with honest ale in regard to nutritive qualities? The 'food value' of ale has certainly been a subject of much controversy, though 
the materials used consist of natural products which, in themselves, admittedly contain nutriment, and this ought in due course to be imparted in some degree to the beverages of which such products form a basis. In spite, therefore, of all questionings, one must assume, on the grounds alike of reason, of research, and of experience, that ale and beer do have a certain food value, whatever the exact amount thereof may be. But when we come to the bottled temperance drinks, there can be no possible suggestion of these having any 'food value' at all. They may be 'palatable,' just as any sweetened, aerated, and agreeably flavoured water might be, and they may satisfy thirst; but it cannot be claimed that they have either stimulating qualities (apart from the actual amount of alcohol they may contain) or nutritive qualities. In these two respects, therefore, they cannot really be regarded as adequate substitutes for the working-man's beer. For a person who has just gone through, say, some heavy manual labour, or is otherwise fatigued from exhausting physical effort, they could not possibly answer the same purpose as a mild stimulant.

It may be claimed that they are still preferable to the working-man's beer because the latter is an alcoholic drink, whereas they are non-alcoholic. But this is a designation to which they are not strictly entitled, because temperance drinks do contain a percentage of alcohol. The makers cannot produce them, as a class, without alcohol, and the Government recognize the fact by allowing them to escape paying duty provided they do not contain more than 2 per cent. of proof spirit by the volume. The alcohol in temperance drinks is due either to the addition of the essences (which are prepared in very strong alcohol), or else to chance fermentation, attributable to the beverage 
having undergone what might well be an injurious decomposition previous to consumption. In some cases temperance drinks sent out well within the legal limit will develop a considerable increase of alcoholic strength while being stored for sale. To prevent these results as far as possible preservatives are employed, and in the well-known cases as to the permissible use of salicylic acid in lime juice and lime juice cordial, the magistrates decided that such acid might be employed within certain limits, although the doctors differed very strongly as to the desirability of allowing its use even in restricted quantity.

The amount of actual alcohol which, from one cause or another, temperance drinks may contain by the time they reach the consumer is well indicated by the following extract from the Report of the Principal Chemist upon the Work of the Government Laboratory for the Year ended March 3I, Igo6:

Herb Beers and Other Beverages sold as Temperance DRINKS.- Nine hundred and twenty-four samples of ginger, herb, and botanic beers were purchased in various parts of the country to ascertain if the proof spirit was within the legal limit of 2 per cent. It was found that 349 contained spirit in excess of the legal limit, and of these-

58 contained 3 per cent., but less than 4 per cent., of proof spirit ; 35 contained 4 per cent., but less than 6 per cent., of proof spirit; 8 contained 6 per cent. or more, the highest containing 9.5 per cent. of proof spirit.

One sees, therefore, that in taking these so-called 'temperance drinks' teetotallers can imbibe fairly substantial quantities of alcohol without, perhaps, being aware of the fact, and it may even be that the stimulating effect of this alcohol is, unconsciously, the real cause of their regarding such drinks with so much satisfaction.

Alcohol is condemned by the prohibitionists because 
of its toxic qualities, or, as they would say, 'because it is a poison.' They show that, injected into animals, it produces various direful results, including death. But alcohol is under no circumstances taken 'neat' by human beings, and the real question is whether the actual amount of alcohol contained in the glass of beer of a moderate drinker-or even in two or three glasses -would produce any really toxic effect. If so, then the same question would arise in regard to those 'temperance ' drinks which, as we have seen, also contain a certain percentage of alcohol. Accepting, for the sake of argument, the theory that the presence in a beverage of even the smallest quantity of an admittedly (in itself) toxic agent is injurious, then the same conditions, even in respect to alcohol alone, apply in principle to temperance as to other drinks, the matter being simply one as to the exact proportion of alcohol contained in each of them. But, as regards the former, the question really goes much further.

There is no doubt whatever that many of the chemical or other substances used in the preparation of temperance drinks are, in themselves, toxic, and that, whereas a glass of beer may contain a minute proportion of one toxic agent-namely, alcohol-a bottle of aerated or mineral waters may contain traces, not only of this same toxic agent, but of others besides. Take the case of ordinary 'stone ' ginger beer, one of the most popular of all temperance drinks. It is considered by the public especially good when it shows a good froth or 'foam. on the top. But this effect is simply produced by the use of a syrup made from quillia bark,* the active prin-

* In Mr. Dubelle's book the recipe for a 'foam preparation,' which he thinks will 'give entire satisfaction,' is: 'Ground soap bark (quillia), I6 ozs.; deodorized alcohol, 8 fl. ozs.; water, a sufficient quantity.' 
ciple of which is a substance called saponin, and this has proved-when taken in sufficient medicinal quantities-to have a very serious action on the heart. As for the essences or flavours which constitute 'the life of the aerated drink,' and allow of so great a variety of temperance beverages being put on the market, these are made largely from substances derived from coal-tar products. I do not say that, for this reason, they are necessarily injurious to the system, and that temperance drinks should therefore be avoided. I make no such suggestion whatever. But it may fairly be said that precisely the same arguments used by the teetotallers in regard to any possible injurious effect on the human system of even minute quantities of alcohol in beer apply to the possibility of like results from the presence in temperance drinks of alcohol, plus these chemical or other toxic compounds. If the argument holds good in the one case, it must hold equally good in the other; and it might, therefore, be suggested to the members of the prohibitionist party that, in the intervals of decrying, not alone the alleged absence of 'food value' from beer, but also the presence therein of a substance they say is harmful to the human system, they should place their own house in order, and show that the beverages they would substitute for those they condemn are not only adequate for the purpose, but themselves above suspicion. 


\section{BEER PAST AND PRESENT}

Not alone is there a tendency on the part of teetotal advocates to bring all alcoholic beverages, whatever their constituent parts, under the same ban of condemnation, but inadequate allowance is generally made for the material changes effected during the last quarter of a century in the alcoholic strength of the weakest but most popular of all among these beverages-the working-man's beer.

These material changes have been directly due to the remarkable advance made during the period in question in the science and art of brewing; and here, in the first place, honour must be paid to Pasteur, the master mind, who discovered the great meaning of fermentation; but credit is also due to the late Cornelius O'Sullivan, Horace Brown, Peter Griess, Heron and Morris, all of Burton-on-Trent, who laid the foundations of that branch of the modern school of chemistry which concerns itself with the technology of the carbohydratesa name comprising starch, sugar, and all the various products which can be obtained from them. The researches thus made have since been adopted by all the well-known brewers of the world as the basis of further work. It was the labours of these investigators concerning the transformation of starch into its various 
products, as the result of fermentation, that rendered possible alike the production of a better beer than our grandfathers drank, and also a reduction in the alcoholic strength thereof.

Whilst English chemists were thus occupied with the chemistry of the carbohydrates, events were occurring in Denmark which led to that country acquiring a foremost position in the scientific investigation of fermentation in its bearing on industrial problems. Mr. Jacobsen, of the celebrated Carlsberg breweries, had visited Pasteur's laboratory in Paris, and had been so much impressed by what he there saw that, on his return to Copenhagen, he set up a thoroughly equipped Institute to carry on the work of research connected with fermentation, with a view to applying, subsequently, to industrial brewing the results so obtained. He appointed as leading scientific adviser to the Institute Emile Christopher Hansen, and he further had the cooperation of chemists of the type of Kjeldahl, whose valuable researches are known all through the chemical world. The results of the work thus done have been, not only greatly to advance scientific knowledge, but also materially to improve the quality of the lager, or low fermentation, beer, as produced on the Continent of Europe.

It is the combination of the successes thus attained in England and Denmark respectively, supplemented by the work done also by scientists in Bavaria, that has brought about such material changes in the constitution of beers in general.

In Great Britain the ordinary beer of five-and-twenty years ago was certainly open to adverse criticism from a temperance standpoint, and it was so for two reasons: (I) The large proportion of hops employed; and (2) the high alcoholic strength of the beverage. 
With regard to the former of these reasons, it should be borne in mind that the presence of an excess of hops in beer has a narcotizing effect, so that the man who gets drunk on beer displays symptoms very different from those of the man who gets drunk on spirits. The latter may readily become violent, and either be destructive - smashing windows, for example-or else quarrel with, or even attack, those around him. But the man whose drunkenness is due to beer becomes stupid rather than violent, and reels about, having, in effect, been 'narcotized' by the influence upon his system of the hops used in the beverage he has taken in excess. These conditions more especially prevailed a generation ago, the old English beer being not only strong in alcohol, but so heavily hopped that the drunkenness it caused had many of the characteristic symptoms of actual narcotic poisoning.

But during the last twenty-five years the 'hop rate' - that is to say, the amount of hops employed in the production of beer-has decreased very largely, with this all-important result : that the quantity thereof used for the production of the working-man's beer of to-day may certainly be defined as 'non-narcotizing.'

Comparing the ordinary beers now being consumed in England with those of the period in question, one finds that in actual alcoholic strength there has been a reduction of between 15 and 20 per cent., or, in other words, a decline of from 7 per cent. to between 4 and 5 per cent., or even less, in terms of absolute alcohol. This fact is proved in a curious way.

In the year I88o Mr. Gladstone brought about what the Beer Materials Committee have well described as ' an epoch in the history of brewing,' by inducing Parliament to repeal the old malt tax, and to substitute for it the so-called 'Free Mash-tun' system, under which 
the beer duty was for the future to be levied upon the wort in terms of 'original gravity' - that is to say, the average strength of the wort prior to fermentation, the brewer being left free in regard to the choice both of his materials and of his methods. The average 'original gravity' on which the duty was thus based was 1057. That figure did, at the time in question, fairly represent the average strength of mild ale throughout the country; but there was then still a very large consumption of strong beer and of old vatted ale which had an original gravity of (say) 1065 and upwards. To-day, following on the introduction and great popularity of milder, lighter, and brighter beers, the production of the old vatted ale has almost wholly disappeared, and the sale of strong beer has been reduced to a vanishing-point, the quantity sold representing only a fractional percentage of the total consumption. As one result of these changes the Government have found it necessary to reduce the standard of strength for duty-levying purposes from 1057 to I055; but it may fairly be said that the bulk of the mild ale now produced in this country, and sold in bottles for household consumption, is much nearer 1048 than 1055 .

When one studies the component parts of what is termed 'the nutriment of beer,' one finds that the object of malting is to change the starch of the barley into a form which shall be capable, in the mash-tun, of conversion into readily assimilable and easily digestible carbohydrates, considerable proportions of which are presented to the drinker in the form of finished ale. In addition to these, there are nitrogenous matters in the barley which undergo modification during the process of malting, and still further modification during the process of brewing, each of such modifications being in turn in the direction of producing readily assimilable 
and easily digestible nitrogenous substances. In effect, the two chief forms of nutriment in beer-namely, the carbohydrates (sugars) and the already digested nitrogenous substances (peptones)-represent two of the most essential constituents of the food requisite for human beings, and it is, perhaps, when taken in a beverage that the nutritive principles in question are most readily absorbed by the system. Of late years the proportion of the carbohydrates used has largely increased, experience showing that when the brewer puts more sugar into his single $\mathrm{X}$, the trade therein goes up at once. It is not the alcohol that people want : it is the sugar, and the larger the amount of the (nutritive) sugar used, the greater the sale.

The reader may be reminded that malt extract is freely prescribed by medical men for children and invalids, and malt extract has, in fact, the same nutritive constituents (less only the alcohol) that are to be found in beer. Teetotal extremists, however, not only seek strenuously to prove that beer has no 'food' or nutritive qualities at all, but they also contend that because it contains a certain low percentage of alcohol, therefore it is a dangerous beverage, and therefore still more stringent laws should be passed in regard to its sale.

Here it may be further remarked that, although numerous experiments have been made as to the effect of alcohol itself on human beings and animals, there is no recorded instance (so far as can be ascertained) of an experiment as to the toxic action on the human system of a solution of (say) 4 per cent. of alcohol in conjunction with nutritive matters, such as we find represented in beer-that is to say, there have been no scientific experiments with actual beer, as distinct from absolute alcohol. This is certainly a weak point 
in the said researches. It is all the more so because such experiments would be far more practical, and bring us into closer touch with the actualities of everyday life, than many of those more elaborate but less convincing investigations of which so much is heard. To state a distinct and concrete proposition, to which any new investigator on these lines might well apply himself: what would be the precise difference between taking at dinner a pint of mild or bitter ale, which would excite and assist the digestive functions, and taking a bottle of lemonade, the free acid in which might be large enough in quantity and of such a character as actually to retard digestion? In regard to the precise amount of alcohol present in a pint of mild ale, containing a proportion of not more than 4 or 5 per cent. of such alcohol, that would represent for any ordinary adult an absolutely negligible quantity.

It is, therefore, certain ( $\mathrm{I}$ ) that there has been a very considerable decline of late years in the alcoholic strength even of English beers; and (2) that those of the prohibitionists who ignore all the changes effected in the science and art of brewing, and talk about the beers of to-day as though they were still identical with those of a quarter of a century or more ago, are placing themselves in a position at once false and illogical.

It may, however, be asked - and it is often asked-why English brewers do not resort more largely than they do to producing for consumption here such still lighter lager beers as those that are so popular on the Continent of Europe.

The main differences between the Continental lager beer and English beer are twofold.

In the first place, the lager beer is mashed on what is known as the decoction system-that is, a portion of the mash is submitted to boiling, and is afterwards 
returned to the mash-tun to be mixed with the remainder of the mash. The effect of this is to render some of the carbohydrates unfermentable, and, at the same time, convert some of the nitrogenous substances into peptones and other highly digestive nitrogenous products.

In the second place, lager beer is fermented by what is called 'bottom yeast,' as opposed to the 'top yeast' system employed here. The fermentation has to be conducted in cellars, the temperature of which is maintained, by artificial means, at or near freezing-point. The beer, when made, has to be stored, or 'lagered' (whence the name), for at least a month prior to sending out. When it is sent out it must be distributed in (about) 4-gallon casks, and carried to its destination in non-conducting covered carts; and, when received by the retail dealers, it must again be kept in their cellars at or near freezing-point, any degree of warmth depriving the beverage of its palatable qualities. To such an extent is the last-mentioned requirement carried, in regard to lager beer in Germany, that there are retailers who only receive from the brewery each morning the quantity of beer they are likely to sell during the day.

It is true that certain brewery firms in our own country have made special efforts to supply lager beer for the home market; but if English brewers generally were to attempt to substitute lager for their ordinary beers, it would mean practically the scrapping of most of, if not all, their existing plant and appliances, and the entire reorganization of their present arrangements, inasmuch as (I) the mild ale of to-day, as sold in public-houses, is generally sent out for consumption within about ten days of being brewed, no lagering or prolonged storage being required; (2) artificial cold is unnecessary; and (3) mild ale is distributed in casks containing 36 or 54 gallons. 
The object of 'lagering' is to bring the lager beer slowly into condition. This process requires the month or so already mentioned, because of the low temperature at which the beer has been fermented; whereas with the high temperature employed by our own brewers the 'conditioning' is rapid, and the beer is ready for use practically as soon as it has been brewed. Tastes may differ; but in England, at least, it would be generally conceded that the quality of ale brewed according to the English system of to-day is far superior to that of the ordinary lager beer, while, unless the latter be drunk when quite cold, there is no comparison between the two. Assuming, however, that this superiority did not exist, and that it might be thought desirable to effect a general substitution of lager beer for English ale, the breweries, to do this, would have to be reconstructed; the methods of consignment would have to be entirely changed; and every public-house cellar would require to be remodelled, if not actually fitted with refrigerating appliances.

All the same, it is a fact beyond dispute that the competition of the lighter German beer with the British beverage did exercise considerable influence in the bringing about of the changes effected in regard to the latter. The lighter beer appealed to public taste, not because it was 'lager' beer, but simply because it was lighter and more easily digested than the old English ale. So there was brought about a keen struggle for supremacy, in which the British brewers showed they were well able to hold their own, for they checked the threatened foreign invasion, and maintained the welfare of a British industry in which many thousands of workers are directly concerned. But in doing this they encountered a Parliamentary opposition of the most active and pertinacious type, concerning which a few words should here be said. 
In dealing with the problem as to the conditions under which lighter beers could best be produced in this country, the British brewers found themselves faced with an initial difficulty. They naturally wished still to use home-grown barley as far as possible; but, owing to the character of our climate, especially as regards the abundance of moisture in our atmosphere, the greater part of British barley develops a larger percentage of nitrogenous elements-difficult to deal with -than does sun-grown foreign barley. Owing to these conditions, the British was much less adapted than the foreign barley for the production of those lighter beers which were now coming into vogue; and, had the brewers depended exclusively on barley itself, they would have had to resort much more to the foreign product and much less to the British. But the researches of scientists had shown that the conversion of starch into sugar in the barley seed, by the soluble ferment that accompanies the sprouting upon the 'floor' which, as an actual process of Nature, occurs in the operation of malting, as in all seed germination, could also be artificially or chemically produced by means of an acid (this acid doing the work of the ferment, but remaining unchanged, and subsequently being entirely removed), the action of which on the starch taken from the grain converts it into sugars of the same group as the sugars obtained by using malt, and, in effect, made from the same source, the main difference being that the operator is a chemist instead of Dame Nature herself. The production in this way of such malt sugars, or malt-dextrins as they are called, was due primarily to O'Sullivan, and a similar product of great fermentative utility was also obtained from cane-sugar.

There are individuals who think that the brewers should use malt and hops only, all the sugar, in that 
case, coming from the malt. Invert sugar, however, obtained in the first instance from the sugar-cane, and representing practically the same sugar as that which is got out of the malt, allows of the production of a lighter and sweeter beer, at once more digestible and more popular; it permits of a larger proportion of British barley being used than would otherwise be possible, and it favours much more exact methods in the process of brewing, thus constituting, in a treble sense, a very great advance indeed in the scientific development of the industry.

But the policy thus adopted has been strongly opposed on the ground that such sugars are 'substitutes' for malt, and that the use of them is prejudicial to the public interests. In fact, Bills have been repeatedly introduced into the House of Commons, since I895, for the purpose of making the use of such brewing sugars unlawful. At first these proposed measures were described as 'Beer Adulteration' Bills, as though the sugars in question represented some noxious adulterant directly injurious to health; but that pretence was dropped in the further Bill of I90I, which, instead of aiming at the maintenance of so-called 'purity,' sought, rather, to divide beer into two classes-- 'malt beer' and 'part malt beer'; while in the Bill of 1902 the use of malt substitutes up to 15 per cent. was practically recognized as essential to the continued employment of large quantities of British barleys, though the use of hop substitutes was prohibited. These latter are, in fact, scarcely ever used.* Nor, even, did the Bill of

* 'The return of 'Brewers' Licenses' shows that during the year ended September 30,1906 , the materials used by over 5,000 brewers in the United Kingdom were as follows :

$$
\begin{array}{llllc}
\text { Malt } \ldots & \ldots & \ldots & \ldots & 52,236, \infty 03 \\
\text { Unmalted corn } & \ldots & \ldots & \ldots & 100,535
\end{array}
$$


I 906 lay down any enactment in the special interests of 'purity,' though styled a 'Pure' Beer Bill.

There is no necessity here to discuss in detail the varying proposals of these different and unsuccessful measures. They one and all owed their origin to agricultural and malting interests, anxious for 'protection,' rather than to any genuine desire to safeguard the welfare of beer-drinkers; but the most significant fact of all, from the present point of view, is that, although any and every possible evidence showing that the use of brewing sugars was injurious to health, or that there had been a serious decline in the quality of the manufactured product, would have been eagerly seized upon by the supporters of the said legislative measures, the suggestion of a lack of 'purity' in English beer as brewed to-day had to be entirely abandoned.

So the British brewers, meeting German competition, and availing themselves of the results of scientific research, produced their lighter qualities of English beer under improved processes without introducing into them substances which were in any way deleterious, though, for the reasons already given, the taking of any further step in the way of a general substitution for 'English' beer of beer on the lager principle was found altogether impracticable. In effect, English beers now coitain, as a rule, so small a percentage of alcohol that they may already count as, practically, temperance beverages. There is only just sufficient alcohol in them

Rice, rice grits, flaked rice, maize grits, flaked maize, and other similar preparations ...

Sugar, including its equivalent of syrups, glucose, and saccharum

Hops

$\begin{array}{lllll}\text { Hop substitutes } \ldots & \ldots & \ldots & 63,952,915 \text { lbs }\end{array}$

I, 257,499 cwt.

$2,84 \mathrm{I}, 976$

24,167 " 
to fulfil the requisite purpose of making them keep, this minimum simply taking the place of the preservatives put into mineral waters. In order to consume, at a single sitting, in the form of light beer, an amount of alcohol equal to that contained in three ordinary drinks of spirits, taken with water or soda water, a man would have to swallow more than his interior arrangements could well accommodate.

The special function performed by alcohol in beer is, perhaps, not sufficiently understood by the Average Person. In effect, the matter can be stated thus : Just as in the human system Nature manufactures sufficient alcohol to preserve from acidity the food taken into the stomach (and to this cause is due the fact that abstainers seem to demand, or are more partial to, sugar and sweets than are people who drink), so in like manner Nature produces her own alcohol in the product called beer to act as a preservative. It is there for a purpose, it fulfils that purpose, and, having done so, it is not necessarily exactly identical with alcohol in some other form which has had no such purpose to accomplish. In any case, the fact remains that if the small percentage of alcohol in the average beer produced to-day were still further diminished, the value of the beer from the point of view of nutritive qualities would have to be reduced as well, because without the presence of a given proportion of alcohol-or, alternatively, of such preservatives as are used in 'temperance drinks'- the 'food ' elements contained in the beer could not be prevented from undergoing deterioration.

That is the position to-day. The resources of science, however, are not exhausted, and if there were really any demand that the working-man's beer should be still further reduced in alcoholic strength, it might certainly be possible to do something more in this direction, 
provided that the brewers had sufficient encouragement offered to them so to do. In my book on 'Licensing and Temperance in Sweden, Norway, and Denmark,' I have shown that when, some years ago, certain of the Danish temperance societies went to the Danish brewers, and asked, in effect, "Could you not brew a type of beer so light in alcoholic strength that it might be consumed by our members without any risk of intoxication, and yet be more palatable than the ordinary so-called, "temperance drinks"? the brewers were able to respond to the suggestion, owing to their previous patient researches into the problems of industrial fermentation. They produced various beers which exactly answered the stated requirements, and were formally accepted and recognized by many of the societies throughout the land. This represented practical encouragement from leaders of the temperance (as distinguished from the 'teetotal') movement, and it suggests a very different, and much more commonsense, policy than that of the extremists in the United Kingdom and in the United States.

But there was another factor of equal importance in the situation thus brought about: the Danish Government levy no duty on beers which contain not more than $2 \frac{1}{2}$ per cent. of absolute alcohol (which is equal to about 6 per cent. of proof spirit by volume). There was thus every inducement given for the brewing and the sale of these exceptionally light beers, the consumption of which both in Denmark and in Sweden (where like conditions prevail) is admitted by certain leading temperance workers to be doing far more good for the cause of sobriety than all the efforts yet made there in the way of restriction or prohibition.

If, therefore, it be thought really desirable and exdedient that the British brewers should follow the 
example of the Danish brewers in reducing to an even lower percentage the present small amount of alcohol in their ordinary beers, British temperance advocates and the British Government should alike be prepared to offer them practical encouragement akin to that which the Danish brewers have received. As regards any possible action by the State, it may be pointed out that, under the existing system, the calculation of the duty on beer is based, not on the amount of alcohol, but on the proportion of solid matter which the beer contains, or, in technical language, on the 'specific gravity.' If, alternatively, the duty were calculated on the alcohol, and especially if, as in Denmark, the duty on beer were remitted altogether when the amount of alcohol did not exceed a stated figure, encouragement would be given for the prosecution of further researches with a view to the production of some form of beer which contained a still less percentage of alcohol than at present, without necessarily involving any decrease in the amount of nutriment.

Such results might especially be secured by a combination of the Continental, or decoction, system of mashing malt and of the English, or infusion, process. It is believed that by some possible combination on these lines, properly worked out, there could be obtained such a preparation of carbohydrates as would permit of the body necessarily being retained in the beer, with an even less amount than the present small quantity of alcohol. In this way the agricultural industry would not suffer, and the drinker, while getting a lower percentage of alcohol, would still find in his pint of beer the same proportion of nutriment as before.

These are among the possibilities of the situation, but inasmuch as any action on the lines here indicated would involve important alterations of plant, etc., it 
could hardly be expected that such a course would be adopted without the practical encouragement of which I have already spoken, coupled with some assurance of freedom from further harassing legislation, so that the new conditions might have a fair chance of showing what results they were capable of producing.

Meanwhile, we have the important fact that the British working-man's beer of to-day is already practically a temperance beverage. That it contains a small percentage of alcohol is perfectly true. But so do all the fermented beverages sold under the name of temperance drinks. The teetotallers who rail against alcohol take it all the same. To this they would reply, 'Yes; but the amount of alcohol contained in the drinks we take would not intoxicate anyone.' In offering that argument they practically abandon the whole position, and reduce the matter from one of principle to one of percentages. It becomes a mere question as to where the line should be drawn between the alleged nonalcoholic and the admittedly alcoholic drinks. In the case of the former the limit has been fixed by the Excise according to their ideas of taxation, rather than because their figure-2 per cent. of proof spirit-is the proportion beyond which alcohol would be physiologically harmful. In regard to the average beer (as distinct from spirits) it is said, in effect, by the makers, 'The proportion of alcohol is certainly somewhat higher than that contained in the duty-free temperance drinks; but it is still so small that, taken in moderation, it could not harm any ordinary person, and therefore it also deserves to rank as a "temperance " drink."

Looked at from this practical standpoint, the whole controversy between the teetotallers and the brewers, at least (without reckoning the distillers), is brought into much narrower limits than those that are generally 
assumed; and there is something altogether inconsistent in the fact that, merely because of a comparatively slight difference in the relative proportions of alcohol, the enormous output of so-called temperance drinks, known as aerated or mineral waters, should be sold duty free and be allowed to contribute nothing to the finances of the country, while another practically temperance drink, known as light beer, should be burdened so heavily. It seems no less unreasonable that so-called ' total abstainers,' who regularly take up to 2 per cent. of proof spirit in their own favourite compounds (even if they do not sometimes, quite unconsciously, much exceed that limit), should still denounce alcohol in every shape or form, and not only condemn, in the most opprobrious terms, the manufacturers, but also seek seriously to interfere with the liberties of the consumers, of a beverage which happens to be somewhat higher in alcoholic strength than their own, though made, with all due deference to them, of materials that are evidently far less dubious and much more nutritive and sustaining. 


\section{LICENSING QUESTIONS OF TO-DAY: REDUCTION, COMPENSATION, AND TIME LIMIT}

THE endeavours which are being made to secure a reduction in the number of licensed houses in the United Kingdom represent an especially important development in the present-day aspects of the general controversy. They proceed from two distinct classes of 'reformers': (I) Those who do not want to abolish the trade altogether, but think there are more publichouses in existence than are really required, and seek to have the number still further reduced (notwithstanding the ample evidence forthcoming that the effect of . such a policy is to increase the number of clubs); and (2) those who are bent on total suppression of the traffic, but, as in the case of local option and other proposals advanced from time to time, regard reduction as a desirable stepping-stone towards the attainment of that ultimate goal. Then, following on reduction, there is the question of compensation, and this, in turn, has been succeeded by the scheme known as 'time limit.' It is to these particular phases of the licensing problem that public attention is more especially being directed at the present moment, and they call for some degree of consideration. 


\section{LICENSING QUESTIONS OF TO-DAY}

Taking, first, the point as to a decrease in the existing number of public-houses being in itself legitimately called for (apart from the ultimate aspirations of the prohibitionists), the combined party favouring reduction is able to present a case which has certainly appealed strongly to public opinion. It is desirable, therefore, to bear in mind the conditions under which the excess spoken of has been brought about.

In the chapter on 'Liquor Legislation in the Past' I have explained how, under the operation of the Beer Act of I830, an altogether excessive number of beerhouses came into existence (see p. 87); and I have further shown that, under the Wine and Beer-house Act of 1869 , the licensing magistrates could not refuse a certificate to the Excise in respect to any beer-houses existing on May I, I869, except on one or other of four specified grounds (see p. 89). These ante-I869 beerhouses, as they are called, represent about one-third of the existing ' on' licences; but prior to the Act of 1904 they constituted a privileged class, with vested interests of their own, and had to be omitted from any scheme that might be advanced for a reduction in the total number of licensed houses in the country. A distinctly anomalous position was thus brought about, and magistrates complained that such reduction as might be effected must be one-sided so long ás they were powerless to deal with the ante-1869 beer-houses.

When, in $189 \mathrm{I}$, the House of Lords gave their decision in the famous case of Sharp v. Wakefield, the hopes of the party in favour of reduction rose high for a time. By this appeal it was held that licensing justices have the power at their absolute discretion to refuse the renewal of a licence merely on the ground that the house is not needed, and apart altogether from any question of the misconduct of the licence-holder. But 
this decision did not, in effect, do much more than formally establish certain points which had already been repeatedly declared in regard to the discretion of magistrates to refuse renewals in individual cases on the ground of non-necessity and remoteness from police supervision. The Lord Chancellor, in his judgment, expressly stated:

An extensive power is confided to the justices in their capacity as justices to be expressed judicially, and discretion means, when it is said that something is to be done within the discretion of the authorities, that that something is to be done according to the rules of reason and justice, not to private opinion; according to law, and not humour. It is to be not arbitrary, vague, and fanciful, but legal and regular; and it must be exercised within the limit to which an honest man competent to the discharge of his office ought to confine himself. ... The Legislature has given credit to the magistrates for exercising a judicial discretion that they will fairly decide the questions submitted to them, and not by evasion attempt to repeal the law which permits public-houses to exist, or evade it by avoiding a plain exposition of the reasons on which they act.

\section{Lord Bramwell supported this view, saying :}

The Legislature has most clearly shown that it supposedcontemplated - that licences would usually be renewed; that the taking away of a man's livelihood would not be practised cruelly or wantonly. True ; and because it showed that plainly, it may have felt it safe to leave an absolute discretion with the justices, a discretion that would be discreetly exercised.

These utterances would seem to suggest that there was no idea on the part of the House of Lords that, following on the decision thus given, the magistrates of the country, influenced by their private opinion, would be able to effect sweeping reductions in the number of licensed houses. For some years, indeed, no such attempts were made, notwithstanding a sense of uneasiness (in which Lord Bramwell himself shared) as to the unfair way in which the decision might operate.

Then came the Licensing Act of I902. The general 


\section{LICENSING QUESTIONS OF TO-DAY}

subject had been brought prominently before the public by Sir William Harcourt through his two Veto Bills. As Mr. Caine expressed it (October 23, I894): 'The Government have taken it out of our hands. It is no longer Sir Wilfrid Lawson's job.' Veto as a remedy was rejected by the country at a general election, and the new Government-as new Governments do-seeking time to look round, appointed a Royal Commission, which sat for the greater part of the three years 1896 to 1899 , and eventually presented, not only a report, but also a minority report, the two indicating important differences in the views of the Commissioners. In this way there was brought about a considerable revival of public interest in the Licensing Law in general, and the eventual outcome was the Act of I902, followed by increased and still more vigorous demands from the 'temperance ' party for public-house reduction.

These demands bore fruit in the licensing sessions of 1903, when 639 licences were refused throughout England and Wales, as compared with an average of I 89 for five previous years for which returns are available. It is true that the net loss was reduced to 480 by successful appeals, but the fact of these appeals being successful suggested that in many instances, at least, the magistrates had not exercised their discretion judicially. The appellants, again, though successful, had still been put to considerable expenditure in the way of costs. Then, the threats made by magistrates in different parts of the country that, unless certain conditions they imposed in a large number of cases were complied with, they would refuse renewals led to the surrender of about 350 more licences; while, inspired by the examples thus set, some 400 benches of justices intimated that they should take up the question of the reduction of licences in I904. 
In giving a decision on a licensing case that came before him, Lord Selborne once said :

Where you are exercising a discretion which the magistracy has had conferred upon it, you must in each case exercise the discretion, and not for any purpose, however praiseworthy, attempt to act the part of legislator, instead of doing that which the Legislature requires you to do-act as judges to determine each particular case.

It is certain, however, that the magistrates did not keep within these limits in regard to their action in I903, but really assumed, for the time being, the rôle of legislators in seeking to act on lines of general policy in accordance with what, in their private judgment, was for the well-being of the country. What the more active of these benches of magistrates seemed to be aiming at was not so much the enforcement of laws already in existence as the carrying out of a policy of prohibition which the Legislature had not yet sanctioned. In the result they inflicted most serious financial loss on a comparatively large number of owners, who themselves had done no wrong, but were merely regarded as unnecessary; while no opportunity was afforded them of claiming compensation, although the sacrifices forced upon them were avowedly ' in the public interest.' 'Compensation' had long been in the air, but although many of the magistrates expressed their regret that compensation was not available (those in nearly 300 licensing divisions even addressed to the Home Secretary a memorial in favour of compensation*), the policy of widespread suppression was carried out all the same.

* This memorial said, among other things : 'The justices have no power to award compensation, and their action is hindered by the invidious duty of selection when it comes to deciding which of a number of licensees, who have committed no fault, shall be deprived of their business, in whicl savings may have been invested. 


\section{LICENSING QUESTIONS OF TO-DAY}

An influential deputation from the trade waited on Mr. Balfour, who was then Prime Minister, to set forth the nature of the grievance under which they suffered, and Mr. Balfour said the Government recognized to the full that all those interested in the liquor trade of the country were being subjected to a very serious and, as he thought, unjust strain. He continued:

I confess I regret the course which the magistrates have pursued, but there are other reasons, and the main reason is the one which every speaker this afternoon lias urged upon me-namely, the insecurity which has been wrought in every branch of the trade, and, as a consequence accompanying that insecurity, the gross injustice which has been done to a large number of individuals. I gather that that which was a legitimate investment is regarded as an investment no longer, or scarcely worth regarding as an investment. I understand that property which was insurable is insurable no longer, and that one immediate result of what has occurred is that, not only does every licence-holder feel that he holds his licence without any fixed or adequate security, but that he cannot even go, like other persons engaged in a hazardous business, to an insurance office, and, by calculating the risks, make provision against loss which may, in a moment, in the twinkling of an eye, reduce a man from a competence to penury. Another result, I gather, is that property which is taxable, and has been taxed, is now treated as if it were not property at all, and, the State having extracted its full quota from a goodwill in which citizens have honestly invested, it now seems that that which everybody taxes as being property has lost all permanent or fixed value. I think either the Inland Revenue endeavoured to extract for public purposes from licence-holders money which they had no right to extract, or else those licence-holders should possess that general security which the law desires to give to all who hold honestly acquired property. It is undeniable, I think, quite apart from all questions of temperance, that the state of things which, if it has not arisen, seems in process of arising-I won't put it more strongly than that-is one which is of the most serious character, and which does not lose any part of its seriousness when I reflect that the magistrates who are effecting these sudden resolutions are

and which provides their means of livelihood. In addition, the statutory position of the privileged beer-houses prevents the justices from refusing the renewals of these licences merely on the ground of redundancy. The licensing authority is therefore precluded from dealing with houses which in some cases are the least desirable. 
themselves the very magistrates, or the successors in office of the very magistrates, who brought about the state of things which is now being rapidly, if not arbitrarily, altered. I cannot believe that any man, whatever his opinions may be, could convince himself that absence of any continuity of policy in a body with a continuity of evidence like our benches of magistrates can be other than a public misfortune. . . . I think that this change of policy has an even further-reaching effect on the interests of temperance itself. For observe that it is out of the power of these magistrates, whatever their views may be, to touch one class of licence-holders whom the temperance reformer, left to himself, would be disposed to deal with in the least merciful fashion-1 mean, of course, the beerhouses which came into existence before 1869 . Those gentlemen who are desirous, apparently, of revolutionizing the whole distribution of licences throughout the country are prevented by law from touching the very licence which probably, most of all, would require to come within the purview of any fair and comprehensive measure dealing with this subject. It cannot be good for temperance. But there is a much more far-reaching effect which, I think, is likely to be produced by what is occurring. I put aside the view of those who think it either desirable, or, if desirable, practicable, to prevent the people of this country indulging moderately in alcoholic liquors. I regard that as an absolutely impossible state of things. I do not know that I should desire it if it could be carried out, and I am perfectly sure it could not be carried out. There is no Northern community in the world which has ever consented to abstain wholly from a moderate indulgence in alcoholic liquor, and I doubt if it is possible for us to hope that anything beyond a moderate rate of consumption can ever be established in this country; but, putting those aside who regard that as a very meagre settlement of the idea at which we ought to aim, and confining myself to more moderate temperance reformers, among whom I should desire to class myself, surely it must stand to reason that if you make property in licences absolutely insecure no man of position or substance will engage in the trade. And, surely, if that be true, the next consequence is quite irrefutablenamely, that a trade which must exist will fall into the hands of men who have nothing to lose by misconduct, who run the thing in a manner which may possibly suit their own interests, but which must be inimical to the public interest ; and, by driving out all men of position and responsibility from the holding of licences, you will inflict not merely a great hardship upon the classes who desire to make use of respectable and well-conducted houses, but you will infict the greatest injury upon the cause of temperance itself. I therefore look with the utmost alarm to anything which would absolutely drive out all the good men, and leave the work which has to be done, and will be done by somebody, legislate how you will, to men who have neither character, nor money, nor osition to lose. ... 
I hope you will content yourself with the statement that what has occurred appears to us to be in many cases, however well intended, but little short in its practical effect of unjust confiscation of property, and that to that unjust confiscation of property it is impossible that either Parliament or His Majesty's Government can remain indifferent.

Following these events came the Act of I904. It set up machinery under which 'on' licences-including those of the ante-r 869 beer-houses-could be suppressed when considered redundant, but established the principle that the holders of licences abolished on the grounds that they were not necessary should be compensated out of a fund to be formed by the members of the trade itself. The levies for this fund amounted in

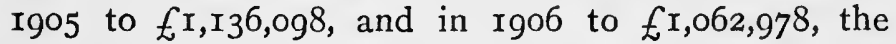
decrease in 1906 being mainly due to the fact that the County of London imposed three-quarters of the maximum rate instead of the maximum, as in 1905. In the case of very many of the large brewery companies the contributions thus paid were equivalent to 2 per cent. on the ordinary shares. Even then the compensation granted did not-and never can-cover the actual loss sustained, all the expenses of both sides having to be met out of the fund, while those paying the levies did not necessarily benefit, inasmuch as, in addition to the payments they had to make, their own houses might be so far away from those abolished that they could not hope to secure any increase of trade for themselves in consequence of the reduction in number. The Act clearly recognized the right of existing licences to a reasonable security of tenure by providing that they should not be suppressed (except for misconduct or other such reasons) without compensation; but such compensation had to be raised by the trade itself, while the inclusion of the ante-I 869 beerhouses within the Act naturally constituted a serious 
set-off to any suggestion of 'advantage,' in the way of an approach to a fixity of tenure, otherwise conferred on the trade. The allegation made by certain critics that the Act of 1904 was 'a brewers' endowment Act' is, therefore, certainly not warranted by the real facts of the case. It is noteworthy, too, that when the Bill was under discussion in the House of Commons speaker after speaker rose and declared, in effect, 'If you pass this Bill you will establish such a legal right for licensed houses that you will render impossible for a generation various reforms we are anxious to see brought about.' Now that the Bill has become law the same party which raised these protests is inclined to ignore the said legal right, and is seeking to bring about the very innovations it had said would be impossible for a generation.

The Act has already, led to a considerable reduction in the number of licensed houses. Even in 1905, when the measure was not yet in full working order, the total number of ' on' licences suppressed, with compensation, was 5 I9; and it is an especially significant fact that this number included no fewer than 315 ante-I 869 beerhouses. The corresponding refusals in 1906 amounted to I,575. These figures, too, are independent of licences surrendered from various causes, including demolitions in the carrying out of public improvements; nor is account taken in them of the considerable reduction in the number of new licences granted. Adding these further items, the net reductions were: in I905, 772 ; in I906, I,839; net total for two years, 2,6II. The average for I894-Igo4 was 359, and for I903-I904, 644 per annum. Between I894 and I905 'on' licences in England and Wales decreased by 4,157 , although in the same period there was an increase of over $4,000,000$ in the population. Bearing all these facts in mind, it might fairly have been assumed that in the course of a 
few more years the number of houses would have been brought well within the actual requirements of the country, and that the Act of 1904 should, therefore, have had a fair chance of proving what it could accomplish.

The small amount of consideration shown to the licence-holders and the substantial increase in the number of suppressed licences have, however, alike failed to satisfy certain sections of the 'reformers,' whose hostility to the trade is, apparently, too great to permit them to exercise the virtues either of justice or of patience.

One fundamental proposition advanced by the party in question is that the members of the trade have no claim to compensation when their licences are suppressed, inasmuch as (they argue) there has never been any legal right to the renewal of an annual licence, or any claim to a fixity of tenure-nothing but an 'expectation' which was not a certainty, the justices always having power to refuse renewal.

This contention ignores, in the first place, those antiI869 beer-houses which, representing one-third of the total number of places holding 'on' licences, had a clearly defined legal right to renewal down to I904, except in certain contingencies. It further ignores various all-important considerations in regard to other houses. While it is true that the licences are granted for one year only, there has hitherto been an 'expectation' which, in practice, amounted to a certainty, that they would be renewed except for misconduct on the part of the holder. This may not have been actual statutory law, but it represents an instance where a custom, in vogue since the fifteenth century, was practically tantamount to law. Following on such custom men have no more hesitated to invest their capital in public-houses, with every confidence in renewal, than 
they would have hesitated to spend money on a costly gun, because the licence granted in respect of it was only an annual one.

The State has recognized continuity in the concession of a public-house licence in the basis on which death duties have been levied, a memorandum issued by the Inland Revenue on May I4, I89o, stating that it is assumed, in the assessment of such duties, 'that the licence will continue to be renewed,' as 'without a licence there would be no goodwill '; and it is this goodwill that is chargeable to duty, many thousands of pounds having, under these conditions, been paid thereon. The Courts of Justice have recognized the continuity by preventing a tenant for life from suppressing licences on a settled estate to the injury of his immediate successor or of a remote remainder man, and also by awarding heavy damages for the loss of a licence against a tenant holding under an agreement not to endanger the licence. Magistrates have recognized the same principle by sanctioning, or even calling upon publicans to make, extensive and costly structural alterations, on a scale which would have been absolutely unjust or reckless, if not ruinous, if there had been no more than a problematical expectation of renewal after a single year. Local authorities have recognized the principle in their assessments of public-house property, and in giving compensation at full market value when taking over such property for public improvements, allowance being made even for a freeholder's reversion at the end of a long period. The Stock Exchange has recognized it by encouraging the formation of companies whose operations were largely based on this principle. Trustees and others have recognized it by investing in publichouse property, in the aggregate, vast sums of money, which a single year's trading could not possibly repay; 
by attributing to such property a distinct market value, because of the expectation of licence-renewal; and by cherishing the assurance that the Legislature would not seek to evade its moral and equitable obligations to licence-holders by a resort to what, in effect, is little more than a legal quibble.

It was left for the teetotal party to start the legalright-for-one-year-only and the no-claim-to-compensation theories; but of these the Act of $\mathrm{IgO}_{4}$ has now effectively disposed, and the effect of this Act must be borne in mind in the framing of all fresh legislation.

While, however, the principle of compensation has thus been definitely recognized, the Temperance Legislation League has put forward a scheme for 'the enactment of a time limit to the operation of the compensation clauses of the Act of 1904, with a provision that thereafter all licences shall be regarded as new licences, and be granted only on payment of the full monopoly value '- that is to say, the difference between the value of the premises when licensed and their value without a licence. It is further proposed to give to localities a power of local option which would $(a)$ authorize the local licensing authorities to shorten hours of sale and require entire closing on Sundays and other special days; $(b)$ enable a substantial majority to prevent the issue of licences to ordinary public-houses, as distinct from special hotel, restaurant, and 'off' licences; and (c) "give power to place all the licences, or all the "on" licences, in a locality under disinterested (not municipal) management, in order that the traffic there might be conducted without the stimulus of private profit, and under statutory regulations which would prevent direct or appreciable pecuniary gain resulting therefrom to the locality itself:'

Looking first at what might be called the working de- 
tails of this time-limit scheme, one finds that during the full period fixed upon (and the suggestions on this point have ranged from five years to thirty) those publichouses that were allowed to remain in operation would have to pay levies as compensation for the extinction of such licences as the magistrates year by year thought fit to suppress. At the end of the term the whole of those which still remained would be deprived of their licences without a penny of compensation, notwithstanding the substantial sums they had been paying to their neighbours, on the same account, during the whole of the period in question. As a matter of detail, too, the least desirable among the licensed houses would naturally have been selected first for extinction during the time limit, and compensation either in full or in part would have been paid in respect to the whole of them. Those that remained at the end of the time limit would belong to the better, if not the best, class of public-houses, and would, in effect, represent the survival of the fittest. Yet, just because they had remained beyond the time limit period, their licences would be suppressed without any compensation whatever. How could such a procedure as this possibly be reconciled with any ordinary conceptions of justice and fair play?

Another serious problem that would arise is in connection with the up-keep of the houses. If the interest of a publican in his licensed house be limited to fifteen, twenty, or any other number of years, he will be disposed to spend on it only just such amount as will be necessary to keep the place going until the end of his term. In the last year or two he will probably spend nothing at all if he can possibly avoid it, and it would certainly not be just on the part of the magistrates to make him go on laying out money on premises he may 


\section{LICENSING QUESTIONS OF TO-DAY}

soon have to quit, especially as the earnings he makes will already fail, in all probability, to form an adequate sinking fund for his loss of capital.

Public-house property would thus be left to deteriorate, and public-house keepers would probably do the same. They would be something more than human if they did not lose heart in a doomed and discredited business. They would naturally try to make all they could out of the concern in the few years still left to them. If one licensee died, or retired before the end of the time limit, much difficulty would probably be found in securing a really desirable man to take his place. So in all these circumstances the condition of British public-houses by the end of the allotted period would probably be worse than ever before in their history, in which fact, were it realized, the prohibitionists would doubtless find fresh arguments for suppressing them altogether.

If at the end of the time limit brewery companies or individual licensees wished still to carry on what they had hitherto regarded as their own business, they would have to follow up the loss they had already sustained in regard to their original capital by getting the licences again (if they could) as new licences, ' on payment of the full monopoly value.' They may already have paid this said value to some one else when they first acquired the premises. They may have greatly increased such value by a generous expenditure on the property, and by the increased reputation which their name, the character of their commodities, and their prudent management, have given to the place. But these things are to count only in assessing the price they must pay over again if they desire still to carry on the business. In the first place, if they are deprived of the monopoly value, 'it is,' as Lord Salisbury declared in the House of 
Lords on August 4, I904, 'absolute pillage; it is robbing them of what they have paid for'; while, in the second place, the higher figure at which such value will be assessed, because of their own expenditure on the property since their original purchase thereof, will be the exact equivalent in the licensing world of what is universally recognized as a great injustice in the agricultural world-the taxing, namely, of a tenant on his own improvements.

The lease of the property would, of course, not be determined by the discontinuance of the licence, and this would be one advantage in favour of the old licensee-when the licence was put up for sale to the highest bidder-over a competitor who had to build a house in which to carry on business under the licence he secured. But the value of the property without a licence would be most seriously depreciated for the existing lessees, and though they might dispose of the place to the new licensee, they would probably get from him no more than a no-licence value. In that case he would enter on the business without paying anything for goodwill to his predecessors, so that he would directly benefit from what they had done in the way of helping to build the business up, and he and the State would thus share the plunder between them.

The more favoured plan, however, among the reformers, and the one specially recommended by the Temperance Legislation League, is that, on the expiration of the "time limit, all the licences or at least all the 'on' licences, in a locality should be placed 'under disinterested (not municipal) management.' This question of disinterested management I have already discussed at some length, and I will here say no more than that if, at the end of the time limit, there should be any attempt to bring the public-houses of Great 


\section{$25^{8}$ LICENSING QUESTIONS OF TO-DAY}

Britain generally under the operation of so thoroughly impracticable a scheme (from the point of view of our national conditions), supervised by groups of philanthropists possessed of no practical experience in the management of so peculiarly complicated, responsible, and worrying a business, the inevitable effect would be to make confusion still worse confounded.

Then there arises this further consideration: Whoever took over the licences from the present holders at the end of the time limit, whether they were individuals or disinterested management companies, would, as we have seen, have to pay for them 'the full monopoly value,' which in many, if not most, cases would represent a considerable sum of money. Presumably the said value would be paid for, not by a sum down, but through the licence, or in the form of a rack-rent. The State, or the taxpayers representing the State, would gain substantially, while a heavier burden would be thrown on those engaging in the reorganized trade, since they would have to provide for this (further) payment of full monopoly value, in addition, it may be, to spending a considerable amount either on properties which the outgoing licensees might towards the end have allowed to deteriorate, or on new premises to take their place. But what guarantee would either individual traders or disinterested management com. panies have that they would secure fixity of tenure for at least a period sufficiently long to allow of their recouping themselves for their outlay, as well as of their getting a reasonable return thereon ?

If there were any question of risks of this sort, it is hardly likely that any discreet individuals or companies would care to enter on so uncertain a business. Alternatively, if, under the fresh conditions, the licences were granted for a fixed term of years-so that the 
holders might have a reasonable prospect of getting their money back-the result would be the creation of vested interests of a type which it is the special desire of the teetotal party to avoid. The fixed term of years, again, would bring in fresh difficulties in regard to both the control of the houses (since the licensee would be in a more independent position than is the case now), and the suppression of the licence in case of misconduct.

In effect, the licensing problem, instead of being solved, would come up afresh at the end of the time limit in a more acute form than ever.

The very essence of that problem lies in the fact that no licensee, sinking in a public-house business a substantial amount of capital, can hope to get it all back, and make a living wage as well, within the one year for which alone, as the teetotal party insist, the licence is granted.

On the other hand, it is the very essence of the Temperance Legislation League proposal that the new licensee shall pay the 'full monopoly value,' so that the total capital invested in the business would be larger than ever, and the difficulty of recoupment would also be greater than ever.

Here one must further remember that, whether the new licences at the end of the time limit were reissued annually or for a stated term of years, it would be an essential factor in the new situation that the licensee must get out of the business the whole of the sum he is to pay in respect to full monopoly value, plus licence, duty and taxes, outlay on premises, wages and other expenses, and profit for himself. He would start handicapped by the dead weight of abnormally heavy payments, and it would consequently be to his direct personal and pecuniary interest to 'push the sales' as much as he could, and extract from the pockets of his customers 
sufficient to cover, not only the ordinary expenses of the business, as at present, but the extraordinary expenses as well. In conditions such as these there does not seem to be much scope for 'temperance,' or even for a really 'disinterested management.' How, indeed, can it possibly be represented that they would be a sufficient improvement on the conditions already existing to justify an attempted reconstruction of the whole licensing system?

Time limit, as proposed by the Temperance Legislation League, really means confiscation. The avowed object of the scheme is to reject, at the end of a specified period, all claim to renewal of licences, and all question of compensation; to deprive licences of the attribute of property from any point of view, and to open up the field for any fresh experiment that parties of philanthropists or others may think fit to suggest. In the circumstances, the first essential for those now engaged in the business is that they should arrange a sinking fund in order to make their financial position secure.

It is all very well to say that the trade made a bad investment in the past in paying so much for monopoly values which properly belonged to the State. It might more reasonably be argued that the State itself made a mistake in parting with such values, though, on the other hand, the State has had an extremely substantial return through the heavy taxation it has imposed on the trade. It does not necessarily follow that, because the State may be dissatisfied with this extremely substantial return, and want to raise still more money out of the trade, it would therefore be justified in going back on its own bargain, and repairing the fault it committed generations ago by now taking these monopoly values out of the hands of the present 
holders. Granted that successive Governments have acted unwisely in giving to some individual a present of a licence having a marketable value of $£$ ro,00o or $£ 20,000$ without themselves retaining the monopoly value of the concession, the factors in the situation become altogether different when the original holder, or his successor, has sold out to (say) a buyer who has paid him the $£$ ro,000 or $£ 20,000$ in question, and enabled him to go into comfortable retirement. It would be a procedure both illogical and unjust for the State now to say to such buyer: "We made a mistake in letting A. B. have that licence for nothing, when it was really worth $£$ ro,ooo. It is true that you have paid A. B. £Io,00o for it, but the State has not had the money. Therefore you must agree to pay the State as well $£$ ro,ooo for full monopoly value before you can be allowed to continue the business you have taken over.'

It is said, again, that the buyers of public-honse property themselves made a mistake in giving as much as they have done for the rights they secured; and it is added (with an entire disregard of the argument advanced on behalf of the State) that therefore they must bear the consequences. One should remember, however, that the buyers acted on the traditions of centuries, and that those of them that are companies operated in raising capital through the Stock Exchange, whose members, and also the investing public in general, believed no less implicitly than themselves in the integrity of the principle of recognized continuity.

Whatever the view taken on all these matters, the practical fact remains that very large sums of money have been invested in public-house property by traders or shareholders, and that, as an ordinary business principle, provision would have to be made against 
the loss of this capital at the end of the time limit. It is suggested that the companies should make use of their increased profits during the time limit period in order to write down steadily the value of the business in their books. But these increased profits are distinctly problematical. They might, and probably would, be fully counterbalanced by the compensation payments to be made; and here one must remember it is proposed that, during the period of the time limit, the compensation charges shall be made national and compulsory, and increased indefinitely, so as 'to render it possible to get rid of as many licences as it is deemed desirable to refuse to renew.' Nor do the proposals of the Temperance Legislation League, in respect to shorter hours and total closing on Sunday, strengthen the idea of increased profits. One can hardly assume, either, that the League would approve a policy of 'pushing the sales' during the time limit period, so that the said greater profits could be assured. Apart from the fact that preference and debenture holders would lose a large proportion of their capital, it is certain that the ordinary profits would not be in any way sufficient to provide for a sinking fund on a really adequate basis.

To illustrate this fact I have obtained, as an example, some facts as to the position of a long-established brewery company which trades in beer only, eight-tenths of its output going to tied houses purchased by the company. The average net profit available for dividends on the ordinary shares is $£ I 2,600$. If the whole of this profit were put annually to a sinking fund for twenty-one years at 3 per cent., it would produce $£ 360,000$. The sums to be provided for out of such fund would be as follows : 
(a) Mortgage debentures, mortgagees, etc. ... $\quad \underset{354,000}{£}$

(b) I. Preference shares ... $\quad \ldots \quad \ldots$ I74,000

2. Ordinary shares (present value) $\quad \ldots \quad 200,000$

(c) Pension fund (for 200 employés) _..

Total $\ldots £ 738$, ooo

But, inasmuch as the sinking fund would produce only $£ 360,000$, there would be a deficit of $£ 378$,000 in meeting all these items. It is clear that the property of the brewery, minus licences and the ability to continue as a going concern, would not satisfy $(a)$. Even if it did, the sinking fund would not satisfy the two items of (b) plus (c); and the pension fund, on which the employés depend for their provision for old age and the reward of thrift, would vanish. Meanwhile the ordinary shareholders would have had no dividends for twenty-one years; all the expert officials and skilled workers would probably have sought some other form of employment, and the debenture shareholders would be left with merely the wreck of the original business.

The net result of time limit would inevitably be to render practically valueless Stock Exchange securities based on licence values estimated by Mr. E. N. Buxton, chairman of Truman, Hanbury, Buxton and Co., Ltd., at $£$ I50,000,000. This huge capital would be absorbed by the State, in the interests of the general taxpayer, and investors-including many trustees who had put money in such securities in the hope of securing from $3 \frac{1}{2}$ to $4 \frac{1}{2}$ per cent. thereon-would find themselves stranded. Well may Mr. Buxton protest, as he does in the National Review for February, 1907, that 'to confiscate these (licence) values, not on the plea of the public advantage of a reduction of licences, which is now fully provided for, but in order that the State may 


\section{LICENSING QUESTIONS OF TO-DAY}

obtain a purchase price for them from other holders, is to advocate public plunder.'

If the position thus brought about were hard for the ordinary brewery shareholder, it would be harder still for the long leaseholder. Take the case of a licensed victualler who has invested the whole of his moneyas many licensed victuallers have-in licensed property, with (say) fifty years of the lease still to run. He will have paid a substantial premium on going into the business; he may have spent a considerable amounteither by desire of the licensing magistrates or otherwise-on rebuilding, altering, or improving premises he expects to remain licensed for the full period of his lease; and he is bound to pay, during such period a rent calculated on the value of the premises as a licensed house, whereas their actual value withou a licence will be only that of an ordinary shop or other place of business. So, through absolutely no fault of his own, but under the operation of the time limit, he loses the licence at the end of twenty-one years, or some other such period; and from that time (I) the money he has paid as a premium is lost; (2) the amount spent on rebuilding or alterations to make the premises more suitable for a public-house will have spoilt the place for any other business; while (3) under the terms of his lease he must still go on paying the enhanced rental for a privilege he no longer enjoys. No sinking fund he could possibly create out of his profits would cover all these contingencies, and no compensation likely to be paid to him, should his licence be suppressed during the operation of the time limit, would save him from heavy loss. As for any freeholder who expects the reversion of licensed property on the expiration of the period for which he has granted a lease, there seems to be no chance of com- 
pensation for him for the eventual sacrifice of his own interest.

Bearing all these things in mind, the word ' confiscation' does not seem to be in any way too harsh a term to use. The whole scheme, if carried out with the authority of the law, would be one of legalized plunder; and the day it was adopted would, in the city of London at least, be gloomier than any Black Friday yet recorded. That the interests concerned in the licensing trade go far beyond brewery companies, distillers, shareholders, and publicans, I purpose to show in the following chapter; but certain it is, in face of the facts already presented, that any approach to serious interference with the trade would inevitably lead to widespread disaster.

Beyond all this, however, the carrying out of such a scheme of confiscation would have further grave results in a loss of confidence in British institutions, and especially in British investments. For 400 years the State has allowed private individuals to receive the monopoly value of public-houses, and many millions of pounds have been advanced to brewery companies by British investors, small and large, in a reasonably cherished faith in the continuance of such custom, the security for those millions being public-house licences. Now, at the bidding of a particular section of the teetotal party, which claims only to represent about Io per cent. of the entire community, and is constituted largely of the type of people known as 'faddists,' the whole position is to be changed : a considerable number of individuals are to be ruined; property regarded as having a distinct market value is to be taken from the hands of one set of traders and put into the hands of another; and the community at large is to approve of the procedure because the millions that are 'recovered,' 
as the result of the plunder, will make such an addition to the State treasury that the taxpayers of the country may expect to benefit therefrom ; though, in truth, if the proposals are seriously made in the cause of temperance, a great decrease in the number of houses and in the consumption of alcoholic liquor must be expected, with a corresponding loss of revenue.

Such, in effect, is the scheme put forward in the joint names of 'temperance' and 'disinterested management.'

Once established, the fundamental principle of this plan of plunder might be carried much further. Why should not a 'Back-to-the-Land ' party, at some future date, induce a weak-minded Government, keen on votes, to give notice of a 'time limit' to landowners, and tell them that, after a certain term of years, during which they could devote the rents to the formation of a sinking fund, their land would be taken from them, and, in the public interests, offered by the State to the highest bidder? What, again, would the Bishops who are supporting the Temperance Legislation League say to a 'time limit' to Church property, as a possible solution of the Disestablishment problem?

If the principle in question can rightly be applied to licensed property sanctioned by the State for four centuries, it can quite as justly be applied to other forms of property as well. In the same way, if, in the words of the Temperance Legislation League, a 'substantial majority' of the people are to have the right to vote for the closing of public-houses which they individually may not want, but which nevertheless fulfil a lawful and reasonable purpose, based on fundamental requirements of our nature, why should not a substantial majority of (say) Dissenters have a right to vote for the suppression of the Church of England, 


\section{BROADER ISSUES}

with whose tenets they may not agree? On the other hand, what would have been the position of Nonconformity itself in its earlier days if a 'substantial majority' had been allowed completely to override the rights of a minority?

It must, in all charity, be supposed that the Bishops and other influential people who have put their names to the scheme of the Temperance Legislation League cannot possibly have appreciated all that it really implies. 


\section{CHAPTER XIX}

\section{THE ECONOMICS OF LICENSING}

IN considering the various schemes and proposals which have been advanced from time to time, having for their object either the immediate suppression of the traffic in intoxicants or the taking of various steps preliminary thereto, it is desirable that the British public should realize somewhat the nature and extent of the trade it is thus proposed to crush out of existence, and the effect such a proceeding might have on the economic conditions of the country.

The actual amount of capital invested in the liquor industries cannot be definitely stated. It is a matter of calculation only. According to the 'Brewers' Almanack' for 1907 , the probable total is $£ 240,000,000$, made up as follows :

Capital value of breweries and distilleries and their licensed property in the United

Kingdom $\ldots$
Capital value of all licensed houses not $\ldots .$. cluded in the above, say $\ldots$. $\ldots$

$£$

$215,000,000$

I $5,000,000$ and all other trades in connection with alcoholic liquors, say

$$
\text { ‥ } \frac{10,000,000}{£ 240,000,000}
$$

Assuming, for the sake of argument, that this calculation is approximately correct, one may at the outset 268 
conclude that any suppression of, or even any serious interference with, a trade of this magnitude, could not fail to have a considerable effect on the money market and on the interests of investors, though many teetotal advocates seem to cherish the impression that the financial disturbance which would inevitably follow on the full achievement of their proposals represents quite a secondary consideration, not worth setting against the 'moral ' results they hope to achieve.

Then, according to these same critics, the profits made by the trade as the result of this large investment of capital are 'enormous,' and this alleged fact is held up against the traders, both as a reproach and as a reason for at least imposing still further burdens upon them. It is easy enough to see how the impression has originated. There are certain specially successful brewery companies which pay exceptionally large dividends (just as there are similarly successful individual enterprises in the chemical and other industries), and because of this, it is assumed that brewery companies in general are accumulating much wealth at the cost of their patrons. The real position is incidentally shown in an article published in The Statist of January 19, 1907, where details are given concerning a list of seventy-eight brewery companies, restricted to (a) those companies that publish accounts; (b) those whose share and loan capital is quoted on the London Stock Exchange; and (c) those only whose combined share and loan capital is not less than $£ 270,000$. In the seventy-eight companies noticed there is a total capital of $£ 90,508,237$ (made up of $£ 41,104,342$ debentures; $£ 25,860,780$ preference; and $£ 23,543$, Ir 5 ordinary); and the writer says: "On this total of $£ 90,508,237$ the net profits earned have amounted to $£ 5,35^{6} 6$,or 4 , or a return of about $5^{\circ} 9$ per cent., which 
cannot by any means be deemed excessive.' While some of the companies on the list show ordinary dividends of I2, I4, I7, 22, and even $22 \frac{1}{2}$ per cent., there are eight whose dividend is mil, nine that pay I, $2,2 \frac{1}{2}$, or 3 per cent., and thirteen that pay between 3 and 5 per cent. It is a question, therefore, of taking an average, as The Statist does, and not of basing an estimate of general conditions on the exceptional successes of a select few.

These considerations detract substantially from the arguments advanced from various quarters that, because the trade is so wealthy, therefore it can stand the imposition of still further financial burdens. The magnitude of those already borne is certainly beyond all dispute. The taxation derived from the trade in Igo6 amounted to $\{29,697,952$ under the head of Excise, and $£ 4,900,146$ under that of Customs, a total of $£ 34,598,098$, which represented nearly a quarter of the total Exchequer receipts. Adding to these amounts a further $£ 3,447,843$ raised from the trade for licences, and on the extra beer and spirit duties in relief of local taxation, we increase the total contribution by the trade to $£ 38,000,000$.

Once again, therefore, one must consider what would happen when, after the prohibitionists had totally suppressed a trade witl a capital of $£ 240,000,000$ (or thereabouts), they left the general taxpayers of the country to contribute an additional $£ 38$,000, 000 a year in the way of an expanded income-tax or otherwise. Prohibitionist advocates make light of this matter of detail when they trouble to deal with it at all, but the question is one that would certainly fall at once within the purview of those laying claim to practical statesmanship. It may or may not be a moral wrong that Governments should depend to so large an extent for their financial resources 
on the amount they can raise from the trade. What we have to deal with, however, is not academical theories of right or wrong, but the logic of accomplished facts; and the essential point of the situation is that if the $£ 38,000,000$ is no longer secured from the trade in alcoholic liquors, it will have to be raised in some other way.

The amount of the total contribution by the trade to the National Exchequer is the more deserving of being borne in mind because of the contention that in the United Kingdom less is paid for public-house licences than in the United States, and that the charges here should therefore be raised. The fact is, however, that in the United Kingdom it is the manufactured article rather than the permit for selling it that is looked to as a means of raising public revenue, and it might reasonably be suggested that a trade which, as we see, adds $£ 38,000,000$ a year to the finances of the country, and pays an average dividend (taking the basis of The Statist figures) of not more than $5^{\circ} 9$ per cent., already contributes its fair share. It is more than open to question whether the limit of taxation as enforced against the licensed trade has not already been reached. The total derived from the trade has been showing a significant decline of late years, as the following figures indicate :

\begin{tabular}{|c|c|c|c|c|c|}
\hline \multicolumn{2}{|c|}{ Year. } & Total. & \multicolumn{2}{|c|}{ Year. } & Total. \\
\hline 1901 & $\cdots$ & $39,138,995$ & 1904 & ... & $36,8 \stackrel{r}{8,7} \times 19$ \\
\hline 1902 & $\ldots$ & 37, I 38,588 & 1905 & $\cdots$ & $35,175,209$ \\
\hline 1903 & $\cdots$ & $37,875,956$ & 1906 & $\cdots$ & $34,598,089$ \\
\hline
\end{tabular}

The fact is that for a long period of years the licensed trade was the milch cow of successive Chancellors of the Exchequer, and the imposition upon it of still 
heavier burdens was always popular in certain quarters, if only because increased taxation was likely to prejudice 'the traffic.' It has so happened that such further taxation has been imposed for a particular purpose, and then diverted to one altogether different, or it has been continued long after the special object has no longer existed. In I890, when fresh licensing proposals were under discussion, Mr. Goschen had a plan that $£ 440,000$, drawn from the trade, should be devoted annually to licence purchase. The licensing proposals were dropped, but the $£ 440$, 000 has been levied ever since and devoted to other purposes, over $£ 7,000,000$ having thus been got out of the trade. Then, the special war taxes of Is. a barrel on beer and 6d. a gallon on spirits, levied in support of the South African campaign, have been continued, notwithstanding the fact that peace was declared in I902, the amount secured from the trade on this account up to March $3 \mathrm{r}$, I907, being close on $£ \mathrm{I} 9,500,000$. Adding to all this the increase in local rates (the burden of which has fallen twice as heavily on the licensed trade as on the rest of the community), and, finally, the weight of the compensation levy, any unprejudiced person must admit that the trade may well be regarded as having already been taxed beyond the limit of its capacity. In fact, the suggestions of further heavy burdens, whether in the way of direct taxation, high licence, or payment of 'full monopoly value' (for which, one would think, the $£ 3^{8}, 000,000$ a year was already a fair equivalent), must be prompted, not by a conscientious conviction that the business is inadequately taxed, but by a desire to pave the way still further for that complete suppression of the trade itself which its enemies know could not be effected by honest and straightforward proposals for effective prohibition. 
These distinctly merciless attacks are persevered in with the less scruple because it is imagined that the liquor trade is in the hands of a comparatively few wealthy brewers, whom it would delight the teetotal extremists to be able to despoil. This, however, is a fallacy as regards the conditions to-day. The conversion of former brewery firms into limited liability companies led to a widespread purchase of shares therein by small investors ; and as typical of the general position reference might be made to one leading company which has about 8,700 share and debenture holders, of whom no fewer than 5,000 have holdings not exceeding $£ 200$ each. Influenced by 'the custom of the country' in regard to the renewal of licences, many of the shrewdest and most cautious business men had become accustomed to regard brewery debentures as a gilt-edged security, and investors of the thrifty, prudent, and careful type, who did not want to speculate, but preferred safety with a modest return, on gilt-edged lines, especially favoured these debentures, the difference in the holding of which and of the ordinary shares is well illustrated by the figures quoted from The Statist on page 269. Individuals of the type here mentioned were surely better judges of business security, under normal conditions, than the average members of the Temperance Legislation League, and they can hardly be blamed now for having failed to anticipate that the latter might one day bring forward a scheme of plunder wholly inconsistent with British traditions either of finance or of justice.

It is mainly on persons of the aforesaid thrifty, prudent, and careful type that there would fall the financial losses following on suppression of, or, alternatively, on undue interference with, the licensed property which practically constitutes the security for 


\section{THE ECONOMICS OF LICENSING}

their investments. The prejudice, therefore, to the interests of a small number of wealthy 'beer-lords,' as the result of any confiscation scheme that might be carried out, would be far outweighed by the serious harm done to a great number of small investors, who would have abundant cause to rue their confidence in British Governments and British institutions.

I pass on now to consider the effect that total suppression, or even undue interference, might have on the industrial conditions of the country. A favourite argument of teetotal speakers or writers is, in effect: - The country spends so many million pounds a year on alcoholic beverages. If this money were only saved, it would suffice to give work to every unemployed man in the country.' This seems very plausible, until one begins to look into the question as to the number of persons employed in the production of alcoholic beverages who would themselves be thrown out of work if these beverages were produced no longer.

Take breweries, for instance. The total output of beer in the United Kingdom in I 906 was $35,019,092$ barrels. The production and delivery per annum in a large, well-organized modern brewery and maltings, including directors, office staff, brewers, draymen, and stablemen, might be assumed to be equal to about 500 barrels for each of these individuals. On this fairly representative basis, the number of persons employed in breweries would be 70,038 . The average wage per man over all classes comprised in the calculation would be about $£$ I I4s. 4d. per week. Therefore the annual wage bill for breweries in the United Kingdom may be put at $£ 6,249,495$. To begin with, therefore, the immediate suppression of breweries alone (apart from distilleries) would mean that 70,000 persons now engaged therein would be deprived alike of their employ- 
ment and of $6 \frac{1}{4}$ millions sterling annually in salaries and wages.

Does the Average Person realize how many different branches of industry may be represented in the personnel of just such a large well-organized brewery as the one here typified? Among them are: bar-fitters, beerallowance servers, billposters, blacksmiths, blenders, boiler-stokers, bottlers, brewers, brewery-men, bricklayers and labourers, carpenters, clerks, coachmen, coopers, coppersmiths, copper-stokers, directors, draymen, electricians, engine-keepers, fire brigade men, fitters, grain-dryers, labourers, maltsters, motor-men, office-cleaners, painters, sign-writers, stable-men, stocktakers, superintendents of houses, travellers, washers (cask), watchmen, wheelwrights, and yardsmen.

Calculating next, on the basis of the actual figures for a typical group of 800 licensed houses, it may be assumed that seven persons (not including the wives of licensees) are employed in every two houses. This may be taken as a general basis for the whole country, employment varying more through size of house than through the extent of the trade turnover. The number of full beer 'on' and beer ' off' licences issued in Igo6 was 138,848 . Therefore, on the basis of seven persons for every two houses, the number of persons actually employed in the public-houses of the United Kingdom is 485,968 . The average wage per person, inclusive of allowance for keep, and again not reckoning wives of licensees, works out at $£ 60$ per annum; therefore the total annual wage list for the retail trade is $£ 29,158$,080. Close all the public-houses, and 485,000 persons now earning their bread will be thrown out of work, and be deprived of $£_{29} 9000,000$ a year in the form either of income or of wages. Taking breweries and public- 
houses together, we get 556,000 persons employed, and a total wage bill of $35^{\frac{1}{4}}$ millions.

Then there are the numerous allied or subsidiary trades which depend to a large extent on the brewing industry for their own success and prosperity. Some of these could not exist if the breweries were closed. Others, while not deriving their business wholly from the breweries, are able to employ a substantially larger number of persons because of the orders they get for the supply of brewers' requisites, the extent of such orders representing, in the aggregate, a very acceptable addition for the merchants or manufacturers to those they obtain in other quarters.

The most important of these subsidiary interests are represented by various branches of agriculture. There is the question of barley production. If the breweries throughout the country were closed, or even if the consumption of beer were seriously interfered with, the effect would be little short of disastrous for such barley-producing counties as Lincolnshire, Cambridge, Wiltshire, Somersetshire, Hampshire, Kent, and Sussex, as well as for various parts of Scotland. Barley merchants, too, would suffer as well as the barley growers, and there would be a still greater inducement than there is already for the flow of agricultural labourers into the towns.

In another department of agriculture we have to consider the supply of brewers' horses. Calculating on the basis of the actual barrelage and of the average deliveries of barrels per horse per annum, it may be estimated that the brewers of the United Kingdom employ 10,500 horses in their business. The brewery life of such horses averages five years, and the number purchased annually would be 2,100. The breeding of these horses may in itself well be a desirable business 
for the agricultural community. In effect, the average price of brewery horses being $£ 60$, the horse-breeders, on this basis, receive $£ \mathrm{I} 26,000$ a year for horses alone. Then there is the keep. The horses are very heavy and hard-worked, and their keep and bedding must, therefore, be put at $£ 40$ per annum. Multiply this sum by the average number of horses, and it will be seen that, in addition to $£ \mathrm{I} 26,000$ for the horses, the farmers get $£ 420,000$ a year for feed-a total of $£ 546,000$. In these hard times for British agriculture an item like that is not to be despised.

Nor must the growers of hops, especially in Kent, Worcestershire, and Sussex, together with the hopfactors and the hop-merchants, be overlooked. Would they still be able to get a living out of providing hops for temperance drinks for the inhabitants of the British Isles? Would, also, the thousands of hop-pickers from the crowded cities and towns who now get remunerative employment and a healthy annual outing in the hopfields be able to obtain as profitable and as pleasant a change in some other direction?

Other trades or occupations which are either wholly or largely dependent on the brewing industry include bar fitters, beer-filter makers, bottle makers, bottlers' machinery makers, brewers' architects, brewers' chemists, brewers' supplies merchants, brewery engineers, brewing instrument makers, caramel manufacturers, cask makers, cask and vat support makers, cold storage companies, cooling-tower makers, coopers and tank builders, dealers in brewers' grains, filter, cloth, and bag makers, isinglass merchants, lorry makers, maize, rice, and grits manufacturers, malt factors, malt-kiln floor makers, maltsters, manufacturing chemists, oil merchants, racking machinemakers, saccharometer makers, shive makers, signwriters, stave importers, sugar manufacturers, tapping 
bung makers, valve makers, and vat makers. All these are in the first rank of trades directly concerned in the prosperity of brewing, with which they are so interwoven that already many of them have felt the result of the depressed conditions that have fallen upon the industry on whose welfare they themselves depend. How many individuals are employed in these various trades it would be impossible to say, but the number must be extremely large. So serious, in fact, is the outlook even for these subsidiary branches, as the result of the campaign against the 'traffic,' that there has now been formed an 'Allied Brewery Traders' Association,' which intends to show that the agitation does not alone affect brewers and publicans, but operates to the prejudice of a great number of other traders and workers throughout an almost endless series of ramifications.

How extensive these ramifications may really be is seen still more clearly by taking count, also, of traders in the second category-that is to say, of those who may not be really dependent on the brewing industry, but to whom, nevertheless, the patronage of the brewers may represent an acceptable addition to their ordinary business, and even, in some cases, allow of their employing many more hands than they would otherwise do. Included in this further list are accountants and auditors, advertisement contractors, ammonia manufacturers, auctioneers and valuers, boiler makers, boiler-composition makers, bottle, box, and case makers, brick makers, brush makers, bucket and tinware makers, builders, castings (iron, brass, etc.) manufacturers, chair makers, coal and coke merchants, coppersmiths, copper tube and sheet manufacturers, cork merchants, engine makers, furniture makers, gas - fittings makers, glass makers, hydrometer makers, insurance companies, iron merchants, iron pipe lubricator manufacturers, mill- 
wrights and machinists, motor-waggon makers, paint makers, preservative makers, printers, pump makers, refrigerating and ice-making machinery makers, sack merchants, stone jar and bottle makers, tap makers, thernometer makers, timber merchants, waggon builders, yeast dealers, etc. (For full list, see Appendix.)

It is only in face of such facts as these that one can begin to realize all that, even from a purely economic and industrial standpoint, the 'total suppression' of the trade in alcoholic beverages would imply, and the idea of bringing about such suppression in order (among other things) to provide work for the unemployed is positively grotesque when we consider how many now active workers might lose their employment if the said suppression were brought about, and how long it would take to 'absorb' them in other industries. The number of persons employed in, or dependent upon, the liquor trade of the United Kingdom has generally been estimated at about 2,000,000. I have before me an elaborate calculation (into the details of which I need not enter) placing the figure at close on 2,500,000. All such estimates are pure guesswork. In making them one does not know where to begin and where to end. The figures are doubtful as regards even the liquor industries themselves. When one comes to all those allied and otherwise interested trades, one gets into a network of complications to which there is scarcely any limit.

But, leaving actual figures aside, no one who appreciates the significance of the facts here given can doubt that any sudden and effective enforcement of prohibition by Act of Parliament, with a 'total suppression' of the 'traffic' in alcoholic beverages, would have so revolutionary an effect, alike on our financial and industrial conditions, that it would spell national disaster. There is, probably, no actual danger 
that the country would ever really be so foolish as to allow of so risky and so dangerous an experiment being tried; but what are we to think of the political and economic sagacity of those who so persistently recommend prohibition and suppression, and whose provisional 'reforms' are, as I have said, merely stepping-stones to the attainment of these final aspirations?

- It is desirable, further, to look somewhat closely into the real nature of the 'Drink Bill,' which often occupies so prominent a position in prohibitionist speeches or writings. The fact that, according to the calculations made, the people of the United Kingdom spent in Igo5 a sum of $£ \mathrm{I} 64,167,94 \mathrm{I}$ in intoxicating drinks will, for instance, be put forward as essentially one that should 'stagger humanity,' and much ingenuity is shown in speculating as to what could be done with that money if the people would only 'save' it, instead of spending so huge a sum on 'drink.'

But, taking these figures as they stand, they represent an expenditure of not more than $2 \frac{1}{2} \mathrm{~d}$. per day per head of the population of the United Kingdom, and that really does not seem so very terrible, however substantial the sum-total. Assuming that one half of the population-children and adult abstainers-spent nothing on alcoholic beverages, this would still leave an expenditure of not more than $5 \mathrm{~d}$. per head per day for the actual consumers. Even this is hardly suggestive of abnormal extravagance, especially considering that it would include the cost of expensive wines consumed by wealthy persons.

One must further remember that of this total amount expended on drink no less than $£ 38$,000,000 represents taxation, which is collected by the dealers in alcoholic beverages, and is paid over by them to the State. It is hardly fair to regard this $£ 38,000,000$ as money 
wasted on 'drink,' since it is available for State purposes, and would have to be raised in some way or other, even though no longer falling on the consumers of intoxicants. Nor can that portion of the expenditure be regarded as lost which represents wages paid to those engaged in the production of raw materials or the distribution of the finished article. Here it is simply a case of one class of the community, known as consumers, helping to support another class of the community, known as producers. From this point of view it is a matter of circulating, rather than of actually wasting, the amount in question.

The real problems for consideration are: (I) Whether or not the cost of the materials used in the beverages consumed represents wasted money; (2) whether or not the expenditure on these particular items is a distinct loss to the consumer himself; and (3) whether or not the money he spends on 'drink' would be 'saved' by him, either in its entirety or in large measure, assuming that he adopted teetotal principles.

The answer to (I) and (2) depends on our conclusions as to the precise benefits to be derived, whether from a physiological, a psychological, or a social standpoint, from the consumption of alcoholic beverages. If one admits that such benefits are so derived, then it follows that the cost of the materials is not wasted, and the expenditure on the part of the consumer is not a distinct loss. If, on the other hand, the benefits are really nil, then the conclusion follows that, while the State gets a good part of its taxation through the Drink Bill, and while many thousands of workers secure employment through the production of 'drink,' the drinker himself derives no advantage from his outlay. Before, therefore, pronouncing definite views on the 'Drink Bill,' the British public require to consider the 
particular purposes-good or evil-that are served by 'drink' itself. Merely sensational appeals to sumtotals of expenditure are of no real value, except for platform or newspaper purposes.

Dealing next with the third point, there is no doubt whatever that many individuals do spend much more on drink than is consistent either with their means or their requirements, and a certain proportion of these probably would 'save' money if they were either not to take intoxicants at all or if they indulged in them to a less degree. Others, again, representing persons of no great moral stamina, might very well apply to pleasures or excesses of other descriptions the money they no longer expended on 'drink.' The instinctive desire for a 'stimulant,' brought under subjection in regard to liquids, might manifest itself in other directionsgambling, betting, and still more harmful forms of excitement or pleasure, ruinous either to the pocket or to the health. These are conditions that are perfectly well known to authorities familiar with the frailties of human nature, and, unless the man himself is changed, the transition merely from one weakness to another may be of no great account, even financially.

The fact is further overlooked that if the average moderate drinker left off beer, wine, or spirits, he would want something else in their place, especially with his meals; and if he took Apollinaris or some other imported water, or fancy 'temperance' drinks made at home, together with more coffee, tea, or cocoa, with a more liberal indulgence in ices as well, he might, and probably would, spend quite as much money as if he had at least kept to bottled beer. I am now dealing, not with the physiological fact as to which beverage would do him the most good, but with the economic fact as to the spending or the saving of his money; and 
it is conceivable that the expenditure of many a pledged teetotaller on the beverages he patronizes is even more than what an average non-teetotaller would spend on malt liquor.

This being so, one cannot assume that even the onethird of the 'Drink Bill' here under consideration would really be 'saved' by the present drinkers if they no longer spent anything on alcoholic beverages. What would mostly happen would be the substitution of one beverage for another. Then, again, inasmuch as beer is not alone a quencher of thirst, but is also widely recognized as an article of diet, which satisfies when solids are temporarily unattainable, or seems to make a certain quantity of solids go further, one may further assume that if people drank less beer they would eat a larger quantity of solid food. Once more, be it remembered, I am here considering questions of finance pure and simple; and I would say that, whilst one part of the money saved by the non-consumption of one class of beverages would go in the purchase of another class, a further part would go in a more generous consumption of food, so that the actual 'saving' would be reduced to still smaller proportions.

In view of all the arguments here advanced, no fallacy could be more complete than that of taking the annual 'Drink Bill,' pointing to the magnitude of the sum-total, and then declaring: 'Look what the country could save if this huge amount were no longer spent on drink !' It is perfectly obvious that the country could do nothing of the kind, even if it were thought expedient to risk the financial and industrial disturbance that would inevitably follow the attempt.

That individuals who now spend an excessive amount on self-indulgence should mend their ways in the interest alike of themselves and of their families represents 


\section{THE ECONOMICS OF LICENSING}

a perfectly reasonable proposition. But this is a matter that rests between the consciences of those individuals and their friends and sympathizers. However foolish the former may be, and however lamentable their procedure, it does not follow that the social and economic conditions of the country, and one of the main bases on which the national finances depend, should be completely changed in the more or less delusive hope of securing the ultimate reform or reclamation of these morally deficients.

The whole position must be looked at from the point of view, not of the weakest members of the community, but of the community itself; and if this be done, the exaggerations indulged in with regard to economic conditions become no less pronounced than those already mentioned in regard to social and physiological conditions. Rather, however, than leave this branch of the subject to depend on my own statements, I would commend to the attention of my readers the following words of wisdom from book iv., chap. iii., of Adam Smith's 'Wealth of Nations ':

It is a losing trade, it is said, which the workman carries on with the alehouse ; and the trade which a manufacturing nation would naturally carry on with a wine country may be considered as a trade of the same nature. I answer that the trade with the alehouse is not necessarily a losing trade. In its own nature it is just as advantageous as any other, though perhaps somewhat more liable to be abused. 'The employment of a brewer, and even that of a retailer of fermented spirits, are as necessarily divisions of labour as any other. It will generally be more advantageous for a workman to buy of the brewer the quantity he has occasion for than to brew it himself; and if he is a poor workman it will generally be more advantageous for him to buy it by little and little from the retailer than a large quantity of the brewer. He may, no doubt, buy too much of either, as he may of any other dealers in his neighbourhood-of the butcher, if he is a glutton; or of the draper, if he affects to be a beau among his companions. It is advantageous to the great body of workmen, notwithstanding, that all these trades should be free, though this freedom may be abused in all of them; and it is more likely to be so, perhaps, 
in some than others. Though individuals, besides, may sometimes ruin their fortunes by an excessive consumption of fermented liquors, there seenss to be no risk that a nation should do so. Though in every country there are many people who spend upon such liquors more than they can afford, there are always many more who spend less. It deserves to be remarked, too, that if we consult experience, the cheapness of wine seems to be a cause, not of drunkenness, but of sobriety. The inhabitants of the wine countries are, in general, the soberest people in Europe. Witness the Spaniards, the Italians, and the inhabitants of the southern provinces of France. People are seldom guilty of excess in what is their daily fare. Nobody affects the character of liberality and good-fellowship by being profuse of a liquor which is as cheap as small-beer. On the contrary, in the countries which, whether from excessive heat or cold, produce no grapes, and where wine, consequently, is dear and a rarity, drunkenness is a common vice, as among the northern nations and all those who live between the tropics-the negroes, for example, on the coast of Guinea. When a French regiment comes from some of the northern provinces of France, where wine is somewhat dear, to be quartered in the southern, where it is very cheap, the soldiers, I have frequently heard it observed, are at first debauched by the cheapness and novelty of good wine ; but after a few months' residence the greater part of them become as sober as the rest of the inhabitants. Were the duties upon foreign wines and the excise upon malt, beer, and ale to be taken away all at once, it might, in the same manner, occasion in Great Britain a pretty general and temporary drunken. ness among the middling and inferior ranks of the people, which would probably be soon followed by a permanent and almost universal sobriety. 
CHAPTER XX

\section{CONCLUSIONS}

'With the same energy,' once wrote Dr. Max Schottelius, in the Deutsche Weinzeitung, 'with which one fights against excessive drinking and its deplorable consequences, must we fight, in turn, against the exaggerated demands of the abstainers who would abolish the use of alcoholic beverages altogether.'

That observation, I think, summarizes very succinctly the first conclusion to which an impartial study of the general problem here dealt with must lead. Nobody wishes to encourage drunkenness, and I honestly believe that those who wish least to encourage it under the licensing conditions of to-day are the very persons engaged in the sale of alcoholic beverages, by reason of the extreme gravity of the risks they would run. But is it not in accordance with reason that a distinction should be drawn between abuse and use? Granted, without the slightest hesitation, that the beverages in question should not be abused, does it follow that therefore they should be entirely discarded? There are many people who eat to excess. A miner, who was a member of the Bedlington Social Club, ate at a single sitting five plates of pork, each with a quantity of vegetables. Then he died, and at the inquest the doctor said that death was due to syncope produced by 
an overloaded stomach; but the jury did not suggest that because the man in question had thus abused good food, therefore everyone else should be prohibited from eating roast pork.

It is, in fact, essential to distinguish in all things between moderation and excess, and that rule certainly applies to alcoholic beverages. That they have their use is quite as undeniable as the pernicious results which may follow their abuse. Whatever decision the experts may eventually arrive at on the disputed question of food values, the fact remains that mankind has been taking alcoholic beverages for very many generations far less as a 'food' than because of their stimulating effects and the enjoyment they afford; and at the end of 5,000 years of human experience on this particular question, we still find that nothing has yet been discovered which can adequately take their place in the direct response they make to instinctive wants and requirements. Many attempts have been made in this direction, but 'temperance drinks' fail to meet the fundamental purpose answered by stimulating beverages, while beer and wine should certainly be the healthier and more nutritive of the two in view of the conditions under which they are made and the materials of which they are composed. It is true that affections of various organs of the body follow from excess in the consumption even of beer-the mildest of all alcoholic drinks. But the crux of the situation is found in that word 'excess,' and it is significant that even the discoverers of what is known in Germany as the 'beerheart '-Professors Bollinger, Bauer, and Strümpellhave expressed themselves as opposed to total abstinence, and in favour of a moderate consumption of alcohol.

They evidently have done so the more willingly 
because they must recognize that instinctive craving for a stimulant which is the greatest of all stumbling. blocks in the way to the full realization of the prohibitionist programme. To achieve their aim the teetotallers should be in a world of ideal conditions. What the world we actually live in is like is well shown by Dr. P. Bauer in his 'Studies and Observations out of the Life of a Naturalist,' where he says :

If beer and wine are withdrawn, people will intoxicate themselves with ether and eau de Cologne; they will use morphia, cocaine, arsenic, camphor, or give themselves up to licentiousness. Such things are not unknown to the Germans, and men who are slaves to their passions have plenty of resources open to them. If I were only to relate things that I have met with in the course of my varied experience, I should have an interesting story to tell!

One must assume, under all these conditions, that this fundamental weakness of our common nature has got to be recognized and allowed for, whether we wish to do so or not; and if, instead of trying to eradicate the ineradicable, the 'reformers' would seek to further the practice of a true temperance-otherwise 'moderation in drinking '-instead of their ideal of compulsory teetotalism, they would be much more likely to carry the opinion of the country with them, and achieve a higher degree of practical good. As it is, they seek to realize unattainable ideas with the help of gross exaggerations and unduly repressive legislation.

The main effect of their exaggerations is to discredit a movement for which, if applied to 'temperance' alone, everyone would have abundant sympathy. They are too ready to attribute all the ills that afflict mankind to one common cause, which they describe as 'drink'; they make assertions on the platform or in their schoolbooks which-not to put the matter too bluntly-are inconsistent with physiological fact; they confound beer having from 3 to 5 per cent. of alcohol, or even 
less, with spirits that may have from 30 to 60 per cent. of alcohol; they ignore the great changes which have been brought about in the manufacture of beer during the last few decades-changes all in the direction of supplying a lighter, more wholesome, and distinctly less intoxicating product; and they ignore equally the changes which have taken place in our social habits, so that the tendency towards moderation in drinking which has already become the fashion in the upper ranks of society is now descending to the lower, and Great Britain, which at one time might truthfully have been described as a drunken country, is steadily becoming a sober one. Judging from the assertions indulged in by the teetotal party generally, they look upon the position to-day as still what it was when, at least, the United Kingdom Alliance started operations half a century ago.

The exaggerations in question are based mainly on the fact that there is in the country an undefined number of persons who are more or less hopeless victims to the drinking habit, and who may be the cause of a certain amount of crime and destitution. But the evidence I have adduced shows that a large proportion of these so-called victims are social failures, mentally defectives, or morally deficients, who represent classes of persons well deserving of our practical sympathy, but calling for exceptional treatment, and not justifying a complete readjustment of our social and economic conditions in their special interests. Individuals of these types are not to be cured of their weakness by reducing the number of public-houses, or otherwise lessening the 'facilities' for obtaining liquor; by the action of Bishops, clergymen, and others in themselves becoming abstainers 'for the sake of example'; or by seeking to enforce compulsory abstinence on a nation 
composed mainly of persons who are in no way prejudiced by such quantity of alcoholic beverages as they themselves may take.

So the next conclusion I arrive at is that the demand for total suppression is uncalled for; and it is the final goal of total suppression that most of the reforms and changes advocated by the teetotal party really have in view. The demands actually advanced may not go beyond Sunday closing, high licence, time limit, and so on; but what the teetotallers want in their heart of hearts is to ' sweep away the traffic altogether.' It is for this reason that prohibition has a broader significance than it would have if considered solely from the point of view of practical politics of to-day. Prohibition is neither reasonable nor practicable. The assumption that total abstinence is necessary to secure moderation is one that is entirely false, and to curtail the relatively few luxuries of the great masses of the people, because certain individuals drink to excess, while their social superiors can drink as they please, would be in the highest degree unjust. Mr. Gladstone once stated the position with unanswerable logic when he said :

How can I, who drink good wine and bitter beer every day of my life in a comfortable room and among friends, coolly stand up and advise hard-wcrking fellow-creatures to take the pledge?

Nor did a daily supply of good wine and bitter beer have any apparent tendency to shorten Mr. Gladstone's life, considering that he lived to attain his eighty-ninth year.

It is not quite clear what ground the prohibitionists have for seeking to enforce their views on the remainder of mankind. In regard to their strength in the United States, the Committee of Fifty say in a report presented by them on the Physiological and Pathological Aspects of the Drink Problem: 
We have no trustworthy data as to the proportions of total abstainers, occasional drinkers, regular moderate drinkers, and positively intemperate persons in the United States. From such information as we have, it seems to us probable that, of the adult males in this country, not more than 20 per cent. are total abstainers, and not more than 5 per cent. are positively intemperate in the sense that they drink to such excess as to cause evident injury to health. Of the remaining 75 per cent., the majority, probably at least 25 per cent. of the whole, are occasional drinkers, while the remaining 25 per cent. might, perhaps, be classed as regular moderate drinkers.

In the United Kingdom the proportion of adult males who are total abstainers is probably only half the total claimed for the United States. Yet this small minority claim the right to inspire laws which shall rigidly control the majority, ignoring the fundamental principle of the local option movement-which is that the desires of the majority shall prevail. Even in this minority, forming what may be called the teetotal party, there are strongly marked divisions hopelessly at variance among themselves, as, for instance, in the matter of disinterested management, while British and American teetotallers are still more at variance with large sections of the temperance party in Continental countries, the former adhering strictly to absolute total abstinence, while the latter favour the recognition of light beers as temperance drinks. Adding, therefore, to their paucity in numbers these wide differences in their own views, it will be seen what very little right the teetotal party have to speak as though they represented the opinion of the country. Public opinion is much less likely to agree with all they say than to resent the tone they adopt towards those who are unable to concur in their views.

There is good reason, again, for the conclusion that such attempts at compulsory teetotalism as have already been made have been far from successful. Speaking at 
a meeting of the Peterborough Branch of the Church of England Temperance Society, Dr. Magee, late Archbishop of York, once said:

It was a very easy thing for one who had his leisure and large house, and comforts all round about him, with varied amusements, to say he felt no temptation to drink; but if be would spend a whole week in any close room, doing one small bit of a great and mighty work, never changing it, and never exercising his mind, exercising only his hands, when the afternoon of the Saturday came he would be desperately inclined to go and have a glass of gin. He did not think that until he had tried it the rich man had any right to cry out against the intemperance of the working classes. In attempting any legislative interference they must be careful that they did not drive the people into some wretched alternative between the public-house - the only resort for refreshment and amusement to many-and no amusement at all.

Then the Rev. H. R. Gamble, Rector of Holy Trinity . Church, Sloane Square, said in a sermon he preached on November I8, Ig06:

We are told it is the duty of all Christians to assist in the total closing of public-houses on Sundays. That for men to drink on Sundays is sinful appears to the Puritan mind an axiom which it is not necessary to prove, and appeals to this purpose are of very frequent occurrence. Clergymen are supposed to echo their sentiments. For my own part 1 must respectfully decline to do so. I entirely deny the justice of endeavouring to deprive the working classes - the great majority of whom are sober and diligent people- of a legitimate pleasure upon their one holiday in the week. ... The really temperate may be deprived of a lawful indulgence; but if there is not legal drinking there will be illegal. Clubs will supplant taverns; open indulgence will be succeeded, as in some prohibition States of America, by an organized hypocrisy.

That drinking clubs are supplanting taverns, that a great injustice is being done to the licensed traders, that there is more drunkenness going on in these clubs than is the case in the licensed houses, and that these developments are the direct result of legislative and magisterial interference alike with the public-houses and the liberties of the people, are facts as to which no 
reasonable doubt can be entertained. So one comes to this further conclusion: that any fresh legislation which is attempted should certainly deal with the club problem, and that it is no use suppressing public-houses, where a full control can be exercised, if they are to be succeeded by clubs, where, under present-day conditions, little or no control can be exercised at all.

Apart from this question of clubs, it might be asked in regard to the general policy of suppression, Can it really be taken for granted that a reduction in the number of licences in any particular town or neighbourhood necessarily leads to a decrease in the amount of drinking? Most of the supporters of the reduction policy assume that it does. On the other hand, the compensation principle assumes that the trade from the houses suppressed goes to those that remain, so that the latter are well able to pay for the former. Both of these theories cannot be right. The probability is that in the towns, at least, reduction has little or no effect on consumption, since the man who wants a drink will not go without it merely because a particular house has been closed and the next is a quarter of a mile away. An individual who is not keen on getting drink, and who would therefore be likely to remain sober, might not care to walk this quarter of a mile; but the same argument would certainly not apply to the average drunkard.

Reduction may more conceivably be of practical advantage when carried out according to the plan adopted in certain parts of Birmingham. By arrangement there between some leading brewers and the magistrates, the licences of an agreed number of houses - mostly beer-houses-are surrendered within a particular area (compensation being duly given by the holders of the remaining licences, as agreed among themselves), and the magistrates allow one (generally 
fully-licensed) house to be reconstructed on such a scale that it offers all the advantages of commodious and well-arranged public rooms and club-rooms, and completely gets rid of the disadvantages associated with houses of a small type, while it practically answers all the real requirements of the area in question. It is admitted by city missionaries and others that drunkenness is much less likely to be found in large than in small houses, and, though no standard has yet been laid down for the ideal public-house (licensing magistrates differing from one another, and even changing their own ideas from one session to another), the principle is a right one, and might be carried still further but for the great difficulty often experienced in inducing magistrates, especially in London, to allow of any addition to the area of a house. Prohibitionists, again, are strongly averse to the said policy, because, they say, it has the effect of making the public-house 'respectable'; and what they aim at is, not merely the sobriety of the people, but the total suppression of what they call 'the traffic.'

There are towns, again, where what is wanted is not so much reduction as redistribution. Excess certainly may exist there locally. Along a certain main thoroughfare in Salford, for instance, I recently counted sixteen licensed houses, mainly beer-houses, in a distance it took me six minutes to walk. This was admitted to be a case of redundancy for that particular neighbourhood, and like conditions might be found in other towns. On the other hand, it is probable that in the newer districts which have grown up around these very towns there are not sufficient public-houses to meet the reasonable requirements of the local residents. Population has shifted from the centre of the town to the outskirts, but the public-houses have remained behind. To-day, 
because of the said migration of the people, there are too many of them where they are. But it does not necessarily follow that they are out of proportion to the sum total of the community.

Might not this position be met by treating a licence as an entity, which could be used in any part of the country, as was found expedient? In that case licences would tend to follow population, and compensation would either not be necessary at all or would not be called for so often.

This movement of population is, indeed, a more important factor in the case than the direct relation between the total number of licensed houses and the total number of people, inasmuch as a person who works all day in a town or city, but lives in the suburbs thereof, requires to have facilities for obtaining refreshment in both places. The position is altogether different from what it was in the days when most people lived in the immediate neighbourhood of the spot where they worked. From this point of view mere statistics as to licences and population may be altogether misleading, while the real effect of the reductions already made in such large numbers is seen to be even greater when these dual requirements are borne in mind.

In any case one may fairly assume, I think, that, under existing conditions, there is no need to resort to further extreme measures to reduce the number of public-houses so as to bring them well within the requirements of the community - that is to say, if such reduction is to be an honest one, and not merely aimed at sweeping away licensed houses altogether.

With regard to the time limit proposal, my view is that it represents a scheme of delayed plunder, if regarded from the point of view of securing 'full monopoly value' for the Treasury; but that, in effect, it is mainly a project 
for doing, not justice to the community, but a great injustice to a trade, the direct suppression of which it is considered inexpedient, if not futile, honestly to propose. 'High licence' is merely another indirect attack, aimed at further undermining the licensed citadel with a view to its final overthrow.

My conclusion in regard to the trade as a trade is that it is a perfectly lawful one; that it responds to a want which has been experienced by men since the very earliest days of which we have any record; that this trade had better be carried on openly, under conditions permitting of police control and magisterial supervision, than allowed to descend into private resorts or secret drinking; that successive rulers, Governments, and authorities have recognized this fact throughout the centuries; that in honourable and well-established practice licences have been renewed from year to year where no question as to misconduct has arisen; that, based upon this custom, large sums of money have been invested in the business, with the knowledge and approval, and sometimes at the direct instigation, of licensing magistrates, under the expectation that the said custom would be maintained; that it would be a cruel wrong if the Government were now virtually to confiscate this money on the ground that a mistake had been made when the licences were originally granted-perhaps several generations ago; that around this one trade a large number of others have grown up, dependent either entirely or in part on its prosperity for their own; that, altogether apart from the sum total of the capital involved, several millions of workers must be engaged in the main or subsidiary industries; that it would be a great injustice if, having approved and licensed the sale of alcoholic beverages for so long, the country were now to change its mind, and bring 
ruin to all these people; and that any problematical good which suppression, or even further undue interference with the trade, might effect would be far surpassed by the magnitude of the social or economic harm, direct or indirect, that would be done in other ways.

There are those who, while agreeing generally with these views, would still maintain that the conditions under which the public-houses are conducted are not desirable, especially as regards tied and managed houses. In effect, however, these conditions, like the clubs of which so much is heard, are mainly due to the action of Governments and magistrates, on the one hand, and the hostility of the teetotal party on the other hand.

Private traders withdrew so largely because they were not prepared to run the, apparently, grave and increasing risk of losing their money in a business which had so many active and influential enemies. They sold out readily enough to brewery companies willing to run the risk ; but it is difficult to see how any Act of Parliament could now lead those private traders to invest their money over again in a form of trading which, under present-day conditions, seems to have greater uncertainties than ever.

But has the change of ownership thus effected really brought about any such undesirable results as the teetotal critics would have the public believe? My conclusion on this point is that it has not, and my reasons for that conclusion are set forth in detail in the chapters on 'Tied' and 'Managed' Houses respectively. I might, however, here so far enlarge on the point as to introduce the following note from a member of a wellknown brewery firm in the Midlands whose views I solicited:

I have known Birmingham intimately during a period extending over fifty-five years. As a type of what the 'tied' licensing trade has 
done, this city affords a striking illustration. At the commencement of the time mentioned there was scarcely a ' tied' house in the town; nearly every licensee brewed his own malt liquors. At that period 90 per cent. of the working men got drunk on Saturday night; drunkenness was common all the week through, and there was no interference with a drunken man by the police unless he became violent. With the imperfect system of brewing in the public-houses, the insanitary condition of the brew-houses, and the unsuitable appliances, the beers brewed were mostly of inferior quality and more alcoholic than is the case now, strong ales being specially demanded by the customers. Since the brewers have had more control over the houses, beers have undergone a great improvement, for with the aid of scientific knowledge, hygienic breweries, and suitable appliances, they have succeeded in producing beers containing 25 per cent. less of alcohol than the beers formerly retailed in Birmingham public-houses. Those now produced are more wholesome, less intoxicating, lighter in character, more palatable, more nutritious, of brighter and better condition, and more suitable for general consumption. Such beers have gradually won the public taste, and are produced and sold at a much lower cost than the heavy and intoxicating ales of the past.

In face of evidence such as this, it is difficult to see how the interests of the public can have suffered from the 'tied' house system. They have suffered still less under the 'managed' house system. The ordinary licensee of a public-house is a man of good character who, as a rule, has been educated to the business. He is the man appointed, so to speak, by the State to control the sale of drinks, and, as a preserver of peace and order, he need only be in a uniform, with his number on his collar, to occupy a position practically similar to that of a policeman. But these conditions are greatly accentuated when such a licensee is himself under the watchful control of a supervisory organization specially appointed to ensure a perfection of good management and a scrupulous regard for the law, in the interests of a company which may have invested a substantial sum of money in the business the said manager conducts. All this is clearly in the interests of the public, and the adverse 
criticism passed upon the system is merely another of those almost endless attempts made to discredit the trade still further, and to weaken its position, so that the final 'suppression' desired may be brought about with the greater ease.

I am further of opinion, from a personal visit to many 'managed' houses, that they offer most of the advantages claimed for the alleged 'disinterested management' system, without those serious disadvantages which must inevitably arise when the management passes from the hands of experts and business men to those of amateurs and philanthropists. The impracticable ideas which individuals of the latter type may have on the whole subject of the licensed trade are well illustrated by some observations reported by the Bristol Daily Mercury to have been made by the Dean of Hereford at a noisy meeting held at Bristol on February 5, 1907, on the subject of Sunday closing. The Dean said 'he could not understand the opposition, because if the butchers and the bakers and barbers and many others were obliged to shut up their places on Sunday, he did not see what reason there was that the publican should not do the same.' These remarks suggest that, in the view of the Dean, because a working man can buy a joint of meat, or a loaf of bread, on the Saturday, with the certainty of finding it still fresh on the Sunday, therefore he might just as well get a jug of ale on the Saturday in readiness for dinner-time the next day. It would also seem that the Dean regards a public-house in the light merely of a shop, where liquor can be purchased in the same way as bread can be bought at a baker's or meat at a butcher's. This view leaves entirely out of sight one essential factor in the situation-the social element in the licensed trade. A large proportion of the 
customers in a public-house go there, not merely to gulp down or buy so much liquor and then depart, but to have either rest or social intercourse as well. A man does not expect to meet acquaintances in the shop of the baker or the butcher, and to find seats provided for them there, so that they can spend the evening together-in the shop-in discussing the events of the day. He is, also, quite prepared to leave the barber's as soon as he has been shaved. But, from his point of view, it may be, a public-house should serve the same purpose that a club would (say) to a Dean. Fellowship, a smoke, and a genial chat may be as much the reason for the visit to the public-house as the desire for a glass of beer. A man's social instinct wants to be satisfied as well as his thirst; and it is just because law-makers and law-administrators, reformers and philanthropists, are apt completely to ignore this social instinct that they are making such deplorable errors in their attempted solutions of what they are pleased to call 'the licensing problem,' and driving men more and more into drinking clubs, where their sense of freedom and their social feelings are alike under no restraint.

I am thus bound to conclude that 'disinterested management' in the hands of amateurs and philanthropists would be a hopeless failure, and that, whatever be the future of the licensed trade, it must still be conducted on business lines under effective control. Nor do I see any real reason for further active interference on the part of the Government, except with regard to those clubs which are simply drinking dens. There has been a steady fall in the consumption of alcoholic beverages; there is already a substantial decrease proceeding in the number of licensed houses; the public-house owners are compensating one another 
without making any demand on the public purse; a trade that is already contributing $£ 38$,000,000 a year to the nation's finance is, surely, paying as much as can reasonably be asked of it ; any increase of drunkenness is due less to the public-houses than to their rivals, the drinking clubs; while much more is to be hoped for (in the interests of that sobriety which constitutes the real 'temperance') from increased education, improved culture, better housing, social improvement and higher public sentiment, than from coercive abstinence, even when backed up by a legalized confiscation.

Coercive abstinence has been a failure all the world over, and the very violence and unreasonableness with which it is still urged can only lead eventually, when the whole facts of the case are thoroughly realized, to a revolt in the public mind which may discredit and hamper even what is good and praiseworthy in the cause of temperance, as against teetotalism. As for legalized confiscation, the country may well be reminded of Lord Rosebery's pronouncement in his speech in the Whitehall Rooms to the members of the Liberal League on March 26, 1907, when, in referring to Sir Henry Campbell-Bannerman's Government, he warned the Liberal party that 'it might find itself, or some of its members, permanently connected with hostility to property in all its forms,' and spoke of the 'predatory elements in politics,' to which Socialism-and also, he might have added, so-called temperance reformerscould specially appeal.

To sum up, I would say:

I. That, operating on lines consistent alike with reason, with common-sense, and with human nature, any real 'temperance' movement, which aims at keeping people 'temperate,' deserves the hearty support of every section of the community, and will answer all the 
reasonable requirements that can be sought in the interests of society; but that, on the other hand, teetotal extremists, whose views and assertions too often cross the border-line which should separate reason from fanaticism, have wrongly applied the word 'temperance' to various schemes for the enforcement of a more or less compulsory general total abstinence, not called for by the actualities of the situation, and altogether beyond the reach of practical attainment.

2. That the evils of 'drink'-admittedly great, even allowing for much exaggeration by the said extremists - are due mostly to persons of feeble minds or weak bodies (morally deficients, mentally defectives, or those otherwise of an abnormal type), to whom, as such, total abstinence may certainly be commended; though one cannot reasonably demand that society as a whole should be remodelled to meet their special conditions and requirements.

3. That, while further legislation in regard to drunkenness and drunkards may well be applied to the classes directly concerned, unfair and unnecessary restrictions should not be imposed on the rights, liberties, and reasonable enjoyment of persons who can use stimulants without either abusing or being prejudiced by them.

4. That, notwithstanding the difference of views among medical authorities on the subject of alcohol, it has not yet been established that a moderate use of alcoholic beverages is injurious to the human system, however pernicious individually may be an excessive indulgence therein ; that successive generations of mankind in all parts of the world have found pleasure and, presumably, benefit in their use; and that, so far from such beverages having checked national advancement, the nations which have been the heaviest drinkers have 
been the most progressive, while the most temperate have been the most backward.

5. That, whatever objections the teetotal party may raise to the ordinary alcoholic beverages, they have not yet invented any drinks which, suitable for all occasions, can adequately take their place; and that many of their own beverages not only themselves contain alcohol, but are much more open to criticism than ' honest English beer' at least.

6. That sufficient count is not taken by the teetotal party of the improvements in brewing and the reduction in the alcoholic strength of beer during the last quarter of a century ; and that they are much too prone to bring beer, with its present low percentage of alcohol, under the same condemnation as spirits in their sweeping references to 'drink' in general.

7. That the trade in alcoholic beverages responds to an instinctive desire for an occasional stimulant which is natural to man, has characterized him since the earliest dawn of history, and, like other instincts, calls for prudent control rather than for actual extinction; that the said trade is consistent with reason and policy, since it allows of this prudent control being exercised over the sale of intoxicants; that it is a legal trade, since the State has countenanced it for many generations; that confidence in the integrity of the State has led many people to invest, in the aggregate, vast sums of money in the trade; that, besides the large numbers of persons directly concerned, as investors or workers, many allied trades and interests would be affected by serious prejudice to its stability, so that any saving in expenditure on the part of particular sections of the community, through the total suppression of the trade, would have the gravest consequences for other sections; that, instead of incessantly harassing a trade which 
meets a distinct public want, and cannot be wholly extinguished (as the failure of prohibition, wherever tried, clearly proves), it would be much more sensible to recognize the need for its continued existence, and to subject it to no more than the present efficient control and supervision, the latter conditions being more especially met under the 'managed house' system.

8. That the attempts already made to impose further restrictions on the trade, and to interfere still more with the liberty of its former patrons, have led to a great increase in both the number and the membership of clubs, where drinking can go on unchecked, and where an amount of drunkenness arises far in excess of what originates in the licensed public-houses.

9. That the proposed time limit represents delayed confiscation; that increased taxation would be unjust (as applied to a trade which already contributes so largely to the national and local exchequers), and is, in effect, mainly advocated as an indirect means of further injuring the traders; that, under the compensation clauses of the Act of 1904, any redundancy in the number of licensed houses is steadily disappearing; that, except for the drunkenness due to the increasing number of clubs, the people of the country are becoming more and more sober in their daily habits; that in these circumstances the Act of 1904 might well be allowed to have a reasonable chance of showing what it can do; and that, finally, there is no just cause for further attempts at harassing, and ill-advised, if not, also, confiscatory, licensing legislation. 


\section{APPENDICES}

\section{A -TYPICAL FORM OF AGREEMENT WITH A TENANT}

THE following is a form of agreement with tenants adopted by leading brewery companies or firms in the principal licensing districts of Lancashire and Cheshire after consultation with the licensing magistrates there:

THIS INDENTURE made the One thousand nine hundred being the Agent of day of

BETWEEN

and the said Agent and also the said Company their successors and assigns as the nature of the context may require (to the intent that the covenants and powers hereinafter contained shall enure to and for the benefit of the said Company their successors and assigns) are hereinafter included in the expression 'the Landlords' of the one part and of hereinafter called the Tenant of the other part WiTnESSETH that in consideration of the rent and covenants hereinafter contained the Landlords let to the tenant who takes ALL that messuage or tenement and licensed situate house known as the

TOGETHER with the use of the licences fixtures and fittings thereunto belonging and the Landlords' trade utensils now in use there To HOLD unto the Tenant from the day of one thousand nine hundred
$\begin{aligned} & \text { for annual rent of } \\ & \text { and so on from to }\end{aligned}$ rent to be paid in advance if required AND the Tenant covenanTS with the Landlords that he the Tenant will pay the rent on the due dates clear of all deductions whatsoever (Landlords' property tax alone excepted) and also all rates taxes and assessments whatsoever ALso that he the Tenant will pay all 
moneys necessary for keeping the licence in full force and will apply from time to time for and use best endeavours to obtain a renewal or new grant of the licence and will not do or permit to be done anything whereby he may or shall forfeit or run risk of forfeiting or imperilling the licence or be likely to cause any objection to be taken to a renewal or new grant of the licence or shall be disqualified to hold any such licence or shall be convicted of any offence against the licensing laws or any other statute affecting Licensed Victuallers or Beersellers AND also will keep and cause to be kept good hours and order in the said premises AND will personally reside on the said premises and keep the licence in own name and use

best endeavours to preserve the standing and character of the house AND also will within twelve hours after any complaint summons arrest alleged misconduct or irregularity or official or other notice affecting the conduct of the house or the licence report the same at the Landlords' head office in Liverpool with 'full particulars AND will take exclusively from and deal exclusively with the Landlords or their nominee or nominees for all the Ales Porters Wines Spirits and Cordials vended or consumed in or from the said premises and will not purchase or permit to be received taken or brought on to the premises on any pretext whatever any Ales Porters Wines Spirits or cordials other than supplied by the Landlords or their nominee or nominees AND will keep the whole of the said premises (except the roof and main walls and the outside paint work) and the trade fittings and fixtures and utensils therein in good and substantial order and repair AND will once every three years during occupancy paint with two coats of the best oil paint and also decorate grain and varnish all such portions of the inside of the said premises as are usually painted decorated grained and varnished respectively and will paper colour and whitewash all parts usually papered coloured or 'whitewashed AND will cleanse and keep in good order and substantial repair all gutters spouts and drains AND at the end or sooner determination of this demise will leave the whole in the same good and substantial order and repair painted decorated grained and varnished papered coloured and whitewashed and cleansed as aforesaid (reasonable wear and tear and damage by fire storm and tempest or inevitable accident only excepted) AND will not make any alteration in or addition to the premises without the consent of the landlords in writing and (if any such alteration affect the business portion of the premises) the consent also of the Licensing Justices AND will make any 
alteration in or addition to the said premises not being in the nature of a structural alteration which shall at any time be required by the Licensing Justices upon plans approved by the Justices and the Tenant shall bear and pay the cost of the preparation and approval by the Justices of such plans AND will keep open the said premises for business at all lawful hours and not close or shut up the said premises either temporarily or otherwise except at such times as by law such licensed houses are required to be closed AND will not assign underlet or part with or deliver possession of the said premises or any part thereof to any person or persons whomsoever AND WILL AT THE END or sooner determination of this demise peaceably and quietly give up to the Landlords or their nominee possession of the said premises and on quitting the said premises or the landlords becoming entitled to take possession will forthwith assign and transfer the licences belonging to the said house to the landlords or their nominee and sign all transfers and papers and consent and do all acts and matters to give effect thereto on a proportionate part of the licence duty for the unexpired term therein being paid to the Tenant (but in the event of the Tenant's refusal or neglect to do so the Landlords by the Secretary or any Director or Officer of the Landlords are hereby empowered to sign the said Notices in the Landlords' name as the authorized agent of the Tenant) AND will sign a withdrawal of the Excise Entry and attend before the Justices both at Petty Session and at the Special Sessions for transferring Licences and duly apply for the transfer as aforesaid at the Tenant's own cost other than reasonable travelling expenses AND IT IS FURTHER AGREED that this demise may be determined by either party giving to the other months' previous notice in writing from any date of or their intention so to do any law or usage to the contrary notwithstanding PROVIDED ALWAYS AND IT IS HEREBY AGREED AND DECLARED that it shall be lawful for the landlords or any person or persons appointed under the hand of their Secretary at any time or times and all lawful hours to enter upon and inspect the premises and every part thereof for the purpose of ascertaining the repair and condition thereof and also how the business is being carried on and to examine the stock and take samples thereof PROVIDED NEVERTHELESS AND IT IS HEREBY AGREED that in case any rent shall be in arrear for fourteen days whether demanded or not or if the Tenant shall do anything with reference to the conduct of the house which may in any way endanger or imperil the licence or be likely to cause any objection to be taken to a 
renewal or new grant of the same or shall become bankrupt or have a receiving order made against or shall die or shall in any respect fail in the due and complete performance and observance of all and each of the covenants and stipulations herein on

part contained then and thereupon or at any time thereafter and notwithstanding any intermediate receipt of rent negotiation or other condonation it shall be lawful for the landlords to put an end to and determine this demise and to enter upon resume or take possession of the said house and premises as if this demise had not been made AND IT IS FURTHER AGREED that if the premises shall be burnt down or otherwise damaged from any cause whatsoever (except by the wilful act or default of the said Tenant or servants) whereby they shall not be fit for use or occupation then the Landlords shall thereupon abate a proportionate part of the rent for the time the same shall be unfit for use or occupation $O R$ the tenancy may thereupon be at an end at the option of Landlords

IN WITNESS whereof the parties have hereunto set their hands and seals the day and year first before written.

\section{B.-TYPICAL FORM OF AGREEMENT WITH A MANAGER}

The following is the form of agreement usually entered into between brewery companies in the Liverpool district and the managers of public-houses owned by them :

THIS AGREEMENT made the one thousand nine hundred and

day of

between

(hereinafter called the owners) of the one part and (hereinafter called the manager of the other part), as follows :

I. The manager will, on the basis of the rules hereto annexed, from the date hereof become the representative of the owners to keep and manage for them their licensed public-house, with the fixtures, fittings, and utensils therein, situate No.

and will hold for them the licences and any renewal thereof, and will reside in the residential portion of the premises.

2. The owners will pay the manager the sum of per week as wages. 
3. The business of the house shall be conducted in all respects in accordance with the law and the rules hereto annexed.

4. The manager shall keep correctly proper books of account (which shall be provided by and be the property of the Owners) in the mode to be prescribed by the Owners, and such books shall remain at the said licensed house, and shall not be removed therefrom by the manager upon any pretence whatever, and shall at all times be open to the inspection of the owners and any person whom they may appoint for that purpose.

5. The manager will pay to the owner or his agents the takings, less trade disbursements, weekly.

6. The manager will, whenever required by the owners, deliver up to them or their nominee, and do all necessary acts for trans. ferring to them or him the then existing magistrates' grant and excise licences. And will also sign any notices and make any applications for obtaining a protection order or the transfer or renewal of the licences or withdrawal of entry with the excise which the owners may require. And will attend before the justices in person and consent to any such transfer or renewal.

7. It shall be lawful for the owners or any person appointed by them in that behalf, and they or he are or is hereby irrevocably empowered to apply for and sign, give and do as the agents or agent of the manager all notices and acts necessary for obtaining such protection order, transfer or renewal or withdrawal of entry as the case may be.

8. On the determination of his engagement the manager shall make and give to the owners a final account of the transactions and shall pay over any balance then due from him, and make no claim for improvensent of the business during his management.

9. If the manager shall at any time after being required by the owners, as provided in the sixth clause of these presents, neglect or refuse to peaceably yield and give up quiet possession of the said licensed house and premises, books, fixtures, fittings, utensils, and stock as aforesaid, or any of them, or any part thereof, it shall be lawful for the owners or their agents or servants to enter into and upon the said premises, or any part thereof, and to eject therefrom the said manager or his family, and to remove his furniture and effects, and take possession at any time of the day or night.

Io. Either party may determine this agreement by giving to the other one week's notice, or paying one week's wages in lieu thereof.

As WITNESS the hands of the parties the day and the year first before written. 


\section{RULES FOR THE OBSERVANCE OF THE LAW AND GOOD ORDER ON ALL THE LICENSED PREMISES BELONGING TO}

1. No credit shall be given to any person under any pretence whatever.

2. No wages shall be paid on the premises except to those employed in the house.

3. No person on duty shall treat or be treated by a customer or other person.

4. No smoking allowed while on duty.

5. No money, watch, parcel, or other thing shall be taken in charge from any customer or other person.

6. No foreign money shall be exchanged, nor any banknotes, unless the parties are well known to be responsible and respectable householders.

7. No army certificate, advance note, sailor's monthly money note, pawnbroker's duplicate ticket, or any other document, article, or thing shall be received, purchased, or taken as security from a customer or other person.

8. No raffle shall be allowed to take place, nor shall gaming of any kind be permitted.

9. No person shall be supplied who is disorderly or apparently under the influence of drink, or (if for consumption on the premises) who is under sixteen years of age.

Io. No young person shall be supplied with liquor for consumption off the premises who is under fourteen years of age, except in corked and sealed bottles of not less than one reputed pint.

The expression 'sealed' means secured with any substance without the destruction of which the cork, plug, or stopper cannot be withdrawn.

II. No police officer shall be served or harboured while on duty, and any complaint against the police to be reported at once to the outdoor manager.

12. Should a police officer or other person at any time point out any matter in the course of business as being in his opinion an infringement of the law, whether he intend to report the same to the authorities or not, the manager or his assistant shall forthwith procure the names and addresses of any witnesses who may be present.

13. Should any person be charged with being intoxicated on the premises, the manager or his assistant must endeavour to at 
once procure the opinion of a doctor as to the said person's condition.

I4. No persons except those employed in the house shall be allowed to remain on the premises during closed hours.

15. Should any police officers or constables in the execution of their duty demand admittance during closed hours, it is the duty of the licensee, or those in charge, to immediately admit them, and give every facility to examine the premises.

16. A full and true account of each day's takings and also a faithful account of all stock sold in, out of, or upon the premises shall be kept and rendered by the manager, and no false entry shall be made in any such account or in the day-book.

17. The manager is responsible for the house being in every respect well conducted, and shall report at once any irregularity or any misconduct of the men under his charge.

I8. The house shall be opened at 6 a.m., and close punctually at I I p.m. ; but on Sundays, Good Friday, and Christmas Day the hours are 12.30 to 2.30 and 6 to Io.

19. Penalty for the breach of any of the above rules-dismissal.

\section{C.-FURTHER RULES FOR 'MANAGED' HOUSES}

THE following is printed on the back of the weekly cash return-sheet of a leading brewery firm in the Midlands, for the guidance of their managers:

\section{RULES AND INSTRUCTIONS.}

You must distinctly understand that the house belongs to

, and that you are here subject to your conduct being honest, steady, and obliging to your customers, and attentive to your duties.

Your Employers reserve to themselves the right to give you any notice whatever of their intention to dispense with your services, should they consider that you are either unsuitable for your duties, or that you are not complying with these Rules.

THE COMPANY DO NOT PERMIT CREDIT BEING GIVEN TO ANYONE. 
Upon no account to allow drunken persons to remain on the premises, and not to sell or supply them with anything whatsoever. In the event of being deceived, return the money and request the person to leave the premises at once.

If the Police should make any charge of drunkenness, and there be any doubt as to the condition of the person so charged, the Manager or Barman will detain the person ; call the attention of the customers present to the person's condition, and ascertain their names and addresses. Notice the time and ask the customers to note any conversation that passes on the subject; and as early as convenient take the person to the nearest Doctor, and again note the time, which is very important. Report the circumstances immediately at the Company's Head Office.

Upon no pretext to serve a Policeman in uniform, unless you are of opinion or have reasonable proof that he is off duty.

Betting or Gambllng in any form is not to be permitted.

NEITHER MANAGERS NOR BARMEN ARE TO Smoke IN THE BAR OR BAR PARLOURS.

KNOWN PROSTITUTES are not to be encouraged to frequent the house, and on no account to allow them to come and go, without their intention is to get refreshments, in which case they must not remain longer than is reasonable for consuming those refreshments.

MUSIC, DANCING, SINGING, except where licensed, and BAD LANGUAGE are to be strictly forbidden.

NEITHER MANAGERS nor BARMEN are to be out except by permission of the Superintendent.

Managers or Barmen are not to receive any money or valuables for safe keeping.

In case of fire or serious accident SEND AT ONCE to the Company's Head Office.

Accidents to plate-glass to be reported on the same day, with full particulars of the occurrence.

\section{IMPORTANT.}

The hour of closing is to be rigidly observed, and all customers and friends off the premises.

No presents of any kind, under any circumstances, are to be given away.

No Bank Cheques or Notes, other than Bank of England Notes are to be cashed. 
No information connected with the Business is to be given to any person outside the Company, either verbally or in writing, but enquirers referred to Brewery.

The cash takings to be counted (coppers as well) at the times named on this Sheet, and entered at once in ink, and it is hoped that Managers will not plead any excuse for not doing so.

You are required to complete this Sheet, and post it to the Brewery, every Monday, together with all vouchers for payments, the balance of cash being retained until next day, that is Tuesday, when it should be banked to our credit by Io o'clock a.m. at such bank as we direct.

All orders for Repairs, Advertisements, Glasses, Coal, and Utensils must be given through the Head Office.

\section{D.-ALLIED TRADES AND INTERESTS}

ON pp. 276-277 some typical examples have been given of allied trades and interests which would themselves be affected, more or less, by either the closing of breweries or any serious interference with the licensed trade. The following much fuller list shows still more clearly the widespread extent of the industrial and commercial ramifications that might be involved were the 'suppression of the liquor traffic' really brought about :

\section{Accountants.}

Accumulator makers.

Advertisement agents and contractors.

Agents-Land and estate.

Anvil makers.

Architects, Brewers'.

Art-metal workers.

Artesian well borers.

$"$ "boring toolmakers.

" $\quad$ engineers.

Artificial stone manufacturers.
Artists' colourmen and material dealers.

Artists in stained glass and glass painters.

Asbestos manufacturers.

", merchants.

" millboard makers.

Asbestos-packed cock manufacturers.

Asphalt manufacturers.

Auctioneers.

Back and vat makers.

Bankers. 
Bag makers.

Band-saw makers.

Barge owners and makers.

Banner manufacturers.

Barley growers.

" merchants.

Barometer and thermometer makers.

Barrel-hoist makers.

Basket makers.

Bass and fibre dressers.

" broom makers.

Bath makers.

Bath brick merchants.

Beer bottlers.

" bottling machinists.

" can makers.

" engine makers.

" finings manufacturers.

"retailers.

Belt-driving manufacturers.

Belting manufacturers.

" syrup makers.

Bent timber manufacturers.

" wood furniture manufacturers.

Benzine and benzole distillers.

Bill-posters.

Billiard and bagatelle table makers.

" ball makers.

" cue makers.

" cushion makers.

" gaslight makers.

" light shade makers.

" room furnishers.

" table-cloth makers.

, table requisite manufacturers.

table slate bed manufacturers.

Birch and heath broom makers.
Blacklead importers and manufacturers.

Blacksmiths.

Blow and blazing lamp manufacturers.

Blowing and exhaust fan manufacturers.

Boiler makers.

" cleaners.

" fluid manufacturers.

" inspecting companies.

" non-conducting composition makers.

" plate makers.

" setters.

" tube makers.

" tube brush manufacturers.

Bolt and nut manufacturers.

Boring tool makers, Artesian.

Bottle makers.

Bottling machine manufac. turers.

Box manufacturers.

Brass and copper wire manufacturers.

" finishers.

" founders.

" and gun-metal casters.

" manufacturers.

" plate makers.

" tube makers.

" turners.

Brewers' chemists.

" supplies merchants

" valuers.

$"$

varnish makers.

Brick makers.

" and tile merchants.

" " machine makers.

" mould makers.

Bricklayers. 


\section{APPENDIX D}

Bricklayers' labourers.

Brush ferrule makers.

" makers.

" " for machinery.

" , pitch manufacturers.

Bucket and tinware makers.

Builders.

Builders' merchants.

Building material dealers.

Cabinet makers.

Camel-hair pencil makers.

Canvas manufacturers and merchants.

Capsule manufacturers.

Caramel manufacturers.

Carbolic acid manufacturers.

Carbonic acid gas makers.

Carmen.

Carpenters.

Carpenters' labourers.

Carvers and gilders.

Casement fastening manufacturers.

Cask makers.

" and vat support makers.

Cellar fittings manufacturers.

Cement makers.

" merchants.

Chain makers.

Chair and sofa makers.

Chimneypiece manufacturers.

Chimney-pot makers.

" shaft climbers and repairers.

sweepers.

China, glass, and earthenware manufacturers, and wholesale glass dealers.

China, glass, and earthenware dealers.

Coal merchants.
Coal owners.

" and ashes handling machinery makers.

Cold-storage engineers.

Colliery and iron companies.

Colour manufacturers.

" merchants.

Contractors.

Contractors' plant makers.

Cooking apparatus makers.

Cooling̨-tower makers.

Cooperage machine makers.

Coopers.

Coopers' tools manufacturers.

Copper merchants.

Coppersmiths and braziers.

Cork merchants.

Corking machine manufacturers.

Corn merchants (stables department).

Corkscrew makers.

Cotton waste manufacturers.

" " merchants.

Crane manufacturers.

Cutlers.

Dealers in brewers' grains.

Decorators.

Disinfecting powder and fluid manufacturers.

Distemper manufacturers.

Door-spring makers.

Drain-pipe (stoneware) manu facturers.

Draughtsmen.

Dynamo makers.

Electric accumulator makers.

" $"$ acidmanufacturers.

bell manufacturers. cable and wire manufacturers. carbon makers. 
Electric crane and lift manu. facturers.

\begin{tabular}{|c|c|}
\hline "צ & light apparatus makers. \\
\hline "9 & " dynamomachines. \\
\hline " & engineers. \\
\hline " & fittings makers. \\
\hline נ, & " lamp makers. \\
\hline & " shade makers. \\
\hline " & $\begin{array}{l}\text { motor manufac- } \\
\text { turers. }\end{array}$ \\
\hline
\end{tabular}

Electrical accessories manufacturers.

" battery makers.

" measuring instrument makers.

" motor brush manufacturers.

Electricians.

switch-board makers.

Electricity meter makers.

Emery and glass cloth and glass paper makers.

Emery wheel and machinery makers.

Enamel manufacturers.

Enamelled iron, Decorators of.

Enamellers (of glass and iron)

Encaustic tile makers and merchants.

Endorsing-press manufacturers. Engineers, Brewers'.

$" \quad$ Consulting.

" Mechanical.

Engineers' machine tool makers. " pattern makers.

Fanlight apparatus manufacturers.

Farriers' tools makers.

Feed-water heater makers.

Fibrous plaster decorators. " $\quad$ slab makers.

File and rasp manufacturers.
Filter and yeast press dealers. " pulp makers.

Fire-alarm makers.

Fire-clay goods manufacturers.

Fitters (engineers) and labourers.

Flag makers.

Flagstaff makers.

Flaked maize malt makers.

Forage cutters and contractors. Forge bellows makers.

" makers.

Founders.

French polish manufacturers.

" polishers.

Galvanized iron and steel manufacturers. tank makers.

Galvanizers.

Gas engine makers.

" engineers.

" fittings manufacturers.

" globe manufacturers.

" lamp manufacturers.

" lantern makers and fitters.

" light companies.

" meter makers.

" pipe makers.

" regulator manufacturers.

" stove manufacturers.

Gasfitters.

Glass benders.

" bevellers.

" cutters.

" embossers.

" letter makers.

, manufacturers.

" merchants, window.

"silverers.

Glazed brick makers.

Glaziers.

Gold and silver beaters.

Grain contractors. 
Grain driers and merchants.

Granite merchants and agents. " polishers.

Granolithic stonemanufacturers.

Green fodder merchants (stables department).

Grill stove makers.

Grindstone makers.

Hammer makers.

Harness makers.

Hay merchants.

Heating apparatus makers.

Hide and skin merchants, etc.

Hop factors.

$"$ growers.

" merchants.

" pocket makers.

Horse dealers.

" clipper makers.

" slaughterers.

Hose makers.

Hot water apparatus makers.

$" \quad$ " engineers.

Hotel bar fitters.

" valuers.

Hydraulic machine makers.

Ice machine makers.

" merchants.

Incandescent gas lamp manufacturers.

lamp makers.
mantle manufac-
turers.

Indiarubber manufacturers and dealers.

"

hose manufacturers.

9)

machine belting manufacturers.

91 steam packing manufacturers.
Insurance companies and agents.

Ironfounders.

Ironfounders' pattern makers.

Iron and steel manufacturers.

,

" merchants and agents.

" and tin-plate workers.

" casement makers.

" chain makers.

" door and room makers.

" girder and joist makers.

" roof manufacturers.

" shutter manufacturers.

" staircase manufacturers.

" tank manufacturers.

Ironmongers (wholesale).

Isinglass manufacturers.

Japanners.

Joiners.

Labourers (general).

Ladder makers.

Lamp manufacturers.

Land agents.

Lath renders.

Lathe and tool makers.

Lead burners.

" glaziers.

", manufacturers.

" merchants.

Leather merchants.

Lift makers.

Lifting apparatus makers.

" jack makers.

Lime merchants.

Linoleum manufacturers.

Lock makers.

" furniture makers.

Locksmiths and bellhangers.

Lubricants, manufacturers of.

Lubricating oil manufacturers.

Lubricator manufacturers. 
Machine chain makers. , strap makers.

Machinery merchants.

Machinists.

Maize, rice, and grits manufacturers.

Malt factors.

, kiln floor makers.

Maltsters.

Marble merchants.

Mat makers.

Mathematical instrument makers.

Metal merchants.

" workers.

Millers (stables department).

Millwrights.

Mop makers.

" and broomstick makers.

Mortar mill makers.

Mosaic workers.

Moss litter companies (stables department).

Motor-car and carriage makers.

Nail makers.

Navvies.

Oil and colour men.

Paint manufacturers.

Painters, glaziers, paperhangers, and house decorators.

Paper makers and warehouses.

Paperhanging manufacturers and warehouses.

Paste merchants.

Pasteurizing apparatus makers.

Paviors.

Pewterers.

Phospor bronze manufacturers. Plasterers.

Plasterers' labourers. " hair manufacturers. Plate-glass manufacturers.

\section{Plumbers.}

Plumbers' labourers.

Power transmission machinery makers.

Preservative manufacturers.

Printers and stationers.

Publicans' bar fitters.

$$
\text { " brokers. }
$$

Pulley makers.

" block makers.

Pump makers-Brewers'.

Pumping machinery manufacturers.

Racking machine makers.

Radiator makers.

Railway companies.

Refrigerator and refrigerating machinery manufacturers.

Restaurant furnishers.

Rivet makers.

Roofing felt makers.

Rope, line, and twine manufacturers.

Saccharum manufacturers.

Sack makers.

Safe (fireproof, ice, etc.) makers. Sand merchants.

Sanitary appliances manufacturers.

Sash line makers.

Saw makers.

" mills.

Scientific instrument makers.

Scrap iron dealers.

Screw makers.

Screwing machine manufacturers.

Shop fitters and front builders.

Shive and spile makers.

Shovel makers.

" spade and fork manufac. turers. 
Show-card and tablet manufacturers.

Shuttermanufacturers, revolving. Sieve and screen makers. Sign painters.

Size manufacturers. Slate enamellers.

" merchants.

" quarry owners.

" tank and cistern makers.

Slaters and tilers.

Smiths.

Solder manufacturers.

Speaking tube makers and fitters. Spelter manufacturers.

Sponge merchants and dealers. cloth manufacturers.

Stable utensil makers.

Stave importers.

Steam engine makers.

" $\quad$ and boiler fittings manufacturers.

" packing makers.

" trap makers.

Steel bar manufacturers.

$"$ founders and casting manufacturers.

" manufacturers.

" pipe manufacturers.

$"$ plate manufacturers.

Stone and marble masons.

" jar makers.

" merchants.

Stove and range makers.

Straw merchants (stables department).

Sugar refiners.

Surgical instrument makers (stables department).

Surveying instrument makers. Surveyors.

Tap makers.
Tar paviors.

Tarpaulin manufacturers.

Telephone contractors.

, manufacturers.

Terra cotta manufacturers.

Thermometer makers.

Tile (roofing) manufacturers.

" merchants.

Tilers (roofing).

Timber merchants.

Tin and copper wire manufac. turers.

"merchants.

" plate manufacturers.

" " merchants.

" " workers.

Tool makers and dealers.

, handle makers.

Tube makers.

Turners (in general).

Valve makers.

Van and truck makers.

Varnish makers.

Ventilator manufacturers.

Veterinary druggists.

Vulcanite stopper makers.

Waggon builders.

Water closet makers.

" meter makers, etc.

" pipe makers.

Wax manufacturers.

Weighing-machine makers.

Well borers.

"s sinkers.

Wheelbarrow makers.

Wheelwrights.

White lead manufacturers.

", metal manufacturers.

Whiting manufacturers.

Window blind makers.

" glass merchants and manufacturers. 
Wire nail makers.

" rope makers.

Wood block flooring manufacturers.

" pulley makers.

Wood-working machine makers. Writers and gilders on glass.
Writers and grainers.

Yarn merchants.

Yeast dealers.

Yellow metal manufacturers.

Zinc merchants.

" roofing manufacturers.

", workers and drawers.

\section{E. - THE USE OF ALCOHOLIC BEVERAGES}

(FROM THE LANCET OF MARCH 30, 1907.)

We have received the following document for publication in The Lancet. As an expression of scientific opinion it deserves to be considered carefully by medical practitioners. The signatories are well-known members of the profession, and the importance of the questions involved, alike from the medical and the social point of view, can hardly be overestimated.

In view of the statements frequently made as to present medical opinion regarding alcohol and alcoholic beverages, we, the undersigned, think it desirable to issue the following short statement on the subject-a statement which we believe represents the opinions of the leading clinical teachers as well as of the great majority of medical practitioners.

Recognizing that, in prescribing alcohol, the requirements of the individual must be the governing rule, we are convinced of the correctness of the opinion, so long and generally held, that in disease alcohol is a rapid and trustworthy restorative. In many cases it may be truly described as life-preserving, owing to its power to sustain cardiac and nervous energy, while protecting the wasting nitrogenous tissues.

As an article of diet we hold that the universal belief of civilized mankind that the moderate use of alcoholic beverages is, for adults, usually beneficial is amply justified.

We deplore the evils arising from the abuse of alcoholic 
beverages. But it is obvious that there is nothing, however beneficial, which does not by excess become injurious.

T. McCall Anderson, M.D., Regius Pro: fessor of Medicine, University of Glasgow. ALFRED G. BARRS.

WILLIAM H. BENNETT, K.C.V.O., F.R.C.S.

JAMES CRICHTON-BROWNE.

W. D. DIXON.

DYCE DUCKWORTH, M.D., LL.D.

T. R. GLYNN.

W. R. GOWERS, M.D., F.R.S.

W. E. HalliburTon, M.D., LL.D., F.R.C.P., F.R.S., Professor of Physiology, King's College, London.

JONATHAN HUTCHISON.

ROBERT HUTCHINSON.

EDMUND OWEN, LL.D., F.R.C.S.

P. H. Pye-SMith.

FRED. T. ROBERTS, M.D., B.SC., F.R.C.P.

Edgcombe VenNing, F.R.C.S.

\section{F.-ALCOHOLIC BEVERAGES : STATISTICS}

From a Parliamentary Return, 'Alcoholic Beverages, r905,' issued while the present work is passing through the press, I take the tables given on pp. 322, 323, showing the annual consumption of alcoholic beverages in the United Kingdom, as compared with various foreign countries, the figures given representing gallons per head of the population.

It will be observed from these tables that the United Kingdom is the lowest on the list in regard to the consumption of wine, is low down on that for spirits, and top but one on that for beer, but that in each instance a decline in consumption-especially noteworthy under the head of 'Beer'-is shown; while for the United 
Average Consumption of Wine per Head of Population.

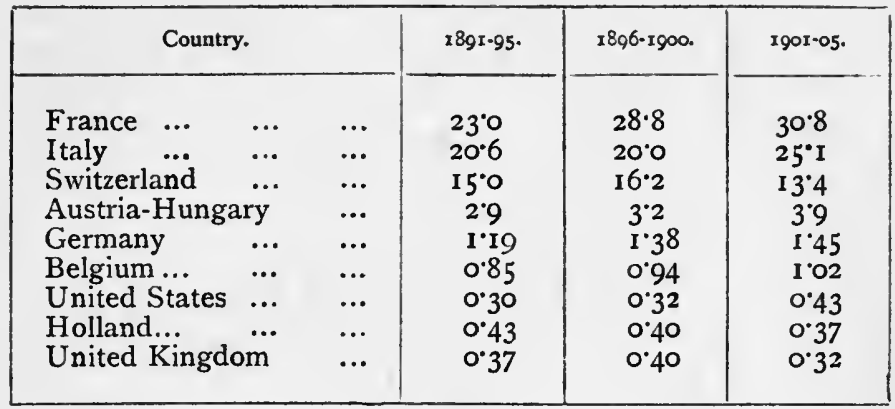

Consumption of Beer per Head of Population.

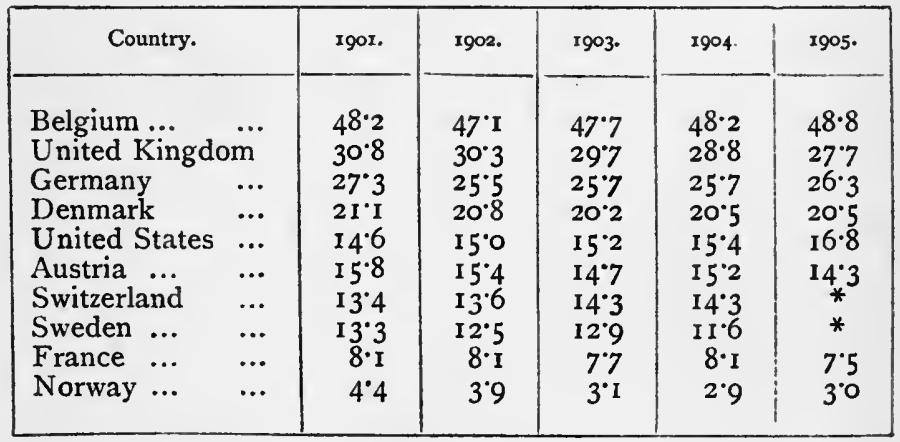

States-the 'home' of prohibition-there is an increase under all three heads.

The return also shows, with regard to revenue raised from the taxation of alcoholic beverages, that the United States comes first, with a total of $£ 40,259,000$, the United Kingdom following with $£ 36$,r 4 I,ooo. The former thus pays $£ 4,000,000$ in excess of the latter; but

* Not available. 
Consumption of Spirits per Head of Population.

(Gallons of Proof Spirit).

\begin{tabular}{|c|c|c|c|c|c|c|}
\hline Country. & & 1901. & 1902. & 1903. & 1904: & 1905. \\
\hline Denmark & .. & $2 \cdot 69$ & $2 \cdot 69$ & 2.50 & $2 \cdot 44$ & $2 \cdot 42$ \\
\hline Austria ... & ... & $2 \cdot 20$ & $2 \cdot 20$ & $I \cdot 98$ & $I \cdot 98$ & I'98 \\
\hline Hungary & .. & $r \cdot 76$ & $1 \cdot 76$ & $I \cdot 98$ & I.98 & I'98 \\
\hline Germany & ... & $I \cdot 63$ & $I \cdot 6 I$ & $I \cdot 54$ & $1 \cdot 54$ & $I^{\circ} 43$ \\
\hline Holland ... & ... & $1 \cdot 56$ & I.54 & $1 \cdot 50$ & 1.50 & $1 \cdot 43$ \\
\hline Sweden ... & ... & $I \cdot 65$ & $I \cdot 52$ & $1 \cdot 43$ & $I \cdot 34$ & $I \cdot 36$ \\
\hline France ... & ... & $1 \cdot 33$ & $I \cdot 24$ & $1 \cdot 35$ & 1.50 & $1 \cdot 37$ \\
\hline United States & $\ldots$ & I'I 3 & $1 \cdot 22$ & $I \cdot 23$ & $I \cdot 2 I$ & $I \cdot 26$ \\
\hline Belgium ... & ... & 1.89 & $I \cdot 6 I$ & I.OI & $I \cdot I 4$ & $1 \cdot 10$ \\
\hline United Kingdor & & I.09 & 1.05 & 0.99 & 0.95 & 0.91 \\
\hline Norway ... & ... & 0.64 & 0.64 & 0.62 & 0.62 & 0.51 \\
\hline Italy $\quad \ldots$ & ... & 0.24 & 0.24 & 0.25 & 0.28 & 0.29 \\
\hline
\end{tabular}

against this difference in totals must be put the enormous difference in the size of the two countries. In each case the proportion of revenue from alcoholic beverages to the total revenue raised is 28 per cent. Following the United Kingdom come Russia with $£ 34,473,000$ (I7 per cent. of total); France, $£$ I7,049,000 (I5 per cent.); the German Empire, £ $13,532,000$ (percentage uncertain); and Austria-Hungary $£ \mathrm{I} 2,796,000$ (II per cent.).

\section{G.-THE TAXATION OF BREWERY COMPANIES}

To illustrate more clearly the taxation already paid by the liquor interests of the country, I have obtained from a leading brewery company the following statement showing the amounts it contributed direct to imperial 
and municipal taxation during the year ended March 3I, 1907 :

$\begin{array}{llccc}\text { IMPERIAL TAXATION : } & & £ & \text { s. d. } \\ \text { Beer duty, twelve months } & \ldots & \text { 2I2,909 } & \text { II } & 0\end{array}$

\begin{tabular}{llllll} 
Less drawbacks ... & $\ldots$ & $\ldots$ & 3,107 & 18 & 3 \\
\hline
\end{tabular}

Income tax :

Paid by direct assessment :

Schedule A ... $\quad \ldots \quad \ldots \quad$ I, 337 o 10

Schedule D ... $\quad \ldots . \quad \ldots .64,851 \quad 18$

Paid by deduction prior to

$$
6,188 \text { I8 10 }
$$
receipt of income :

Interest on loans $\ldots £ 5,489$

Interest on investments $\quad . . \quad \ldots \quad 7$ Io

12,387 I 8 10 222,189 II 7

MUNiCipal TAXATION

Borough rates

$\underline{6,199 \circ 0}$

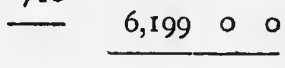

$\begin{array}{llllllllll}\cdots & \ldots & \ldots & \ldots & \ldots & 7,140 & 10 & 7\end{array}$

Total

$\$ 229,33022$

NoTE.-The sum total of this taxation for revenue and municipal purposes amounts to no less than 24 per cent. of the annual trading receipts (not profits) of the company. Barrels sold for same period, 529,982 .

The above statement is exclusive of licence duties and rates and taxes on about 550 public-houses controlled by the company, the total payments under these two heads being estimated to exceed another $£^{\mathrm{I} 20} 0,000$. It includes compensation levy paid by publicans, but not that paid by the brewery direct.

\section{H.-PROHIBITION IN THE UNITED STATES}

IN a report on 'Liquor Traffic Legislation of the United States,' prepared by Mr. R. C. Lindsay, Second Secretary to His Majesty's Embassy at Washington, 
and issued by the Foreign Office in April, 1907, it is said :

The liquor traffic takes up much attention in the Legislatures; amendments are constantly being passed to existing laws, and new systems introduced generally or locally. During the past three years the States have enacted 164 separate laws directly affecting the liquor traffic.

\section{On the subject of prohibition Mr. Lindsay observes:}

At one time or another seventeen States have had stringent prohibition; it is now only retained by three, and in those it cannot be looked upon as a success. Parts of prohibitory States have always been in open rebellion against the law ; drinking has never been impossible; the sale of liquor has always been profitable, and seldom disreputable in the eyes of the public. Violation of the law has been open and avowed. Federal law requires the payment of a special annual tax on retail liquor dealers, and most States, including those under prohibition, provide that the payment of this tax shall be prima facie evidence of a sale of liquor having been made, thus utilizing the Federal officials in the detection of illegal traffic. During the fiscal year ending June 30 , 1906, the numbers of persons paying the special taxes as retail liquor dealers and retail dealers in malt liquors were, in the State of Kansas, 4,019; in Maine, 599; and in North Dakota, I,582-these being the three prohibition States.

In urban districts, at any rate, it has not been possible to find any sound ethical basis for the law, or to persuade the majority to regard its violation as immoral. Without the backing of public opinion, no enforcement of prohibition has been obtained except at the price of raising animosities between rival factions of such intensity as seriously to disturb the community. Juries have violated their oaths; judges have hesitated to impose statutory penalties; blackmail and corruption have been directly instigated, and the law in general brought into contempt. Persistent disregard of the liquor laws is supposed to encourage disobedience to other enactments, and an example is cited in Kansas, where the fact that an anti-gambling law is almost a dead-letter has been attributed to the lax enforcement of prohibition in the cities of the State.

It should also be mentioned that prohibition prevents a community from passing any laws for reclaiming or protecting its drunkards. Where in theory there is no drinking, in theory there can be no intoxication; but from the practical point of view such arguments cannot be justified. 


\section{N D E X}

AFRICA, DRINK IN, 9

AGRICULTURAL INTERESTS, 276-7

AlCOHOL: Food value of, 25: found in fresh bread, 29 ; alcohol and national progress, 30 ; alcohol in drugs and patent medicines, 33-38; views of medical experts, 69-78; percentage in beer and spirits, I8I ; teaching in schools respecting, 20I-8; in temperance drinks, 224-5 ; amount of, in beer, 229230; purpose served by, 238

ALE-CONNERS, I6

Ale : Early, Io; use of hops in, II: difference between ale and beer, II-I2; the national beverage, 12-13; old laws and regulations, $I_{4} \cdot I_{9}$

Allied Brewery Traders' AsSOCIATION, 278

Allied TradeS, 276-9

AlRECK, KING OF Hordoland, 13

ARSENIC, 288

Assize of Bread and Ale, I5

AtKInson, RICHARD, 13

Augsiurg, Common Council of, I5

BALFOUR, Mr., 248

Bauer, Dr. P., 288

Bavaria, EARLy Laws IN, II

BeEr ACT (1830), 86-7

- Beer-heart' in Germany, 287

BEER-HOUSEs: Origin of, 87 ; laws concerning, 88 ; law of I 869, 88.9; reduction in number of, 244-25I

Berr: Primitive, 7-9 ; introduction of hops, i i ; 'liquid bread,' 25 ; sale of beer through 'tied' houses, I04; ditto 'managed ' houses, I17-120; beer in Norway, I80-I; advance in science of brewing, 227-232 ; lager beer, 232-4; lighter qualities, 229230; use of ' substitutes,' $236-7$; beer in Denmark, 239-240; beer a temperance drink, 24I: production of, 274-5

Bennett, M.P., MR. E. N., 135

BIRMINGHAM WHOLESALE Brewers' Association, 108

BRAMWELL, LORD, 245

BRANDT, Mr. M. VON, 133

Branthwaite, Mr. R. Welsh, $55-68$

Brazil, DRINK IN, 9

BREAD, AlCOHOL iN, 29

Brewers : Advances by, 93.4: succeed individual owners, 95-7; arrangements with tenants, 97 I02: 'managed' houses controlled by, 106-128; beer-supply to own houses, II7.120; how affected by time-limit, 262-3 ; dividends, 269-270

BREWER'' Company OF LoNDON, II, I7, 82

Brewhouses, Domestic, I3

BREwiNG: Early, in Egypt, 7: in England, IO-1 I, 13-18; scientific progress in, 227-232 ; commodities used in, $235-8$; in Denmark, 239-240: persons employed in, 274-5

Brewsters, I4

Brinton, DR., 74

Brown, Mr. Horace, 227

Brunton, Sir LaUder, 32, 75

Buxton, Mr. E. N., $26_{3}$

Calne, Mr., 246

Capital invested in LiguOR INDUSTRIES, 268-9 
Carter, Dr. R. Brundenell, 75

Chamberlain, Mr. Arthur, I87

Chester, Miracle Play at, I 4

Chloral, 33, 34

Cider, 6

Clubs: Statistics concerning, r89rgr ; membership, I9I ; Sunday entertainments, I92-3; drinking at, 193.4 ; reasons for resort to, 195.8; the club problem, 292-300

Cobbett, William, 13

Cocaine, 27, 288

Coca Plant, 9

COFFEE: Introduction of, 12 ; use of, as stimulant, 27, 28, 29; excessive consumption of, 2 II

Cola-nut, 9

COMMitTEe OF Fifty, 202.7, 290

Compensation, 247, 250-4

Confiscation, 265

Crichton-Browne, Sir James, 75

CRIME ANd DRINK, 40-7, 289

Davies, Mr. Frederick, 220

DEAN OF HEREFORD, The, 299

Deane, Mr. Justice Bargrave, 153

DEBENTURE-HOLDERS' INTERESTS, 262-3

DE FOE, 23

Denmark, Temperance Beers IN, 239

Dewar, Sir Thomas R., I32

Disinterested MANAGEMENT, I $70-188,257-8,300$

DisTILLING, 20, 82

Dogberry Wine, 7

- Drink Bill, The,' 280-3

Drunkards, Habitual, 54-68

DRUNKENNESS : Prohibitionists and, $39-53$; habitual, $54-68$; in Scotland, I 43-7 : Belfast, $x_{47-8}$; Wales, I49; New Zealand, 163.5: Norway, 178-180; encouraged by clubs, 193-5, 304

DUBelLe, Mr. G. H., 22I

DUCKWORTH, Sir DYCE, 75

Dutton, Dr. Thomas, 76

EGYPt, BREWING IN, 7

Embrocations, 3 I

EWALD, PROF. DR., 7 I
Falkenheim, Pror. Dr., 73

FarQUHARSON, Dr. ROBERT, 22

FieldiNG, 85

Food-supply in Public-houses, $12 \mathrm{~J} \cdot 4$

FoOD VALUE, 25, 75, 222-3, 230-I, 238,283

FORBES-MACKENZIE ACT, 88, 142

Fox, Sir William, ${ }_{54}$

Gamble, The Rev. H. R., 292

Garrod, Dr. Alfred B., 75

GIN, 2I, 83-6

Gladstone, Mr., 229, 290

Goldscheiden, ProF. DR. A., 7 I

Goschen, Mr., 272

GothenbURg System, The, $x_{7} \mathrm{I}$ 2,184

Grant, Principal, I4O

Griess, Mr. Peter, 227

Grinnell, Dr. Ashbel P., 27. 33-6

Grocers' Licences, 88

Grutzner, Prof. Dr. von, 73

Guarana, 9

Gull, Sir William, 74

Hansen, Mr. Emile C., 228

Harcourt, Sir William, 246

HaUser, Prof. Dr., 73

High LiCENCE, 272, 290, 296

Holiday Closing : In Scotland, $145-7$; in Belfast, $147-8$

HoPS: Introduction of, IO-II: use of, 228-9; hop industry, 277

Hop Substitutes, 237

HORSLEX, Sir VICTOR, 201, 208

HUNT, Mrs. Mary H., 202-3

Illicit Trading, 83, 132, 138 , $\mathrm{I}_{4} \mathrm{O}, \mathrm{r}_{4} 8, \mathrm{I}_{3}$

InDUSTRIAL Considerations, 274-9

INSANITy AND ALCOHOL, 47-9, 567,65

INVESTORS IN BREWERY COM. PANIES, 265, 273

JACOBSEN, Mr., 228

Japan, National Beverage of, 9-ro

KaVA, 9

KIRKBY, MR. WILLIAM, 2 Y2 
LADDEVIN, 178

LAGER BEER, 232-4

- Lancet' Manifesto, 78

LEASE-HOLDER, POSITION OF, 264

LECKY, Mr., 86

LEGISLATION : Early, II, 15, I6 ; story of past legislation, 80-90: Sharp v. Wakefield, 244 ; Veto Bills, 246; Act of 1902, 246; Act of 1904, 250-I, 254

LOCAL OPTION, I5O-2, I77, 246 , 254

lombroso, Prof. Cesare, 44

LONDON, CITY OF, AND BREWING, II, I6-I8

'LORD OF THE TAP,' I9

MACDONNELL, SiR JOHn, 45-6

MacEwan, Mr. Peter, 2 I9

MAGEe, DR., 292

Magistrates AND the Licensed Trade, 102-4, III-2, I24, 127 , $253,294,297$

'MANAGED' Houses: A phase of ordinary commercial conditions, 106; how system operates, I07-III ; position of managers, II2-7 ; beer supply, II7-I20 ; food supply, r20-r24; managerial compared with tenancy system, 124-8

MARKs, M.P., Mr. H. H., 199

MARY, QUEEN OF SCOTS, I2

MCKeAGUe, Mr. John, 165

MeAD, 6

Methylated Spirits, i8o

MeXico, Drink IN, 9

Miracle Play at Chester, 14

MONOPOLY VALUE, 254-267, 295

MORPHIA, 32, 34, 288

MoRTILLET, M. G. DE, 6

NaRcotics, 32

NeWbegin, The Rev. E. H., I33

New Zealand, No - Licence MOVEMENT IN, I 54-I 69

NORWAY : Drinking habits in, I70I : Norwegian system, I7I-3; Samlag profits, 173-5; liquor comsumption in, 176

OldFirld, DR. Josiah, 76

OpIUM, 10, 27, 32, 34
O'Sullivan, Mr Cornelius, 227, 235

Paget, Sir James, 74

PASTEUR, 227

Patent Medicines, $35-8$

PEACOCK, Mr. ROBERT, 194

Peru, Drink in, 9

Pickles as Stimulants, 27

Police and the TRADE, 107, IIO,

II 5, 162-3, 197-8

Politur, 3I, I80

POVERTY AND DRINK, 49-5I, 289

Preservatives, USE OF, 217,224 , 238

Prohibition: In the United States of America, 33-6, 130-7 ; in Canada, I37-I40; in Australia, I40-I; judicial views of, I 53 ; in New Zealand, I54-169

PROHIBITIONISTS, EXAGGERATIONS OF, 39-53

Public-houses: 'Tied,' 9I-105: 'managed,' I06-128 ; reduction in number of, 244-25I, 293-5: continuity of licences for, 253-4; how affected by time limit, 255-7, 295: persons employed, 275: public-houses and population, 295; social purposes served by, 299-300

PUlque, 9

PURe BeEr Agitation, 236-7

PURE FOOD ACt (U.S.A.), 37

QUAin, Dr. Richard, 74

QUeEN Elizabeth, I2

QUININE, 27

RALEigh, Sir Walter, I2

REDUCTION IN NUMBER OF LICENSED Houses, 243-25I, 293-5

REED, Dr. A. J., 36

REID, Mr. G. A. A., 76-7

RibBert, PROF. DR., 72

ROBERTSON, DR., I4I

Robertson, The Rev. J. CartMEL, 4I

ROSEBERY, LORD, 3OI

SAKÉ, 9

SALISBURY, LORD, 256

SALtex, Prof. H. R., 72 
Schmidt, Herr Carl E., 30

Schmidt, Proz. Dr. 73

Schotrelius, Dr. MAX, 29, 286

ScotLAND: Sunday closing in, $88, \mathrm{I}_{42}$; early closing in, I 43.5 ; holiday closing in, I $_{45-7}$

Scotr Act, The, 137.8

SCOTtish Commissioners' REPORT ON NORWAY, 173-182

ScotTish Laws, Old, I6

Selborne, LORD, 247

SHADWELL, DR., 84

SharP $v$. WAKEFIELD, 244

Shrötter, Prof., 73

Sinking Fund Theory, 262-3

SMITH, ADAM, 284

Smith, Prof. Goldwin, 137

SPIRITS : Introduction of, 20 ; compared with beer, 40; gave rise to the 'liquor question,' 40 ; increased consumption, 82-6; spirits $v$. beer, I32, I38, I6I: spirit drinking in Norway, I $70-\mathbf{I}$, I80

Stimulants : Purposes served by, 25: response of, to natural instinct, 26-3I, 38, 288; varieties of, 27.29 ; medical views on, $69-78$

STORCH, DR. E., 73

SUBSTITOTES FOR AlCOHOLIC BEVERAGES: Methylated spirits, $3 I$; politur, $3 I$; dental washes, 31; embrocations, 3I; ether, 32 ; drugs, 33-37; general, 288

SUBStitutes, USE OF, IN BEER, 235-7

Sunday Closing, 88, 142, 148-9, $254,262,290,299$

Taverns, in the Past, 22.4

TAXATION, I89, 260, 270-2, 280

TEA : Introduction of, 12 ; use of as stimulant, 27,29 ; excessive consumption, 2 IO-II

TEa-rooms iN PUblic-houses, I2I
Teetotallers, AtTitdde of, TOWARDS THE LICENSED TRADE, 3. 24, 39-40, 91, I29, I55, 243, 289

Temperance Drinks, 29, 209-226, $24 \mathrm{I}, 282$

TEMPERANCE LEGISLATION LEAGUE, 254, 257.260, 262, 266

Temperance Party, Policy or, 40, I29-I30, I42, I 53, I 70, I82-8, I $89,20 I, 243,252,254-266,287$. 8,294

TEMPERANCE TEACHING IN SCHOOLS, $201-8$

Tenants, Position of, 92, 105, I24-6

' TIED' Hocses : Origin of, 93 ; how system operates, 94-I05: advantages for tenant, 95; reasons for transfer, 95.7 ; quality of beer supplied, II 7120; general effect of tied house system, 298

Time LIMIT, 254-266, 295

Transfers of Licences, II 2

- Trust ' Public-houses, I85-7

Toczek, Prof., 72

United Kingdom Alliance, 289

UNITED States: Use of drugs in, 27, 33-8; prohibition in, 33 , 130-7; temperance teaching in schools ; 20I-7; temperance party in, 290-I

UNIVERSITY OF OXFORD, I8

VaUghan, Father Bernard, 5 I

Whittaker, Sir Thomas, 136

WINE, 7, 20

WOMAN'S CHRISTIAN TEMPER. ANCE UNION, 202

Yerkes, Mr. JOHN W., 37

ZUNKER, Dr. ERNEST, 70 

Large Crown 8vo. Half a Crown net.

\section{LICENSING AND TEMPERANCE}

IN

\section{SWEDEN, NORWAY, AND DENMARK.}

\section{By EDWIN A. PRATT,}

AUTHOR OF

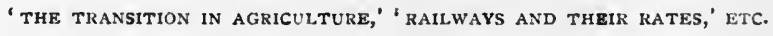

Contents.-The Gothenburg System: Early DaysGothenburg City : Bars, Bottles, and Drunkenness-Private Profits and Public Gain-The Position in Norway-Drunkenness and Beer-drinking-Temperance $v$. Teetotalism The Copenhagen System-Conclusions and Recommendations-Appendix: Abuses of the Company System-Drunkenness Declines : Immorality Increases- 'Fruits of Fanaticism' in Norway-The Company System in Finland-Index.

LONDON : JOHN MURRAY, ALBEMARLE STREET, W. Igo6.

\section{OPINIONS OF THE PRESS.}

Newcastle Chronicle.- Many books have been written about the Gothenburg System, but Mr. Pratt's volume is welcome because it contains a recent and careful review of results, while its chief value lies in the information it conveys with regard to the Copenhagen system, about which the British public knows but little.'

The Field.- 'The book is a grave, unbiased, and, to our thinking, an unanswerable statement.' 
Record.- - In view of the probable legislative efforts of the present Government, there should be a large demand for the book.'

Yorkshire Daily Post.- 'It is worth considering, even at this late hour of the day, whether the so-called temperance party could not, by a change of policy, attract a larger measure of public support and sympathy by doing something themselves than by expecting successive Governments to "do something" for them, and by seeking to co. operate with the licensed trade rather than to rob and ruin it. The proposal is not so outrageous as it may seem. In support of it some interesting evidence has been collected by Mr. Edwin A. Pratt, and published by Mr. John Murray, which all temperance workers owe it to themselves and their cause to study-as far as possible without prejudice.'

Aberdeen Journal.- A contribution of considerable importance to the controversy about the precise value of the Gothenburg System as a remedial agency in lessening drunkenness and the consumption of alcoholic liquor.'

Birmingham Post.- ' With all these facts before us it can scarcely be said that the Gothenburg System has been in any sense a success. ... It will be very difficult for the advocates of the adoption of a similar system in this country (if any are to be found at this late date) to offer any reply to Mr. Pratt's arguments.'

Sheffield Daily Telegraph.- ' The whole book will be found eminently readable and informative, even by those who do not accept the author's conclusions.'

Monitor.-' Certainly a valuable and practical contribution on the subject.'

Catholic Times.- ' It is difficult to understand how the Gothenburg System has come to be considered and to be praised to so great an extent. Certainly there would be nothing gained by handing over a monopoly of part of the drink business to a huge company, with 5 per cent. assured to the shareholders, and with city councils, county councils, and the Imperial Exchequer scrambling for the profits. Two thoughts emerge into prominence from a consideration of this useful and ably written book-one, the justice of Mr. Pratt's contention " that the sobriety of a nation is much more likely to be promoted by en. couraging the consumption of light and harmless beverages, of a kind acceptable to the people at large, than by merely seeking to enforce oppressive and coercive measures on either consumers or suppliers ": and the other, not expressed in the pages of Mr. Pratt's little treatise. is yet implied on almost every page, that the cause of sobriety can be served better by religious and moral ideals acting upon individuals than by legislation not reflecting the real wishes of the people.' 
Alliance News. - 'Mr. Pratt's book appears at a singularly opportune time, for, though it is written with a most obvious prejudice against teetotalism and prohibition, and contains opinions and theories which no instructed temperance reformer can accept for one moment, it is a veritable storehouse of facts-the latest and best authenticated factsestablishing the utter failure of those principles and theories upon which the "Disinterested Management" party have grounded their whole case.'

Churchman.- 'A readable account of the Gothenburg System and the present conditions of the drink problem in Scandinavia.'

Eastern Morning Newr. - There are enthusiasts on both sides, and each can study the book with satisfaction.'

Church Times. - Not only does Mr. Pratt smash into atoms certain ideas which had become almost nationalized in England, but in dealing with the Norwegian "Samlag" he arrives at a conclusion amazingly different from that which has been given to the world this week by the Special Committee employed by the Scottish Temperance Legislation Board. ... Who shall decide ? The Committee praise the "Samlag" and condemn the "Bolag." Mr. Pratt condemns both, and in no measured terms, quoting an array of precise statements of fact. But we are coming nearer the light when we read Mr. Pratt's discussion of the system in force in Copenhagen. This system sets out to encourage the consumption of lighter beers, and at the same time provides a type of public-house which seems to recognize the human need of social intercourse. Mr. Pratt describes them fully. ... Private enterprise, using public opinion as its weapon, seems to be accomplishing in Denmark what "disinterested management" fails to accomplish in Norway and Sweden alike. It is significant that in Denmark "the temperance party has no political programme. It does not worry the national Parliament for all sorts of coercive measures, but quietly sets about doing all it can to promote sobriety on the broadest and most common-sense lines." We leave the statement without comment. It is food for leisurely reflection.'

The Northern Whig.- ' A good deal, certainly, was written on the Gothenburg System ten or fifteen years ago, but it is interesting to hear how it is going on, and Mr. Pratt has something of his own to say about it. He did not, like too many of his predecessors, form his opinion on an inquiry lasting a few hours, or a visit of a couple of days. In Norway, in Sweden, and in Denmark, he not only inquired from the authorities, but he visited the artisan and slum districts. The result is a work of great importance on a profoundly important sociological problem, which at present bulks largely in the outlook of our own country.' 
Month. - The author ... begins with a very clear exposition of the nature of the system. Its root-principle is to confine to a certain authorized body the sale of the native spirit-known as "bränvin" in Norway and "brændevin" in Sweden-the abnormal consumption of which, the result of unwise legislation, had become a national calamity. The remedy devised was to make the sale of this liquor a monopoly. consigned to a "disinterested management "company, the philanthropic shareholders in which should consent to forego more than 5 per cent. on their invested money, any surplus being assigned to the State for national purposes, it being assumed that the origin of evil is the greed of private enterprise, each manufacturer or vendor being anxious only for his own profits, and that all would be well if the trade were left in the hands of the State, "in whose wisdom and absolute disinterestedness confidence can alone be placed." Mr. Pratt's investigations have convinced him that such an assumption is not borne out by facts. Not only is it that the demon of private avarice is by no means exorcised, but officials can be no less eager to secure revenue by extending the sale of spirits than are individuals to replenish their own pockets. There is, therefore, nothing in the system to check the spread of intemperance, and, as a matter of fact, he finds it is not checked. . . . Rightly to estimate the value of Mr. Pratt's conclusions, his book must be carefully studied, and it may be cordially recommended to all who are interested-as who is not?-in the vital question with which it deals.'

Daily News.- 'A bright and interesting treatise.'

Sheffield Independent. - The author . . . has come to the conclusion that systems like the Gothenburg Bolag are a mistake, and do not lessen the aggregate purchase of drink, but drive it, rather, into secrecy in the home. . . . What he does bring out clearly, amid much that is one-sided, is the vastness of the drink sale, in quiet ways, in countries which are trying plans for producing sobriety, while strong liquors are easily-though not ostentatiously-procurable.'

Brewing Trade Review.- There can be no doubt that Mr. Pratt's investigations on this question are the most complete that have yet been published.'

Licensed Victuallers' Gazette.- 'The book holds a moral. You cannot make people good or sober or wise by mistrusting them.' 

UNIVERSITY OF CALIFORNIA, LOS ANGELES THE UNIVERSITY LIBRARY

This book is DUE on the last date stamped below

APR 291947

MLAY 81950

JUN $2 \quad 1950$

AUG 121952

OEC 291953

IFC 13 1958

NOK 8 195

Dec 15158

औ月1 191955

\section{OCT $231959^{\circ}$}

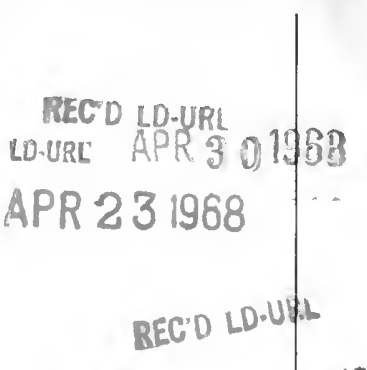

DURL MAY 201968

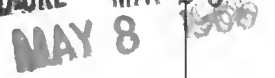


UC SOUTHERN REGIONAL LIBAAAY FACILITY 


$$
\begin{aligned}
& \text { \% } \\
& \text { \% } \\
& \text { \% }
\end{aligned}
$$<smiles></smiles>

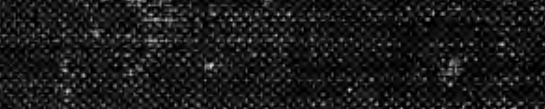
40

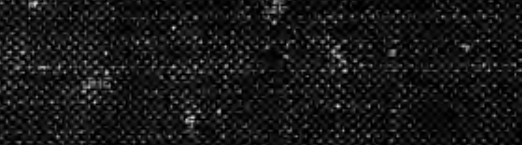

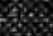

$$
\text { F. }
$$

